\title{
Combinação de classificadores simbólicos utilizando medidas de regras de conhecimento e algoritmos genéticos
}





\section{Combinação de classificadores simbólicos utilizando medidas de regras de conhecimento e algoritmos genéticos*}

\section{Flávia Cristina Bernardini}

Orientadora: Prof ${ }^{a} \mathrm{Dr}^{a}$ Maria Carolina Monard

Tese apresentada ao Instituto de Ciências Matemáticas e de Computação — ICMC/USP como parte dos requisitos para obtenção do título de Doutor em Ciências de Computação e Matemática Computacional.

\section{"VERSÃO REVISADA APÓS A DEFESA"}

Data da Defesa: 29/08/2006

Visto da Orientadora:

\section{USP - São Carlos}

Outubro/2006

${ }^{*}$ Trabalho realizado com auxílio financeiro da FAPESP (Proc. $\mathrm{N}^{\circ}$ 02/06914-0) http://www.fapesp.br 

Aos meus pais, Gilson e Iris, por tanto apoio e força.

Aos meus filhos, Caio César e Maria Eduarda, quem tanto amo. 

Esta tese foi preparada com o formatador de textos $\mathrm{ET}_{\mathrm{E}} \mathrm{X}$. Foi utilizado um estilo (style) desenvolvido por Ronaldo Cristiano Prati. O sistema de citações de referências bibliográficas utiliza o padrão Apalike do sistema BIBTEX.

Algumas abreviações utilizadas neste trabalho não foram traduzidas da língua inglesa para a portuguesa por serem amplamente conhecidas e difundidas na comunidade acadêmica.

(C) Copyright 2006 por Flavia Cristina Bernardini Todos os Direitos Reservados 

"O sucesso nasce do querer. Sempre que o homem aplicar a determinação

e a persistência para um objetivo, ele vencerá os obstáculos, e se não atingir o alvo, pelo menos fará coisas admiráveis." - José de Alencar 



\section{AgRADECIMENTOS}

À Profa. Maria Carolina Monard. Eu a conheci em 1999, e esta grande mulher, a quem tive o orgulho de chamar de orientadora por aproximadamente sete anos, foi não somente minha orientadora de mestrado e doutorado mas também minha orientadora de vida. Tanto aconteceu nesses sete anos em minha vida pessoal, e quanta força recebi da Carolina, com suas sábias palavras de experiência de vida que jamais esquecerei. E obviamente não foi só na minha vida pessoal que aprendi muitas coisas. Minha dissertação, esta tese, publicações, são todos trabalhos resultantes de muita dedicação também por parte da Carolina, quem tanto admiro. Não há palavras suficientes para expressar o quanto a agradeço e o quanto aprendi durante todos esses anos.

Também, não há palavras suficientes para agradecer a meus amigos do LABIC, que sempre, mas sempre mesmo, a qualquer hora, estavam dispostos a me ajudar. Assim, aqui vai meu muito obrigada à Katti, à Huei, ao Ronaldo, ao Edson, ao Gustavo, à Cláudia Milaré, ao Richardson, ao Adriano, à Mariza, ao Tiago, ao Rodrigo, ao Eduardo, à Ana Carolina, e a tantos outros que direta ou indiretamente sempre estiveram presentes, me ajudando com ações ou palavras. Agradeço muito também a todos os funcionários do ICMC porteiros, bibliotecários, secretários, seguranças, e outros - e em especial à Laura, à Ana Paula, à Beth e à Tatiana, que resolveram tantos problemas para mim durante esses sete anos, facilitando muito minha passagem pelo ICMC. E não poderia deixar de mencionar meu muito obrigada à FAPESP pelo apoio financeiro, primordial para o bom desenvolvimento deste trabalho.

Ações e palavras foi o que não faltou na minha vida não só dos meus amigos do laboratório e da minha orientadora. Muito obrigada também ao Paulo, meu noivo, que já me ajudou e me ajuda muito a superar todas as dificuldades. Também agradeço a tantas outras pessoas que me deram uma palavra amiga na hora da necessidade.

Bem, todas essas pessoas a quem agradeci até então conheci nos últimos sete anos. Mas existem algumas pessoas que sempre estiveram presentes durante toda minha vida e pra quem tenho muito, mas muito mesmo, o que agradecer: meus pais e minhas irmãs. Afinal, foram muitos momentos em que contei 
com eles, e foram muitos os momentos que me ajudaram a me reerguer e a construir esta pessoa que sou hoje e que aqui chegou. A essas pessoas, tão especiais, fica aqui, de coração, meu MUITO OBRIGADA. E pensando em vida toda, muito obrigada a meus filhos, que estão presentes na minha vida desde que abriram seus olhinhos pela primeira vez neste mundo e que me motivam a todo instante.

Por último, e tão importante quanto, ou até mais, agradeço a Deus e a seus anjos por toda a força concedida para eu vencer todas, e mais essa, batalha na minha vida.

Por fim, nesta versão revisada, muito obrigada aos membros da banca de defesa de doutorado, Professores Alexandre Evsukoff, Solange Oliveira Rezende, Anna Helena Reali Costa e Ana Cristina Bicharra Garcia, pelos comentários valiosos e pelas críticas bastante construtivas, que auxiliaram muito no processo de revisão desta tese.

A todos vocês, muito obrigada. E lembrem-se, se acham que talvez não tenham feito tanto assim:

"Não se pode ensinar tudo a alguém, pode-se apenas ajudá-lo a encontrar por si mesmo." 


\section{RESUMO}

$\mathcal{A}$

qualidade das hipóteses induzidas pelos atuais sistemas de aprendizado de máquina supervisionado depende da quantidade dos exemplos no conjunto de treinamento. Por outro lado, muitos dos sistemas de aprendizado de máquina conhecidos não estão preparados para trabalhar com uma grande quantidade de exemplos. Grandes conjuntos de dados são típicos em mineração de dados. Uma maneira para resolver este problema consiste em construir ensembles de classificadores. Um ensemble é um conjunto de classificadores cujas decisões de classificação são combinadas de alguma maneira para classificar um novo caso. Ensembles de classificadores são capazes de melhorar o poder de predição dos algoritmos de aprendizado; entretanto podem ser compostos por muitos classificadores, o que pode ser indesejável. Ainda, apesar de ensembles classificarem novos exemplos melhor que cada classificador individual, eles se comportam como caixas pretas, no sentido de não oferecer ao usuário alguma explicação relacionada à classificação por eles fornecida. Assim, neste trabalho propomos uma abordagem que utiliza algoritmos de aprendizado simbólico para construir ensembles de classificadores simbólicos que explicam suas decisões de classificação e são tão ou mais precisos que o mais preciso dos seus classificadores individuais. Além disso, considerando que algoritmos de aprendizado simbólico utilizam métodos de busca local para induzir classificadores quanto que algoritmos genéticos utilizam métodos de busca global, propomos uma segunda abordagem para aprender conceitos simbólicos de grandes bases de dados utilizando algoritmos genéticos para evoluir classificadores simbólicos em um único classificador simbólico, de maneira que o classificador evoluído é mais preciso que os classificadores iniciais. Ambas propostas foram implementadas em dois sistemas computacionais. Diversos experimentos usando diferentes conjuntos de dados foram conduzidos para avaliar ambas as propostas. Ainda que os resultados experimentais das duas soluções propostas são promissores, os melhores resultados foram obtidos utilizando a abordagem relacionada a algoritmos genéticos. 



\section{ABSTRACT}

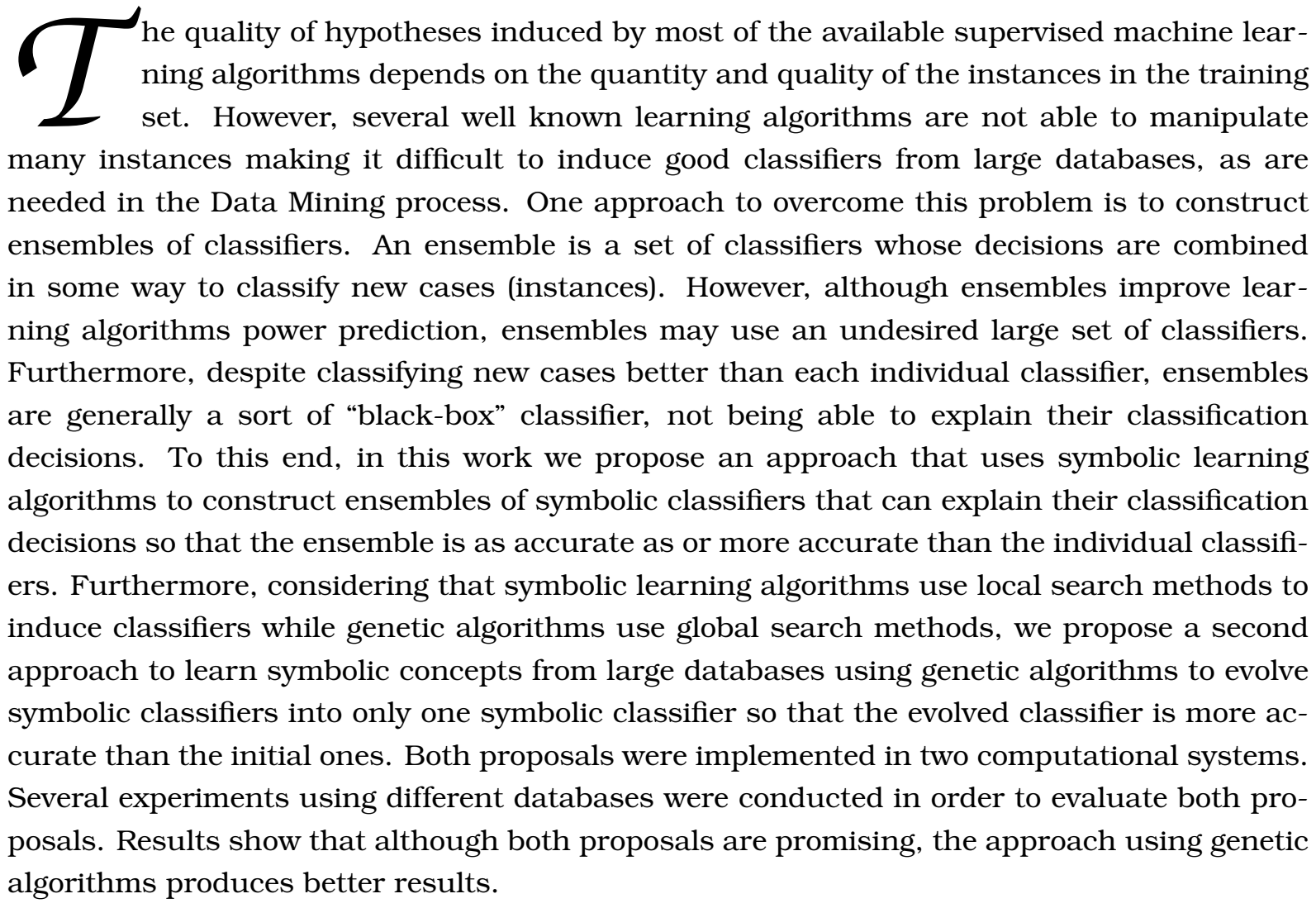





\section{CONTEÚdo}

Resumo ....................... i i

Abstract ...................... i i

Conteúdo ........................ . i

Lista de Figuras . . . . . . . . . . . . . . . . iv

Lista de Tabelas ....................... . viii

Lista de Algoritmos . . . . . . . . . . . . . . . . . xi

Lista de Abreviaturas . . . . . . . . . . . . . . . xiii

1 Introdução 1

1.1 Objetivos e Principais Contribuições . . . . . . . . . . . 4

1.2 Organização da Tese . . . . . . . . . . . . . . . 7

2 Aprendizado de Máquina $\quad 11$

2.1 Aprendizado de Máquina Supervisionado . . . . . . . . . . . . 12

2.2 Classificadores Simbólicos . . . . . . . . . . . . . . 12

2.3 Avaliação de Classificadores . . . . . . . . . . . . . 13

2.4 Avaliação de Regras . . . . . . . . . . . . . . . . . . . 18

2.5 Generalização e Especialização de Regras . . . . . . . . . . . 23

2.6 Regras de Associação . . . . . . . . . . . . . . . . . . 24

2.7 Considerações Finais . . . . . . . . . . . . . . 25

3 O Ambiente Discover $\quad 27$ 
3.1 O Ambiente Computacional DLE . . . . . . . . . . . 30

3.2 A Biblioteca de Classes DOL . . . . . . . . . . . . . . . . 30

3.3 O Ambiente Computacional SNiffer . . . . . . . . . . . . 32

3.4 Extensão do Ambiente SNIfFER . . . . . . . . . . . . . . . . 36

3.5 O Sistema Computacional NNRUles $\ldots \ldots \ldots \ldots$

3.6 Considerações Finais . . . . . . . . . . . . . . . . . . . 39

4 Ensembles de Classificadores $\quad 41$

4.1 Motivos para Construir Ensembles de Classificadores . . . . . . 45

4.2 Métodos de Construção de Ensembles . . . . . . . . . . . . . 47

4.2 .1 Técnica Bagging . . . . . . . . . . . . . . . . 47

4.2 .2 Técnica Boosting . . . . . . . . . . . . . . . . . 48

4.3 Métodos de Construção de Ensembles Propostos . . . . . . . . . 50

4.4 Um Método para Simplificar a Explicação de Ensembles de Classificadores . . . . . . . . . . . . . . . . . . . 54

4.5 Considerações Finais $\ldots \ldots \ldots \ldots$

5 O Ambiente ELE $\quad 57$

5.1 Proposta para Construção e Avaliação de Ensembles de Classificadores Simbólicos . . . . . . . . . . . . . . 58

5.2 O Módulo Computacional EnsembleTree . . . . . . . . . . 68

5.3 A Biblioteca de Classes Ensemblemethods . . . . . . . . . . 70

5.4 Um Exemplo de Execução do Módulo EnsembleTree . . . . . . . 73

5.5 Considerações Finais . . . . . . . . . . . . . . . . 78

6 Evolução de Classificadores Simbólicos $\quad 81$

6.1 Algoritmos Evolutivos . . . . . . . . . . . . . . . . . 82

6.2 Algoritmos Genéticos . . . . . . . . . . . . . . . 84

6.2.1 Algoritmo Genético Clássico _ . . . . . . . . . . . . 85

6.2.2 Componentes de um AG Clássico _ . . . . . . . . . . 87

6.2.3 Um Exemplo de Execução do AG Clássico . . . . . . . . . 89 
6.3 Algoritmos Genéticos Aplicados na Evolução de Classificadores Simbólicos ..................... . 92

6.4 Proposta de um Algoritmo Genético para Evoluir Classificadores Simbólicos .................... 96

6.4 .1 Codificação dos Indivíduos . . . . . . . . . . . . 97

6.4 .2 Operadores Genéticos . . . . . . . . . . . 98

6.4 .3 Funções de Avaliação . . . . . . . . . . . . . . . . . 99

6.4.4 Critério de Parada ................. 102

6.4.5 Pós-processamento do Indivíduo Resultante . . . . . . . . . 102

6.5 Considerações Finais . . . . . . . . . . . . . . 103

7 O Ambiente GAERE 105

7.1 Avaliação Experimental do Algoritmo Genético Proposto . . . . . . 106

7.2 O Módulo GATreE . . . . . . . . . . . . . . . . 113

7.3 O Módulo RuleStruct . . . . . . . . . . . . . . . . . 115

7.4 O Módulo RuleSetGA . . . . . . . . . . . . . . 116

7.5 O Módulo GA . . . . . . . . . . . . . . . . . 116

7.6 Considerações Finais . . . . . . . . . . . . . 117

8 Avaliação Experimental $\quad 119$

8.1 Descrição dos Experimentos — Fase I . . . . . . . . . . . . 120

8.1.1 Avaliação da Performance dos Métodos de Construção de Ensembles . . . . . . . . . . . . . . 121

8.1.2 Avaliação da Performance do Algoritmo de Simplificação da Explicação . . . . . . . . . . . . . . . . . 125

8.2 Descrição dos Experimentos — Fase II . . . . . . . . . . . . . . 129

8.2.1 Avaliação da Performance do Algoritmo Genético . . . . . . 130

8.2.2 Análise do Classificador Evoluído com o Algoritmo Genético 141

8.3 Considerações Finais . . . . . . . . . . . . . . . . . . . 142

9 Conclusão $\quad 149$

9.1 Resumo dos Objetivos e Resultados Obtidos . . . . . . . . . . . . 149 
9.2 Principais Contribuições e Limitações . . . . . . . . . . . . . . 152

9.3 Trabalhos Futuros . . . . . . . . . . . . . . . . . . . . . . 153

A Análise Qualitativa de Regras $\quad 155$

A.1 Uma Visão Unificada de Medidas de Avaliação de Regras . . . . . 155

A.2 Outros Critérios para Seleção de Regras . . . . . . . . . . . . 156

B Resultados Obtidos com o AG Proposto 161

$\begin{array}{ll}\text { Referências Bibliográficas } & 168\end{array}$ 


\section{LISTA DE FiguRAS}

2.1 Técnica de validação simples . . . . . . . . . . . . . . . . 17

2.2 Exemplo de $k$-fold cross-validation, $\operatorname{com} k=3 \ldots \ldots \ldots$

2.3 Regras ordenadas entre classes - conjunto de subconjuntos de regras ......................... 22

3.1 Exemplo de experimento organizado em diretórios para o ambiente SNIFFER . . . . . . . . . . . . . . . . . . . 34

4.1 Ensemble de três classificadores . . . . . . . . . . . . . . . 43

4.2 Probabilidade do voto majoritário estar errado com $L$ hipóteses, $L=1, \ldots, 150$, com taxa de erro de cada hipótese igual a $0.3,0.4 \mathrm{e}$ $0.45 \ldots \ldots \ldots \ldots \ldots \ldots \ldots \ldots \ldots$

4.3 Probabilidade do voto majoritário estar errado com $L$ hipóteses, $L=1, \ldots, 150$, com taxa de erro de cada hipótese igual a $0.7 \ldots 44$

4.4 Três motivos fundamentais que explicam porque os ensembles funcionam melhor que um único classificador . . . . . . . 45

4.5 Comportamento da função $\log \left(\frac{1-x}{x}\right) \ldots \ldots \ldots$. . . . . . 49

4.6 Um esquema dos métodos de construção de ensembles propostos 51

5.1 Configuração da árvore de diretórios para executar o SNiffer para obter a estimativa da taxa de erro verdadeira para cada uma das hipóteses $\mathbf{h}_{1}, \ldots, \mathbf{h}_{L} \ldots \ldots \ldots \ldots$. . . . . . . . 60

5.2 Configuração da árvore de diretórios após executar o Sniffer para obter a estimativa da taxa de erro verdadeira para cada uma das hipóteses $\mathbf{h}_{1}, \ldots, \mathbf{h}_{L} \ldots \ldots \ldots \ldots 60 \ldots$ 
5.3 Configuração da árvore de diretórios para construir um ensemble $\mathbf{h}^{*}$ composto pelas hipóteses $\mathbf{h}_{1}, \ldots, \mathbf{h}_{L} \ldots \ldots \ldots 6$

5.4 Configuração da árvore de diretórios para estimar o erro de um ensemble $\mathbf{h}^{*}$ composto pelas hipóteses $\mathbf{h}_{1}, \ldots, \mathbf{h}_{L} \ldots \ldots \ldots 62$

5.5 Estimativa da taxa de erro de um ensemble de classificadores . . 66

5.6 Estimativa da taxa de erro do classificador $\mathbf{h}_{11}$, construído sobre o conjunto de dados $S_{11} \ldots \ldots \ldots$. . . . . . . . 67

5.7 Configuração da árvore de diretórios para utilizar os métodos de construção de ensembles . . . . . . . . . . . . . . . . . 67

5.8 Configuração da árvore de diretórios para comparar diferentes métodos de construção de ensembles . . . . . . . . . . . . 68

5.9 Diagrama de classes em UML do projeto dos módulos de combinação e de classificação . . . . . . . . . . . . . . . . . . 73

5.10 Exemplo do primeiro passo de execução do módulo EnSEMBLETREE 74

5.11 Exemplo do segundo passo de execução do módulo EnSEMBLETREe 76

5.12 Exemplo do terceiro e último passo de execução do módulo ENSEMBlETREE . . . . . . . . . . . . . . . . . 79

6.1 Uma geração de um algoritmo genético . . . . . . . . . . . . 87

6.2 Base de regras na sintaxe padrão $\mathcal{P} \mathcal{B} \mathcal{M} \ldots \ldots$. . . . . . . . . 97

6.3 Exemplo de codificação de um individuo, composto por identificadores de regras . . . . . . . . . . . . . . . . 97

7.1 Estimativa de erro $\varepsilon^{*}$ de um classificador $\mathbf{h}^{*}$ evoluído com o AG proposto . . . . . . . . . . . . . . . 110

7.2 Configuração da árvore de diretórios para induzir os classificadores simbólicos cujas regras compõem a população inicial do(s) $\mathrm{AG}(\mathrm{s})$ a $\operatorname{ser}(\mathrm{em})$ executado(s) . . . . . . . . . . . . . . 111

7.3 Configuração da árvore de diretórios para executar o algoritmo genético proposto . . . . . . . . . . . . 111

7.4 Árvore de diretórios instanciada para induzir os classificadores simbólicos cujas regras compõem a população inicial do(s) AG(s) a ser(em) executado(s) . . . . . . . . . . . . . . . . . . . . . 114

7.5 Instanciação da árvore de diretórios para executar os AGs representados pelos identificadores GA.mracc.hqprec, GA.mracc.hqpc e GA.srlap.hqprec . . . . . . . . . . . . . . . . . . . . . . . 114 
7.6 Diagrama UML dos módulos RuleStruct, RuleSetGA e GA . 118

8.1 Gráfico dos resultados dos experimentos utilizando o conjunto de dados Nursery - Fase I de experimentos . . . . . . . . . . . 125

8.2 Gráfico dos resultados dos experimentos utilizando o conjunto de dados Chess - Fase I de experimentos . . . . . . . . . . . 126

8.3 Gráfico dos resultados dos experimentos utilizando o conjunto de dados Splice - Fase I de experimentos . . . . . . . . . . . . 127

8.4 Gráfico dos resultados dos experimentos utilizando o conjunto de dados Autos e métodos de classificação $M R$ - Fase II de experimentos

8.5 Gráfico dos resultados dos experimentos utilizando o conjunto de dados Balance e métodos de classificação $M R$ - Fase II de

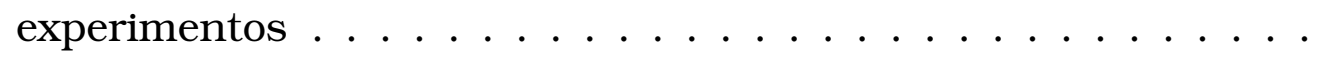

8.6 Gráfico dos resultados dos experimentos utilizando o conjunto de dados Heart e métodos de classificação $M R$ - Fase II de experimentos

8.7 Gráfico dos resultados dos experimentos utilizando o conjunto de dados Ionosphere e métodos de classificação $M R$ - Fase II de experimentos

8.8 Gráfico dos resultados dos experimentos utilizando o conjunto de dados Autos e métodos de classificação $S R$ - Fase II de experimentos

8.9 Gráfico dos resultados dos experimentos utilizando o conjunto de dados Balance e métodos de classificação $S R$ - Fase II de

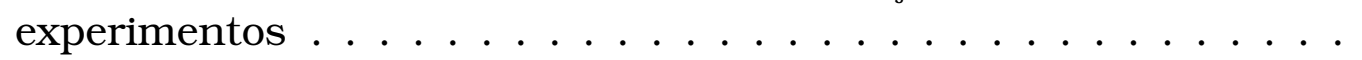

8.10 Gráfico dos resultados dos experimentos utilizando o conjunto de dados Heart e métodos de classificação $S R$ - Fase II de experi-

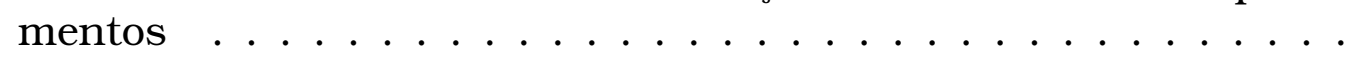

8.11 Gráfico dos resultados dos experimentos utilizando o conjunto de dados Ionosphere e métodos de classificação $S R$ - Fase II de

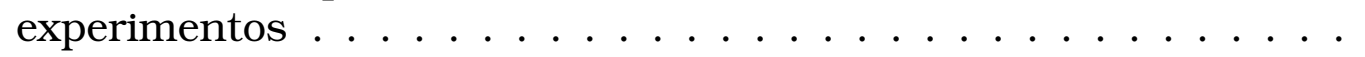

8.12 Gráfico de convergência da função de avaliação $M R_{L a c c} H Q_{F 1}$ utilizando o conjunto de dados Autos no cenário ScnII 1 . . . . . . 144

8.13Regras pertencentes ao classificador induzido $\mathcal{C N} 2$ no formato padrão de regras $\mathcal{P B M} \ldots \ldots$. . . . . . . . . . . . 145

8.14 Regras pertencentes ao classificador induzido $\mathcal{C} 4.5$ no formato padrão de regras $\mathcal{P B M} \ldots \ldots . \ldots . \ldots 146$ 
8.15Regras pertencentes ao classificador induzido $\mathcal{C} 4.5$ rules no formato padrão de regras $\mathcal{P B M} \ldots \ldots$. . . . . . . . . . . 146

8.16 Regras pertencentes ao classificador evoluído pelo AG no formato padrão de regras $\mathcal{P B M} \ldots \ldots \ldots$. . . . . . . . 147 


\section{LISTA DE TABELAS}

2.1 Conjunto de exemplos no formato atributo-valor . . . . . . . . . 12

2.2 Matriz de confusão . . . . . . . . . . . . . . . . . . 14

2.3 Matriz de confusão para problemas de classificação com somente

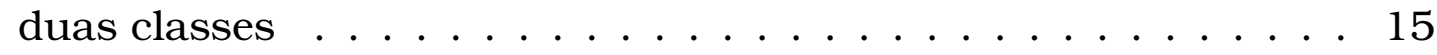

2.4 Matriz de contingência de uma regra . . . . . . . . . . . 19

3.1 Identificadores especiais para diretórios reconhecidos atualmente pelo SNIFFER para algoritmos de aprendizado simbólico . . . . . 35

5.1 Identificadores de métodos de construção de ensembles reconhecidos pelo SNIFFER . . . . . . . . . . . . . . . . . 65

7.1 Identificadores que indicam qual função de avaliação utilizar na execução do algoritmo genético . . . . . . . . . . . . . 109

8.1 Resumo das características dos conjuntos de dados utilizados na Fase I de experimentos . . . . . . . . . . . . . . . 121

8.2 Descrição dos cenários utilizados para realização dos experimentos na Fase I de experimentos . . . . . . . . . . . . . . . 122

8.3 Resultados experimentais obtidos utilizando o conjunto de dados Nursery — Fase I de experimentos . . . . . . . . . . . . . . 123

8.4 Resultados experimentais obtidos utilizando o conjunto de dados Chess — Fase I de experimentos . . . . . . . . . . . . . . . . . 123

8.5 Resultados experimentais obtidos utilizando o conjunto de dados Splice — Fase I de experimentos . . . . . . . . . . . . . . . . 124 
8.6 Resultados obtidos utilizando o conjunto de dados Nursery na fase de simplificação de explicação — Fase I de experimentos . 128

8.7 Resultados obtidos utilizando o conjunto de dados Chess na fase de simplificação de explicação — Fase I de experimentos . . . . 128

8.8 Resultados obtidos utilizando o conjunto de dados Splice na fase de simplificação de explicação - Fase I de experimentos . . . . . . 128

8.9 Resumo das características dos conjuntos de dados utilizados na Fase II de experimentos . . . . . . . . . . . . . . . . . . 130

8.10 Resultados obtidos na Fase de Experimentos II utilizando os métodos de construção de ensembles propostos - Fase II de experimentos 131

8.11 Descrição dos cenários utilizados para realização dos experimentos com o AG na fase II . . . . . . . . . . . . . . . . 132

8.12 Comparação dos resultados do AG utilizando os métodos $M R$ (Multiple Rule) com o melhor classsificador da respectiva população utilizando o teste $t$. Resultado do AG em relação ao melhor classificador da população inicial: " $\Delta$ " indica melhora significativa com 95\% de confiança; " $\triangle$ " indica melhora com diferença não significativa; " $\downarrow$ ” indica piora significativa com 95\% de confiança; “ $\downarrow "$ indica piora com diferença não significativa. . . . . . . . . . . . 138

8.13Número de regras e atributos diferentes relacionados aos classificadores induzidos pelos algoritmos $\mathcal{C N} 2, \mathcal{C} 4.5$ e $\mathcal{C} 4.5$ rules e ao classificador evoluído pelo AG no cenário ScnII 1 utilizando como função de avaliação $M R_{L a c c} H Q_{F 1}$ no conjunto de dados Autos . 143

8.14 Origem das regras que compõem o classificador evoluído pelo algoritmo genético . . . . . . . . . . . . . . . . . 143

A.1 Medidas genéricas de avaliação de regras . . . . . . . . . . . 159

A.2 Medidas relativas de avaliação de regras . . . . . . . . . . . 160

A.3 Medidas relativas de avaliação de regras com peso . . . . . . . 160

B.1 Resultados obtidos na Fase de Experimentos II, Cenário ScnII 1, utilizando o algoritmo genético proposto. . . . . . . . . . . . . 162

B.2 Resultados obtidos na Fase de Experimentos II, Cenário ScnII 2, utilizando o algoritmo genético proposto. . . . . . . . . . 163

B.3 Resultados obtidos na Fase de Experimentos II, Cenário ScnII 3, utilizando o algoritmo genético proposto. . . . . . . . . . . . 164 
B.4 Resultados obtidos na Fase de Experimentos II, Cenário ScnII 4, utilizando o algoritmo genético proposto. . . . . . . . . . . . . 165

B.5 Resultados obtidos na Fase de Experimentos II, Cenário ScnII 5, utilizando o algoritmo genético proposto. . . . . . . . . . . . . 166

B.6 Resultados obtidos na Fase de Experimentos II, Cenário ScnII 6, utilizando o algoritmo genético proposto. . . . . . . . . . . . . 167 
Lista de Tabelas 


\section{LisTA DE AlgoritMos}

1 Cálculo de informações para a avaliação de regras não-ordenadas 20

2 Cálculo de informações para a avaliação de regras ordenadas . . 21

3 Simplificação da explicação . . . . . . . . . . . . . . . . . . 55

4 Algoritmo genético clássico. . . . . . . . . . . . . . 86

5 Algoritmo genético proposto. . . . . . . . . . . . . . 96 
Lista de Algoritmos 


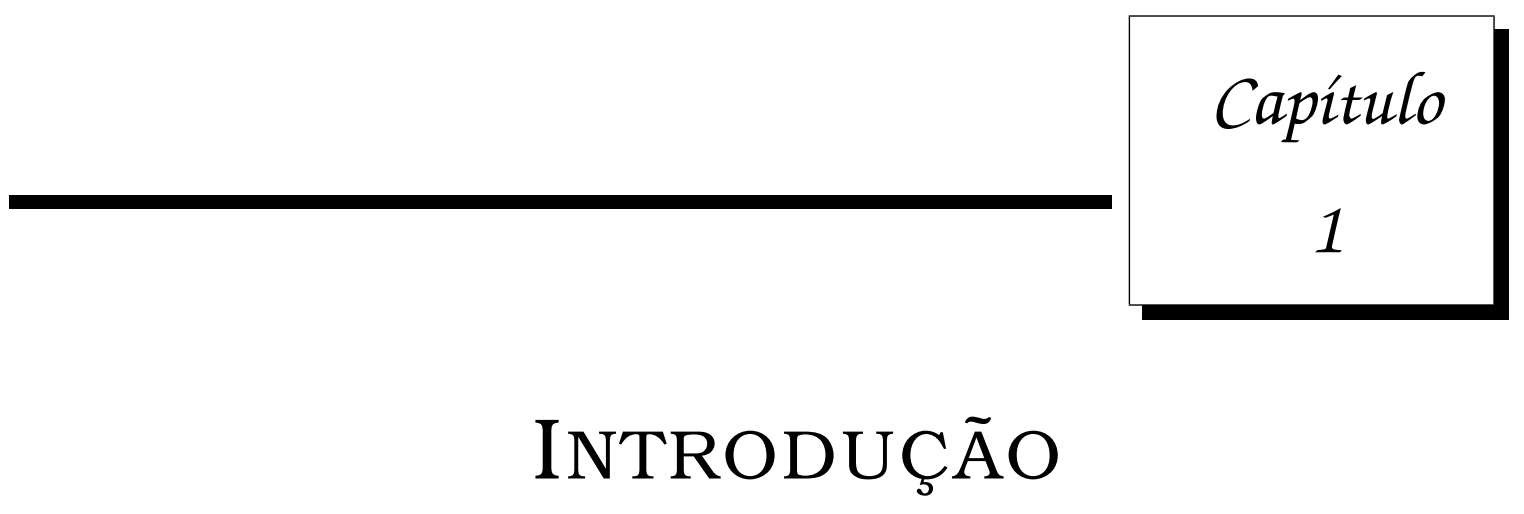

"A mente humana estendida para absorver uma nova idéia nunca volta às dimensões originais."

- Oliver Wendell Holmes

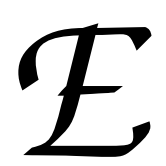

m muitos domínios nos quais existe uma necessidade de se obter novos conhecimentos para auxílio à tomada de decisões futuras a partir de bases de dados existentes, o conhecimento extraído deve estar em uma linguagem compreensivel por seres humanos. Problemas como esse são tipicamente tratados utilizando-se algoritmos de Aprendizado de Máquina (AM) simbólicos. Entretanto, em alguns domínios nos quais existe essa necessidade de expressar conhecimento em uma linguagem compreensivel por seres humanos, estão disponiveis bases de dados muito grandes, as quais muitas vezes não são processáveis pelos algoritmos de aprendizado simbólico disponíveis. Uma área de pesquisa em aprendizado de máquina está relacionada à procura de novos métodos para ampliar a capacidade dos algoritmos de aprendizado para manipulação de grandes bases, ou seja, para processar muitos exemplos, atributos e classes. Esse problema é típico da área de Mineração de $\operatorname{Dados}^{1}$ (MD) em grandes bases de dados (Cabena et al., 1998; Mannila,

\footnotetext{
${ }^{1}$ Data Mining
} 
1996; Mitchell, 1999; Rezende et al., 2003; Weiss and Indurkhya, 1998). Para tentar resolver os problemas de manipulação de grandes bases e descoberta de conhecimento em uma linguagem compreensivel por seres humanos, propomos neste trabalho duas abordagens. A primeira abordagem está relacionada à construção de ensembles de classificadores, e a segunda está relacionada a Algoritmos Genéticos (AGs) (Goldberg, 1989; Mitchell, 1997a).

Um ensemble é um conjunto de classificadores cujas decisões individuais são combinadas de alguma forma para classificar um novo caso (Dietterich, 2000b; Breiman, 1996; Freund and Schapire, 1997). Nessa abordagem, primeiramente são retiradas, por exemplo, $L$ amostras (subconjuntos) do conjunto de exemplos (dados) disponível para realizar o aprendizado. Logo após, cada um desses $L$ subconjuntos é submetido a algum algoritmo de aprendizado, induzindo assim $L$ classificadores (hipóteses), os quais podem ser construídos em paralelo. Apesar de melhorar o poder preditivo dos algoritmos de aprendizado, os métodos de construção de ensembles normalmente geram classificadores grandes, o que pode ser indesejável. Por exemplo, em (Margineantu and Dietterich, 1997), usando o conjunto de dados Frey-Slater (Blake et al., 1998) com 16 atributos numéricos e 16000 exemplos, é obtida uma boa precisão no conjunto de teste com 4000 exemplos utilizando 200 hipóteses unindo-as com votação. Incluindo o conjunto de treinamento e o conjunto de teste, o conjunto de dados requer aproximadamente 700Kbytes. Todavia, cada classificador ocupa 295Kbytes de memória, o que implica que o ensemble de 200 classificadores requer 58Mbytes - mais de 85 vezes o tamanho do conjunto de dados completo! Porém, considerando um ensemble simulado com 21 hipóteses, cada uma delas possuindo uma taxa de erro de 0.3 , e considerando um modelo ideal de ensembles, no qual as hipóteses são independentes, a probabilidade de 11 ou mais hipóteses serem simultaneamente incorretas é 0.026, ou seja, a taxa de erro desse ensemble é muito menor que a taxa de erro das hipóteses individuais que constituem o ensemble. Assim, teoricamente, é possivel construir ensembles de classificadores com uma quantidade pequena de classificadores componentes. Além do mais, ainda que ensembles classifiquem novos exemplos melhor que cada classificador individual, eles se comportam como caixas pretas, no sentido de não oferecer ao usuário alguma explicação relacionada à classificação por eles fornecida. Observa-se ainda que classificadores simbólicos individuais não oferecem sempre uma explicação que justifique a classificação de novos casos, apesar de ser simples o processo de fornecer tal explicação. Em algumas situações, essas 
explicações são obrigatórias. Por exemplo, em certos países, para informar ao cliente de um banco se seu crédito foi aprovado ou não, há uma necessidade legal de se justificar o motivo da aprovação ou negação do crédito. Em outro exemplo, nos problemas relacionados à medicina, é necessário fornecer uma explicação relacionada ao diagnóstico do paciente estar ou não estar com uma determinada doença. Nesses casos, algoritmos de aprendizado de máquina que induzem classificadores com comportamento do tipo "caixa preta" não podem ser utilizados.

Em relação à segunda abordagem mencionada para resolver problemas de manipulação de grandes bases de dados, relacionada a algoritmos genéticos, tendo em vista que algoritmos de aprendizado simbólico realizam busca local e tendo em vista que algoritmos genéticos são um método de busca global, são encontradas na literatura algumas propostas de algoritmos genéticos para evoluir conjuntos de classificadores induzidos por esses algoritmos de aprendizado em um único classificador, desejavelmente mais preciso que os classificadores iniciais (Freitas, 2002a,b; Michalewicz, 1999; De Jong et al., 1993; Janikow, 1993; Pei et al., 1997; Llorà and i Guiu, 1999; Ruta and Gabrys, 2001; Setzkorn and Paton, 2003). Para evoluir esses classificadores iniciais, podem ser retiradas amostras do conjunto de dados disponível. No caso específico de classificadores simbólicos, para evoluir esses classificadores podem ser utilizadas duas abordagens: a abordagem Michigan, na qual cada indivíduo codificado para evolução consiste de uma única regra de conhecimento, e a abordagem Pittsburgh, na qual cada indivíduo codificado para evolução consiste de um classificador composto por um conjunto de regras de conhecimento. Essa última abordagem, Pittsburgh, é a abordagem mais apropriada por estar relacionada à evolução de classificadores compostos por regras de classificação. Assim, essa é a abordagem utilizada neste trabalho. Para utilizar a abordagem Pittsburgh, é necessário projetar vários componentes do AG, tais como a estrutura de dados que representará os indivíduos (classificadores simbólicos) e os operadores genéticos responsáveis pela evolução dos indivíduos. A dificuldade encontrada nos trabalhos relacionados na literatura está fortemente relacionada à codificação desses indivíduos e ao número de iterações que o AG deve executar para atingir bons resultados.

Guando são utilizados ou propostos métodos de aprendizado de máquina para extração de conhecimento, devem ser realizados estudos experimentais para avaliar o desempenho desses métodos (Dietterich, 1990; Langley, 2000). 
Para uma boa avaliação é fundamental projetar criteriosamente os experimentos a serem realizados, identificando os critérios de avaliação e variáveis independentes, além da neutralização de variáveis aleatórias que fogem ao controle do experimentador. Quanto à identificação das variáveis independentes, a abordagem freqüentemente empregada inclui a utilização de um ou mais métodos de controle para a comparação com novos métodos ou algoritmos propostos. Outros fatores, tais como a acomodação do algoritmo a um conjunto de dados em particular, são geralmente tratados pela repetição da execução do algoritmo várias vezes em diferentes (sub) amostras dos dados. Nesse sentido, os métodos mais aplicados são validação cruzada ( $k$-fold cross-validation) e amostragem bootstrap (Kohavi and Li, 1995), além de se testar um modelo em uma amostra de dados diferente daquela utilizada na sua indução, i.e., conjunto de dados de teste. Finalmente, é importante ressaltar que para se tirar conclusões a respeito de estudos em aprendizado de máquina é muito importante a utilização de testes de hipóteses (Demšar, 2006), para se determinar o grau de confiança em que as conclusões foram tiradas.

\subsection{Objetivos e Principais Contribuições}

No trabalho de mestrado realizado por Bernardini (2002), foram investigados métodos para combinação de classificadores simbólicos. A proposta do trabalho de mestrado consistia em selecionar regras que compunham classificadores previamente construídas por algoritmos de aprendizado simbólicos para compor um único classificador final. Para selecionar as regras, eram utilizadas medidas de avaliação de regras. Entretanto, nos experimentos realizados verificamos que as taxas de erro obtidas para os classificadores era grande quando comparadas às taxas de erro dos classificadores iniciais. Entretanto, segundo um especialista em um estudo de caso que realizamos, eram boas as regras que participavam desses classificadores finais. Dessa maneira, decidimos continuar investigando com maior profundidade outros métodos de combinação de classificadores. Assim, inicialmente, foram colocadas as seguintes duas questões a serem respondidas neste trabalho:

1. É possivel obter um bom poder de predição combinando classificadores simbólicos induzidos sobre conjuntos dispersos de dados sobre algum domínio em questão? Ou seja, dado um conjunto de dados grande o suficiente a ponto de não poder ser manipulado pelos algoritmos de apren- 
dizado simbólico disponíveis atualmente, é possível extrair amostras disjuntas (ou não) desse conjunto de dados, induzir classificadores, combiná-los e melhorar o poder de predição desses classificadores, com a capacidade de também fornecer uma explicação relacionada à classificação de novos exemplos?

2. Mesmo em conjuntos tratáveis por algoritmos de aprendizado simbólico, induzindo classificadores com diferentes algoritmos sobre a mesma base de dados, é possivel melhorar a predição desses classificadores, combinando-os com os métodos propostos, mantendo a capacidade de explicação?

Para responder a essas questões, utilizando algoritmos de aprendizado de máquina simbólicos que expressam o conhecimento como regras proposicionais if-then, os objetivos deste trabalho compreendem:

1. Propor e avaliar métodos para construção de ensembles de classificadores simbólicos que possam fornecer uma explicação de suas decisões; e

2. Propor um algoritmo genético para evoluir classificadores simbólicos em um único classificador simbólico, preferencialmente mais preciso que os classificadores individuais.

Tendo em vista os objetivos acima descritos, as principais contribuições desta tese de doutoramento podem ser reunidas nos seguintes três principais grupos:

1. Novos métodos de construção de ensembles de classificadores simbólicos que explicam suas decisões;

2. Um método para resumir explicações fornecidas pelos ensembles construídos utilizando os métodos de construção de ensembles propostos;

3. Um algoritmo genético para evoluir classificadores simbólicos em um único classificador, de maneira a facilitar a codificação dos indivíduos (classificadores), característica essa que facilita a proposta e utilização de diferentes funções de avaliação. 
Essas contribuições foram divulgadas no meio científico e deram lugar a diversas publicações, brevemente descritas a seguir.

Em (Bernardini and Monard, 2005a; Bernardini et al., 2005, 2006), foram propostos diversos métodos de construção de ensembles de classificadores. Tais métodos consistem de duas fases. Na primeira fase, são utilizados diversos métodos para classificação de exemplos utilizando medidas de avaliação de regras; na segunda fase, são propostos métodos para combinação das classificações (decisões) tomadas pelos classificadores na primeira fase. Esses métodos foram bastante eficientes para combinar classificadores induzidos sobre amostras de conjuntos de dados de porte médio, disponíveis na UCI (Blake et al., 1998). Em (Bernardini and Monard, 2005b), é proposto um método para resumir as explicações fornecidas pelos ensembles construídos com os métodos propostos. Os resultados obtidos são bastante interessantes, tendo em vista, entre outros, que o número de regras a serem analisadas pelo usuário relacionadas à explicação da classificação é reduzido pela metade.

Em (Bernardini and Monard, 2006b,c), é proposto um algoritmo genético para evolução (combinação) de classificadores simbólicos. A principal vantagem de nossa proposta em relação a outras propostas encontradas na literatura está relacionada à codificação dos indivíduos (classificadores), a qual é mais simples que as maneiras de codificação usualmente propostas, o que facilita a implementação dos operadores do algoritmo genético. Ainda, em nossa proposta, os classificadores iniciais podem ser classificadores induzidos por algoritmos de aprendizado simbólico, o que muitas vezes facilita o processo de busca por parte do AG, tendo em vista que esses classificadores foram construídos visando um bom poder de predição, e, portanto, estão provavelmente mais próximos do da solução ótima global, ou seja, do melhor classificador do domínio no qual está sendo trabalhado. Nesse AG, propomos diversas funções de avaliação assim como diferentes critérios de parada. Os resultados obtidos em experimentos utilizando conjuntos de dados de porte médio foram muito bons.

Em ambas as abordagens - construção de ensembles de classificadores simbólicos e utilização de um algoritmo genético para evolução de classificadores simbólicos —, uma contribuição importante está relacionada à maneira de avaliação desses métodos, a qual foi cuidadosamente planejada para avaliar de maneira coerente as propostas deste trabalho. O critério de avaliação dos resultados obtidos, ou seja, dos classificadores obtidos, com a aplicação 
dos métodos propostos neste trabalho está relacionado à uma medida de desempenho - a taxa de erro de classificação. O método de controle utilizado para avaliação dos métodos propostos para construção de ensembles de classificadores e do método proposto para evolução de classificadores simbólicos está relacionado com a utilização dos classificadores iniciais utilizados na construção de ensembles e/ou processo de evolução.

\subsection{Organização da Tese}

Esta tese está dividida em 9 capítulos:

\section{Capitulo 2 - Conceitos de Aprendizado de Máquina.}

Nesse capítulo, são descritos conceitos de aprendizado de máquina relacionados à indução de classificadores supervisionados e simbólicos, ou seja, classificadores compostos por regras proposicionais if-then. Também, são abordadas as maneiras de se avaliar classificadores como um todo, assim como maneiras de se avaliar cada uma das regras individualmente.

\section{Capitulo 3 - Ambiente Discover.}

O ambiente Discover é um projeto de grande porte em desenvolvimento no nosso laboratório de pesquisa - LABIC —, voltado para mineração de dados. Nesse ambiente, estão implementados métodos para englobar todo o processo de mineração de dados, desde métodos para pré-processamento de dados, passando por métodos de extração de modelos e padrões dos dados, até métodos de pós-processamento de dados. Em relação aos métodos de extração de modelos e padrões dos dados, estão implementados diversos paradigmas de aprendizado simbólico. Nesse capítulo, é feita uma descrição concisa do ambiente Discover, bem como dos módulos do Discover utilizados, direta ou indiretamente, no desenvolvimento dos sistemas descritos para atender os objetivos deste trabalho, os quais são descritos em capítulos posteriores.

\section{Capitulo 4 - Ensembles de Classificadores.}

Nesse capítulo, inicialmente são descritos alguns conceitos teóricos que motivam a construção de ensembles de classificadores para melhorar o poder preditivo de algoritmos de aprendizado supervisionado. São encontrados na literatura diversos métodos de construção de en- 
sembles de classificadores que inspiraram a proposta dos métodos de construção de ensembles de classificadores simbólicos propostos neste trabalho. Alguns desses métodos são também descritos nesse capítulo. Ainda, são descritos os métodos que propomos para construção de ensembles de classificadores, assim como é descrito o método proposto para simplificar a explicação fornecida pelos ensembles.

\section{Capitulo 5 - O Ambiente ELE.}

Nesse capítulo, é feita uma descrição do sistema computacional implementado como um módulo pertencente ao Discover, o qual implementa os métodos de construção de ensembles propostos neste trabalho, bem como implementa o método que resume as explicações fornecidas pelos ensembles construídos com os métodos propostos.

\section{Capitulo 6 - Evolução de Classificadores Simbólicos.}

Nesse capítulo, é feita uma descrição dos Algoritmos Evolutivos propostos na literatura relacionados a este trabalho, e uma descrição dos Algoritmos Genéticos propostos na literatura relacionados a quaisquer problemas de otimização e em particular os relacionados à evolução de classificadores simbólicos. Também, é descrito nesse capítulo o Algoritmo Genético proposto para evolução de classificadores simbólicos, o qual tenta resolver os problemas encontrados nos trabalhos propostos na literatura. São descritos também os operadores genéticos, as diversas funções de avaliação por nós propostas e os critérios de parada relacionados ao algoritmo genético proposto.

\section{Capitulo 7 - O Ambiente GAERE.}

Nesse capítulo, é feita uma descrição do sistema computacional implementado como um módulo pertencente ao Discover, o qual implementa o algoritmo genético proposto neste trabalho para evolução de classificadores simbólicos.

\section{Capitulo 8 - Avaliação Experimental.}

Nesse capítulo, são descritos os experimentos realizados sobre conjuntos de dados naturais utilizando as propostas deste trabalho. Os resultados mostram que ambos os métodos são bastante promissores, com destaque para o método de evolução de classificadores simbólicos que apresenta muito bons resultados.

\section{Capitulo 9 - Conclusão.}

Nesse capítulo, são feitas as conclusões deste trabalho e comenta- 
mos as vantagens e desvantagens dos métodos propostos, bem como possiveis trabalhos futuros. 


\section{Capítulo}

\section{APRENDIZADO DE MÁQuina}

"Melhor que tudo é aprender; o dinheiro pode ser perdido ou roubado, a saúde e a força podem faltar, mas aquilo que você coloca na sua mente será para sempre seu”.

\section{- Louis L'Amour}

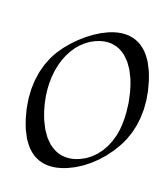

tema desta tese de doutoramento está relacionada ao uso de algoritmos de aprendizado simbólico para induzir classificadores com bom poder de predição sobre (grandes) conjuntos de dados. É essencial, então, que sejam descritos diversos conceitos de aprendizado de máquina para facilitar a compreensão deste trabalho. Assim, neste capítulo são descritos conceitos de aprendizado de máquina relacionados à indução de classificadores supervisionados e simbólicos, ou seja, classificadores compostos por regras proposicionais if-then. Também, são abordadas as maneiras de se avaliar classificadores como um todo, assim como maneiras de se avaliar cada uma das regras individualmente. 


\subsection{Aprendizado de Máquina Supervisionado}

No problema padrão de aprendizado supervisionado, a entrada do algoritmo consiste de um conjunto de exemplos $S$, com $N$ exemplos $T_{i}, i=1, \ldots, N$, escolhidos de um domínio $X$ com uma distribuição $D$ fixa, desconhecida e arbitrária, da forma $\left\{\left(\mathbf{x}_{1}, y_{1}\right), \ldots,\left(\mathbf{x}_{N}, y_{N}\right)\right\}$ para alguma função desconhecida $y=$ $f(\mathbf{x})$. Os $\mathbf{x}_{i}$ são tipicamente vetores da forma $\left(x_{i 1}, x_{i 2}, \ldots, x_{i M}\right)$ com valores discretos ou numéricos. $x_{i j}$ refere-se ao valor do atributo $j$, denominado $\mathbf{X}_{j}$, do exemplo $T_{i}$, como mostra a Tabela 2.1. Os valores $y_{i}$ referem-se ao valor do atributo $Y$, freqüentemente denominado classe.

\begin{tabular}{c|cccc|c|}
\cline { 2 - 6 }$T_{1}$ & $X_{1}$ & $X_{2}$ & $\ldots$ & $X_{M}$ & $Y$ \\
\cline { 2 - 6 }$T_{2}$ & $x_{11}$ & $x_{12}$ & $\ldots$ & $x_{1 M}$ & $y_{1}$ \\
$x_{21}$ & $x_{22}$ & $\ldots$ & $x_{2 M}$ & $y_{2}$ \\
$T_{N}$ & $\vdots$ & $\vdots$ & $\ddots$ & $\vdots$ & $\vdots$ \\
\cline { 2 - 6 } & $x_{N 1}$ & $x_{N 2}$ & $\ldots$ & $x_{N M}$ & $y_{N}$ \\
\hline
\end{tabular}

Tabela 2.1: Conjunto de exemplos no formato atributo-valor

Os valores de $y$ são tipicamente pertencentes a um conjunto discreto de classes $C_{v}, v=1, \ldots, N_{C l}$, i.e $y \in\left\{C_{1}, \ldots, C_{N_{C l}}\right\}$, quando se trata de classificação, ou ao conjunto de números reais em caso de regressão. O enfoque deste trabalho é problemas de classificação. Assim, quando for dito que um exemplo pertence à uma determinada classe $C_{v}$, isso significa que o exemplo possui $C_{v}$ como valor de $y$, ou, ainda, o valor $C_{v}$ foi associado a $y$ quando o problema é associar uma classe a um exemplo.

Dado um conjunto $S$ de exemplos a um algoritmo de aprendizado, um classificador h será induzido. O classificador consiste da hipótese feita sobre a verdadeira (mas desconhecida) função $f$. Dados novos exemplos $\mathbf{x}$, o classificador, ou hipótese, h prediz o valor correspondente $y$.

\subsection{Classificadores Simbólicos}

Algoritmos de aprendizado simbólicos induzem o classificador $\mathrm{h}$ de tal forma que o conceito descrito por h é facilmente interpretável por seres humanos (Mitchell, 1997b; Monard and Baranauskas, 2003). Neste trabalho, são considerados simbólicos os classificadores cuja linguagem de descrição pode ser transformada em um conjunto de $N_{R}$ regras proposicionais if-then, i.e. $\mathbf{h}=\left\{R_{1}, R_{2}, \ldots, R_{N_{R}}\right\}$, do tipo 


$$
\text { Corpo } \rightarrow \text { Cabeça ou Body } \rightarrow \text { Head }
$$

Um complexo é uma disjunção de conjunções de testes de atributos da forma $X_{i}$ op Valor, onde $X_{i}$ é o nome de um atributo, op é um operador pertencente ao conjunto $\{=, \neq,<, \leq,>, \geq\}$ e Valor é um valor válido do atributo $X_{i}$. Uma regra $R$ assume a forma if $B$ then $H$ ou simbolicamente $B \rightarrow H$, onde $H$ é a cabeça, ou conclusão da regra, e $B$ é o corpo, ou condição da regra. $H$ e $B$ são ambos complexos sem nenhum atributo em comum. Em uma regra de classificação, $H$ (a cabeça da regra) assume a forma class $=C_{i}$, onde $C_{i} \in\left\{C_{1}, \ldots, C_{N_{C l}}\right\}$. Classificadores compostos por regras podem incluir uma regra especial - a regra default - , a qual possui Corpo vazio e a Cabeça é dada pela classe predita pela maioria dos exemplos no conjunto de treinamento.

O conjunto de regras que constituem um classificador $\mathbf{h}=\left\{R_{1}, \ldots, R_{N_{R}}\right\}$ simbólico pode ser avaliado tanto considerando a precisão de $\mathbf{h}$ como um todo, ou seja, como um classificador tipo caixa preta - Seção 2.3 - , ou avaliando separadamente cada uma das regras que constituem $\mathbf{h}$ - Seção 2.4.

\subsection{Avaliação de Classificadores}

Dado um conjunto de exemplos $S$, esse conjunto de exemplos deve ser utilizado em diferentes fases do aprendizado. Para cada fase, é utilizado um subconjunto desse conjunto de exemplos, os quais são identificados como:

Conjunto de Treinamento: Esse conjunto é a principal entrada dos algoritmos de aprendizado. É a partir dele que são construídos os modelos, e, portanto, ele deve ser um subconjunto representativo do conjunto original, ou seja, que tenha uma distribuição o mais semelhante possivel do conjunto original, para que seja realizada inferência sobre $S$. Na literatura, esse conjunto também é conhecido como seen cases, pois se refere aos exemplos que foram "vistos" pelo algoritmo de aprendizado durante a construção do modelo.

Conjunto de Teste: Esse conjunto é utilizado para avaliar o modelo construído. O conjunto de teste, também conhecido como unseen cases, não deve ser apresentado ao algoritmo de aprendizado durante a construção do modelo. Idealmente, esse conjunto não deve ter exemplos em comum com o conjunto de treinamento. 
Conjunto de Validação: Em alguns casos, pode ser necessário utilizar exemplos para realizar ajustes no modelo construído pelo algoritmo de aprendizado. Esses exemplos não são utilizados para construir o modelo, mas são utilizados para seu "ajuste". Dessa maneira, esses exemplos são indiretamente "vistos" durante o processo de aprendizado, o que obriga que os exemplos de validação sejam distintos dos exemplos de teste.

Para avaliar um classificador h, é necessário coletar informações das decisões tomadas pelo classificador no conjunto de teste $S=\left\{\left(\mathbf{x}_{1}, y_{1}\right), \ldots,\left(\mathbf{x}_{N}, y_{N}\right)\right\}$, $y_{i} \in\left\{C_{1}, \ldots, C_{N_{C l}}\right\}$. Para isso, constrói-se uma matriz bi-dimensional, cujas dimensões são denominadas classe verdadeira e classe predita. A essa matriz dá-se o nome de matriz de confusão, mostrada na Tabela 2.2 para $N_{C l}$ classes. Cada elemento $M\left(C_{i}, C_{j}\right)$ da matriz, definido pela Equação 2.1, indica o número de exemplos que pertencem à classe $C_{i}$ e foram preditos como pertencentes à classe $C_{j}$; nessa equação, $\left\|h(\mathbf{x})=C_{j}\right\|$ é igual a 1 se a igualdade $h(\mathbf{x})=C_{j}$ for verdadeira, ou é igual a 0 se a igualdade for falsa. O número de predições corretas para cada classe são os apresentados na diagonal principal da matriz de confusão, ou seja, os valores associados a $M\left(C_{i}, C_{i}\right)$. Todos os outros elementos da matriz $M\left(C_{i}, C_{j}\right)$, para $i \neq j$, são referentes ao número de erros cometidos em cada classe.

\begin{tabular}{c|cccc}
\hline \hline Classe & Predita & Predita & $\ldots$ & Predita \\
Verdadeira & $C_{1}$ & $C_{2}$ & & $C_{N_{C l}}$ \\
\hline$C_{1}$ & $M\left(C_{1}, C_{1}\right)$ & $M\left(C_{1}, C_{2}\right)$ & $\ldots$ & $M\left(C_{1}, C_{N_{C l}}\right)$ \\
$C_{2}$ & $M\left(C_{2}, C_{1}\right)$ & $M\left(C_{2}, C_{2}\right)$ & $\ldots$ & $M\left(C_{2}, C_{N_{C l}}\right)$ \\
$\vdots$ & $\vdots$ & $\vdots$ & $\ddots$ & $\vdots$ \\
$C_{N_{C l}}$ & $M\left(C_{N_{C l}}, C_{1}\right)$ & $M\left(C_{N_{C l}}, C_{2}\right)$ & $\ldots$ & $M\left(C_{N_{C l}}, C_{N_{C l}}\right)$ \\
\hline \hline
\end{tabular}

Tabela 2.2: Matriz de confusão

$$
M\left(C_{i}, C_{j}\right)=\sum_{\forall(\mathbf{x}, y) \in S \mid y=C_{i}}\left\|h(\mathbf{x})=C_{j}\right\|
$$

Para simplificar, considere um problema de classificação com duas classes, geralmente rotulados como sendo exemplos positivos "+" e negativos "-" de um conceito. Na Tabela 2.3 é ilustrada a matriz de confusão para problemas com somente dois valores no atributo classe, onde $T_{P}$ é o número de exemplos positivos classificados corretamente, $F_{N}$ é o número de exemplos positivos classificados erroneamente, $F_{P}$ é o número de exemplos negativos 
classificados erroneamente, e $T_{N}$ é o número de exemplos negativos classificados corretamente, de um total de $N=\left(T_{P}+F_{N}+F_{P}+T_{N}\right)$ exemplos.

\begin{tabular}{c|cc}
\hline \hline Classe & Predita + & Predita - \\
Verdadeira & Verdadeiros Positivos & Falsos Negativos \\
\hline+ & $T_{P}$ & $F_{N}$ \\
& & \\
- & Falsos Positivos & Verdadeiros Negativos \\
& $F_{P}$ & $T_{N}$ \\
\hline \hline
\end{tabular}

Tabela 2.3: Matriz de confusão para problemas de classificação com somente duas classes

A acurácia e a taxa de erro, definidas pelas Equações 2.2 e 2.3 respectivamente, são duas das medidas mais utilizadas para avaliar a performance de uma hipótese. Outras medidas que também podem ser utilizadas para avaliar um classificador são sensibilidade ou recall (Equação 2.4), precisão (Equação 2.5) e $F_{1}$ (Equação 2.6). Para podermos compreender melhor o que a medida $F_{1}$ significa em termos dos valores $T_{P}, F_{P}$ e $F_{N}$, a Equação 2.6 foi desenvolvida na Equação 2.7. Deve ser observado que, para serem utilizadas tais medidas em problemas com mais de dois valores para o atributo classe, o processo que se utiliza geralmente é tornar cada classe como sendo a classe positiva e a união de todas as outras é considerada a classe negativa. Entretanto, para facilitar a utilização das medidas de recall e precisão, foram utilizadas neste trabalho as Equações 2.8 e 2.9, respectivamente ${ }^{1}$.

$$
\begin{gathered}
\operatorname{Acc}(\mathbf{h})=\frac{T_{P}+T_{N}}{N} \\
\operatorname{Err}(\mathbf{h})=1-\operatorname{Acc}(\mathbf{h}) . \\
\operatorname{Recall}(\mathbf{h})=\frac{T_{P}}{T_{P}+F_{N}} . \\
\operatorname{Prec}(\mathbf{h})=\frac{T_{P}}{T_{P}+F_{P}} .
\end{gathered}
$$

\footnotetext{
${ }^{1}$ A definição das medidas Recall e Prec para classes com mais de dois valores foi baseada na definição utilizada no KDD-Cup de 2005 - http://www.acm.org/sigs/sigkdd/kdd2005/ kddcup.html.
} 


$$
\begin{gathered}
F_{1}(\mathbf{h})=\frac{2 \times \operatorname{Prec}(\mathbf{h}) \times \operatorname{Recall}(\mathbf{h})}{\operatorname{Prec}(\mathbf{h})+\operatorname{Recall}(\mathbf{h})} . \\
F 1(\mathbf{h})=\frac{2 \times \operatorname{Prec}(\mathbf{h}) \times \operatorname{Recall}(\mathbf{h})}{\operatorname{Prec}(\mathbf{h})+\operatorname{Recall}(\mathbf{h})} \\
=\frac{2 \times \frac{T_{P}}{T_{P}+F_{P}} \times \frac{T_{P}}{T_{P}+F_{N}}}{\frac{T_{P}}{T_{P}+F_{P}}+\frac{T_{P}}{T_{P}+F_{N}}} \\
=\frac{2 T_{P}^{2}}{T_{P}\left(T_{P}+F_{N}+T_{P}+F_{P}\right)}=\frac{2 T_{P}}{2 T_{P}+F_{N}+F_{P}} \\
\operatorname{Recall}(\mathbf{h})=\frac{\sum_{v=1}^{N_{C l}} T_{P_{C_{v}}}}{\sum_{v=1}^{N_{C l} T_{P_{C_{v}}}+F_{N_{C_{v}}}} .} \\
\operatorname{Prec}(\mathbf{h})=\frac{\sum_{v=1}^{N_{C l}} T_{P_{C_{v}}}}{\sum_{v=1}^{N_{C l} T_{P_{C_{v}}}+F_{P_{C_{v}}}} .}
\end{gathered}
$$

Como mencionado, para estimar o erro, deve ser utilizado o conjunto de teste com exemplos não vistos pelo algoritmo na indução do classificador. A fim de estimar o erro verdadeiro, existem diversas técnicas para construir o conjunto de treinamento e teste, dentre elas pode-se citar:

Validação Simples: Nesta técnica, retiram-se de 5 a 33\% dos exemplos da base de dados para teste e o restante é utilizado para a construção do classificador. Após construído o classificador, esse conjunto de teste é usado para estimar o erro verdadeiro do classificador. Na Figura 2.1 é ilustrada a técnica de validação simples.

K-Fold Cross-Validation: Se existe uma quantidade limitada de dados (exemplos) para construir o classificador, fica difícil utilizar a técnica de validação simples, já que retirar uma porcentagem dos dados pode significar ter poucos dados para treinamento. Na técnica de $k$-fold cross-validation, o conjunto $S$ de dados é dividido aleatoriamente em $k$ partições $S_{1}, \ldots, S_{k}$ disjuntas, sendo todas as partições de conjuntos de dados de aproximadamente o mesmo tamanho. Após, são executadas $k$ iterações de indução e teste de um classificador. Na primeira iteração, é induzido o classificador $\mathbf{h}_{1}$ com os conjuntos de dados $S_{2}, \ldots, S_{k}$, sendo depois testado com o 


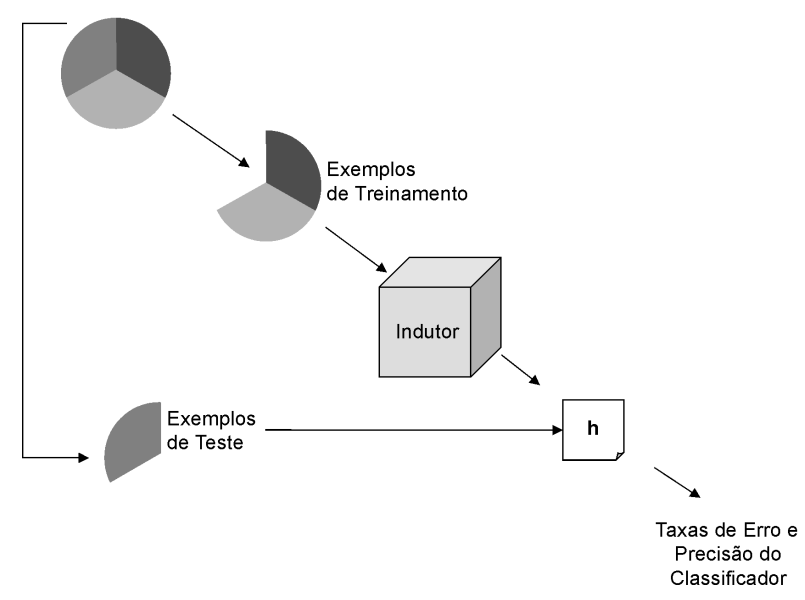

Figura 2.1: Técnica de validação simples

conjunto $S_{1}$, obtendo assim a taxa de erro $\operatorname{Err}\left(\mathbf{h}_{1}\right)^{2}$. Na segunda iteração, é induzido o classificador $\mathbf{h}_{2}$ com os conjuntos $S_{1}, S_{3}, \ldots, S_{k}$, sendo depois testado com o conjunto $S_{2}$, obtendo assim a taxa de erro $\operatorname{Err}\left(\mathbf{h}_{2}\right)$, e assim sucessivamente. Tendo em vista que agora existem $k$ estimadores de erro independentes ${ }^{3} \operatorname{Err}\left(\mathbf{h}_{1}\right), \ldots, \operatorname{Err}\left(\mathbf{h}_{k}\right)$, com eles pode-se estimar a média e o erro padrão do erro, definidos respectivamente pelas Equações 2.10 e 2.11, do modelo final. Esse modelo final é construído utilizando todos os exemplos disponiveis. Na Figura 2.2 é ilustrada a técnica de $k$-fold cross-validation, com $k=3$.

$$
\begin{gathered}
m_{-} \operatorname{err}(\mathbf{h})=\frac{1}{k} \sum_{k=1}^{k} \operatorname{Err}\left(\mathbf{h}_{k}\right) \\
\operatorname{se\_ err}(\mathbf{h})=\frac{1}{\sqrt{k-1}} \sqrt{\frac{1}{k} \sum_{k=1}^{k}\left(\operatorname{Err}\left(\mathbf{h}_{k}\right)-m_{-} \operatorname{err}\left(\mathbf{h}_{k}\right)\right)^{2}}
\end{gathered}
$$

K-Fold Cross-Validation Estratificado: Esta técnica é semelhante à técnica $k$-fold cross-validation. A diferença está na maneira em que é feita a divisão do conjunto de dados original em $k$ partições. No método de $k$ fold cross-validation estratificado, as partições são feitas de modo que seja respeitada a distribuição dos exemplos nas classes. Ou seja, se no conjunto de dados original existem $22 \%$ dos exemplos na classe $C_{1}$ e $78 \%$

\footnotetext{
${ }^{2}$ também denominado neste trabalho por $\varepsilon\left(\mathbf{h}_{1}\right)$

${ }^{3} \mathrm{Na}$ realidade, são "aproximadamente" independentes
} 


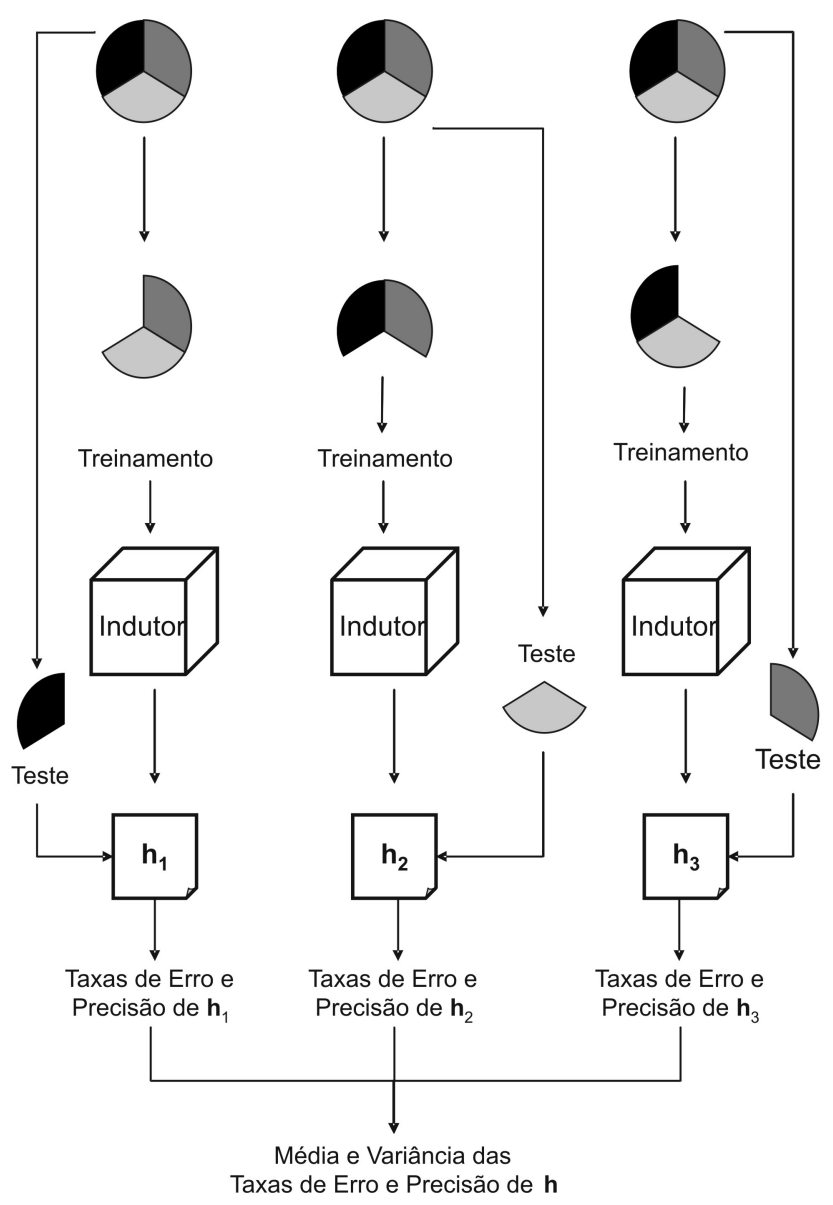

Figura 2.2: Exemplo de $k$-fold cross-validation, $\operatorname{com} k=3$

dos exemplos na classe $C_{2}$, em cada partição construída com a técnica de $k$-fold cross-validation estratificado existem aproximadamente $22 \%$ dos exemplos pertencentes à classe $C_{1}$ e $78 \%$ dos exemplos pertencentes à classe $C_{2}$.

\subsection{Avaliação de Regras}

Dada uma regra $R=B \rightarrow H$ e um conjunto de exemplos $S=\left\{\left(\mathbf{x}_{1}, y_{1}\right), \ldots\right.$, $\left.\left(\mathbf{x}_{N}, y_{N}\right)\right\}$, a cobertura de uma regra é definida como segue: os exemplos que satisfazem o corpo da regra, ou seja, que satisfazem $B$, compõem o conjunto de cobertura de $R$, denominado conjunto $B$; em outras palavras, esses exemplos são cobertos por $R$. Exemplos que satisfazem $B$ e $H$ são corretamente cobertos por $R$, e tais exemplos pertencem ao conjunto $B \cap H$. Exemplos que satisfazem $B$ mas não $H$ são incorretamente cobertos pela regra, e pertencem ao conjunto $B \cap \bar{H}$. Por outro lado, exemplos que não satisfazem $B$ não são cobertos pela 
regra, e pertencem ao conjunto $\bar{B}$. Dados uma regra e um conjunto de dados, uma maneira de avaliar a performance dessa regra é calculando a matriz de contingência dessa regra (Lavrac et al., 1999), como mostrada na Tabela 2.4. Denotando a cardinalidade de um conjunto $A$ como $a$, i.e. $a=|A|$, então $b$ e $h$ na Tabela 2.4 denotam respectivamente o número de exemplos pertencentes aos conjuntos $B$ e $H$, ou seja, $b=|B|$ e $h=|H|$. Similarmente, $\bar{b}=|\bar{B}| ; \bar{h}=|\bar{H}|$; $b h=|B \cap H| ; \bar{b} h=|\bar{B} \cap H| ; b \bar{h}=|B \cap \bar{H}| ;$ e $\overline{b h}=|\bar{B} \cap \bar{H}|$.

\begin{tabular}{c|cc|c} 
& $H$ & $\bar{H}$ & \\
\hline$B$ & $h b$ & $\bar{h} b$ & $b$ \\
$\bar{B}$ & $h \bar{b}$ & $\overline{h b}$ & $\bar{b}$ \\
\hline & $h$ & $\bar{h}$ & $N$
\end{tabular}

onde:

$h b$ : Número de exemplos para os quais $H$ é verdadeira e $B$ é verdadeiro

$\bar{h} b$ : Número de exemplos para os quais $H$ é falsa e $B$ é verdadeiro

$h \bar{b}$ : Número de exemplos para os quais $H$ é verdadeira e $B$ é falso

$\overline{h b}$ : Número de exemplos para os quais $H$ é falsa e $B$ é falso

$b$ : Número de exemplos para os quais $B$ é verdadeiro

$\bar{b}$ : Número de exemplos para os quais $B$ é falso

$h$ : Número de exemplos para os quais $H$ é verdadeira

$\bar{h}$ : Número de exemplos para os quais $H$ é falsa

$N$ : Número total de exemplos

Tabela 2.4: Matriz de contingência de uma regra

Quando se consideram regras pertencente a um classificador $\mathbf{h}$, para calcular tal matriz, deve ser considerado o procedimento utilizado pelo algoritmo de aprendizado para induzir as regras que constituem o classificador simbólico h. Os procedimentos de indução de regras utilizados pelos algoritmos de aprendizado induzem basicamente 3(três) tipos de conjuntos de regras:

1. Regras não-ordenadas (Unordered);

2. Regras ordenadas (Ordered); e

3. Regras ordenadas entre as classes (Interclass)

descritos a seguir.

\section{Regras não-ordenadas}

Para um conjunto de regras não-ordenadas, as informações da matriz 
de contingência são calculadas verificando a cobertura de cada regra do classificador simbólico $\mathbf{h}=\left\{R_{1}, \ldots, R_{N_{R}}\right\}$ no conjunto de exemplos $S$. No Algoritmo 1 é mostrado como é realizado o cálculo dessas informações para cada regra de um conjunto de regras não-ordenadas. Nesse algoritmo, $L$ é uma lista de quatro elementos, os quais armazenam os valores de $h b, \bar{h} b, \overline{h b}$ e $h \bar{b}$, respectivamente, que são os elementos da matriz de contingência da regra. A função cobertura $\left(R_{u},\left(\mathbf{x}_{i}, y_{i}\right)\right)$ retorna um número inteiro no intervalo $1, \ldots, 4$, o qual é usado como índice para incrementar o elemento correspondente da lista $L$. O índice 1 corresponde a $h b, 2$ a $\bar{h} b$, 3 a $\overline{h b}$ e 4 a $h \bar{b}$.

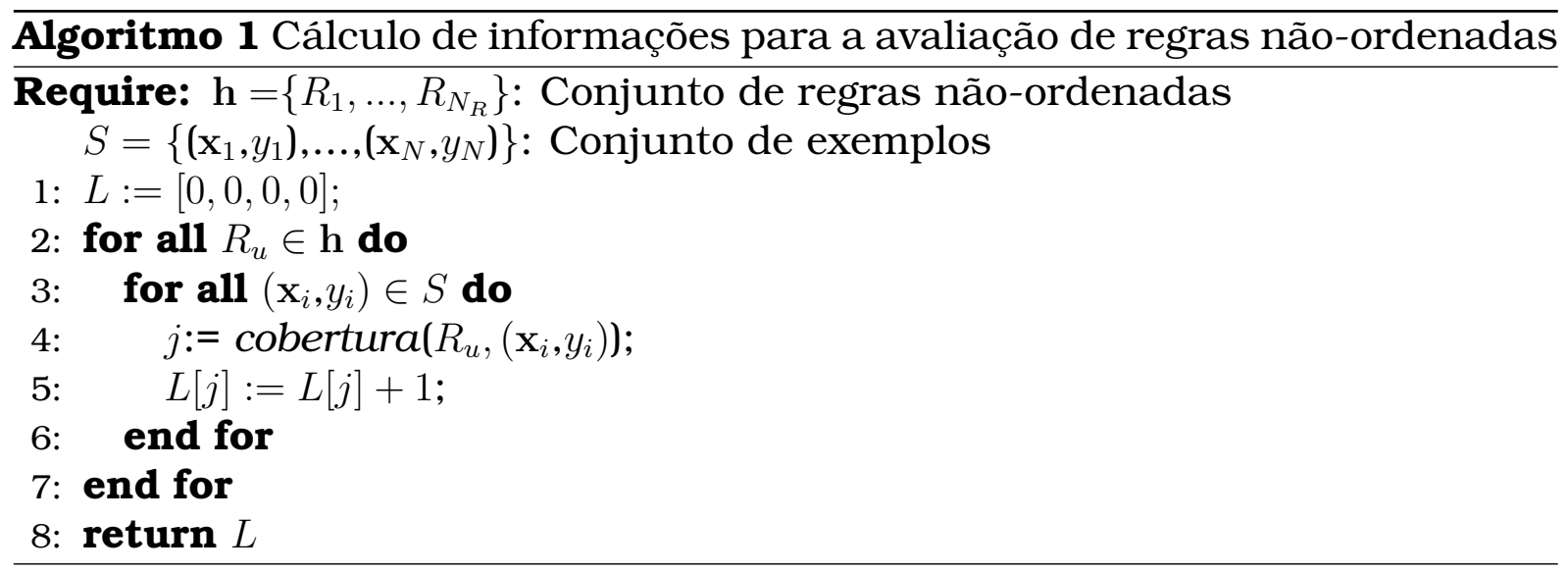

\section{Regras ordenadas}

No caso de regras ordenadas, existe um "else" implícito entre cada regra que constitui o classificador. Assim, a cobertura do exemplo deve ser analisada a partir da primeira regra, até que uma delas cubra esse exemplo ( $B$ é verdadeiro para o exemplo). Esse exemplo é coberto apenas por essa regra. Para as regras seguintes àquela que cobre o exemplo, as informações devem ser atualizadas incrementando-se os valores de $h \bar{b}$ e $\overline{h b}$ conforme a classe $C_{v}$ do exemplo. No Algoritmo 2 é mostrado como é realizado o cálculo dessas informações para um conjunto de regras ordenadas. A variável first está associada a cada exemplo $\left(\mathbf{x}_{i}, y_{i}\right)$ e recebe false se o exemplo não foi coberto por uma regra ou true se já foi coberto por uma regra.

\section{Regras ordenadas entre as classes}

As regras ordenadas entre as classes são separadas em $N_{C l}$ blocos para cada uma das $N_{C l}$ diferentes classes, existindo um "else" implícito entre cada um desses blocos. Para regras em um mesmo bloco $C_{v}$, as 


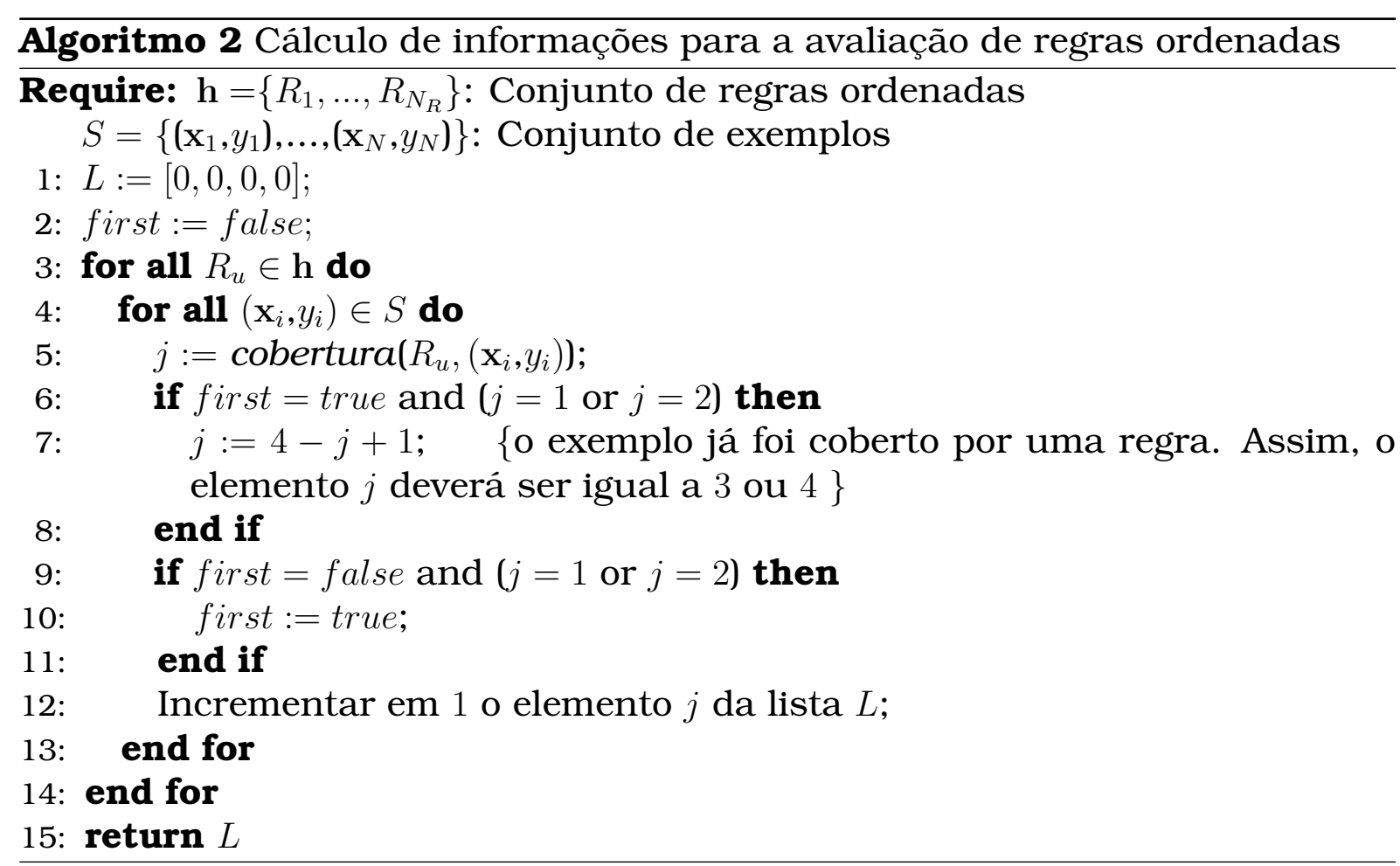

informações são calculadas como descrito anteriormente para regras nãoordenadas. Ao ser encontrada uma regra que cubra o exemplo em um bloco $C_{v}$, as informações extraídas das regras subseqüentes devem ser atualizadas nos $C_{N_{C l}-v}$ blocos seguintes, como descrito anteriormente para regras ordenadas. Por exemplo, na Figura 2.3 é mostrado que, para cada classe, existe um conjunto de subconjuntos de regras $\mathbf{h}^{\prime}=$ $\left\{\mathbf{h}_{1}^{\prime}, \ldots, \mathbf{h}_{N_{C l}}^{\prime}\right\}^{4}$.

É importante observar que, além do "else" implícito entre cada um desses subconjuntos de regras, esses subconjuntos são formados conforme a ordem em que o algoritmo de aprendizado induz as regras correspondentes às classes que compõem a hipótese $\mathbf{h}$. Cada elemento de $\mathbf{h}^{\prime}$, ou seja, $\mathbf{h}_{1}^{\prime}, \ldots, \mathbf{h}_{N_{C l}}^{\prime}$, é uma hipótese constituída por um subconjunto de regras que predizem a mesma classe. Assim, o exemplo deve ser aplicado a todas as regras de $\mathbf{h}_{1}^{\prime}$ e as informações são calculadas como descrito anteriormente para regras não-ordenadas. Se nenhuma regra de $\mathbf{h}_{1}^{\prime}$ cobrir o exemplo, ele deve ser aplicado a $\mathbf{h}_{2}^{\prime}$ e assim por diante. Ao ser encontrada uma regra em um $\mathbf{h}_{v}^{\prime}$ que cobre o exemplo, as informações extraídas das

\footnotetext{
${ }^{4}$ Observar que $\mathbf{h}^{\prime}=\mathbf{h}-\{$ default $\}$. Como mencionado, a regra default é uma regra especial cujo corpo é vazio e a cabeça é a classe de maior freqüência no conjunto de exemplos ou aquela que minimiza a taxa de erro do classificador. Assim, no caso de não existir uma regra que cubra algum exemplo, uma hipótese $\mathbf{h}$ irá classificar esse exemplo pela regra default.
} 


$$
\begin{gathered}
\mathbf{h}_{1}^{\prime} \quad \begin{array}{l}
R_{1}: \text { Corpo then CLASS }=\alpha \\
R_{2}: \text { Corpo then CLASS }=\alpha
\end{array} \\
\text { else } \\
\mathbf{h}_{2}^{\prime}\left\{\begin{array}{l}
R_{3}: \text { Corpo then CLASS }=\beta \\
R_{4}: \text { Corpo then CLASS }=\beta \\
R_{5}: \text { Corpo then CLASS }=\beta
\end{array}\right. \\
\text { else } \\
\quad \begin{array}{l}
R_{u-2}: \text { Corpo then CLASS }=\gamma \\
R_{u-1}: \text { Corpo then CLASS }=\gamma
\end{array} \\
\mathbf{h}_{N_{C l}}^{\prime} \quad \text { com } \alpha, \beta, \gamma \in C=C_{1}, \ldots, C_{N_{C l}} .
\end{gathered}
$$

Figura 2.3: Regras ordenadas entre classes - conjunto de subconjuntos de regras

regras subseqüentes são atualizadas como descrito anteriormente para regras ordenadas, nos $\mathbf{h}_{N_{C l}-v}^{\prime}$ subconjuntos seguintes.

Após determinar as informações para cada uma das regras $R_{u}{ }^{5}$ de um classificador simbólico $\mathbf{h}$, os valores encontrados podem ser expressos sob a forma de freqüências relativas, as quais são utilizadas neste trabalho como uma estimativa de probabilidade. Por exemplo, a probabilidade $P(H B)$ pode ser determinada da seguinte forma:

$$
P(H B)=f_{b h}=\frac{h b}{N}
$$

onde $N$ é o número total de exemplos no conjunto de exemplos $S$.

De forma semelhante podem ser determinados os valores das probabilidades $P(\bar{H} B), P(\overline{H B})$ e $P(H \bar{B})$. Conhecidas essas probabilidades, os valores de $P(B), P(\bar{B}), P(H)$ e $P(\bar{H})$ podem ser determinados da seguinte forma:

$$
P(B)=P(\bar{H} B)+P(H B) \quad \text { ou } P(\bar{B})=P(H \bar{B})+P(\overline{H B})
$$

Tais probabilidades são utilizadas para calcular as medidas de avaliação de regras. Várias medidas de regras têm sido propostas na literatura (Lavrac

\footnotetext{
${ }^{5}$ Se $R_{u}$ é a regra default, então as informações não são calculadas para essa regra.
} 
et al., 1999; Freitas, 1998b,a; Hilderman and Hamilton, 1999). Neste trabalho, serão utilizadas tanto medidas de avaliação de regras unificadas em um framework proposto por Lavrac et al. (1999), quanto outras medidas encontradas na literatura que não estão presentes nesse framework. No Anexo A, encontra-se uma descrição de medidas de avaliação de regras.

\subsection{Generalização e Especialização de Regras}

Dadas duas regras de classificação $R_{i}=B_{i} \rightarrow H_{i}$ e $R_{j}=B_{j} \rightarrow H_{j}$ com cabeças iguais $\left(H_{i}=H_{j}\right)$, é muito simples determinar se $R_{i}$ é uma generalização de $R_{j}$, i.e $R_{i}$ subsume $R_{j}$, ou se $R_{i}$ é uma especialização de $R_{j}$, i.e $R_{j}$ subsume $R_{i}$, considerando o conjunto de testes de atributos que participam do corpo dessas regras. Sejam $A_{i}$ e $A_{j}$, respectivamente, os conjuntos de testes de atributos que participam nos corpos $B_{i}$ e $B_{j}$ das regras $R_{i}$ e $R_{j}$ respectivamente. Então, $R_{i}$ é uma generalização de $R_{j}$, ou $R_{j}$ é uma especialização de $R_{i}$ se $A_{i} \subseteq A_{j}$. Por exemplo, considerando as duas regras de classificação:

$$
\begin{aligned}
& R_{i}=\text { If } a t_{1}=2 \text { and } a t_{2}>4 \text { then class }=+ \\
& \mathrm{e} \\
& R_{j}=\text { If } a t_{1}=2 \text { and } a t_{2}>4 \text { and } a t_{3}=5 \text { then class }=+
\end{aligned}
$$

então

$$
\begin{aligned}
& A_{i}=\left\{a t_{1}=2, a t_{2}>4\right\} \\
& \mathrm{e} \\
& A_{j}=\left\{a t_{1}=2, a t_{2}>4, a t_{3}=5\right\} .
\end{aligned}
$$

Assim, $R_{i}$ é uma generalização de $R_{j}$ pois $A_{i} \subseteq A_{j}{ }^{6}$. Com a finalidade de simplificar sintaticamente uma explicação composta por um conjunto de regras $\mathbf{R}_{\text {expl }}$, a explicação continua sendo válida removendo-se de $\mathbf{R}_{\text {expl }}=\left\{R_{1}, \ldots, R_{P}\right\}$ as regras que são especialização de outras regras também pertencentes a $R_{\text {expl }}$,

\footnotetext{
${ }^{6}$ Deve ser observado que a comparação entre conjuntos $A_{i} \subseteq A_{j}$ considera também, para testes de um mesmo atributo, análise de subconjuntos em relação a operadores. Dado um atributo $X_{i}$, para o qual existe uma condição $X_{i} o p_{1}$ Valor em $A_{i}$, e existe uma condição $X_{i}$ $o p_{2}$ Valor em $A_{j}$, considerando que o operador " $\leq$ " é uma generalização de " $<$ ", se $o p_{1}=\leq$ e se $o p_{2}=<$, então $X_{i} o p_{1}$ Valor é uma generalização de $X_{i} o p_{2}$ Valor. O mesmo acontece para outros operadores, pois " $\geq$ " é uma generalização de " $>$ ", e assim sucessivamente.
} 
pois, dadas duas regras $R_{i}$ e $R_{j}$, e dado que $R_{i}$ é uma generalização de $R_{j}$, os exemplos cobertos por $R_{j}$ são também cobertos pela regra mais geral $R_{i}$.

\subsection{Regras de Associação}

Na terminologia de regras de associação, dada uma base de dados $S$ no formato atributo-valor, cada exemplo é denominado transação e cada atributo seguido de um valor (válido) é denominado item. Uma regra de associação é composta por duas partes: antecedente (left-hand side) e conseqüente (righthand side) na forma

$$
L H S \Rightarrow R H S
$$

onde ambos antecedente e conseqüente são compostos por um conjunto de itens - itemset - que freqüentemente ocorrem juntos em $S$ e $L H S \cap R H S=\varnothing$. A tarefa de descoberta de regras de associação é determinística e bem definida. Foi desenvolvida inicialmente a partir da análise dos itens presentes em compras de supermercados, com o objetivo de identificar relações do tipo "um cliente que compra os produtos $p r_{1}, p r_{2}, \ldots, p r_{i}$ também irá comprar os produtos $p r_{k}, p r_{q}, \ldots, p r_{j}$ com probabilidade c\%" (Agrawal and Srikant, 1994). Em termos gerais, uma regra de associação $L H S \Rightarrow R H S$ determina o quanto a presença de um conjunto de itens $I t_{1}$ nos registros de uma base de dados implica na presença de algum outro conjunto distinto de itens $I t_{2}$ nos mesmos registros. A regra $L H S \Rightarrow R H S$ ocorre no conjunto de transações $S$ com confiança conf se em conf\% das transações de $S$ em que ocorre LHS ocorre também RHS. A regra $L H S \Rightarrow R H S$ tem suporte sup se em sup\% das transações em $S$ ocorre $L H S \cup R H S$. Os algoritmos utilizados para descobrir essas regras procuram em todo o conjunto de regras descobertas por aquelas regras que possuem um critério de qualidade (confiança conf e suporte sup) maior que o limite inferior especificado pelo usuário.

Ainda que é utilizado o modo de aprendizado não-supervisionado para obter regras de associação, como cada conjunto de itens pode ser interpretado como um conjunto de condições atributo-valor, regras de classificação podem ser derivadas de um conjunto de regras de associação filtrando desse conjunto todas as regras cujo conseqüente possui somente um item referente a um específico atributo alvo (atributo classe). Esse tipo de regras de classificação 
será também utilizado neste trabalho.

\subsection{Considerações Finais}

Neste capítulo, foram abordados diversos conceitos relacionados com aprendizado de máquina. Foram descritas algumas maneiras de realizar avaliação de classificadores como um todo, assim como, caso o classificador seja simbólico, i.e. composto por regras proposicionais if-then, foram descritas maneiras de se avaliar as regras individuais que o compõem individualmente. Ainda, foi descrita uma maneira de se verificar quando uma regra de classificação é uma generalização de outra regra de classificação. Também, foram abordadas regras de associação, e como essas regras podem ser utilizadas como regras de classificação. No próximo capítulo, é descrito o projeto denominado Discover (Baranauskas and Batista, 2000), que tem como principal objetivo integrar e padronizar os diversos projetos desenvolvidos pelos pesquisadores do LABIC relacionados com aquisição automática de conhecimento e avaliação de conhecimento. 


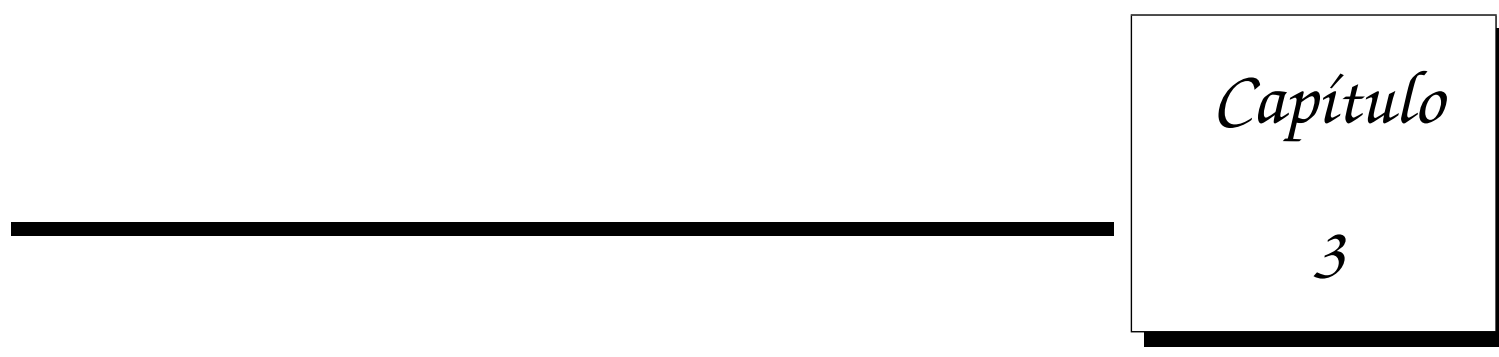

\section{O Ambiente Discover}

"Simplicidade é a complexidade resolvida."

\section{- Constantin Brancusi}

a maioria dos projetos desenvolvidos pelos pesquisadores do La-
boratório de Inteligência Computacional - LABIC - relacionados
com aquisição automática de conhecimento e avaliação de conhecimento, inclusive no projeto no qual está inserido este trabalho, diversas tarefas como transformação de dados e formatos, execução de algoritmos de aprendizado, medições, entre outras, devem ser executadas diversas vezes. Muitas dessas funcionalidades podem ser realizadas de maneira semi-automática por sistemas comerciais. Porém, além da aquisição desses sistemas demandar um alto custo, muitas vezes proibitivo para as universidades públicas, esses sistemas fazem uso de algoritmos e ferramentas proprietários, o que dificulta sua utilização por pesquisadores que pretendem analisar e desenvolver novos algoritmos e ferramentas (Batista, 2003).

Assim, muitas vezes, alguns algoritmos e ferramentas são re-implementados por pesquisadores do próprio LABIC, ou por outros pesquisadores, que 
disponibilizam ferramentas de domínio público, tais como $\mathcal{M L \mathcal { C } ^ { + + }}$ (Kohavi et al., 1994), WEKA (Witten and Frank, 2005) e YALE (Fischer et al., 2002). Entretanto, eventuais problemas decorrentes da utilização de algoritmos re-implementados, tais como um funcionamento diferente do proposto originalmente, fazem com que os algoritmos implementados pelos próprios idealizadores sejam preferidos para a realização de experimentos para avaliar diferentes algoritmos. Adicionalmente, muitas ferramentas são implementadas para automatizar parcial ou integralmente algumas tarefas. Desse modo, não é incomum a ocorrência de sobreposições de implementações pela falta de comunicação e documentação do que já foi implementado pelos pesquisadores do laboratório. Ainda, também não é incomum a perda de implementações quando seus autores se desligam do laboratório ao final de seu projeto de pósgraduação.

Para tentar resolver tais problemas, foi inicialmente proposto por Baranauskas and Batista (2000) um projeto denominado Projeto Discover, que tem como principal objetivo integrar e padronizar os diversos projetos e ferramentas desenvolvidos pelos pesquisadores do LABIC relacionados com aquisição automática de conhecimento e avaliação de conhecimento. No início, o projeto DISCOVER consistiria apenas de um repositório de scripts para facilitar a configuração e execução de experimentos, mas surgiu a proposta de criação de um ambiente integrado no qual os scripts seriam substituídos por bibliotecas de classes desenvolvidas em PERL (PERL, 1999). Deve ser ressaltado que todo o processo de implementação do projeto foi estudado segundo os fundamentos da Engenharia de Software (Rozante, 2003). Além disso, quanto a arquitetura do ambiente DISCOVER, foi proposto em Prati (2003) um framework para a integração dos componentes do ambiente DISCOVER utilizando software patterns, no qual os componentes são integrados por meio de uma linguagem denominada xDML, baseada em XML. A implementação da interface gráfica para essa integração será realizada futuramente.

O ambiente DISCOVER oferece vantagens em relação a outros sistemas com objetivos semelhantes, pois permite a visão unificada que os formatos baseados em padrões proporcionam ao pesquisador (desenvolvedor) de novos componentes. Os padrões de representação foram sendo definidos por área, sendo que em (Prati et al., 2001a) é proposta uma sintaxe padrão para representação de conhecimento de diversos indutores simbólicos denominada $\mathcal{P B M}$ (Prati et al., 2001b). Para a representação de dados foi proposta uma 
sintaxe padrão (Batista, 2001), denominada DSX - Discover Dataset Syntax, a qual permite a utilização da biblioteca de classes DOL (Batista and Monard, 2006), para converter os arquivos de dados para a sintaxe utilizada por diversos sistemas de aprendizado simbólico, tais como $\mathcal{C} 4.5, \mathcal{C} 4.5$ rules e $\mathcal{C N} 2$ entre outros. Mais especificamente, o ambiente DISCOVER Learning Environment DLE é composto pela biblioteca de classes DISCOVER Object Library - DOL e pelo ambiente para gerenciamento de experimentos SNIFFER, que foram desenvolvidos para diferentes tarefas de pré-processamento em mineração de dados (Batista and Monard, 2006). Novas funcionalidades estão sendo especificadas, principalmente, para regras de regressão (Pugliesi, 2004) e regras de associação (Melanda, 2004). Além disso, outros trabalhos foram ou estão sendo desenvolvidos na área de aprendizado de máquina relacional e proposicional (Prati, 2006; Ferro, 2006; Lee, 2005), aprendizado de máquina semi-supervisionado (Sanches, 2003; Matsubara, 2004), aprendizado nãosupervisionado (Metz, 2004), mineração de dados (Paula, 2003; Pila, 2003; Chiara, 2003) e mineração de textos (Matsubara, 2004; Martins, 2003).

Para desenvolver os sistemas de combinação de classificadores simbólicos e o sistema que implementa o AG proposto neste trabalho, foram utilizados os seguintes ambientes do DISCOVER:

1. O ambiente computacional DLE, composto pela biblioteca de classes DOL e pelo ambiente computacional SNIFFER, que possui funcionalidades que facilitam a implementação de sistemas a serem integrados no Discover;

2. O ambiente computacional NNRULES, sobre o qual foram utilizadas técnicas de reuso de software para construir o ambiente computacional GAERE.

Para desenvolver os sistemas relacionados às propostas deste trabalho, foi necessário estender as funcionalidades do ambiente Sniffer. Assim, antes de serem detalhadas as propostas deste trabalho e de ser detalhado o desenvolvimento dos sistemas implementados, são descritos a seguir os objetivos e as principais funcionalidades dos ambientes computacionais Discover Learning Environment - DLE (Batista and Monard, 2003, 2006) e NNRules (Milaré, 2003) e ELE (Bernardini and Monard, 2004), bem como a extensão realizada no ambiente SNIFFER. 


\subsection{O Ambiente Computacional DLE}

O ambiente computacional DLE tem como principal objetivo prover um framework para que novas técnicas de pré-processamento de dados possam ser facilmente e rapidamente implementadas e avaliadas experimentalmente. $\mathrm{O}$ ambiente computacional DLE é composto por dois módulos distintos: a biblioteca de classes Discover Object Library - DOL, cujo objetivo principal é ser uma biblioteca de métodos de pré-processamento de dados, e o ambiente para gerenciamento de experimentos SNIFFER, cujo objetivo principal é automatizar avaliações e comparações experimentais de algoritmos de aprendizado. Para utilizar a biblioteca de classes DOL, foi proposta uma sintaxe padrão para representação de dados, denominada DSX - Discover Dataset Syntax (Batista, 2001). A seguir, são descritas as principais funcionalidades da biblioteca de classes DOL e do ambiente computacional SNIFFER. As descrições aqui apresentadas estão baseadas em (Batista and Monard, 2003). Maiores detalhes do ambiente computacional DLE, tais como detalhes de arquitetura, projeto e implementação do ambiente, os quais fogem do escopo deste trabalho, podem ser encontrados em (Batista and Monard, 2003; Batista, 2003).

\subsection{A Biblioteca de Classes DOL}

Entre as principais funcionalidades da biblioteca DOL, pode-se citar:

Manipulação de atributos e dados A biblioteca DOL provê métodos que fornecem informações do conjunto de $\operatorname{dados}^{1}$ que está sendo pré-processado. Utilizando a biblioteca, os dados podem ser manipulados, ou seja, lidos e modificados. Entre as principais tarefas de manipulação de atributos e dados pode-se citar: alteração de nomes de atributos, conversão de tipos de atributos, modificação de posição de atributos na tabela de dados, modificação do atributo classe, remoção temporária ou efetiva de atributos e exemplos, adição de exemplos ao conjunto de dados, entre outras.

Integração com diversos sistemas de AM A biblioteca DOL pode ser integrada com os principais sistemas de aprendizado acadêmicos disponi-

\footnotetext{
${ }^{1}$ Atualmente são considerados dados no formato atributo-valor — Tabela 2.1 na página 12 .
} 
bilizados pelos autores. Para que essa funcionalidade fosse possível, foram criados conversores de dados que convertem os dados carregados da sintaxe da biblioteca $D O L$ para as sintaxes requeridas pelos seguintes sistemas de aprendizado simbólico: $\mathcal{C} 4.5$ (Quinlan, 1988), C 4.5 rules (Quinlan, 1987), ID3 (Quinlan, 1986), NewID (Boswell, 1990), CN2 (Clark and Boswell, 1991), dentre outros.

Filtro de Exemplos e Atributos A biblioteca DOL oferece um sistema de filtros que permite ocultar temporariamente parte dos exemplos ou dos atributos de um conjunto de dados. Os filtros podem ser criados a partir de expressões lógicas envolvendo atributos ou utilizando uma lista que indica explicitamente quais exemplos devem ser filtrados. A biblioteca permite que vários filtros sejam definidos. Além disso, é possivel definir filtros em função de outros filtros previamente definidos. O sistema de filtragem de exemplos é, por exemplo, a base para a criação de um conjunto de classes PERL que criam amostras aleatórias e estratificadas de um conjunto de exemplos.

Estatísticas Descritivas e Correlações Estatísticas descritivas podem ser utilizadas tanto pelo usuário quanto por métodos de pré-processamento de dados. Ainda, informações sobre correlações entre atributos, como correlação linear e covariância, são a base para a construção de diversos métodos de pré-processamento de dados.

Métodos de Resampling Como mencionado, os métodos de resampling são métodos estatísticos capazes de estimar apropriadamente a taxa de erro verdadeira, mesmo em um conjunto reduzido de dados. Os métodos de resampling utilizam conjuntos de teste para estimar a taxa de erro verdadeira, os quais contém exemplos que não foram utilizados no treinamento do sistema de aprendizado. Diferentes métodos de resampling particionam de diferentes formas o conjunto de dados original em conjuntos de treinamento e teste. Atualmente, a biblioteca de classes DOL provê dois métodos de resampling: o $k$-fold cross-validation e o $k$-fold cross validation estratificado, descritos na Seção 2.3 na página 13. 


\subsection{O Ambiente Computacional SNIFFER}

Conforme dito anteriormente, o ambiente SNIFFER (Batista and Monard, 2003) é um ambiente computacional para gerenciamento de avaliações e comparações experimentais de algoritmos de aprendizado. Tal ambiente está integrado com diversos sistemas de aprendizado, citados anteriormente. Freqüentemente, para realizar avaliações e comparações de algoritmos de aprendizado, é necessário executar um experimento diversas vezes. Primeiro, porque a repetição dos experimentos utilizando os métodos de resampling fornece ao usuário uma estimativa da variância das médias dos resultados; segundo, porque na maioria das vezes é necessário ajustar alguns parâmetros para cada conjunto de dados; e finalmente, porque as análises experimentais freqüentemente devem ser executadas em diversos conjuntos de dados, utilizando diferentes algoritmos de aprendizado, para uma melhor compreensão dos resultados. Dessa maneira, é bastante comum que o usuário seja obrigado a executar um determinado experimento centenas de vezes. Diante de tantas execuções, torna-se muito difícil gerenciar os experimentos manualmente, sendo necessário automatizar essa tarefa. O ambiente computacional SNIFFER foi desenvolvido com esse fim. Tal ambiente possui as seguintes principais funcionalidades:

\section{Gerenciamento de sintaxes dos sistemas de aprendizado}

Em experimentos que envolvem execuções de diferentes sistemas de aprendizado, é comum que os sistemas utilizem sintaxes distintas para os arquivos de declaração de dados e de atributos. O ambiente SNIFFER converte, quando necessário, o conjunto de dados na sintaxe do DISCOVER para a sintaxe do sistema de aprendizado a ser executado.

\section{Aplicação de métodos de resampling}

Como mencionado na Seção 2.3, os conjuntos de dados devem ser divididos em conjuntos de treinamento e teste para que a taxa de erro verdadeira seja estimada no conjunto de teste. O ambiente SNIFFER realiza essa tarefa, desde que solicitado pelo usuário. O usuário pode também escolher qual método de resampling deve ser aplicado ao conjunto de dados, bem como definir explicitamente os conjuntos de treinamento e teste.

\section{Recuperação das taxas de erro}

Os principais sistemas de aprendizado permitem que sejam fornecidos 
conjuntos de treinamento e teste para a criação do modelo e a estimativa da taxa de erro verdadeira, respectivamente. Normalmente, os sistemas de aprendizado gravam a matriz de confusão em um arquivo texto com sintaxe proprietária. O ambiente SNIFFER recupera essa matriz de confusão e a armazena para posterior análise dos resultados.

\section{Cálculo de medidas de desempenho}

Recuperadas as matrizes de confusão para cada iteração do método de resampling, é necessário calcular estatísticas que fornecem um indicativo de desempenho do sistema de aprendizado no conjunto de dados analisado. O ambiente SNIFFER calcula medidas de desempenho geral levando em consideração todos os valores do atributo classe.

\section{Comparação de medidas de desempenho}

Uma vez que as medidas de desempenho foram calculadas, é necessário compará-las para verificar se existem diferenças significativas entre elas, ou seja, se um método superou outro com uma diferença significativa de $95 \%$ ou $99 \%$ de confiabilidade. O ambiente SNIFFER utiliza o teste $t$ para realizar essa tarefa.

Um outro objetivo importante do SNIFFER é automatizar, sempre que possível, a publicação dos resultados. Assim, o ambiente fornece ao usuário uma segurança maior de que os resultados publicados são fiéis aos resultados obtidos nos experimentos. Como freqüentemente os resultados dos experimentos envolvem uma grande quantidade de valores numéricos, é muito comum a introdução de erros durante o processo manual de confecção de tabelas e gráficos. O ambiente SNIFFER fornece ao usuário relatórios resumidos e detalhados dos resultados obtidos, além de tabular os resultados em um formato que pode ser utilizado para gerar gráficos no Gnuplot ${ }^{2}$ e tabelas no processador de textos $\mathrm{HT}_{\mathrm{E}} \mathrm{X}^{3}$.

Para organizar um experimento, o ambiente SNIFFER utiliza a estrutura do sistema de arquivos do sistema operacional no qual está sendo executado. Os conjuntos de dados a serem analisados devem ser dispostos em diretórios, sendo que alguns identificadores de diretórios possuem significado especial para o ambiente Sniffer. Para tornar mais simples a descrição do funcionamento do ambiente SNIFFER, o mesmo é ilustrado utilizando o exemplo a seguir.

\footnotetext{
$2_{\text {http: / / www.gnuplot.info }}$

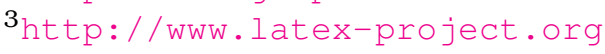




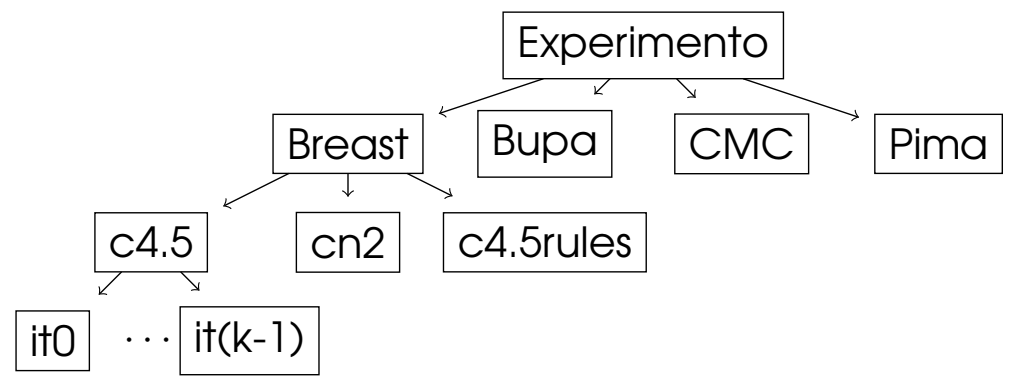

Figura 3.1: Exemplo de experimento organizado em diretórios para o ambiente SNIFFER (Batista and Monard, 2003)

Considere que desejamos comparar o desempenho de três sistemas de aprendizado - $\mathcal{C} 4.5, \mathcal{C} 4.5$ rules e $\mathcal{C N} 2$ - sobre quatro conjuntos de dados da UCI (Blake et al., 1998) - Breast, Bupa, CMC e Pima. Inicialmente, o usuário deve organizar os conjuntos de dados em diretórios. A forma que os diretórios devem ser organizados depende de como o usuário deseja que os testes de hipótese sejam feitos. Por hora, vamos pensar que os conjuntos de dados foram organizados pelo usuário da forma em que são mostrados na Figura 3.1. Existe um diretório raiz para o experimento clamado Experimento. Dentro desse diretório, o qual engloba todo o experimento, foram criados quatro diretórios: Breast, Bupa, CMC e Pima, ou seja, um para cada conjunto de dados que será analisado. Dentro de cada diretório dos conjuntos de dados, foram criados outros três diretórios: c4.5, cn2 e c4.5rules (um para cada sistema de aprendizado a ser utilizado). Na Figura 3.1 são mostrados somente os diretórios contidos no diretório Breast, os demais foram omitidos por motivo de simplificação. Por fim, opcionalmente, o usuário pode criar diretórios enumerados que devem seguir o padrão it0, it 1, .. , it(k-1), ou seja, um para cada iteração do método de resampling por ele considerado, sendo k o número total de iterações do método de resampling utilizado. Nesse caso, o usuário necessita colocar embaixo de cada um desses diretórios os conjuntos de treinamento e de teste respectivos. Caso o usuário especificar um dos métodos de resampling definidos atualmente no SNIFFER, i.e $k$-fold cross-validation ou $k$ fold cross-validation estratificado, esses diretórios it 0 , it $1, \ldots$, , it $(k-1)$ são automaticamente criados pelo SNIFFER bem como os conjuntos de treinamento e teste correspondentes dentro de cada um desses diretórios.

Ao ambiente SNIFFER deve ser fornecido um ponto de entrada, ou seja, um diretório que seja a raiz para todo o experimento. A partir desse diretório, o 
ambiente vasculha a árvore de diretório contida no ponto de entrada a procura de diretórios com identificadores especiais. Os identificadores especiais identificam um sistema de aprendizado especifico. Atualmente, os identificadores especiais para algoritmos de aprendizado simbólico que o ambiente reconhece estão listados na Tabela 3.1. Entretanto, o SNIFFER está preparado para acomodar facilmente outros sistemas de aprendizado.

\begin{tabular}{|c|c|}
\hline Identificador & Sistema de Aprendizado \\
\hline c4.5 & C4.5 (Quinlan, 1988) \\
c4.5rules & C4.5rules (Quinlan, 1987) \\
id3 & ID 3 (Quinlan, 1986) \\
cn2 & $\mathcal{C N} 2$ (Clark and Boswell, 1991) \\
newid & $\mathcal{N}$ ewID (Boswell, 1990) \\
\hline
\end{tabular}

Tabela 3.1: Identificadores especiais para diretórios reconhecidos atualmente pelo SNIFFER para algoritmos de aprendizado simbólico

Quando um diretório com identificador especial é encontrado, o ambiente SNIFFER realiza uma das seguintes tarefas:

1. Caso for solicitado pelo usuário, o ambiente executa um método de resampling dividindo os dados em diversos conjuntos de treinamento e teste. Nesse caso, os arquivos com extensão . data e . names correspondentes a todo o conjunto de dados precisam estar presentes no diretório com o identificador especial. Como resultado, são criados $k$ diretórios com os identificadores it $0, \ldots$, it $(k-1)$, um para cada iteração do método de resampling, sendo $k$ o número total de iterações do método. Dentro de cada um desses diretórios o ambiente grava três arquivos com as extensões . data, . test e . names, os quais contém, respectivamente, o conjunto de dados de treinamento e teste dessa iteração, e o arquivo de declaração de atributos desses dados;

2. Se o usuário não desejar que o ambiente aplique um método de resampling, o usuário pode criar os diretórios com os conjuntos de treinamento e teste, que ele deve fornecer, os quais devem ser nomeados ito, ... , it $(k-1)$. Isso é útil em algumas situações quando o usuário deseja avaliar dois ou mais sistemas de aprendizado nos mesmos conjuntos de treinamento e teste. Nesse caso, o usuário solicita que o ambiente não execute um método de resampling, e o ambiente utiliza os arquivos de dados com as extensões . data, . test e names que foram fornecidos e 
armazenados pelo usuário dentro de cada diretório com o identificador it correspondente.

A partir daí, o ambiente passa a executar sobre esses dados o sistema de aprendizado identificado pelo nome do diretório atual - Tabela 3.1. Para isso, o ambiente SNIFFER acessa cada diretório it e realiza as seguintes tarefas:

1. Caso for solicitado pelo usuário, converte os arquivos de dados, ou seja, converte os exemplos presentes nos arquivos . data, . names e .test, que estão na sintaxe padrão DSX, para a sintaxe do sistema de aprendizado a ser executado;

2. Executa o sistema de aprendizado selecionado sobre o conjunto de treinamento e estima o erro de classificação sobre o conjunto de teste correspondente;

3. Por fim, extrai a matriz de confusão dos arquivos de saída do sistema de aprendizado, a qual contém o número de classificações incorretas feitas pelo classificador induzido sobre o conjunto de teste. As matrizes de confusão são armazenadas pelo ambiente para a realização de cálculos de desempenho.

O ambiente SNIFFER percorre toda a árvore de diretórios contida no ponto de entrada fornecido pelo usuário. Ao final, o ambiente pode tanto gerar relatórios descrevendo os resultados obtidos (por exemplo, média e desvio padrão dos erros cometidos pelo indutor nas $k$ iterações de resampling, bem como a comparação entre os resultados obtidos para cada um dos conjuntos de dados utilizados) quanto ser acessado através de sua API para que o usuário recupere determinados dados ou estatísticas de desempenho.

\subsection{Extensão do Ambiente SNIFFER}

Para atender as necessidades dos ambientes ELE, descrito no Capítulo 5, e do sistema GAERE, descrito no Capítulo 7, foi necessário estender o ambiente SNIFFER. Para realizar as extensões necessárias, foram construídos os módulos SNifferELE, SNiffERGA e SNifferClassind, os quais estendem algumas funcionalidades do módulo SNIFFER. As funcionalidades de cada um desses módulos são: 
SNIFFERGA: Reconhecer identificadores relacionados à execução do AG, descritos no Capítulo 7.

SNIFFERELE: Reconhecer identificadores relacionados aos métodos de construção de ensembles, descritos no Capítulo 5.

SNIFFERClassINd: É responsável por indicar ao SNIFFER que somente sejam induzidos classificadores sem estimativa de erro. Além dos algoritmos de aprendizado já reconhecidos pelo SNIFFER, SNIFFERCLASSIND também reconhece o Apriori (Borgelt and Kruse, 2002), representado pelo identificador apriori. Quando este algoritmo é reconhecido, são geradas regras de associação que possuem no lado direito da regra somente um valor o valor do atributo classe. Isso é necessário para que as regras geradas possam ser consideradas como regras de classificação.

Maiores detalhes dessa extensão podem ser encontradas em (Bernardini and Monard, 2006a).

\subsection{O Sistema Computacional NNRULES}

O principal objetivo do desenvolvimento do ambiente NNRULES (Milaré, 2003) foi construir um ambiente que permite avaliar experimentalmente o uso de sistemas de aprendizado simbólico e AGs para a extração de conhecimento simbólico de Redes Neurais Artificiais (RNAs). O projeto do ambiente NNRULES foi criado tendo-se em vista o desenvolvimento de um ambiente flexível que pudesse ser facilmente modificado para avaliar e testar novas idéias. Por esse motivo, decidiu-se dividir o ambiente em módulos, os quais podem ser compostos da forma mais adequada para a realização de um determinado experimento.

Os módulos do NNRules, os quais são implementados por meio de classes, podem ser vistos como bibliotecas. Foi implementado, também, um conjunto de scripts, os quais utilizam os métodos implementados pelos módulos para automatizar uma determinada tarefa. Os scripts utilizados nos experimentos realizam tarefas que vão desde o pré-processamento dos dados até a execução dos métodos de extração de conhecimento de RNAs.

Como mencionado, o ambiente NNRUles faz parte do projeto Discover. Assim como os outros módulos do DISCOVER, o ambiente NNRULEs foi também 
implementado em Perl (PERL, 1999) e orientado a objeto. O ambiente NNRULES está dividido em três módulos principais: RuleBASE, RuleSet e GA, descritos a seguir.

O Módulo RuleBase: O módulo RuleBase armazena e gerencia uma base de regras. As regras armazenadas em uma mesma instância do módulo RULEBASE devem pertencer a um domínio comum, isto é, devem fazer referência a um conjunto comum de atributos. As regras são armazenadas em uma instância do módulo RULEBASE na sintaxe padrão de regras $\mathcal{P B M}$ (Prati et al., 2001b). Também, para as regras armazenadas, o módulo calcula a matriz de contingência das regras - Tabela 2.4 - para posterior avaliação das regras armazenadas. Para converter as regras da sintaxe do algoritmo de indução para a sintaxe $\mathcal{P B M}$ bem como para calcular as matrizes de contingência, o módulo RULEBASE utiliza uma classe chamada RuleStream.

O módulo RULEBASE provê diversas funcionalidades para a manipulação de regras. Entre as principais estão prover informações sobre a matriz de contingência das regras e sobre o sistema de aprendizado que induziu essas regras; informar quais são as regras default e remover essas regras da base; prover informações sobre a complexidade sintática das regras; verificar se uma regra cobre um determinado exemplo, entre outras.

O Módulo RuleSet: O módulo RuleSet permite implementar classificadores com subconjuntos de regras armazenadas em uma instância do módulo RuleBase. Uma instância do módulo RuleSeT não armazena as regras diretamente, mas somente uma lista com os índices das regras que pertencem ao classificador. Como mencionado anteriormente, essas regras estão armazenadas em uma instância do módulo RULEBASE.

Pode-se criar diversas instâncias do módulo RULESET para uma mesma base de regras armazenada em uma instância do módulo RULEBASE. Cada classificador pode ser composto por diferentes regras, bem como por diferentes quantidades de regras. Uma das principais características do módulo RULESET é que ele permite classificar um exemplo segundo um conjunto de regras nele armazenado, utilizando as abordagens descritas na Seção 2.4 na página 18 - ordenada, não-ordenada e ordenada entre as classes. 
O Módulo GA: O módulo GA implementa um Algoritmo Genético para realizar uma busca por um conjunto de regras que possua grande fidelidade com uma RNA. O ambiente NNRULES utiliza um AG na busca por um conjunto de regras que classifique um conjunto de exemplos da mesma forma que uma RNA treinada classifica esses exemplos. Dessa forma, o conjunto de regras pode ser utilizado para explicar essa RNA. Sendo assim, o AG tem como principal objetivo encontrar um conjunto de regras que maximize a taxa de fidelidade entre o conjunto de regras e a RNA, tal que a explicação correspondente à classificação de novos exemplos pela RNA é realizada utilizando esse conjunto de regras.

No AG implementado no ambiente NNRULES, cada indivíduo é um conjunto de regras gerenciado por uma instância do módulo RULESET. As operações de crossover e mutação foram implementadas no módulo AG por meio dos métodos de adição e remoção de regras provida pela interface do módulo RuLESET.

Os classificadores simbólicos induzidos pelos sistemas de aprendizado são convertidos para regras na sintaxe $\mathcal{P B} \mathcal{M}$ e carregados em uma instância do módulo RulEBASE. Uma vez que as regras estão armazenadas na base de regras, o AG inicia a busca por um conjunto de regras com alta fidelidade com a RNA que gerou os novos valores do atributo classe. Nos experimentos descritos em (Milaré, 2003), a taxa de fidelidade é utilizada como função de aptidão. A taxa de fidelidade é o percentual de exemplos de um conjunto de dados classificados de forma idêntica pelo conjunto de regras, isto é, um individuo, e a RNA que se deseja explicar.

\subsection{Considerações Finais}

Nesta seção, foram descritas as principais funcionalidades presentes no DISCOVER bem como algumas extensões realizadas nos módulos existentes para adequar as necessidades dos sistemas relacionados a este trabalho. $\mathrm{Na}$ próxima seção, serão abordados alguns conceitos de ensembles de classificadores bem como métodos de construção de ensembles de classificadores propostos neste trabalho. 


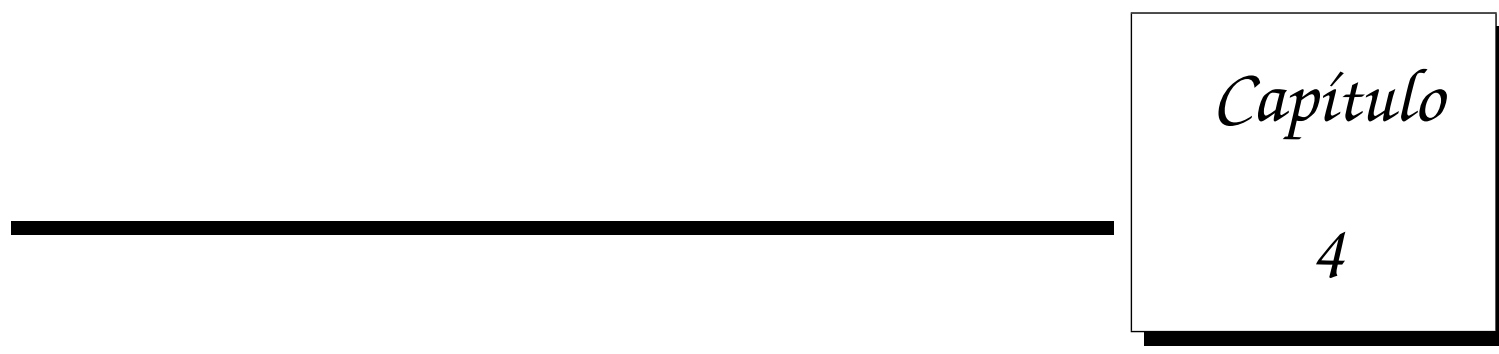

\section{Ensembles DE ClASSIFICADORES}

"O conhecimento acumulado somado à uma visão de futuro são as bases para nossas ações presentes.”

\section{- Martius}

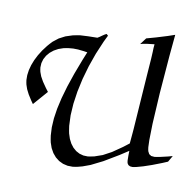
ma das áreas ativas em aprendizado de máquina supervisionado estuda métodos de construção de ensembles de classificadores. Um ensemble é um conjunto de classificadores cujas decisões individuais são combinadas de alguma forma para classificar um novo caso. Um resultado interessante é que ensembles de classificadores podem ser mais precisos que os classificadores individuais que compõem o ensemble. Uma condição para que um ensemble de classificadores seja mais preciso que seus componentes é que os classificadores que compõem o ensemble sejam distintos (Hansen and Salamon, 1990). Um classificador preciso é um classificador que faz a predição da classe de um novo exemplo x com uma margem de erro menor do que simplesmente adivinhar o valor de $y$ dado $\mathrm{x}$. Dois classificadores são distintos se cometem erros diferentes em novos conjuntos de exemplos. 
Por exemplo, considere um ensemble de três classificadores $\mathbf{h}_{1}, \mathbf{h}_{2}, \mathbf{h}_{3}$ e um novo caso (ou exemplo) $\mathrm{x}$, ilustrado na Figura 4.1 (Dietterich, 2000b). Esse novo exemplo x será classificado por cada classificador $\mathbf{h}_{1}, \mathbf{h}_{2}$ e $\mathbf{h}_{3}$ com uma das classes do conjunto discreto de classes $\left\{C_{1}, \ldots, C_{N_{C l}}\right\}$. Seja $\mathbf{h}_{1}(\mathbf{x})$ a classificação atribuída a esse novo exemplo $x$ pelo classificador $h_{1}, h_{2}(x)$ pelo classificador $\mathbf{h}_{2}$ e $\mathbf{h}_{3}(\mathbf{x})$ pelo classificador $\mathbf{h}_{3}$. Se os três classificadores são idênticos então, quando $\mathbf{h}_{1}(\mathbf{x})$ está errado, $\mathbf{h}_{2}(\mathbf{x})$ e $\mathbf{h}_{3}(\mathbf{x})$ também estão. Entretanto, se os erros cometidos pelos classificadores forem não correlacionados, então quando $\mathbf{h}_{1}(\mathbf{x})$ está errado, $\mathbf{h}_{2}(\mathbf{x})$ e $\mathbf{h}_{3}(\mathbf{x})$ podem estar corretos, de forma que o voto majoritário pode classificar corretamente o exemplo x. Em geral, dado um ensemble composto por $L$ classificadores $\mathbf{h}_{1}, \ldots, \mathbf{h}_{L}$, para cada novo exemplo $\mathbf{x}$ a ser classificado por esses classificadores, tem-se uma série de $L$ ensaios. Considerando que cada um desses ensaios é independente e que cada ensaio é um sucesso na classificação de $\mathrm{x}$ com probabilidade ${ }^{1} p$ ou uma falha com probabilidade $1-p$, então a probabilidade do número de sucessos ser $l$ em $L$ ensaios é dada por

$$
P(Z=l)=\left(\begin{array}{l}
L \\
l
\end{array}\right) p^{l}(1-p)^{L-l}
$$

Mais precisamente, se as taxas de erro de $L$ classificadores $\mathbf{h}_{1}, \ldots, \mathbf{h}_{L}$ são todas iguais a $p<\frac{1}{2}$ e se os erros são independentes, então a probabilidade do voto majoritário estar errado, ou seja, a probabilidade do ensemble ter mais de $50 \%$ de classificadores que classificam erroneamente, é dada por

$$
P\left(Z>\frac{L}{2}\right)=1-\sum_{l=0}^{\frac{L}{2}}\left(\begin{array}{l}
L \\
l
\end{array}\right) p^{l}(1-p)^{L-l}
$$

que corresponde à área sob o gráfico da distribuição binomial na qual mais que $\frac{L}{2}$ hipóteses estão erradas.

Na Figura 4.2 são mostrados ensembles ideais compostos por hipóteses independentes, todas com taxas de erro de 0.3 , 0.4 e 0.45 respectivamente. Pode ser observado que quanto maior o valor da taxa de erro das hipóteses, maior é a taxa de erro do ensemble, mas ainda assim a taxa de erro do ensemble é menor que a taxa de erro de cada hipótese que o compõe. Por exemplo,

\footnotetext{
${ }^{1}$ É considerado que essa probabilidade é a taxa de erro do ensaio, ou seja, da hipótese $\mathbf{h}_{l}$
} 


\section{Ensemble}

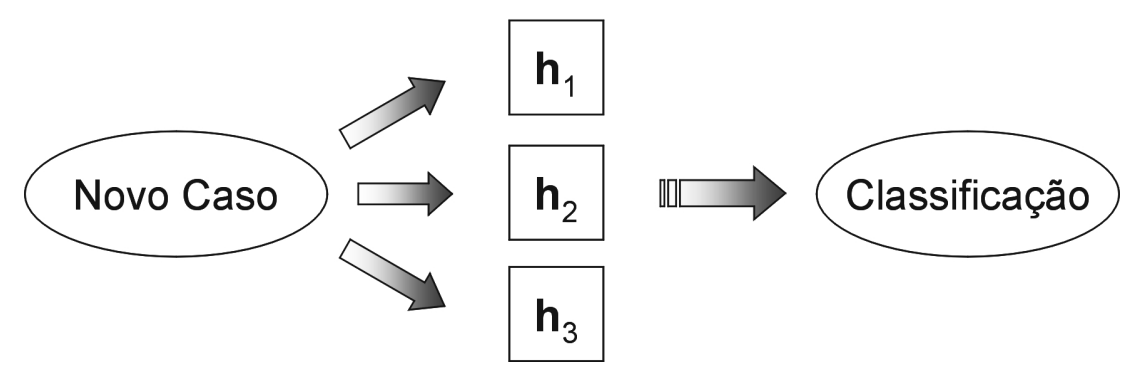

Figura 4.1: Ensemble de três classificadores

para um ensemble simulado com 21 hipóteses, cada uma delas possuindo uma taxa de erro de 0.3 , a área de curva para 11 ou mais hipóteses simultaneamente incorretas é 0.026, o qual é muito menor que a taxa de erro das hipóteses individuais, conforme pode ser observado na Figura 4.2. Observa-se também que quanto maior o número de hipóteses independentes, menor é a taxa de erro do ensemble.

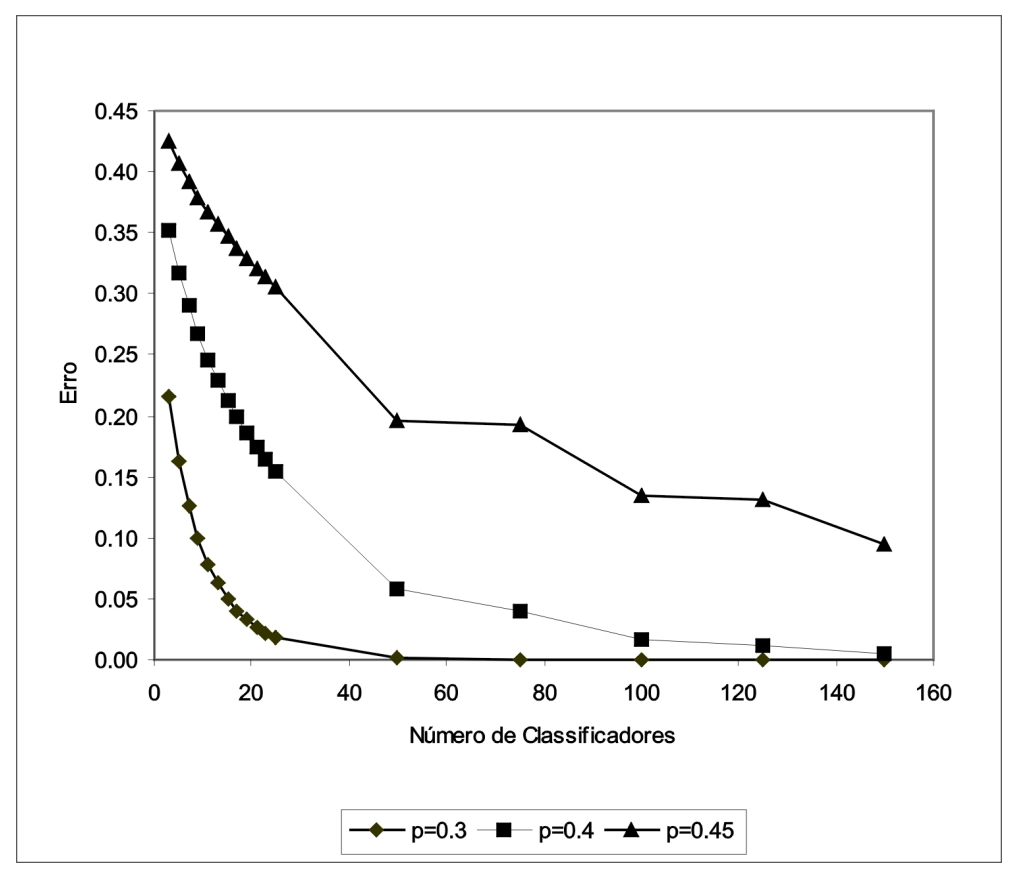

Figura 4.2: Probabilidade do voto majoritário estar errado com $L$ hipóteses, $L=1, \ldots, 150$, com taxa de erro de cada hipótese igual a $0.3,0.4$ e 0.45

Entretanto, se as hipóteses individuais têm erros não correlacionados mas com taxas de erro excedendo 0.5, então a taxa de erro do ensemble aumentará como resultado da votação. Na Figura 4.3 na próxima página, é mostrada a 
curva do erro de um ensemble ideal composto por hipóteses independentes, todas com taxa de erro de 0.7. Pode ser observado que, nesse caso, o erro cometido pelo ensemble aumenta ao incrementar o número de hipóteses.

Assim, considerando a probabilidade do voto majoritário estar errado no modelo ideal de ensembles, definido pela equação 4.2, a chave para o sucesso dos métodos de criação de ensembles está em construir classificadores individuais independentes com taxas de erro abaixo de 0.5. Deve ficar claro que as simulações mostradas tratam situações ideais, nas quais todas as hipóteses que compõem o ensemble são ensaios independentes, ou seja, não correlacionados. Em aprendizado de máquina, o que se tenta fazer é tornar os ensaios (as hipóteses) não correlacionados, ou, se a correlação existir - na prática geralmente essa correlação existe -, torná-la mínima.

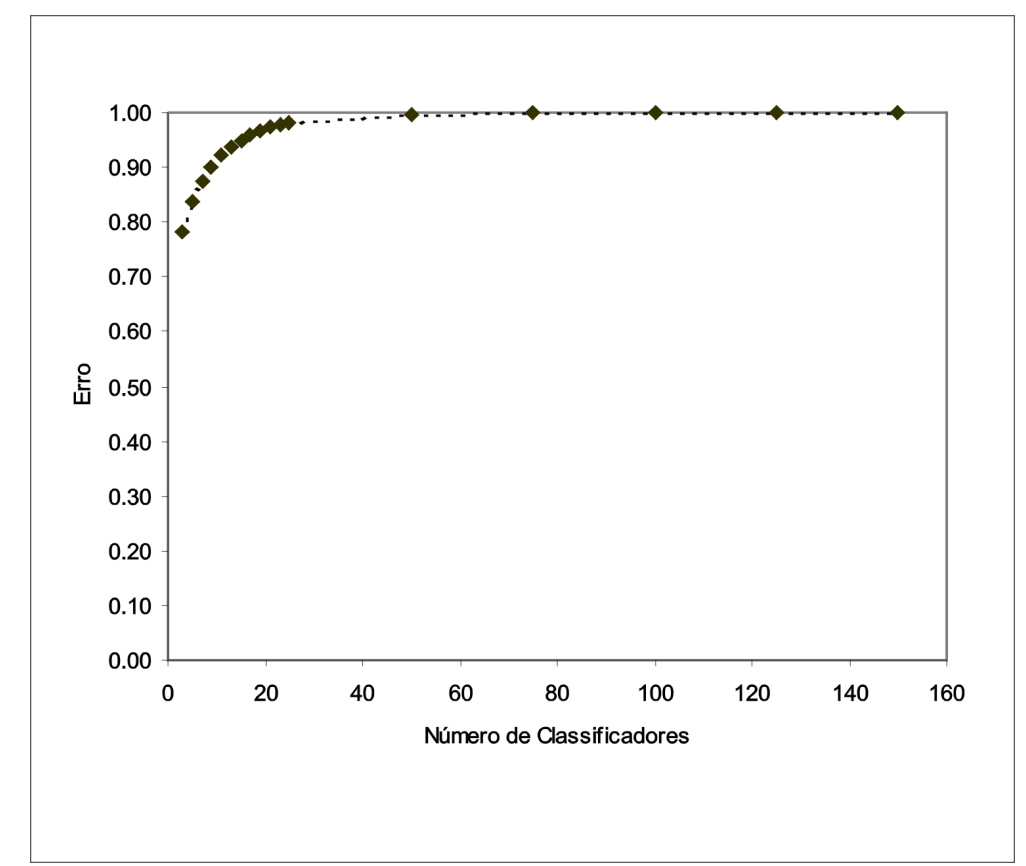

Figura 4.3: Probabilidade do voto majoritário estar errado com $L$ hipóteses, $L=1, \ldots, 150$, com taxa de erro de cada hipótese igual a 0.7

Levando em consideração a possibilidade de construção de ensembles com pequeno número de classificadores, teoria esta utilizada para dar suporte às nossas propostas relacionadas à construção de ensembles de classificadores, neste capítulo são descritas as razões para construir ensembles de classificadores, alguns métodos de construção de ensembles de classificadores, e os métodos por nós propostos para construção de ensembles de classificadores simbólicos, i.e, ensembles de classificadores que explicam suas decisões de 
classificação.

\subsection{Motivos para Construir Ensembles de Classifica- dores}

Como mencionado, os ensembles são construídos para tentar melhorar o poder de predição dos algoritmos de aprendizado. Mas quais os motivos que levam a construir ensembles? Uma ilustração desses motivos pode ser vista na Figura 4.4, os quais são fundamentalmente três, segundo Dietterich (2000b):

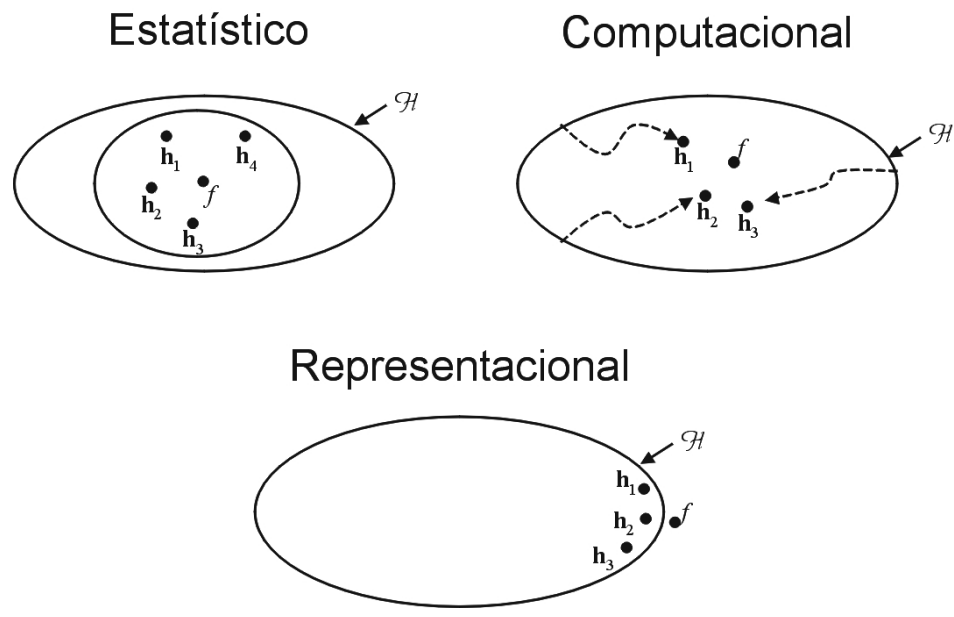

Figura 4.4: Três motivos fundamentais que explicam porque os ensembles funcionam melhor que um único classificador

Três motivos fundamentais que explicam porque os ensembles funcionam melhor que um único classificador (Dietterich, 2000b)

1. Estatístico. Um algoritmo de aprendizado pode ser visto como um algoritmo de busca no espaço de hipóteses $\mathcal{H}$ para identificar a melhor hipótese. O problema estatístico aparece quando a quantidade de dados disponiveis para treinamento é muito pequena comparada ao tamanho do espaço de hipóteses. Sem dados suficientes, o algoritmo de aprendizado pode encontrar muitas hipóteses diferentes em $\mathcal{H}$, as quais têm a mesma precisão sobre os dados de treinamento. Construindo um ensemble com todos esses classificadores, o algoritmo pode calcular a média de seus votos e reduzir o risco de escolher o classificador errado. Na Figura 4.4 (topo à esquerda) é ilustrada essa situação. A curva externa denota o 
espaço de hipóteses $\mathcal{H}$ e a interna denota o conjunto de hipóteses que têm uma boa precisão sobre o conjunto de treinamento. O ponto rotulado com a letra $f$ é a hipótese verdadeira, onde pode-se observar que tirando a média da precisão das hipóteses, podemos encontrar uma boa aproximação de $f$.

2. Computacional. Muitos algoritmos de aprendizado trabalham fazendo alguma busca local, podendo, assim, parar em algum ótimo local. Por exemplo, alguns algoritmos de construção de redes neurais utilizam métodos de busca local - como gradiente descendente - para encontrar pesos localmente ótimos para a rede; e algoritmos de indução de árvore de decisão aplicam regras gulosas de particionamento para induzir as árvores. Nos casos em que há uma quantidade suficiente de dados de treinamento, o que indica que o problema estatístico é mínimo, muitas vezes é computacionalmente dificil para o algoritmo de aprendizado encontrar a melhor hipótese. De fato, o problema de encontrar a menor árvore de decisão que seja consistente com um conjunto de treinamento é NP-hard (Hyafil and Rivest, 1976). Similarmente, encontrar os pesos para a menor rede neural possível consistente com os exemplos de treinamento é também NP-hard (Blum and Rivest, 1988). Entretanto, construindo um ensemble executando várias vezes o algoritmo de busca local partindo, a cada iteração, de diferentes pontos, pode-se obter uma melhor aproximação da verdadeira (e desconhecida) função $f$ que seja mais precisa que qualquer um dos classificadores individuais, como é ilustrado na Figura 4.4 (topo à direita).

3. Representacional. Às vezes, não é possível representar a verdadeira função $f$ pelas hipóteses em $\mathcal{H}$. Entretanto, simplesmente unindo as hipóteses, ou dando pesos a cada uma delas e unindo-as posteriormente, pode ser possível expandir o espaço das funções representáveis. A Figura 4.4 (inferior) ilustra essa situação. 


\subsection{Métodos de Construção de Ensembles}

Muitos métodos de construção de ensembles têm sido desenvolvidos (Dietterich, 2000b). Entretanto, há somente dois métodos de construção de ensembles que consideramos interessante para o desenvolvimento deste trabalho e que inspiraram a proposta dos métodos de construção de ensembles neste trabalho (Seção 4.3): bagging e boosting, descritos a seguir.

\subsubsection{Técnica Bagging}

A técnica Bagging (Breiman, 1996) consiste basicamente de 3(três) passos. O primeiro passo consiste em construir $L$ conjuntos de exemplos por meio de replicações bootstrap de um conjunto de exemplos inicial. Dado um conjunto de treinamento $S=\left\{\left(\mathbf{x}_{i}, y_{i}\right), i=1, \ldots, N\right\}$, uma seqüência de conjuntos de treinamento $\left\{S_{l}\right\}, l=1, \ldots, L$ é construída, sendo que cada conjunto de treinamento consiste de $N$ observações. Os elementos de cada um dos conjuntos da seqüencia $\left\{S_{l}\right\}, l=1, \ldots, L$ são obtidos randomicamente com reposição do conjunto original $S$. Como a amostragem é com reposição, podem haver elementos repetidos na amostra. Cada conjunto de treinamento $\left\{S_{l}\right\}, l=1, \ldots, L$ é chamado de replicação booststrap do conjunto de treinamento original (Efron and Tibshirani, 1993). Cada replicação bootstrap contém, em média, 63.2\% dos exemplos do conjunto original, com exemplos de treinamento aparecendo várias vezes.

O segundo passo consiste em construir $L$ classificadores a partir de cada um dos conjuntos de exemplos $S_{l}, l=1, \ldots, L$, utilizando algum algoritmo de aprendizado. Cada um dos conjuntos de exemplos $S_{l}$ é utilizado para criar a hipótese $\mathbf{h}_{l}$ correspondente.

O terceiro passo consiste em classificar novos exemplos. Para classificar um novo exemplo $\mathrm{x}$ utilizando as hipóteses construídas, se $y=\mathbf{h}^{*}(\mathbf{x})$ (o rótulo de $\mathbf{x}$ ) é numérico, calcula-se a média dos $y_{l}$ resultantes de cada hipótese $\mathbf{h}_{l}$ Equação 4.3.

$$
\mathbf{h}^{*}(\mathbf{x})=\frac{1}{L} \sum_{l=1}^{L} \mathbf{h}_{l}(\mathbf{x})
$$


Por outro lado, se $y$ é um valor discreto, classifica-se $\mathrm{x}$ fazendo-se uma votação entre os resultados das hipóteses $\mathbf{h}_{l}$, a qual é denominada votação por maioria - Equação 4.4 .

$$
\mathbf{h}^{*}(\mathbf{x})=\underset{y \in\left\{C_{1}, \ldots, C_{N_{C l}}\right\}}{\operatorname{argmax}} \sum_{l=1}^{L} \mathbf{h}_{l}(\mathbf{x})
$$

Esta técnica é denominada bootstrap aggregating - daí o termo bagging. O que faz esta técnica funcionar é a instabilidade do algoritmo de aprendizado, pois se as hipóteses não mudam para os diversos conjuntos de treinamento $S_{l}, l=1, \ldots, L$, a agregação não irá ajudar. Assim, quanto mais diferirem entre si as hipóteses geradas, maior será a colaboração desta técnica para o aumento da precisão da classificação.

\subsubsection{Técnica Boosting}

Boosting refere-se ao problema geral de produzir predições precisas utilizando combinação de hipóteses "rústicas" e menos precisas. Uma descrição do algoritmo de boosting AdaBoost.M1, projetado por Freund and Schapire (1997), é mostrada a seguir.

Inicialmente, é dado um conjunto de treinamento $S=\left\{\left(\mathbf{x}_{i}, y_{i}\right), i=1, \ldots, N\right\}$, tal que, para cada par $\left(\mathbf{x}_{i}, y_{i}\right)$, existe um peso $w_{i}$, ou seja, existe um vetor de pesos $W$ com $N$ elementos. Esse vetor é inicializado com $w_{i}=1 / N, i=1, \ldots, N$. Daí, para cada iteração $l=1, \ldots, L$, o algoritmo executa os seguintes passos:

- O algoritmo de aprendizado constrói uma hipótese $\mathbf{h}_{l}$ utilizando o conjunto de treinamento $S$ e o vetor de pesos $W$;

- O erro $\alpha_{l}$ de $\mathbf{h}_{l}$ sobre o conjunto de treinamento é calculado como sendo a soma dos pesos $w_{l_{i}}$ dos exemplos erronemante classificados pela hipótese $\mathbf{h}_{l}$;

- Se $\alpha_{l}=0$ ou $\alpha_{l} \geq 1 / 2$, o processo termina. Senão, os pesos $w_{(l+1)_{i}}$ para a próxima iteração são recalculados como sendo

$$
w_{(l+1)_{i}}=w_{l_{i}} \frac{\alpha_{l}}{1-\alpha_{l}}
$$


se $\mathbf{h}_{l}$ acerta na classificação do exemplo $i$. Ou seja, os exemplos classificados corretamente têm seus pesos reduzidos.

A hipótese $\mathbf{h}^{*}$ é obtida pela votação das hipóteses geradas $\mathbf{h}_{l}, l=1, \ldots, L$. Se $\mathbf{h}_{l}$ classifica um exemplo $\mathbf{x}$ como sendo da classe $C_{v}$, o voto total para a classe $C_{v}$ é incrementado de $\log \left(\left(1-\alpha_{l}\right) / \alpha_{l}\right)$. $\mathbf{h}^{*}$ então associa a $\mathbf{x}$ a classe com maior valor total de voto.

A Figura 4.5 mostra o comportamento da função $\log \left(\frac{1-x}{x}\right)$. Pode-se observar na curva plotada que hipóteses com taxas de erro menores que 50\% possuem pesos positivos, os quais diminuem quanto mais a taxa de erro se aproxima de 0\%. Hipóteses com taxas de erro maiores que 50\% possuem pesos negativos e, quanto mais a taxa de erro se aproxima a 100\%, maior é o valor absoluto do peso. Também, é interessante observar o comportamento da curva como um todo, tendo em vista que hipóteses com taxas de erro bem próximas de $0 \%$ (entre 1 e 10\%, por exemplo) possuem pesos bastante distintos, quando comparados com os pesos, bastante próximos entre si, associados às hipóteses com taxas de erro bem próximas de 50\% (entre 40\% e 49\%, por exemplo). Essas observações mostram um favorecimento muito grande às decisões tomadas por hipóteses com taxas de erro "pequenas" (próximas de 0\%). Em relação às hipóteses com taxas de erro maiores que 50\%, apesar dessa função fornecer um critério de atribuição de pesos bastante interessante, deve ser lembrado que tais hipóteses não fazem parte dos ensembles construídos com a técnica boosting.

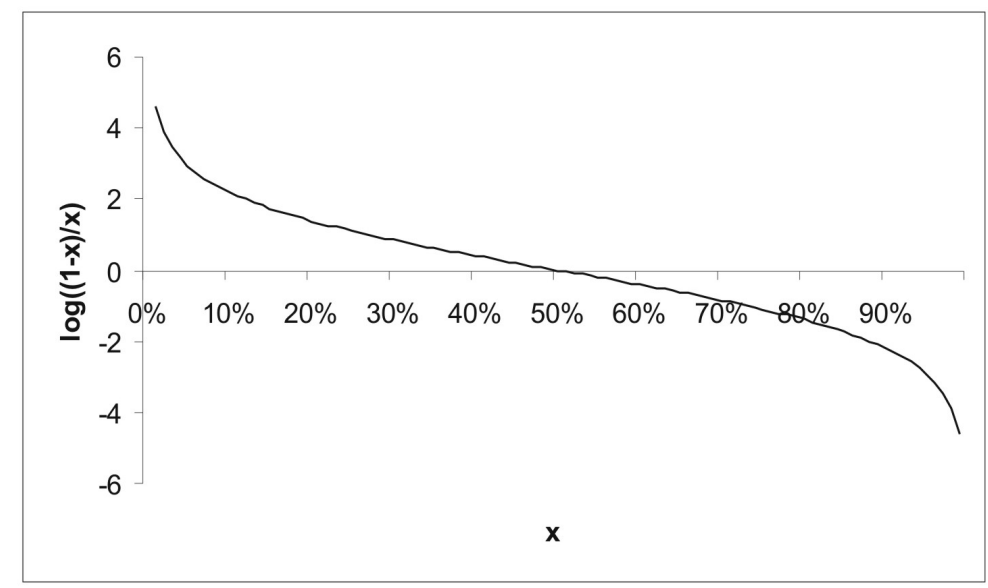

Figura 4.5: Comportamento da função $\log \left(\frac{1-x}{x}\right)$

Com esta técnica, a taxa de erro de $\mathbf{h}^{*}$ cai exponencialmente para próximo 
de 0 (zero) conforme o valor de $L$ aumenta. Assim, se fossem consideradas as hipóteses com uma taxa de erro menor que 50\% nos exemplos de teste, ou seja, uma seqüência de classificadores fracos, pode-se criar um classificador forte $\mathbf{h}^{*}$ que é, no mínimo, tão preciso quanto, e usualmente mais preciso que, o menos preciso dos classificadores fracos (Bauer and Kohavi, 1999).

\subsection{Métodos de Construção de Ensembles Propostos}

Nos métodos de construção de ensembles descritos anteriormente (bagging e boosting), para que sejam obtidas melhores taxas de erro de classificação, são necessários muitos classificadores para compor o ensemble final, o que dificulta bastante a tarefa de interpretação humana do conhecimento embutido nos ensembles de classificadores finais. Entretanto, o método de combinação utilizado por boosting é considerado bastante interessante, por atribuir pesos aos classificadores que compõem o ensemble conforme o comportamento desses classificadores; e o método de construção de ensembles utilizado por bagging é considerado bastante interessante por ser simples. Assim, baseando-se nas teorias de construção de ensembles descritas anteriormente, e utilizando os métodos de construção de ensembles bagging e boosting como inspiração para realizar combinação de classificadores, propomos neste trabalho métodos de construção de ensembles simbólicos que consistem de uma combinação de métodos de combinação de classificadores e de critérios de classificação de novos exemplos por um classificador. A Figura 4.6 ilustra a maneira proposta nesta seção para construção de ensembles simbólicos. Nessa figura, deve ser observado que os $L$ algoritmos de aprendizado utilizados para induzir os classificadores podem ser todos distintos ou ate o mesmo algoritmo. Ainda, como os $L$ classificadores são convertidos para o formato padrão de regras $\mathcal{P B M}-$ Capítulo 3 -, a tarefa de combinar classificadores provenientes de diferentes algoritmos de aprendizado simbólico é facilitada.

Assim, dados $L$ classificadores simbólicos, os quais podem ser induzidos utilizando o mesmo algoritmo de aprendizado ou algoritmos diferentes, e um exemplo x a ser classificado, os métodos de combinação de classificadores que podem ser utilizados são:

Votação sem peso (Unweighted Voting - UV): Cada classificador classifica o exemplo dado. A classificação do ensemble para o exemplo x é dada 


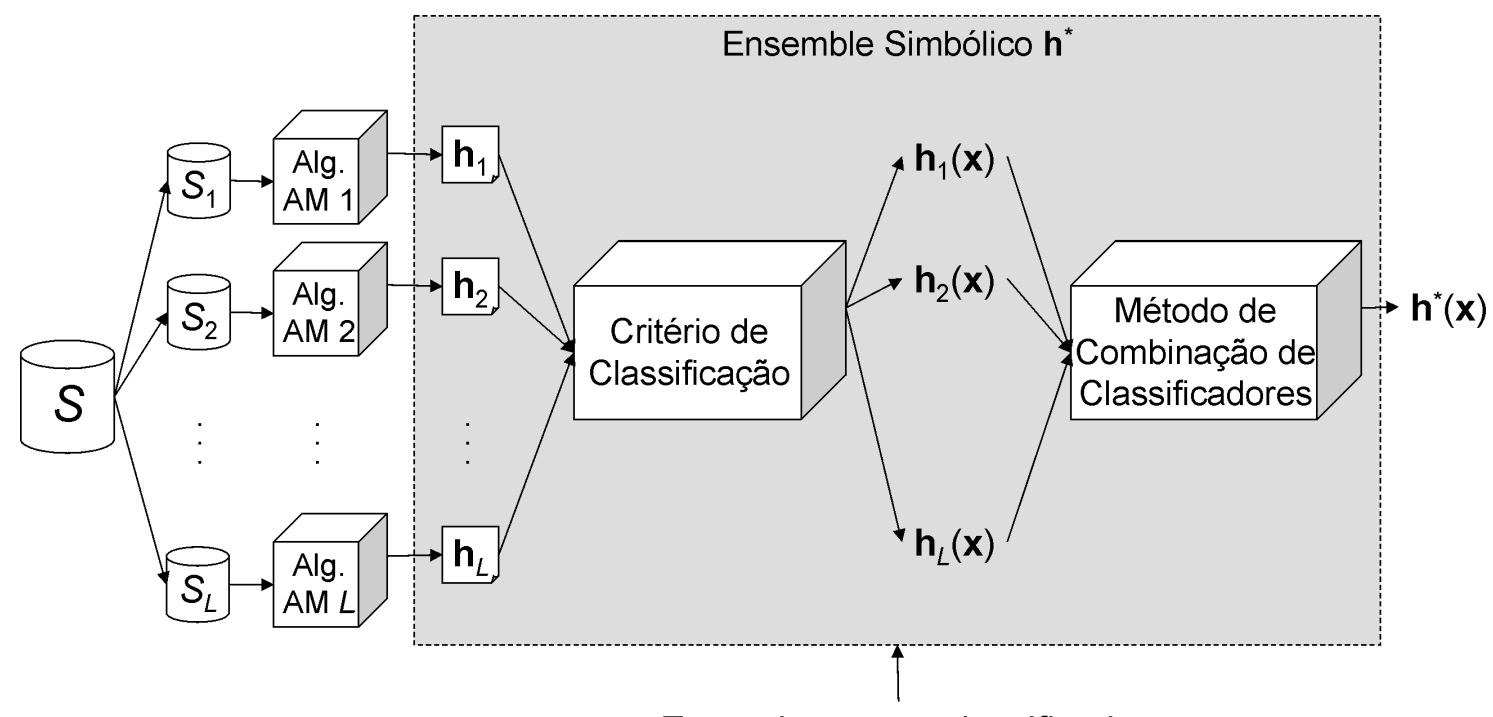

Exemplo $\mathbf{x}$ a ser classificado

Figura 4.6: Um esquema dos métodos de construção de ensembles propostos pela classe que mais recebeu votos dos $L$ classificadores.

Votação com peso (Weighted by Mean Voting - WMV e Weighted by Mean and Standard Error Voting - WMSV): O voto de cada classificador é ponderado por algum peso associado a ele. Uma possível técnica de votação com peso é a adaptada da técnica de boosting para construção de ensembles (Freund and Schapire, 1997), a qual classifica um exemplo segundo o seguinte algoritmo:

1. Para cada hipótese $\mathbf{h}_{l}, l=1, \ldots, L$ :

(a) Classificar o exemplo $\mathrm{x}$;

(b) O novo valor total de voto $(v t)$ da classe $C_{v}, v=1, \ldots, N_{C l}$ à qual o exemplo $\mathrm{x}$ pertence é dado por

$$
v t\left(C_{v}\right)=\sum_{l=1}^{L} f\left(\mathbf{h}_{l}(\mathbf{x}), C_{v}\right)
$$

com

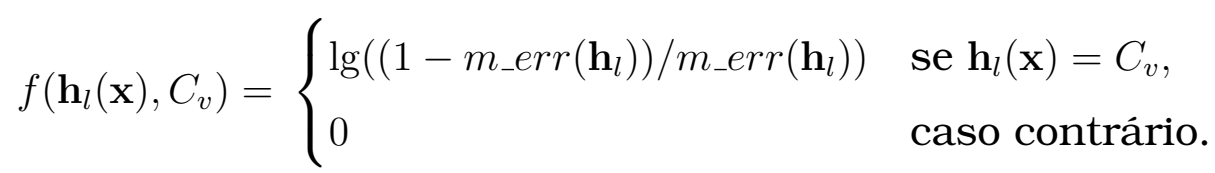

onde $m_{-} e r r\left(\mathbf{h}_{l}\right)$ é a estimativa da média da taxa de erro associada 
à hipótese que classifica o exemplo na classe $C_{v}$ - Equação 2.10;

2. Associar ao exemplo x a classe com maior valor total de voto.

Neste trabalho, a taxa de erro associada à hipótese consiste de uma estimativa da média da taxa de erro verdadeiro, utilizando o método $k$-fold cross-validation estratificado, descritos na Seção 2.3. Esse método é nomeado Weighted by Mean Voting - WMV. Também, já que a técnica fornece mais uma informação além da estimativa da média da taxa de erro verdadeiro das hipóteses - a estimativa do erro padrão (se) - , além de utilizar o critério acima descrito, também utilizamos outro critério, o qual atribui o seguinte peso à decisão da hipótese: o novo valor total de voto (vt) da classe $C_{v}, v=1, \ldots, N_{C l}$ à qual o exemplo x pertence é dado por

$$
v t\left(C_{v}\right)=\sum_{l=1}^{L} g\left(\mathbf{h}_{l}(\mathbf{x}), C_{v}\right)
$$

com

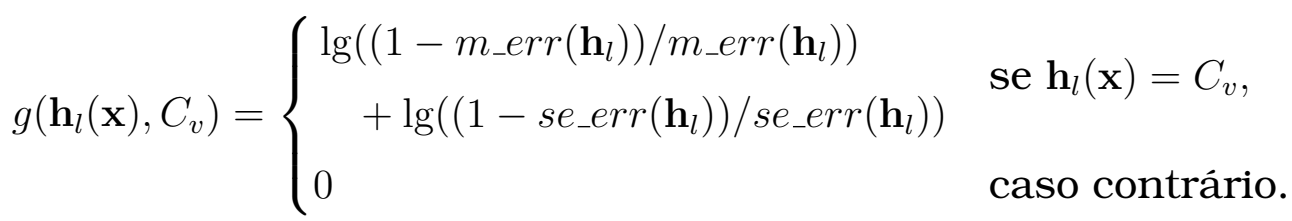

onde $m_{-} e r r\left(\mathbf{h}_{l}\right)$ é a estimativa da média da taxa de erro e $\operatorname{se\_ } e r r\left(\mathbf{h}_{l}\right)$ é a estimativa do erro padrão da taxa de erro - Equação $2.11-$, associados à hipótese que classifica o exemplo na classe $C_{v}$. Esse método é nomeado Weighted by Mean and Standard Error Voting - WMSV.

Pode-se pensar que em ambas situações, votação com e sem peso, o resultado da classificação de um novo exemplo x é o mesmo. O seguinte exemplo mostra que isso não é necessariamente verdade: dadas 3(três) hipóteses $\mathbf{h}_{1}, \mathbf{h}_{2}$ e $\mathbf{h}_{3}$, um exemplo $\mathrm{x}$ a ser classificado e as taxas de erro das hipóteses $\alpha_{1}=0,10, \alpha_{2}=0,30$ e $\alpha_{3}=0,30$. Supondo que a classificação para o exemplo x seja $C_{1}$ segundo a hipótese $\mathbf{h}_{1}$ e $C_{2}$ segundo as hipóteses $\mathbf{h}_{2}$ e $\mathbf{h}_{3}$, caso for utilizado o método de votação sem peso, a classificação do ensemble para o exemplo x é a classe $C_{2}$; entretanto, se for utilizado o método de votação com peso, então: 
valor total de votos para a classe $C_{1}$ :

$$
\begin{aligned}
v t\left(C_{1}\right) & =\lg \left(\left(1-m_{-} \operatorname{err}\left(\mathbf{h}_{1}\right)\right) / m_{-} \operatorname{err}\left(\mathbf{h}_{1}\right)\right)+0+0 \\
& =\lg ((1-0,1) / 0,1)=0,95
\end{aligned}
$$

valor total de votos para a classe $C_{2}$ :

$$
\begin{aligned}
v t\left(C_{2}\right) & =0+\lg \frac{1-m_{-} \operatorname{err}\left(\mathbf{h}_{1}\right)}{m_{-} \operatorname{err}\left(\mathbf{h}_{1}\right)}+\lg \frac{1-m_{-} \operatorname{err}\left(\mathbf{h}_{2}\right)}{m_{-} \operatorname{err}\left(\mathbf{h}_{2}\right)} \\
& =\lg ((1-0,3) / 0,3)+\lg ((1-0,3) / 0,3)=0,74
\end{aligned}
$$

e a classificação do ensemble é a classe $C_{1}$.

Já em relação ao critério de classificação, dado um exemplo x a ser classificado e um classificador $\mathbf{h}$, podem ser considerados dois critérios para se classificar esse exemplo:

Decisão do próprio classificador: O método implementado no algoritmo de aprendizado que induziu o classificador é o responsável pela classificação do exemplo;

Decisão pela melhor regra do classificador: A "melhor" regra do classificador que cobre o exemplo, segundo alguma medida de avaliação de regra de conhecimento (Apêndice A na página 155), é responsável pela classificação do exemplo.

Existem diversas medidas de avaliação de regras, como pode ser observado no Apêndice A, que podem ser utilizadas, o que aumenta o número de métodos de construção de ensembles simbólicos. Para melhor compreender essa afirmação, é necessário explicitar a maneira que se pretende construir os ensembles simbólicos. Dados $L$ conjuntos de exemplos $S_{1}, \ldots, S_{L} \subset S$, pode-se induzir $L$ classificadores $\mathbf{h}_{1}, \ldots, \mathbf{h}_{L}$. O critério de classificação utilizado por cada classificador $\mathbf{h}_{l}$ para classificar novos exemplos, juntamente com o método de combinação para combinar as decisões realizadas pelas hipóteses para fornecer a classificação final desses novos exemplos, caracterizam um ensemble simbólico $\mathbf{h}^{*}$. Assim, o número de métodos de construção de ensembles simbólicos que podem ser testados é uma combinação do número de métodos 
de combinação de classificadores com o número de critérios de classificação considerados.

Como saída, os métodos aqui propostos fornecem a classificação de um exemplo dado e um conjunto de regras que cobrem esse exemplo. Entretanto, em muitos casos esse conjunto de regras contém regras que são especializações de outras regras. Para facilitar a explicação ao usuário, foi decidido fornecer como explicação ao usuário somente as regras mais gerais, por ser essa a explicação sintaticamente mais simples. Assim, na próxima seção, é proposto um método para resumir esse conjunto de regras, baseado nas definições descritas na Seção 2.5, relacionadas à especificação e generalização de regras.

\subsection{Um Método para Simplificar a Explicação de En- sembles de Classificadores}

Dado um ensemble de classificadores simbólicos e um exemplo $\mathrm{x}$ a ser classificado, pode-se utilizar uma das 3 (três) maneiras descritas na seção anterior para combinar as decisões de cada um dos classificadores componentes - UV, WMV e WMSV. Como os classificadores são simbólicos, o ensemble oferece como saída, além da classificação final do exemplo $\mathrm{x}$, todas as regras que cobrem esse exemplo. Dessas regras, são selecionadas aquelas cuja cabeça (classe) $H_{i}$ prediz para o exemplo x a mesma classe que o ensemble, as quais formam o conjunto de regras $\mathbf{R}_{\text {expl }}$. Entretanto, nesse conjunto podem existir regras mais gerais que outras e, como mencionado na Seção 2.5, para tornar a explicação mais simples, retira-se de $\mathbf{R}_{\operatorname{expl}}$ as regras mais especializadas em relação a outras também pertencentes a $\mathbf{R}_{\text {expl }}$. Ou seja, analisando as regras em $\mathbf{R}_{\text {expl }}$ duas a duas, ficam no conjunto final $\mathbf{R}_{\text {expl }}^{\prime}$ somente as regras que subsumem outras regras.

O procedimento para encontrar a explicação final $\mathbf{R}_{\text {expl }}^{\prime}$ é o seguinte: o corpo de cada regra $R_{e}$ pertencente a $\mathbf{R}_{e x p l}, B_{e}$, consiste de uma conjunção de testes de atributos; cada corpo, então, é transformado no conjunto correspondente $A_{e}$ de testes de atributos. O conjunto composto por esses conjuntos $A_{e}$ é denominado $\mathbf{A}_{\text {expl }}$. Após construído o conjunto $\mathbf{A}_{\text {expl }}$, o Algoritmo 3 descreve como é construída a explicação mais geral da classificação atribuída pelo ensemble ao exemplo x, a qual será mostrada ao usuário. 


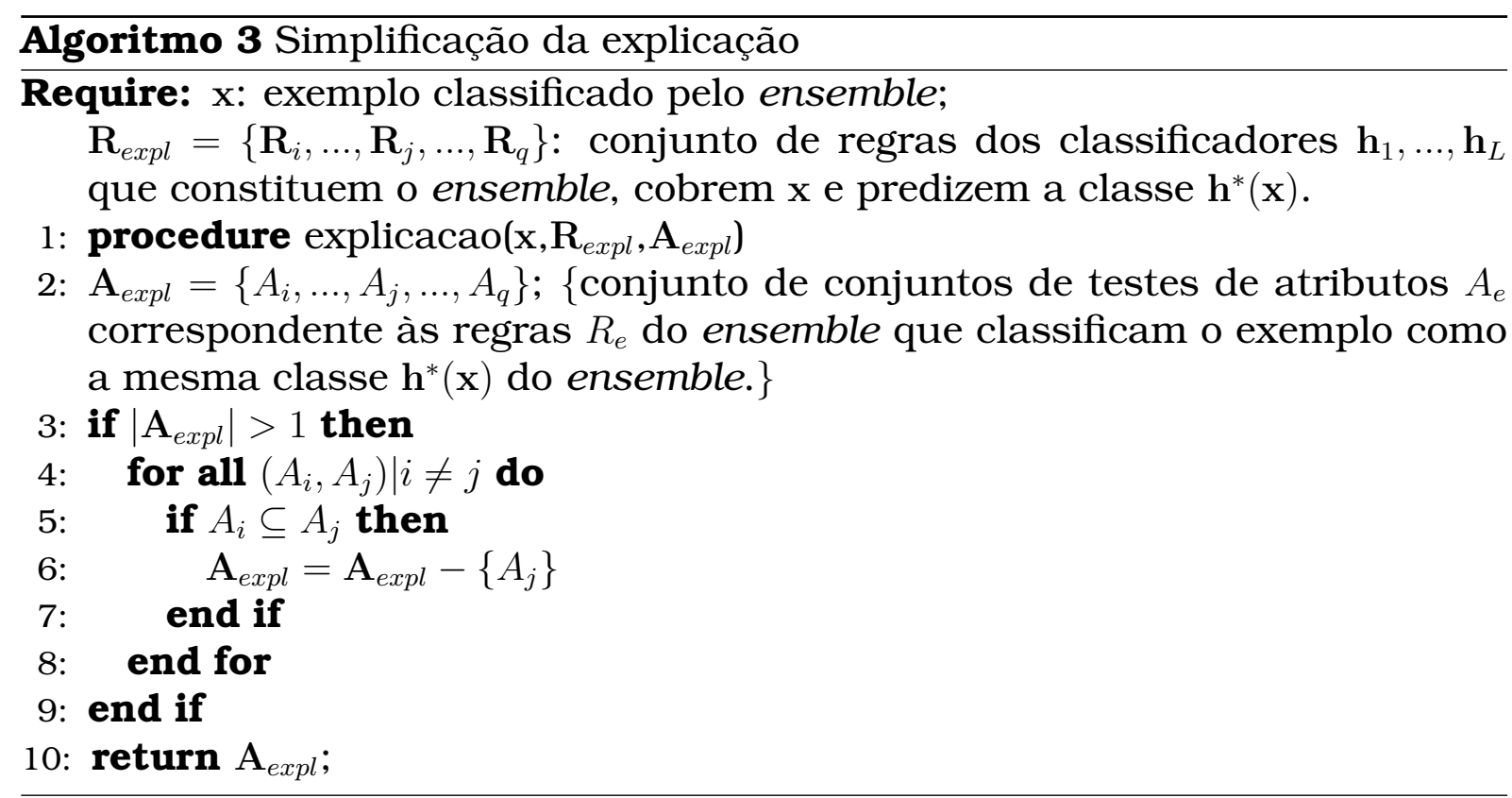

\subsection{Considerações Finais}

Neste capítulo, foram descritos conceitos de ensembles de classificadores, foram propostos métodos de construção de ensembles de classificadores simbólicos, e foi proposto um método para simplificar a explicação fornecida pelos ensembles construídos. No próximo capítulo, é descrito o ambiente ELE - Ensemble Learning Environment — , integrado ao DISCOVER, que implementa os métodos propostos neste capitulo, bem como implementa métodos para avaliação desses métodos de construção de ensembles. 


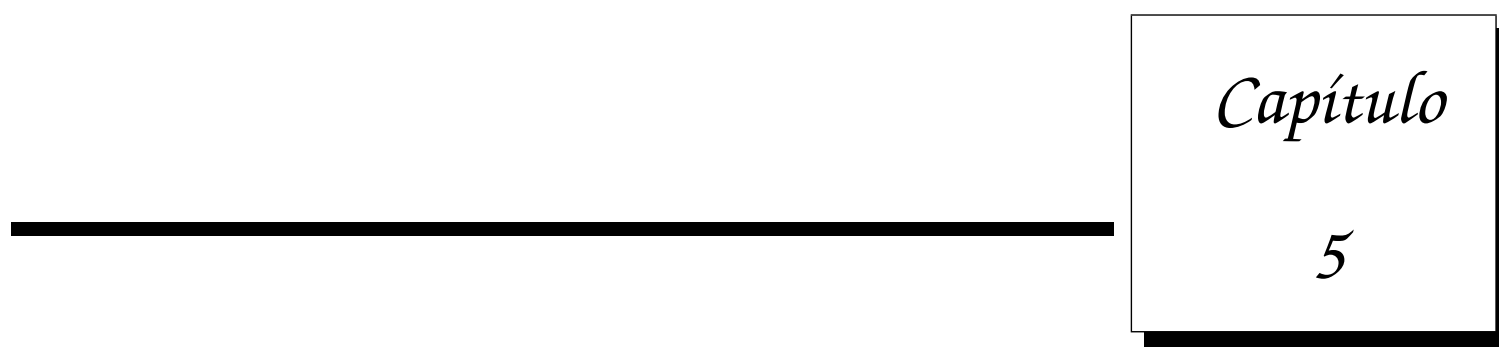

\section{O AMBiEnTE ELE}

"O pessimista se queixa do vento, o otimista espera que ele mude e o realista ajusta as velas."

- Willian George Ward

uando são considerados métodos de aprendizado, um dos aspectos mais importantes é a avaliação experimental dos classificadores construídos por esses métodos, pois não existem instrumentos formais para decidir qual método é ótimo para um dado problema (Dietterich, 1989; Kibler and Langley, 1988; Schaffer, 1994). Assim, é necessário realizar a avaliação experimental dos vários métodos de construção de ensembles considerados neste trabalho, propostos na Seção 4.3. Em outras palavras, dados dois ensembles $\mathbf{h}_{1}^{*}$ e $\mathbf{h}_{2}^{*}$, constituídos pela combinação de $L_{1}$ e $L_{2}$ hipóteses respectivamente, ou seja,

$$
\begin{gathered}
\mathbf{h}_{1}^{*}=\left\{\mathbf{h}_{11}, \mathbf{h}_{12}, \ldots, \mathbf{h}_{1 L_{1}}\right\} \\
\mathrm{e} \\
\mathbf{h}_{2}^{*}=\left\{\mathbf{h}_{21}, \mathbf{h}_{22}, \ldots, \mathbf{h}_{2 L_{2}}\right\}
\end{gathered}
$$


são vários os testes que devem ser realizados. Entre eles:

1. considerando qualquer ensemble $\mathbf{h}^{*}$ isoladamente, verificar se o erro de $\mathbf{h}^{*}$ é menor que o erro de cada um dos classificadores $\mathbf{h}_{1}, \ldots, \mathbf{h}_{L}$ que o compõe. Ou seja, se $\operatorname{err}(\mathbf{h})^{*} \leq \operatorname{err}\left(\mathbf{h}_{l}\right), l=1, \ldots, L$. Para fazer essa verificação, deve ser utilizado um teste de hipóteses, o que faz necessário estimar a média e a variância do erro (a taxa do erro) de cada hipótese $\mathbf{h}_{1}, \ldots, \mathbf{h}_{L}$ e da hipótese $\mathbf{h}^{*}$. Neste trabalho, as taxas de erro de $\mathbf{h}^{*}$ e de $\mathbf{h}_{l}, l=1, \ldots L$ serão estimadas utilizando a técnica $k$-fold cross-validation estratificado.

2. considerando ambos os ensembles $\mathbf{h}_{1}^{*}$ e $\mathbf{h}_{2}^{*}$, construídos com métodos de construção de ensembles distintos, verificar a relação de erro entre ambos, ou seja, a relação entre $\operatorname{err}\left(\mathbf{h}_{1}^{*}\right)$ e $\operatorname{err}\left(\mathbf{h}_{2}^{*}\right)$. Também, para poder afirmar se um método de construção de ensemble é melhor que outro, é necessário utilizar um teste de hipóteses, o que implica na estimativa da variância do erro desses dois ensembles.

Para realizar esses testes, ou seja, essas avaliações, neste capítulo são descritas as implementações dos módulos computacionais que utilizam estruturas de árvores de diretórios para executar os métodos de construção de ensembles. Foi decidido utilizar estruturas de árvores de diretórios para que o ambiente computacional SNIFFER pudesse ser utilizado, o que facilitou a tarefa de implementação do ambiente ELE. A seguir, é descrito como é construída a árvore de experimentos, sendo descritos os módulos que compõem o ambiente ELE, sendo este um sub-ambiente do ambiente DISCOVER, para construção de ensembles de classificadores. Também, é descrito neste capítulo um exemplo de utilização do ambiente computacional implementado para melhor compreensão de seu funcionamento.

\subsection{Proposta para Construção e Avaliação de Ensem- bles de Classificadores Simbólicos}

Para avaliar os métodos de construção de ensembles de classificadores propostos na Seção 4.3, pensamos em avaliar a taxa de erro dos ensembles construídos. Para realizar essa avaliação, além de comparar a taxa de erro de um ensemble construído com o erro majoritário do conjunto de dados utilizado 
para construção do ensemble, também é necessário comparar a taxa de erro desse ensemble com as taxas de erro dos classificadores que o compõem. Para obter tais taxas de erro, é necessário que exista conjuntos de treinamento e teste para a fase de construção do ensemble e estimativa do erro do ensemble, respectivamente. Para ter controle nos experimentos realizados para avaliação dos métodos de construção de ensembles de classificadores, são utilizados conjuntos de dados de pequeno a médio porte. Como os conjuntos de dados são relativamente pequenos, é necessário utilizar outras técnicas de validação, como a de validação cruzada ( $k$-fold cross-validation - Seção 2.3). Em nosso caso, utilizamos $k$-fold cross-validation estratificado tanto para para estimativa de erro do ensemble quanto para estimativa de erro dos classificadores que o compõem. Para facilitar a implementação do $k$-fold cross-validation estratificado no ambiente ELE, utilizamos as funcionalidades do ambiente Discover disponíveis.

Tendo em vista o funcionamento do SNIFFER para implementar um módulo para realizar esses testes, inicialmente é necessário pensar em uma maneira de estimar a taxa de erro verdadeiro de cada hipótese pertencente a $\mathbf{h}^{*}$ para utilizar a estimativa do erro de cada hipótese nos métodos de combinação com peso e sem peso. Para utilizar o SNIFfer, é necessário construir uma árvore de diretórios para ser utilizada como ponto de entrada para o SNIFFER, conforme a árvore de diretórios exibida na Figura 5.1. Nessa figura, $S_{-} 1, \ldots, S_{-} L$ referem-se a diretórios que contém, respectivamente, $S_{1}, \ldots, S_{L}$ conjuntos de exemplos; e Alg_1,...,Alg_L são identificadores de algoritmos de aprendizado simbólico, reconhecidos pelo Sniffer. Guando o SNiffer é executado, são criados os diretórios it0,.., it(k-1), é realizado o método de resampling $k$-fold cross-validation estratificado, e são executados os respectivos algoritmos de aprendizado. Na Figura 5.2 é mostrado como fica o estado da árvore de diretórios após a execução do SNIFFER na árvore mostrada na Figura 5.1.

Para construir um ensemble simbólico, é necessário construir previamente as hipóteses que o compõem. Para isso, é induzido com cada conjunto de exemplos $S_{1}, \ldots, S_{L}$ uma hipótese com os respectivos algoritmos Alg_1,..,Alg_L. Para tanto, é necessário construir uma árvore de diretórios como a mostrada na Figura 5.3. Os diretórios it 0 devem estar presentes nessa árvore para que o SNIFFER induza somente um classificador com todo o conjunto de dados, que devem estar nesse diretório, sem que seja estimado o erro e sem que realize o método de resampling $k$-fold cross-validation estratificado. Note que para 


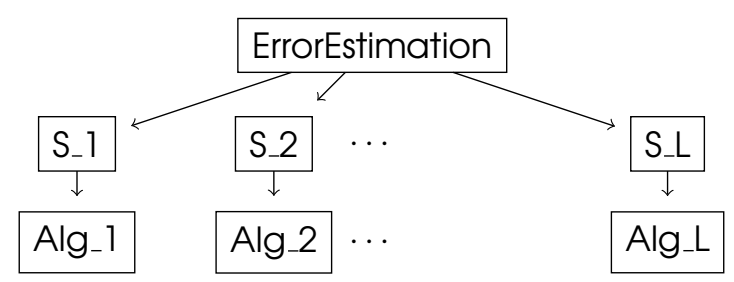

Figura 5.1: Configuração da árvore de diretórios para executar o SNIFFER para obter a estimativa da taxa de erro verdadeira para cada uma das hipóteses $\mathbf{h}_{1}, \ldots, \mathbf{h}_{L}$

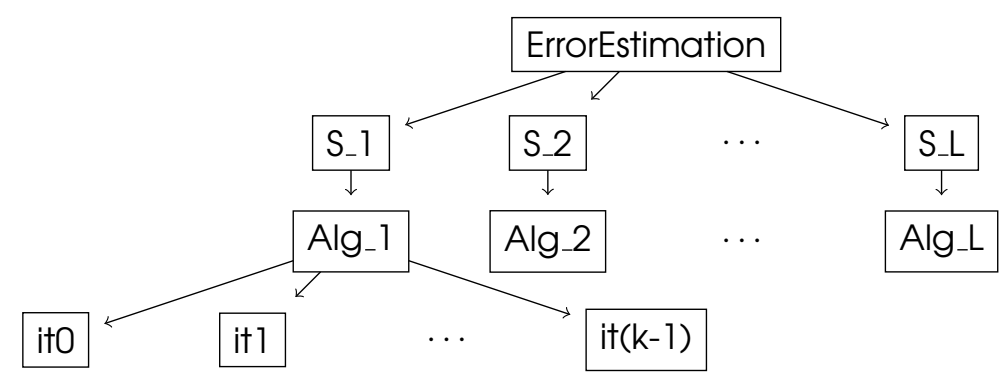

Figura 5.2: Configuração da árvore de diretórios após executar o SNIFFER para obter a estimativa da taxa de erro verdadeira para cada uma das hipóteses $\mathbf{h}_{1}, \ldots, \mathbf{h}_{L}$ 


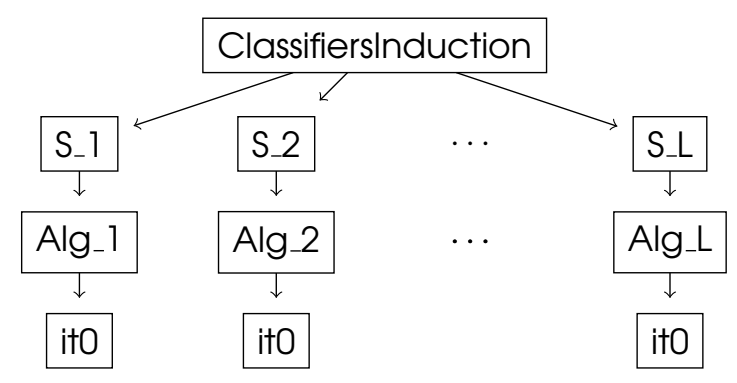

Figura 5.3: Configuração da árvore de diretórios para construir um ensemble $\mathbf{h}^{*}$ composto pelas hipóteses $\mathbf{h}_{1}, \ldots, \mathbf{h}_{L}$

induzir os classificadores $\mathbf{h}_{1}, \ldots, \mathbf{h}_{L}$ que compõem $\mathbf{h}^{*}$, devem ser utilizados os mesmos conjuntos de dados utilizados para estimar o erro de $\mathbf{h}_{1}, \ldots, \mathbf{h}_{L}$. Nesta árvore, é chamado o módulo SNIFFERCLASSIND, o qual estende funcionalidades do SNIFFER, conforme descrito na Seção 3.4.

Como o objetivo é verificar se o erro do ensemble $\mathbf{h}^{*}$ é menor que o erro das hipóteses que o compõem, é necessário utilizar um teste de hipóteses, ou seja, é necessário estimar o erro do ensemble. Assim, utilizando a técnica $k$-fold cross-validation estratificado, obtém-se uma estimativa da média e da variância do erro verdadeiro para o ensemble $\mathbf{h}^{*}$. Para isso, deve ser construída uma árvore de diretórios que repita $k$ vezes o processo de construção de ensemble, ou seja, que repita $k$ vezes as árvores mostradas nas Figuras 5.1 e 5.3. Tal árvore pode ser observada na Figura 5.4. Em cada diretório it0,..., it(k-1), filhos do diretório Experimento, existe um arquivo contendo um conjunto de dados de treinamento e outro contendo um conjunto de dados de teste. Em cada iteração, para construir as $L$ hipóteses e seus respectivos erros, deve ser utilizado o conjunto de dados de treinamento. Para obter os conjuntos de dados presentes nos diretórios $S_{-} 1, \ldots, S_{-} L$, pode-se replicar o conjunto de treinamento em cada um desses diretórios ou pode-se utilizar um método de resampling com ou sem reposição sobre o conjunto de treinamento.

Para melhor compreensão do método anteriormente descrito, são mostradas duas figuras para ilustrar esse processo. Nas Figuras 5.5 e 5.6 é ilustrada a maneira que propomos para realizar o $k$-fold cross-validation.

Na Figura 5.5, dado um conjunto de dados inicial $S$, inicialmente esse conjunto deve ser dividido em $k$ subconjuntos $S_{1}^{\prime}, \ldots, S_{k}^{\prime}$. Na primeira iteração do $k-$ fold, os conjuntos $S_{2}^{\prime}, \ldots, S_{k}^{\prime}$ formam o conjunto de treinamento $S_{t r 1}$ e o 


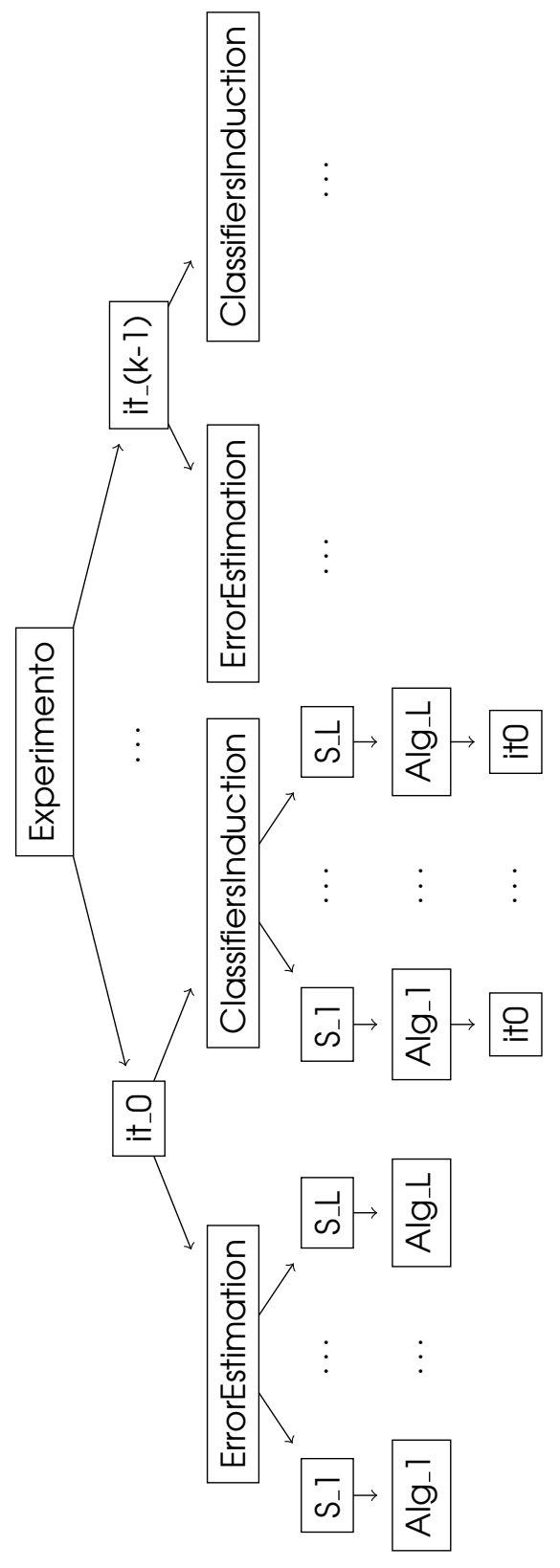

Figura 5.4: Configuração da árvore de diretórios para estimar o erro de um ensemble $\mathbf{h}^{*}$ composto pelas hipóteses $\mathbf{h}_{1}, \ldots, \mathbf{h}_{L}$ 
conjunto $S_{1}^{\prime}$ forma o conjunto de teste $S_{t e 1}$. Do conjunto $S_{t r 1}$, são extraídas $L$ amostras de conjuntos de dados com ou sem reposição, sendo que cada amostra forma os respectivos conjuntos $S_{11}, \ldots, S_{1 L}$. A partir de cada um desses conjuntos $S_{11}, \ldots, S_{1 L}$, é induzido um classificador simbólico e é estimada a taxa de erro desse classificador (esse processo é explicado na descrição da Figura 5.6), ou seja, a partir de $S_{11}$ é induzida a hipótese $\mathbf{h}_{11}$ e é estimada sua taxa de erro $\varepsilon_{11}$, a partir de $S_{12}$ é induzida a hipótese $\mathbf{h}_{12}$ e é estimada sua taxa de erro $\varepsilon_{12}$ e assim sucessivamente. As hipóteses $\mathbf{h}_{11}, \ldots, \mathbf{h}_{1 L}$ e suas respectivas taxas de erro $\varepsilon_{11}, \ldots, \varepsilon_{1 L}$ formam os dados de entradas (os classificadores componentes) do ensemble de classificadores $\mathbf{h}_{1}^{*}$. Dado um método de combinação e um método de classificação de exemplos dentre os métodos propostos, descritos na Seção 4.3, o ensemble $\mathbf{h}_{1}^{*}$ é testado, obtendo assim a taxa de erro $\varepsilon_{1}^{*}$. De maneira análoga, na segunda iteração do $k$-fold, os conjuntos $S_{1}^{\prime}, S_{3}^{\prime}, \ldots, S_{k}^{\prime}$ formam o conjunto de treinamento $S_{t r 2}$ e o conjunto $S_{2}^{\prime}$ forma o conjunto de teste $S_{t e 2}$. Do conjunto $S_{t r 2}$, são extraídas $L$ amostras formando os conjuntos $S_{21}, \ldots, S_{2 L}$, a partir dos quais são induzidas as hipóteses $\mathbf{h}_{21}, \ldots, \mathbf{h}_{2 L}$ e suas respectivas taxas de erro $\varepsilon_{21}, \ldots, \varepsilon_{2 L}$. Tais hipóteses e taxas de erro formam os dados de entradas (os classificadores componentes) do ensemble de classificadores $\mathbf{h}_{2}^{*}$. Dado um método de combinação e um método de classificação de exemplos, o ensemble $\mathbf{h}_{2}^{*}$ é testado, obtendo assim a taxa de erro $\varepsilon_{2}^{*}$. Da mesma maneira, são realizados os outros $k-2$ folds.

Na Figura 5.6, é ilustrado como é realizado o $k$-fold cross-validation quando é dado um conjunto de dados e um algoritmo de aprendizado de máquina simbólico para ser induzida uma hipótese e como é estimada a taxa de erro dessa hipótese. Nessa figura, dado o conjunto de exemplos $S_{11}$, é realizado o $k$-fold de maneira usual, ou seja, inicialmente o conjunto $S_{11}$ é dividido em $k$ partições estratificadas $S_{11_{-} 1}, \ldots, S_{11 \_k}$. Na primeira iteração, o conjunto $S_{11_{\_} 1}$ é utilizado como conjunto de teste $S_{11_{\_} t e 1}$, e os conjuntos $S_{11_{\_} 2}, \ldots, S_{11_{\_} k}$ formam o conjunto de treinamento $S_{11 \_t r 1}$. O algoritmo de aprendizado simbólico dado é utilizado para induzir o classificador $\mathbf{h}_{111}$, o qual é testado com o conjunto de teste $S_{11 \_t e 1}$, obtendo assim a taxa de erro $\varepsilon_{111}$. De maneira análoga, são criados os conjuntos de treinamento $S_{11_{\iota} t r 2}$, com a união dos conjuntos $S_{11_{\_} 1}, S_{11_{\_} 3}, \ldots, S_{11_{\_} k}$, e de teste $S_{11_{\_} t e 2}$, sendo este o conjunto $S_{11_{2} 2}$, a partir dos quais é induzida a hipótese $\mathbf{h}_{111}$ e testada obtendo assim a taxa de erro $\varepsilon_{112}$, e assim sucessivamente. Esse mesmo processo ilustrado na Figura 5.6 ocorre para cada um dos conjuntos $S_{i, j}, i=1, \ldots, k, j=1, \ldots, L$. 
Após a execução do SNiffer em todos os diretórios ErrorEstimation e Classifiersinduction, o que se tem são $k$ conjuntos compostos cada um por $L$ classificadores com suas respectivas estimativas de erro. Para estimar o erro dos métodos de combinação dos classificadores, é necessário executar o método desejado $k$ vezes em $k$ arquivos de teste distintos (presentes nos diretórios it0,..., it(k-1) filhos do diretório Experimento) para obter $k$ matrizes de confusão e, conseqüentemente, obter a estimativa da média e da variância do erro desse método sobre o domínio utilizado. Assim, é necessário, então, construir uma outra árvore onde o método de construção de ensemble é executado. Como, nesse processo, é necessário ter em mãos em cada execução $K, K=1, \ldots, k$, as $L$ hipóteses pertencentes à hipótese $\mathbf{h}_{K}^{*}$ juntamente com seus respectivos erros, tais informações são armazenadas em arquivos nos diretórios it_0,..., it_(k1) no segundo nível da árvore mostrada na Figura 5.4. Com esses arquivos em fácil localização para serem recuperados, deve-se construir a árvore mostrada na Figura 5.7. Nessa figura, o diretório nomeado Method deve ser nomeado, na prática, com algum identificador válido para o SNIFFER, o qual indica o método de construção de ensemble que deve ser utilizado. Os identificadores atualmente reconhecidos pelo SNIFFER são, inicialmente, os listados na Tabela 5.1. Futuramente, os métodos de construção de ensembles e os respectivos classificadores podem ser ampliados, tendo em vista que podem ser utilizadas outras medidas de avaliação de regras de conhecimento para decisões de classificação.

Para comparar entre si os métodos de construção de ensembles simbólicos propostos neste trabalho e compará-los com os classificadores que os compõem (testes 1 e 2 na página 58), pode-se ampliar a estrutura da árvore mostrada na Figura 5.7, colocando outros diretórios de métodos sob o diretório EnsembleMethodsExecution. Na Figura 5.8 é ilustrada essa ampliação. Deve ser observado que no diretório it(k-1) filho do diretório Alg_1 por exemplo - Figura $5.8-$, devem estar presentes os seguintes arquivos da árvore mostrada na Figura 5.4:

- o arquivo com o conjunto de treinamento presente no diretório it0 do nível $6^{1}$, descendente do nó (diretório) it(k-1); e

- o arquivo com o conjunto de teste armazenado no diretório it(k-1) do nível

\footnotetext{
${ }^{1}$ Nas árvores de diretórios apresentadas neste trabalho, denominamos nível 1 o nível da árvore onde está seu nó raíz; nível 2 o nível onde estão os nós filhos do nó raíz e assim sucessivamente.
} 


\begin{tabular}{c|l} 
Identificador & Descrição \\
\hline \hline unweighted.byclassifier* & $\begin{array}{l}\text { Combinação sem peso, utilizando como critério de } \\
\text { classificação o critério do próprio classificador } \\
\text { Combinação com peso tomando como peso a média do } \\
\text { erro, utilizando como criterio de classificação o critério do } \\
\text { próprio classificador } \\
\text { Combinação com peso tomando como peso a média e o erro } \\
\text { padrão do erro, utilizando como critério de classificação o } \\
\text { critério do próprio classificador }\end{array}$ \\
\hline unweightedmeanse.byclassifier \\
weightedmean.accr \\
weightedmeanse.accr & $\begin{array}{l}\text { Combinação sem peso, utilizando como critério de } \\
\text { classificação a regra mais precisa do classificador } \\
\text { Combinação com peso tomando como peso a média do } \\
\text { erro, utilizando como critério de classificação a regra mais } \\
\text { precisa do classificador }\end{array}$ \\
Combinação com peso tomando como peso a média e o erro \\
padrão do erro, utilizando como critério de classificação a \\
regra mais precisa do classificador
\end{tabular}

Tabela 5.1: Identificadores de métodos de construção de ensembles reconhecidos pelo SNIFFER

\footnotetext{
${ }^{a}$ Os identificadores marcados com * utilizam como método de classificação o classificador como um todo.

2.

De maneira análoga, são construídos os diretórios it0,..., it(k-1), filhos dos diretórios Alg_1,..., Alg_L pertencentes à árvore de diretórios mostrada na Figura 5.8.
} 


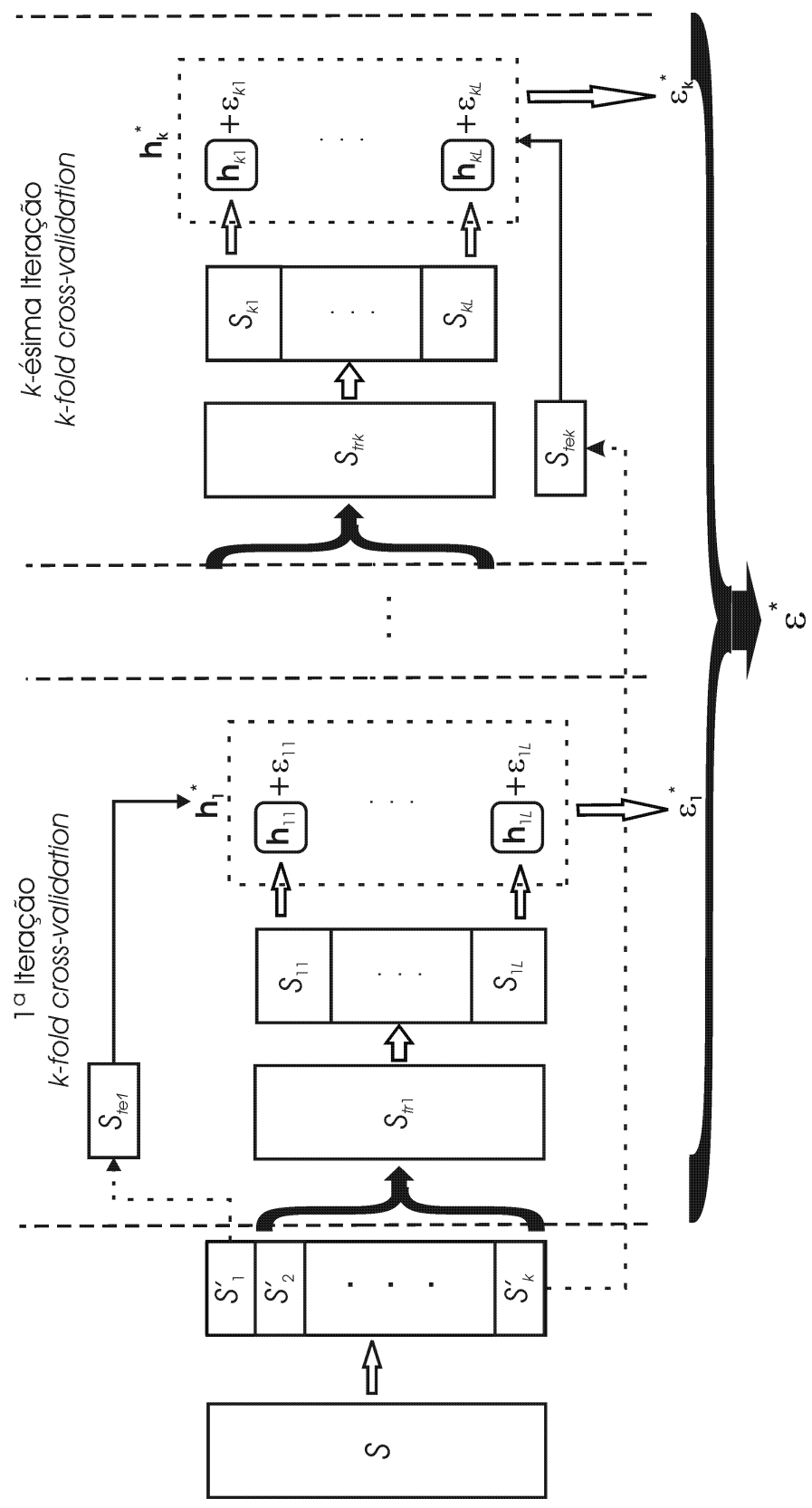

Figura 5.5: Estimativa da taxa de erro de um ensemble de classificadores 


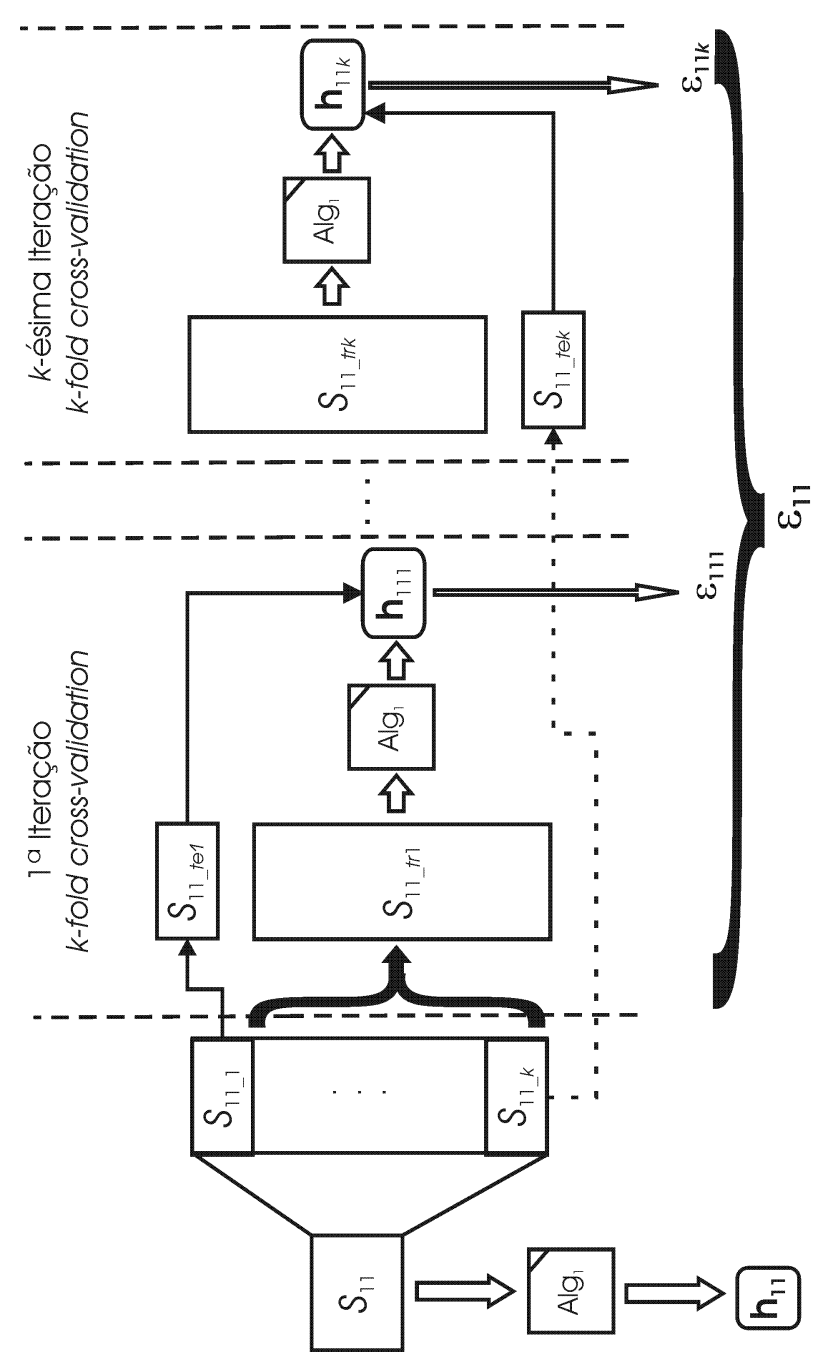

Figura 5.6: Estimativa da taxa de erro do classificador $\mathbf{h}_{11}$, construído sobre o conjunto de dados $S_{11}$

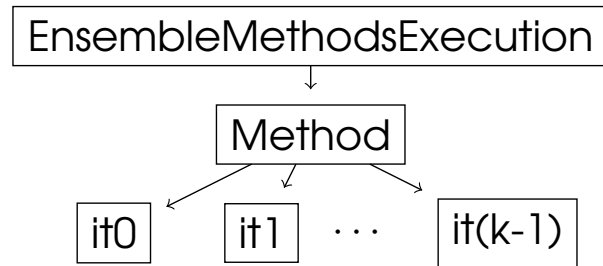

Figura 5.7: Configuração da árvore de diretórios para utilizar os métodos de construção de ensembles 


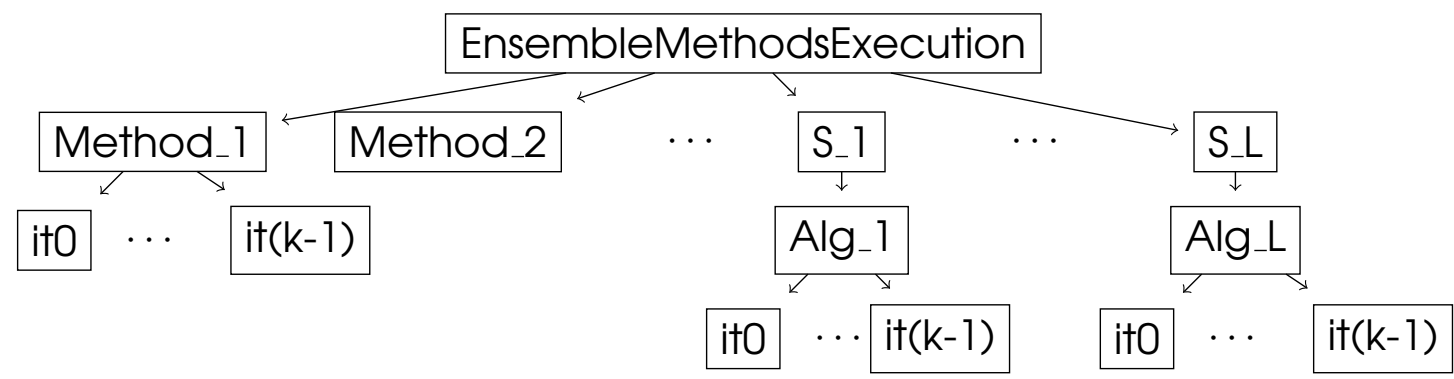

Figura 5.8: Configuração da árvore de diretórios para comparar diferentes métodos de construção de ensembles

Deve ser observado que esse projeto do módulo permite que o usuário consiga construir um único ensemble para ser utilizado para classificar novos exemplos, e não somente para avaliação de métodos de construção de ensembles. Para isso, basta configurar a árvore de diretórios mostrada na Figura 5.4 colocando somente uma iteração ito no segundo nível da árvore, o que implica em somente uma iteração na árvore mostrada na Figura 5.7.

Para construir as referidas estruturas de diretórios e executar os métodos de combinação de classificadores e classificação de exemplos, foi desenvolvido neste trabalho o ambiente ELE (Ensemble Learning Environment), composto por dois módulos distintos - EnsembleTree e EnsEMbleMeThods. A principal funcionalidade do módulo computacional ENSEMBLETREE é construir as árvores de diretórios descritas, e o módulo computacional ENSEMBLEMethods implementa os métodos de construção de ensembles descritos na Seção 4.3. O módulo EnsembleMethods també pode ser visto como uma biblioteca de classes, já que cada método de classificação de exemplo e cada método de combinação de classificadores é implementado em uma classe diferente. A seguir, são descritos o módulo computacional EnsEMBLETREe e a biblioteca de classes EnsEMBLEMETHODS.

\subsection{O Módulo Computacional EnsembleTree}

O ambiente computacional ENSEMBLETREE tem como objetivo:

- construir as estruturas de diretórios mostradas nas Figuras 5.4 e 5.8 e descritas anteriormente;

- executar o SNIFFER para induzir os classificadores que compõem os ensembles e estimar o erro desses classificadores; e 
- executar o SNIFFER para estimar o erro dos métodos de construção de ensembles.

Dados um número de iterações de $k$-fold cross-validation para estimar o erro dos métodos de combinação, o número de iterações do $k$-fold crossvalidation para estimar o erro dos classificadores que compõem os ensembles e um diretório de experimento (um ponto de entrada) contendo um arquivo com um conjunto de dados e um arquivo com a descrição dos atributos desses dados, ambos no formato DSX (Batista, 2001), inicialmente é chamada a técnica de resampling $k$-fold cross-validation estratificado, implementada no DLE, a qual constrói $k$ diretórios it $0, \ldots$, it $(\mathrm{k}-1)$ e distribui nesses $k$ diretórios os respectivos conjuntos de dados de treinamento e teste. Em cada diretório it0,..., it(k-1) são construídos os diretórios ErrorEstimation e Classifierslnduction. Dentro do diretório ErrorEstimation, são construídos os diretórios $S_{-} 1, \ldots, S_{-} L$, onde são armazenados arquivos de conjuntos de dados. Esses conjuntos de dados são partições com ou sem reposição do conjunto de treinamento presente em seu respectivo diretório i† ascendente ou, ainda, replicações do próprio conjunto de treinamento, segundo a opção do usuário. Em cada diretório $S_{-} 1, \ldots, S_{-} L$, é construído um diretório Alg, sendo Alg um identificador de algoritmos de aprendizado válido para o SNIFFER. Analogamente, é construída a estrutura do diretório Classifierslnduction, mas com uma diferença: é construído um diretório filho itO em cada um dos diretórios Alg_1,..,Alg_L. Dentro de cada diretório itO deve ser copiado duas vezes o conjunto de dados presente em seu ascendente $S_{-} 1, \ldots, S_{-} L$, sendo uma cópia o conjunto de dados de treinamento e a outra cópia o conjunto de dados de teste. Dessa maneira, é construída a árvore mostrada na Figura 5.4. Após construída essa árvore, o SNIFfer é chamado em cada um dos diretórios ClassifiersInduction e ErrorEstimation. O SNIFFER deve ser chamado dessa maneira para facilitar a recuperação das taxas de erro estimadas nos diretórios ErrorEstimation. Após, são armazenados em cada diretório ito,..., it(k-1), filhos do ponto de entrada, todos os arquivos de saída presentes nos diretórios ito descendentes de ClassifiersInduction e o respectivo arquivo contendo as taxas de erro de cada classificador, estimadas em ErrorEstimation.

Para construir a árvore mostrada na Figura 5.8, é construído um diretório denominado EnsembleMethodsExecution, filho do ponto de entrada. Dentro desse diretório, são construídos: 
- os diretórios cujos nomes são identificadores de métodos de construção de ensembles reconhecidos pelo SNIFFER - Meth 1,..,MethJ;

- os diretórios $S_{-} 1, \ldots, S_{-} L$ com seus respectivos diretórios Alg_1,..,Alg_L; e

- opcionalmente, um diretório $S$, tendo como filhos diretórios nomeados com identificadores de todos os algoritmos de aprendizado utilizados.

Dentro de cada um dos diretórios cujos nomes são identificadores reconhecidos pelo SNIFFER, são construídos os diretórios it0,..., it(k-1). Dentro dos diretórios it pertencentes a Meth 1,..,.MethJ, são armazenados os $L$ classificadores induzidos pelos algoritmos de aprendizado simbólico e os $L$ arquivos com as taxas de erro desses classificadores. Todos esses arquivos estão presentes nos diretórios i†0,...,i†(k-1) do nó 2 da árvore. Nos diretórios i†O,...,it(k-1), filhos de Alg_1,..,Alg_L, são armazenados os respectivos arquivos de teste presentes nos diretórios it0,..., it(k-1), filhos do ponto de entrada, e os arquivos de treinamento presentes nos diretórios $S_{-} 1, \ldots, S_{-} L$, descendentes de i†O,..., it(k-1). Por exemplo, no diretório it1, filho de Alg_2, é armazenado, como conjunto de treinamento, o conjunto de dados presente em S_2, descendente do diretório i†l do nível 2. Dentro dos diretórios it0,..., it(k-1), descendentes do diretório $S$, são armazenados os arquivos de treinamento e teste presentes nos respectivos diretótios ito,..., it(k-1) filhos do ponto de entrada. Para finalizar, o SNIffer é chamado no diretório EnsembleMethodsExecution.

\subsection{A Biblioteca de Classes EnsembleMethods}

A biblioteca de classes EnsEMBLEMETHODS implementada neste trabalho é uma biblioteca orientada a objeto que tem como objetivo dar suporte ao teste de diferentes métodos de construção de ensembles, compostos por métodos de classificação de exemplos e de combinação de classificadores, existentes e a serem futuramente propostos. Assim, as principais funcionalidades da biblioteca ENSEMBLEMETHODS são:

Métodos de classificação de exemplos: Além de classificar exemplos utilizando o classificador como um todo, pode-se também classificar um novo exemplo utilizando a melhor regra dada uma determinada heurística (medida de regra) para selecionar essa regra. A biblioteca ENSEMBLE- 
Methods provê os métodos de classificação de exemplos descritos na Seção 4.3.

Métodos de combinação de classificadores: Pode-se utilizar diversos métodos de combinação de classificadores. A biblioteca ENSEMBLEMETHODS provê os métodos de combinação de classificadores descritos na Seção 4.3.

O projeto da biblioteca EnsEMBLEMETHODs foi realizado utilizando os conceitos de padrões de projeto de Engenharia de Software (Gamma et al., 1995; Shalloway and Trott, 2002). Essa biblioteca possui uma arquitetura modular. Cada módulo é constituído de uma ou mais classes e realiza um conjunto bem definido de tarefas. Atualmente, a biblioteca EnsembleMethods é composta por 5 métodos implementados em 10 classes e usa o ambiente computacional DLE (Batista and Monard, 2003), cujo objetivo é dar suporte à manipulação de classificadores simbólicos. Segue uma breve descrição dos módulos de combinação e classificação implementados:

\section{Módulos de combinação de classificadores.}

Os módulos CombinationWeightedMeanVotes, CombinationWeightedMeanSEVotes, CombinationUnweightedVotes e CombinationByBestRule são utilizados para fazer a combinação de classificadores simbólicos realizando votação com peso utilizando somente a média do erro, votação com peso utilizando a média e o erro padrão do erro, votação sem peso e classificação pela melhor das regras selecionadas em todos os classificadores componentes do ensemble, respectivamente.

\section{Módulos de classificação de exemplos.}

Os módulos ClassificationByClassifier, ClassificationByRuleAccR e ClassificationByRuleLaplace são utilizados para fazer classificação de exemplos realizando classificação com o classificador como um todo e realizando classificação com as medidas de regra precisão e precisão de Laplace - Equação A.19 - , respectivamente. Inicialmente foram implementados somente os métodos de classificação utilizando essas duas medidas; entretanto é uma tarefa simples implementar outros métodos de classificação de exemplos utilizando outras medidas de regras.

Apesar de fazer uso do ambiente computacional DLE, do ponto de vista do usuário essa tarefa é transparente, já que os módulos carregam os outros 
módulos necessários para execução sem que o usuário necessite se preocupar com essa tarefa.

Conforme dito anteriormente, o projeto da biblioteca EnsembleMethods utiliza padrões de projeto (Gamma et al., 1995; Shalloway and Trott, 2002), já que padrões de projeto fazem com que o reuso de projetos e arquiteturas de sucesso se torne mais fácil. Neste projeto, foi utilizado o padrão de projeto Bridge, utilizado para separar um conjunto de implementações dos objetos que os utilizam.

A seguir são apresentadas as descrições de classes pertencentes a cada um dos módulos. Para ajudar na descrição das classes pertencentes aos módulos é utilizado um diagrama de classe em UML (Unified Modelling Language) (Booch et al., 1998).

As classes abstratas CombinationAbstract e ClassificationAbstract criam as estruturas básicas para a implementação dos métodos de combinação e classificação. Devem ser fornecidos um diretório que contenha os classificadores induzidos por algoritmos de aprendizado de máquina simbólicos e um conjunto de dados para ser classificado.

A classe ConfMatrix fornece a estrutura básica para a criação e manipulação de matrizes de confusão. Ela é necessária já que um dos objetivos do projeto é observar a estimativa da média e do desvio padrão do erro cometido pelos métodos de combinação de classificadores em diferentes domínios.

Na Figura 5.9 é mostrado o diagrama de classes em UML que ilustra a interação entre as classes dos módulos ClassificationByClassifier, ClassificationByRuleAccR, ClassificationByRuleLaplace, CombinationUnweightedVotes, CombinationWeightedMeanVotes, CombinationWeightedMeanSEVotes, CombinationByBestRule e ConfMatrix.

A biblioteca EnsembleMethods foi projetada de maneira que se torna fácil agregar novos métodos de combinação de classificadores e classificação de exemplos, desde que tais métodos possam ser empregados em conjuntos de classificadores simbólicos, compostos por regras de classificação e que tenham sido induzidos por algoritmos de aprendizado que possuam identificadores reconheciveis pelo SNIFFer (Batista and Monard, 2003), e que possam ser convertidos para o formato padrão $\mathcal{P B M}$ (Prati et al., 2001b,a) - Capítulo 3. 


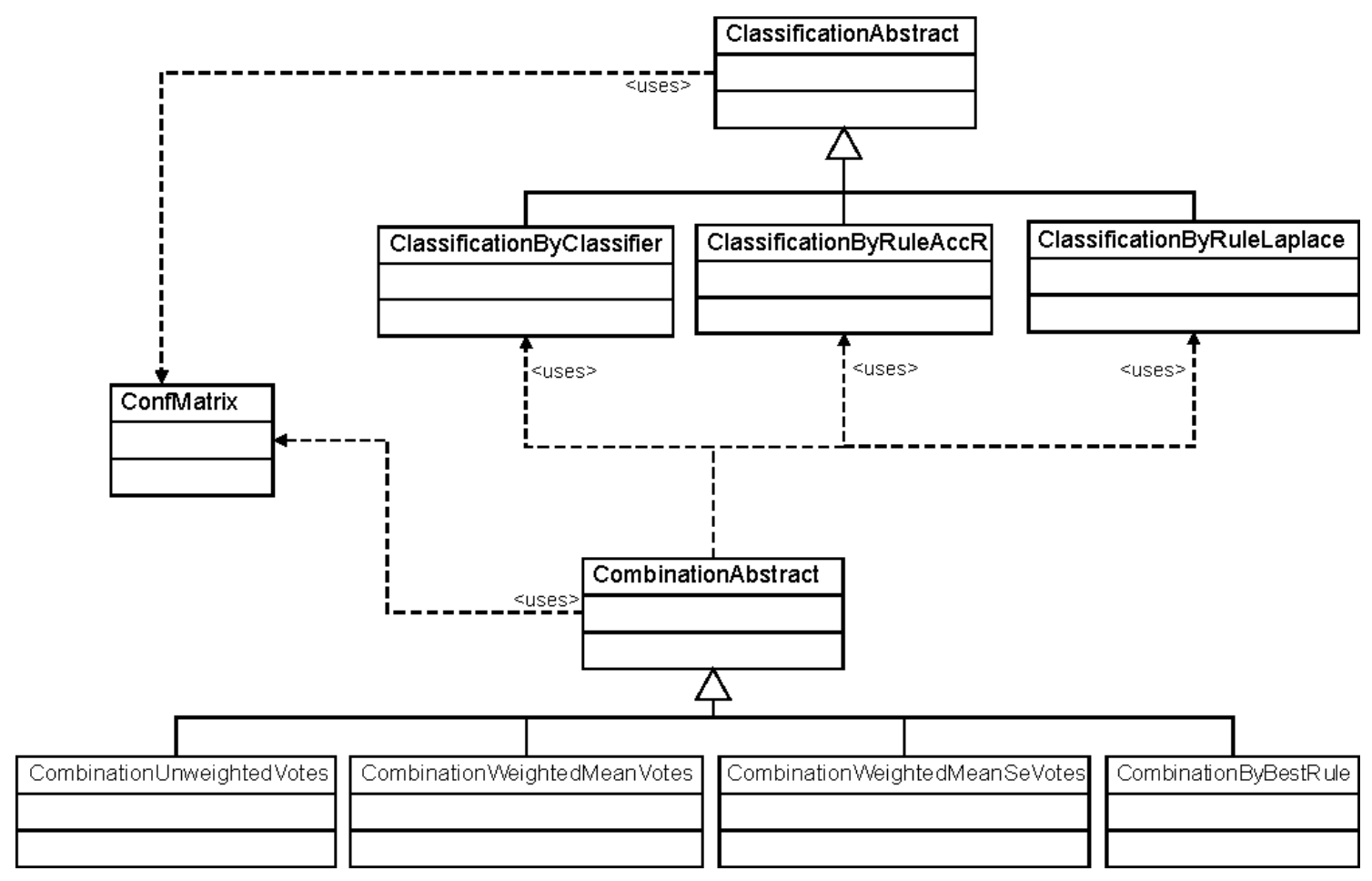

Figura 5.9: Diagrama de classes em UML do projeto dos módulos de combinação e de classificação

\subsection{Um Exemplo de Execução do Módulo EnsEMBLE- TREE}

Para facilitar a compreensão do funcionamento do módulo implementado, nesta seção é descrito um exemplo de utilização e funcionamento desse módulo. Suponha que o usuário queira testar dois métodos de construção de ensembles, identificados por unweighted.byclassifier e weightedmean.byclassifier, sobre uma base de dados, cujos arquivos de descrição de atributos e de dados são, respectivamente, ds.names e ds.data. Dado que:

- Cada ensemble deve ser composto por 3 classificadores, sendo dois deles induzidos pelo algoritmo de aprendizado simbólico $\mathcal{C N} 2$ e o outro pelo algoritmo $\mathcal{C} 4.5$;

- A estimativa de erro de cada ensemble deve ser realizada com 10-fold cross-validation estratificado; e

- A estimativa de erro de cada classificador que compõe o ensemble deve 
ser realizada com 5-fold cross-validation estratificado,

para realizar essa tarefa, o usuário faz uma chamada ao módulo passando por parâmetros, além desses dados, um diretório de entrada, o qual aqui o denominaremos Experimento, contendo os dois arquivos ds.names e ds. data, ambos no formato DSX. O primeiro passo do módulo consiste em criar, como filhos do diretório Experimento, os diretórios it0,...,i†9, os quais contém uma cópia do arquivo ds.names armazenado em Experimento e os arquivos ds. data e ds.test, referentes à cada iteração do 10-fold cross-validation estratificado. Na Figura 5.10 é ilustrado o resultado desse passo do processo.

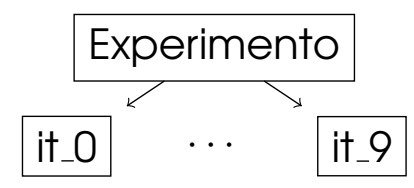

Figura 5.10: Exemplo do primeiro passo de execução do módulo EnSEMBleTREE

No segundo passo, em cada diretório it0,..., it9 são criados os diretórios ClassifiersInduction e ErrorEstimation - Figura 5.11. No diretório ErrorEstimation, filho do diretório it0, são criados os diretórios S_1,...,S_3 (são 3 os classificadores que compõem o ensemble). Do conjunto de dados contido no arquivo ds.data armazenado em ito, são extraídas 3(três) amostras $S_{1}, S_{2}$ e $S_{3}$ (o tipo de amostragem é especificado pelo usuário ao fazer a chamada ao módulo). No diretório S_l é criado o diretório cn2 (o primeiro classificador deve ser induzido com o algoritmo $\mathcal{C N}$ 2), onde é armazenado o arquivo ds.data, o qual contém a primeira amostra $S_{1}$, e uma cópia do arquivo ds.names; no diretório S_2 é criado o diretório $\mathrm{cn} 2$ (o segundo classificador deve ser induzido com o algoritmo $\mathcal{C N} 2$ ), onde é armazenado o arquivo ds.data, o qual contém a segunda amostra $S_{2}$, e uma cópia do arquivo ds.names; e, finalmente, no diretório S_3 é criado o diretório c4.5 (o terceiro classificador deve ser induzido com o algoritmo $\mathcal{C} 4.5$ ), onde é armazenado o arquivo ds.data, o qual contém a terceira e última amostra $S_{3}$, e uma cópia do arquivo ds.names. Toda essa sub-árvore filha de ErrorEstimation é copiada no diretório Classifiersinduction. No diretório ClassifiersInduction/S_l/cn2 é criado o diretório ito, para onde são movidos os arquivos ds.names e ds.data presentes em Classifierslnduction/S_1/cn2. Também, é feita uma cópia do arquivo ds.data para o 
arquivo ds.test no diretório Classifierslnduction/S_1/cn2/itO. O mesmo é realizado nos diretórios ClassifiersInduction/S_2/cn2 e ClassifiersInduction/S_3/c4.5. De maneira análoga, são construídas as estruturas das sub-árvores dos diretórios it $1, \ldots$, it9. Em cada diretório ClassifiersInduction e ErrorEstimation, filhos de it0,...,it9, é feita uma chamado ao Sniffer. Deve ser observado que em ErrorEstimation deve ser passado como parâmetro o número de folds do $k$-fold cross-validation estratificado, ou seja, 5. Na Figura 5.11 é ilustrado o resultado desse passo do processo.

No terceiro passo, no diretório Experimento/it0 são colocados os arquivos:

- ds 1.out - uma cópia do arquivo ds_CN2.rules armazenado em Experimento/it0/ClassifiersInduction/S_1/cn2/it0 - ds 1.err - construído pelo módulo com os resultados obtidos no 5-fold cross-validation no diretório Experimento/it0/ErrorEstimation/S_1/cn2 - e ds1.data - uma cópia do arquivo ds.data armazenado em Experimento/itO/ClassifiersInduction/S_1/ cn2/it0;

- ds2.out - uma cópia do arquivo ds_CN2.rules armazenado em Experimento/it0/ClassifiersInduction/S_2/cn2/it0 - ds2.err - construído pelo módulo com os resultados obtidos no 5-fold cross-validation no diretório Experimento/ito/ErrorEstimation/S_2/cn2 - e ds2.data - uma cópia do arquivo ds.data armazenado em Experimento/it0/ClassifiersInduction/S_2/ cn2/it0; e

- ds3.out - uma cópia do arquivo ds_C45.out armazenado em Experimento/itO/ClassifiersInduction/S_3/c4.5/it0 - ds3.err - construído pelo módulo com os resultados obtidos no 5-fold cross-validation no diretório Experimento/ito/ErrorEstimation/S_3/c4.5 - e ds3.data - uma cópia do arquivo ds.data armazenado em Experimento/ito/ClassifiersInduction/S_3/ c4.5/it0.

Um exemplo dos arquivos com extensão .err pode ser encontrado em (Bernardini and Monard, 2004). Os arquivos com extensão .data (no formato DSX) são necessários para calcular as matrizes de contingência de cada regra presente no arquivo de saída dos indutores (arquivos com extensão .out) para executar os métodos de construção de ensembles. Analogamente, são armazenados esses arquivos nos diretórios it 1,..., it9 filhos de Experimento. Com os arquivos referentes aos classificadores que compõem o ensemble, devese passar ao passo de construção da árvore para execução dos métodos de 


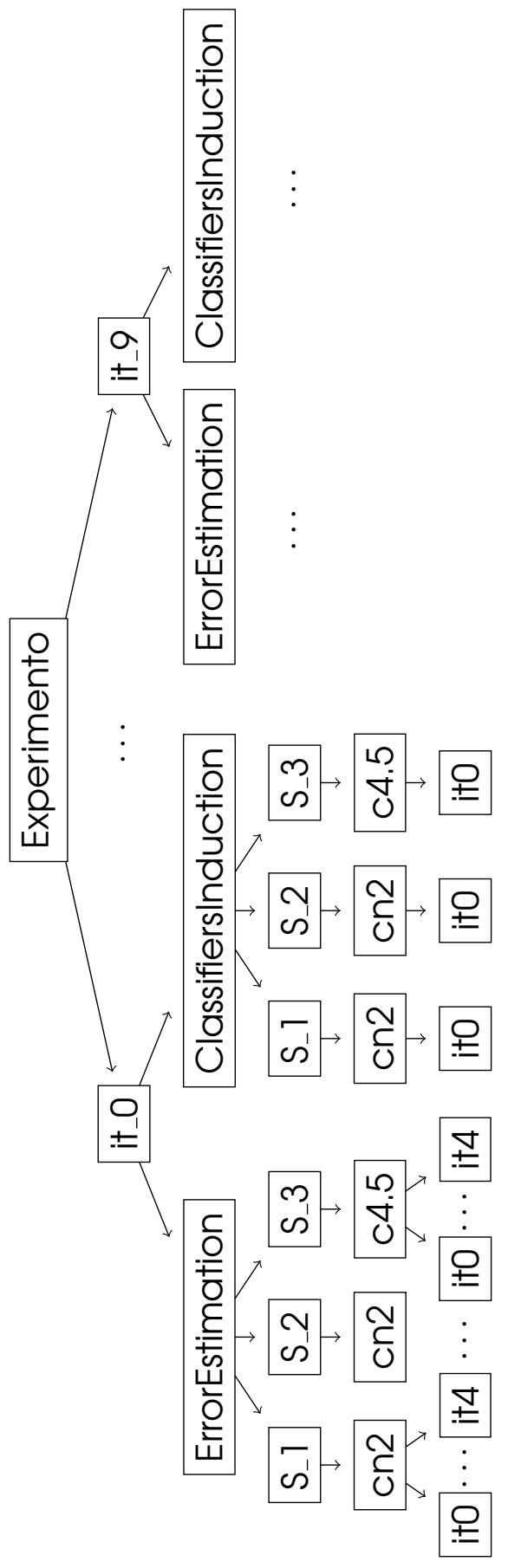

Figura 5.11: Exemplo do segundo passo de execução do módulo ENSEMBLETREE 
construção de ensemble. Assim, é criado o diretório EnsembleMethodsExecution em Experimento. Nesse diretório (EnsembleMethodsExecution), são criados os diretórios S_1, S_2, S_3, unweighted.byclassifier e weightedmean.byclassifier. Em S_1 é criado o diretório cn2; em S_2 também é criado o diretório cn2; e, finalmente, em S_3 é criado o diretório c4.5. Em S_1/cn2, S_2/cn2, S_3/c4.5, unweighted.byclassifier e weightedmean.byclassifier são criados os diretórios it0,..., it9 (lembrando, a estimativa de erro dos métodos de construção de ensembles deve ser realizada com 10-fold cross validation e, como é necessário comparar as taxas de erro dos ensembles com os classificadores que o compõe, é necessário estimar o erro dos classificadores também com 10-fold cross-validation). No diretório Experimento/EnsembleMethodsExecution/S_1/cn2/it0, é armazenada uma cópia do arquivo ds 1.data (renomeado para ds.data), do arquivo ds.names e do arquivo ds.test, presentes em Experimento/itO. Analogamente, no diretório Experimento/EnsembleMethodsExecution/S_2/cn2/it0, é armazenada uma cópia do arquivo ds2.data (renomeado para ds.data), do arquivo ds.names e do arquivo ds.test, presentes em Experimento/it0; e no diretório Experimento/EnsembleMethodsExecution/S_3/ c4.5/it0, é armazenada uma cópia do arquivo ds3.data (renomeado para ds.data), do arquivo ds.names e do arquivo ds.test, presentes em Experimento/itO. Da mesma maneira são armazenados arquivos em Experimento/EnsembleMethodsExecution/S_1/cn2/it1,..., S_1/cn2/it9, S_2/cn2/it1,...,S_2/cn2/it9 e S_3/c4.5/it 1,...,S_3/c4.5/it9. Em unweighted.byclassifier/it0 e weightedmean.byclassifier/it0 são copiados os arquivos ds.test (duas vezes - um renomeado para ds.data e outro deixado como ds.test. Isso é necessário para que o SNIFFER não acuse erro na execução do método de construção de ensemble), ds.names, ds1.data, ds1.out, ds1.det, ds2.data, ds2.out, ds2.det, ds3.data, ds3.out e ds3.det presentes em Experimento/it0. De maneira análoga, são armazenados os arquivos em unweighted.byclassifier/it1,..., it9 e em weightedmean.byclassifier/it1,..., it9. O SNiffer é então chamado, sendo passado como parâmetro o caminho para o diretório EnsembleMethodsExecution. Quando o SNiffer encontra o diretório denominado unweighted.byclassifier, ele chama o método CombinationUnweightedVotes, passando como parâmetro o tipo de classificação que deve ser realizada (no caso, "ClassificationByClassifier"). Ao ser executado esse método de construção de ensembles, são construídos os seguintes dois arquivos em cada diretório unweighted.byclassifier/it0,..., it9:

1. ds.out, o qual contém a saída da execução do método de construção de 
ensembles - as matrizes de confusão para cada hipótese ao executar o método de classificação utilizado e a matriz de confusão do método de combinação final; e

2. ds.det, o qual contém, para cada exemplo classificado, a classificação e as regras que cobrem o exemplo de cada hipótese componente do ensemble e a classificação final dada pelo método de combinação com o número de votos atribuído a cada classe.

Um exemplo de ambos os arquivos pode ser visualizado em (Bernardini and Monard, 2004). Processo análogo ocorre quando o SNiffer encontra o identificador (diretório nomeado) weightedmean.byclassifier. Na Figura 5.12 pode ser visualizado o resultado desse último passo do processo.

\subsection{Considerações Finais}

Neste capítulo, foi descrito o ambiente ELE, que implementa os métodos de construção de ensembles de classificadores simbólicos propostos na Seção 4.3. Também, foi descrito o método de avaliação dos métodos de construção de ensembles propostos. Deve ser enfatizado que foi grande o esforço requerido para projetar e implementar esse método de avaliação utilizado, já que tal método deve ser cuidadosamente projetado e bastante rigoroso para garantir a qualidade dos resultados obtidos bem como a qualidade da análise realizada sobre esses resultados. No próximo capítulo são abordados algoritmos evolutivos e algoritmos genéticos, com enfoque na aplicação em aprendizado de máquina simbólico. Também, é proposto um algoritmo genético para evoluir classificadores simbólicos. 


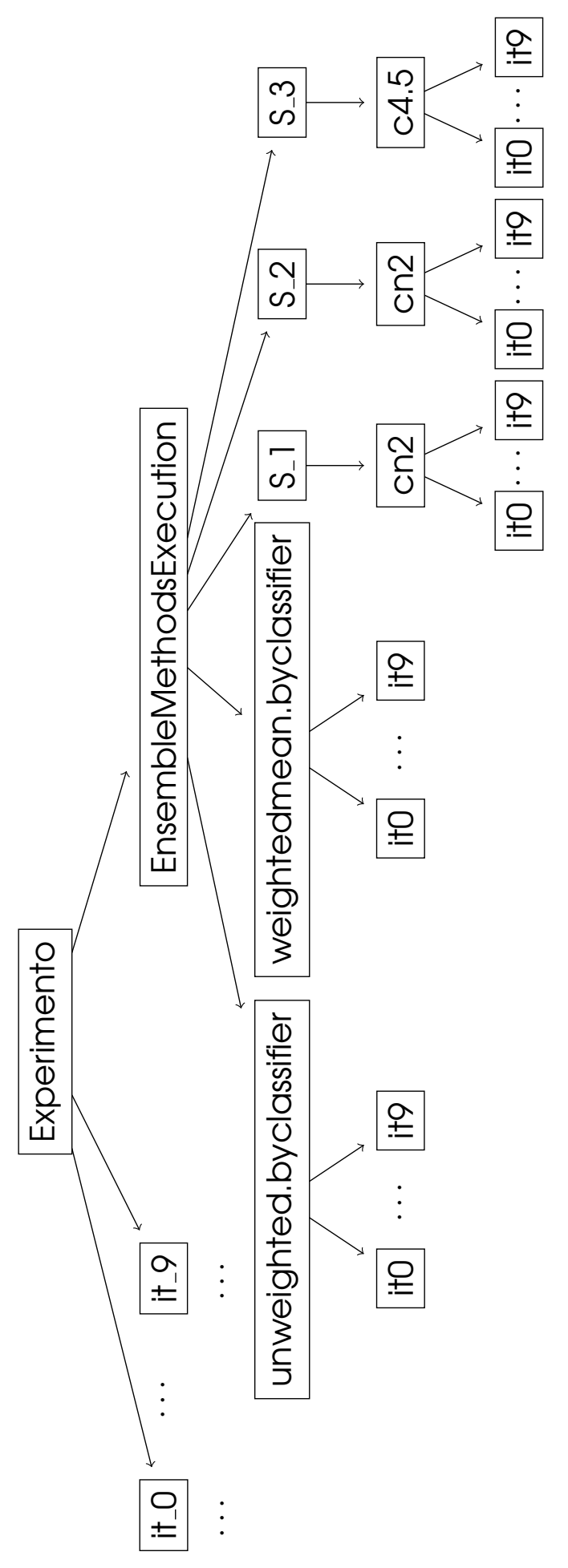

Figura 5.12: Exemplo do terceiro e último passo de execução do módulo ENSEMBLETREE 


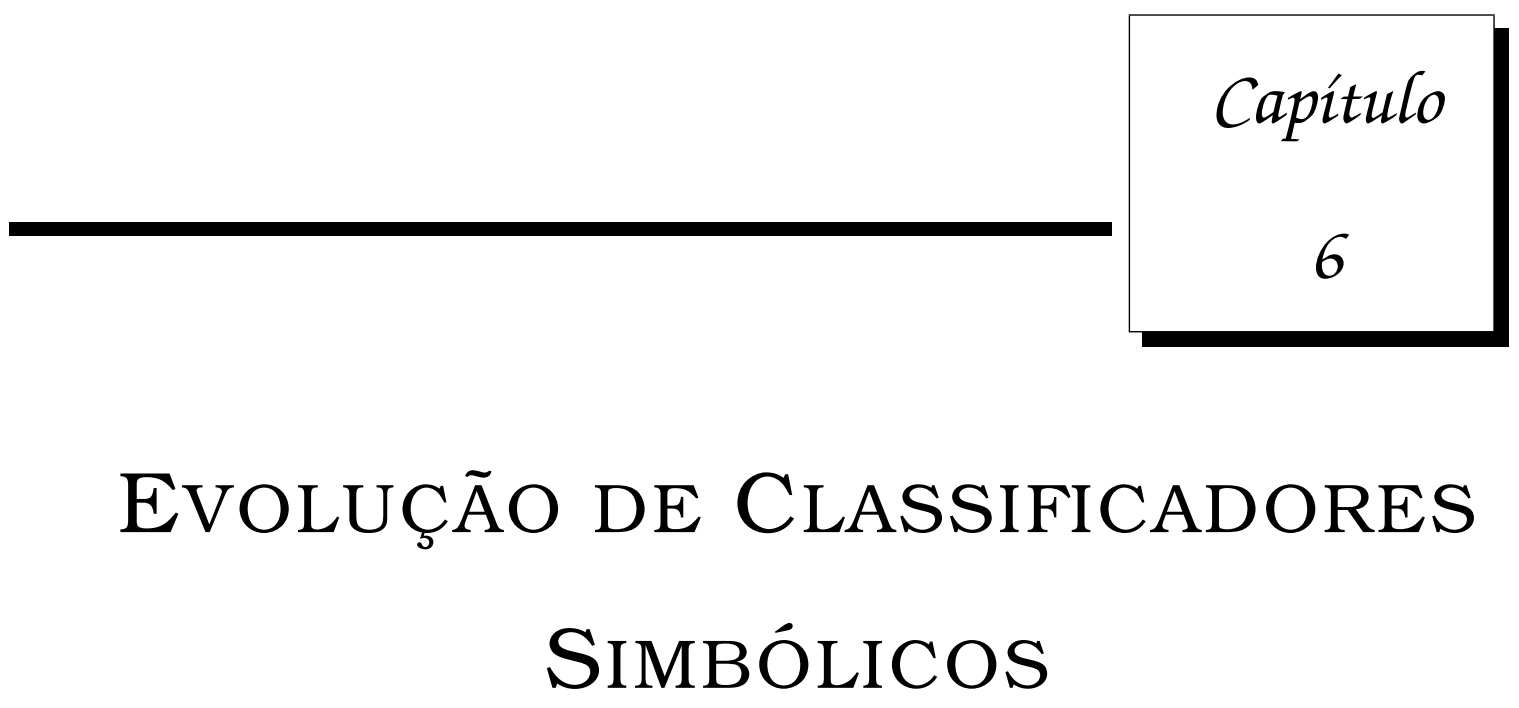

"Há grandeza neste modo de ver a vida, com as suas potencialidades, que o sopro do criador originalmente imprimiu em algumas formas ou numa só; e assim, enquanto este planeta foi girando de acordo com a lei imutável da gravidade, a partir de um início tão simples evoluíram inúmeras formas mais belas e mais maravilhosas."

\section{- Charles Darwin}

endo em vista que algoritmos de aprendizado simbólico realizam busca local e tendo em vista que algoritmos genéticos são um método de busca global, algoritmos genéticos podem, então, ser utilizados para evoluir conjuntos de classificadores induzidos por esses algoritmos de aprendizado em um único classificador, desejavelmente mais preciso que os classificadores iniciais. Algoritmos Genéticos são considerados um sub-paradigma de uma classe de algoritmos de busca estocástica (Freitas, 2002a), denominada 
Algoritmos Evolutivos (AEs). Neste capítulo, inicialmente é feita uma descrição dos algoritmos evolutivos. Logo após é feita uma introdução às definições de algoritmos genéticos bem como é feita uma descrição de métodos encontrados na literatura para evoluir classificadores simbólicos. Finalmente, é proposto um algoritmo genético para evoluir classificadores simbólicos, estando detalhadamente descritos os operadores genéticos e os critérios de parada utilizados, bem como as funções de avaliação propostas neste trabalho.

\subsection{Algoritmos Evolutivos}

O paradigma de algoritmos evolutivos consiste de algoritmos de busca estocástica baseados na abstração dos processos de evolução Darwiniana. Ainda que diversos tipos de algoritmos evolutivos (como discutido mais adiante nesta seção) têm sido propostos, quase todos eles têm alguns elementos e características básicas em comum Freitas (2002a), tais como:

- AEs tipicamente trabalham com uma população de indivíduos (soluções candidatas) a cada iteração, ao invés de uma única solução candidata por vez;

- Usam um método de seleção baseado na aptidão do indivíduo, ou seja, uma medida de qualidade da solução candidata representada por um indivíduo. Assim, quanto melhor a aptidão do indivíduo, maior a probabilidade do indivíduo ser selecionado e maior a chance de algumas partes de seu "material genético" (partes da solução candidata) ser passada para as gerações futuras de indivíduos;

- Geram novos indivíduos através de um mecanismo de herança dos indivíduos existentes. Descendentes dos indivíduos são gerados aplicandose operadores estocásticos (probabilísticos) nos indivíduos existentes na geração corrente. Dois operadores freqüentemente utilizados são crossover (recombinação) e mutação. Em essência, o operador de crossover mistura o material genético de dois ou mais indivíduos, enquanto que o operador de mutação muda o valor de uma pequena parte do material genético de um indivíduo para um valor aleatório, simulando a autoreplicação errônea dos indivíduos.

Segundo (Freitas, 2002a), existem quatro sub-paradigmas de AEs: 
1. Estratégias Evolutivas: tipicamente utilizam um vetor de valores reais para representar os indivíduos. As primeiras estratégias evolutivas deram ênfase ao operador de mutação como o principal operador de exploração no espaço de busca, mas atualmente tanto mutação quanto crossover são utilizados. Um indivíduo geralmente representa não somente variáveis com valores reais do problema a ser resolvido mas também parâmetros que controlam a distribuição de mutação, caracterizando uma auto-adaptação dos parâmetros de mutação. O operador de mutação geralmente modifica os indivíduos segundo uma distribuição normal multi-variada, na qual pequenas mutações têm preferência em relação a grandes mutações.

2. Programação Evolutiva: foi originalmente desenvolvida para evoluir máquinas de estado finito. Diferentemente das estratégias evolutivas, programação evolutiva geralmente não utiliza crossover; similarmente às estratégias evolutivas, também utiliza mutação com probabilidade segundo uma distribuição normal e auto-adaptação dos parâmetros de mutação.

3. Algoritmos Genéticos (AGs): dão ênfase ao operador de crossover como principal operador de exploração no espaço de busca e consideram a mutação como um operador menor, tipicamente aplicado com probabilidade muito baixa. No início, os AGs clássicos utilizavam cadeias de bits para representar os indivíduos, mas, atualmente, representações mais elaboradas são também utilizadas.

4. Programação Genética: bastante semelhante aos AGs, entretanto, os indivíduos são geralmente algum tipo de programa de computador, ou seja, consistem não somente de estruturas de dados mas também de funções (ou operações) aplicáveis a essas estruturas. A idéia de ter os indivíduos explicitamente representando tanto dados quanto funções e operadores (ao invés de somente parâmetros de funções) parece ser relativamente pouco usada nos outros sub-paradigmas de AEs.

Neste trabalho, propomos o uso de AGs para evoluir classificadores simbólicos. Assim, a seguir são descritos os AGs, dando ênfase ao funcionamento do AG clássico. Na seqüência, é feita uma descrição das características de AGs utilizadas para evoluir classificadores simbólicos. 


\subsection{Algoritmos Genéticos}

AGs são métodos de otimização e busca inspirados nos mecanismos de evolução de populações de seres vivos. Foram introduzidos por John Holland (Holland, 1975) e popularizados por um dos seus alunos, David Goldberg (Goldberg, 1989). Esses algoritmos seguem o princípio da seleção natural e sobrevivência do mais apto, enunciado em 1859 pelo naturalista e fisiologista inglês Charles Darwin em seu livro A Origem das Espécies. De acordo com Charles Darwin,

Quanto melhor um individuo se adaptar ao seu meio ambiente, maior será sua chance de sobreviver e gerar descendentes.

A otimização é a busca da melhor solução para um dado problema. Consiste em tentar várias soluções e utilizar a informação obtida nesse processo de forma a encontrar soluções cada vez melhores. As técnicas de busca e otimização geralmente apresentam:

1. Um espaço de busca, onde estão todas as possíveis soluções do problema;

2. Uma função de aptidão (ou função objetivo), que é utilizada para avaliar as possiveis soluções, associando a cada uma delas uma nota.

Em termos matemáticos, a otimização consiste em achar a solução ótima da função objetivo, ou seja, a solução que corresponda ao ponto de máximo ou mínimo da função objetivo. Entretanto, em muitas funções, existem várias soluções ótimas locais (pontos ótimos locais), ou seja, soluções que otimizam o valor da função objetivo. Tais pontos são denominados ótimos locais porque a função atinge, nesses pontos, valores ótimos em relação à vizinhança desses pontos. Entretanto, a melhor solução para esse problema está no ponto em que a função atinge seu "melhor" valor ótimo, denominado ótimo global. Em muitas funções, uma grande quantidade de técnicas de otimização (por exemplo, os métodos de gradiente) não são capazes de localizar o ponto de ótimo global de uma função com múltiplos pontos ótimos. Nesses casos, AGs geralmente são capazes de encontrá-los.

A terminologia descrita a seguir foi baseada em (Mitchell, 1997a). Em AGs, necessita-se de uma estrutura de dados que codifica uma solução para 
um problema que se deseja resolver, ou seja, uma representação para um ponto no espaço de busca. Tal estrutura é denominada genoma e tal ponto no espaço é denominado cromossomo. A união de um cromossomo com sua aptidão é denominada indivíduo. Um parâmetro codificado no cromossomo é denominado gene, e aos valores que um gene pode assumir dá-se o nome de alelo. O genótipo representa a informação contida no cromossomo (ou genoma). Quando se decodifica o cromossomo, essa decodificação recebe o nome de fenótipo. Por exemplo, se um cromossomo codifica parâmetros de um conjunto de regras, o fenótipo é o conjunto de regras; se um cromossomo codifica os parâmetros de uma rede neural, o fenótipo é a rede neural.

Existem problemas nos quais há uma interação entre genes do cromossomo, ou seja, um valor de gene influencia o valor de outro gene. A essa interação, dá-se o nome de epistasia. Deve ser observado que problemas com alta epistasia são difíceis de se resolver utilizando AGs.

A seguir, é descrito o algoritmo genético clássico, bem como é feita uma descrição mais detalhada de alguns componentes de um AG clássico. É também mostrado um exemplo de funcionamento de um AG clássico e são feitas algumas considerações em relação ao uso de AGs.

\subsubsection{Algoritmo Genético Clássico}

Dados:

- Um espaço de busca;

- Uma função de aptidão;

- Um conjunto de operadores genéticos a serem aplicados aos cromossomos para criar uma nova população. Esse conjunto geralmente é composto pelos operadores de seleção, crossover e mutação. O operador de seleção seleciona os cromossomos mais aptos para produzir uma população de genitores; o operador de crossover produz um ou mais cromossomos filhos a partir da recombinação dos genes de seus pais (população de descendentes); e o de mutação substitui o valor de um ou mais locus de um cromossomo por outro valor. Tais operadores são melhor descritos na Seção 6.2.2;

o algoritmo genético clássico segue os passos descritos no Algoritmo 4 . 


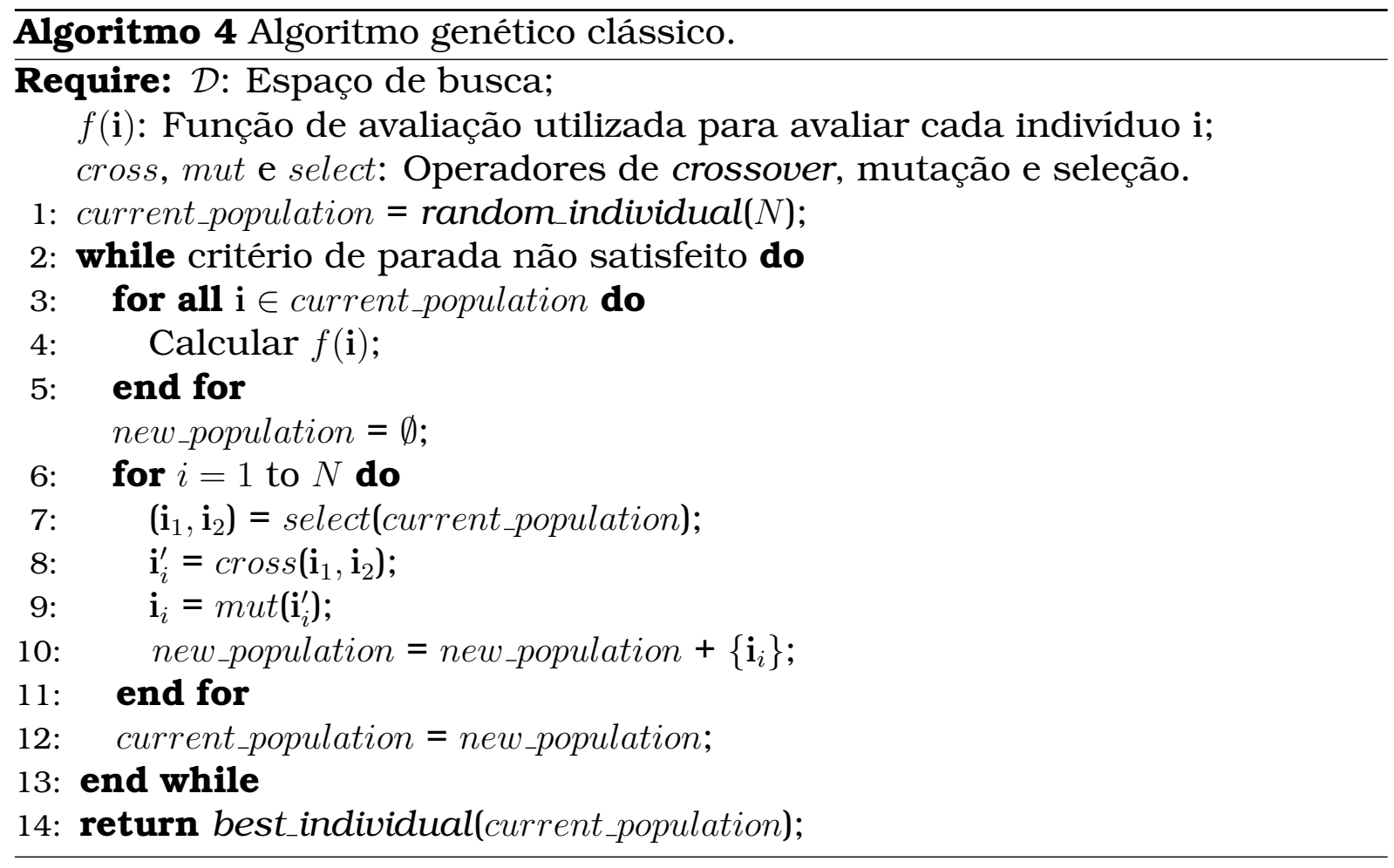

No Algoritmo 4, a função randomindividual retorna $N$ indivíduos gerados aleatoriamente, pertencentes ao espaço de busca $\mathcal{D}$, e a função best_individual retorna o melhor indivíduo da última população gerada pelo AG segundo a função de avaliação $f$.

Podem existir diversos critérios de parada, tais como não ocorrer alterações da população anterior para a população atual ou alcançar um número préfixado de gerações. Geração é o nome dado a cada iteração do algoritmo descrito. Geralmente, o número de gerações de um AG típico é de 50 a 500. Ainda, pode-se fixar um número maior de gerações. O conjunto completo de iterações é denominado execução ${ }^{1}$. Ao final de uma execução, há um ou mais cromossomos com alta aptidão na população. Duas execuções diferentes utilizando sementes aleatórias distintas contém detalhes distintos devido à aleatoriedade amplamente utilizada. Na Figura 6.1 é ilustrada uma geração de um AG, com início em população não avaliada.

\footnotetext{
${ }^{1}$ run.
} 


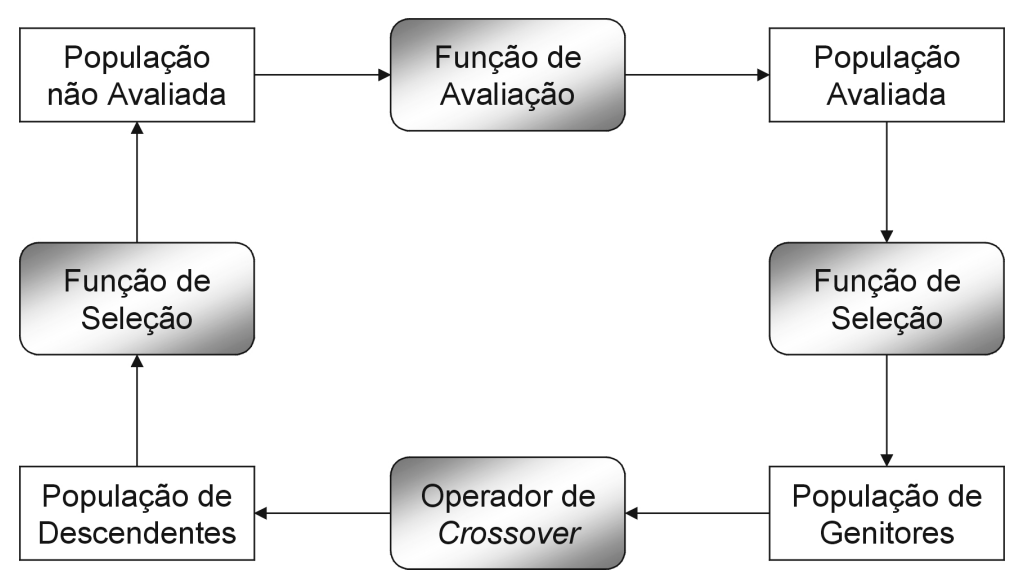

Figura 6.1: Uma geração de um algoritmo genético (Milaré, 2003)

\subsubsection{Componentes de um AG Clássico}

Nesta seção são descritos em maiores detalhes a função de aptidão, o método de seleção de indivíduos, os operadores genéticos e os valores dos parâmetros utilizados pelos AGs. Esta descrição está baseada no trabalho de Milaré (2003).

Função de Aptidão: A função de aptidão ${ }^{2}$ determina a aptidão de cada indivíduo, ou seja, quão boa a solução por ele representada é para a resolução de um problema. Ela é responsável por determinar se o indivíduo continuará fazendo parte da população ou não. A escolha da função de aptidão, também denominada função de avaliação, está diretamente relacionada ao domínio do problema.

Método de Seleção: Uma vez que os AGs baseiam-se no princípio da seleção natural, eles devem ser capazes de identificar os individuos mais aptos, para que eles permaneçam na população durante o processo de evolução (procedimento iterativo), e os mais fracos, para que eles sejam excluídos do processo. Existem vários métodos que podem ser utilizados para selecionar indivíduos para formar uma nova população (Michalewicz, 1999; Freitas, 2002a; Carvalho et al., 2003). Um critério de seleção bastante comum em AG é a seleção proporcional, que consiste em selecionar os indivíduos com probabilidade proporcional à sua aptidão. Conceitualmente, a seleção proporcional é equivalente a dividir uma roleta em $n$

\footnotetext{
${ }^{2}$ Fitness.
} 
partes, sendo $n$ o número de indivíduos da população. Cada uma das partes da roleta é proporcional à aptidão do indivíduo associado àquela parte. A roleta é girada $n$ vezes, e a cada uma delas o indivíduo indicado pelo ponteiro é selecionado e inserido na nova população.

Com o objetivo de preservar e usar na próxima geração as melhores soluções encontradas na geração atual, pode-se utilizar uma estratégia denominada elitismo. Essa estratégia consiste em conservar os $m$ melhores indivíduos da população atual, copiando-os para a próxima geração sem nenhuma alteração. O restante dos indivíduos, $n-m$, são normalmente gerados por meio do método de seleção.

Operadores Genéticos: Os operadores genéticos quando aplicados à população geram novos indivíduos e constituem os principais mecanismos utilizados pelos AGs para explorar regiões desconhecidas do espaço de busca. Deve ser observado que crossover e mutação são os operadores genéticos mais utilizados e fazem parte do AG clássico.

- Crossover: Esse operador genético permite a troca de informação entre soluções diferentes. Ele combina características de dois indivíduos pais para formar dois indivíduos filhos por meio da troca de segmentos correspondentes dos indivíduos pais. Por exemplo, considere os seguintes indivíduos pais representados por uma cadeia de 0's e 1's de comprimento 8:

$$
\begin{aligned}
& \mathrm{pai}_{1} 00100000 \\
& \text { pai }_{2} \quad 1000111111
\end{aligned}
$$

aplicando o operador de crossover depois da terceira posição:

$$
\begin{array}{llll|lllll}
\text { pai }_{1} & 0 & 0 & 1 & 0 & 0 & 0 & 0 & 0 \\
\text { pai }_{2} & 1 & 0 & 0 & 1 & 1 & 1 & 1 & 1
\end{array}
$$

são gerados os seguintes indivíduos filhos:

$$
\begin{aligned}
& \text { filho }_{1} \text { OOO111111 } \\
& \text { filho }_{2} 10000000
\end{aligned}
$$


- Mutação: Esse operador genético introduz variabilidade dentro da população e consiste em arbitrariamente alterar o valor de um ou mais genes de um indivíduo. Por exemplo, considere o seguinte indivíduo representado por uma cadeia de 0's e 1's de comprimento 8:

$$
1000000001
$$

aplicando o operador de mutação na quarta posição, o seguinte indivíduo é gerado:

10010001

Valores de Parâmetros: Um AG utiliza vários parâmetros, entre eles: o tamanho da população, o número de genes dos indivíduos, a probabilidade de aplicação dos operadores genéticos, o número máximo de gerações, e outros. Os valores para esses parâmetros são definidos geralmente por tentativa e erro.

\subsubsection{Um Exemplo de Execução do AG Clássico}

Para ilustrar o funcionamento de um AG, considere um exemplo bem simples apresentado em (Mitchell, 1997a), no qual os indivíduos são representados por um vetor binário de comprimento 8 e a função de aptidão é igual ao número de 1's do indivíduo. Os outros parâmetros são: tamanho da população $n=4$, probabilidade de crossover $p_{c}=0.5$ e probabilidade de mutação $p_{m}=0.1$. Todos os valores dos parâmetros do AG, assim como a função de aptidão, foram escolhidos para simplificar o exemplo.

Inicialmente, os indivíduos da população são criados inicializando aleatoriamente todos os 8 elementos do vetor que representam cada gene do indivíduo. Considere que os seguintes quatro indivíduos formam a população inicial: 


$$
\begin{aligned}
& A=\left(\begin{array}{llllllll}
0 & 0 & 0 & 0 & 0 & 1 & 1 & 0
\end{array}\right) \\
& B=\left(\begin{array}{lllllllll}
1 & 1 & 1 & 0 & 1 & 1 & 1 & 0
\end{array}\right) \\
& C=\left(\begin{array}{llllllll}
0 & 0 & 1 & 0 & 0 & 0 & 0 & 0
\end{array}\right) \\
& D=\left(\begin{array}{lllllll}
0 & 0 & 1 & 1 & 0 & 1 & 0
\end{array}\right)
\end{aligned}
$$

O próximo passo consiste em calcular a função de aptidão para cada indivíduo. Lembrando que a função de aptidão, para esse exemplo, é o número de 1's presentes em cada indivíduo, o valor da função de aptidão para os quatro indivíduos é:

$$
\begin{aligned}
& A=\left(\begin{array}{llllllll}
0 & 0 & 0 & 0 & 0 & 1 & 1 & 0
\end{array}\right)=2 \\
& B=\left(\begin{array}{lllllllll}
1 & 1 & 1 & 0 & 1 & 1 & 1 & 0
\end{array}\right)=6 \\
& C=\left(\begin{array}{llllllll}
0 & 0 & 1 & 0 & 0 & 0 & 0 & 0
\end{array}\right)=1 \\
& D=\left(\begin{array}{llllllll}
0 & 0 & 1 & 1 & 0 & 1 & 0 & 0
\end{array}\right)=3
\end{aligned}
$$

Deve-se agora selecionar alguns indivíduos para formar uma nova população. Considere que, utilizando a seleção proporcional, foram selecionados para formar a nova população os seguintes individuos (os identificadores entre parênteses referem-se aos identificadores dos indivíduos selecionados da população anterior):

$$
\begin{aligned}
& A^{\prime}=\left(\begin{array}{llllllll}
1 & 1 & 1 & 0 & 1 & 1 & 1 & 0
\end{array}\right)(B) \\
& B^{\prime}=\left(\begin{array}{llllllllll}
0 & 0 & 1 & 1 & 0 & 1 & 0 & 0
\end{array}\right)(D) \\
& C^{\prime}=\left(\begin{array}{llllllll}
1 & 1 & 1 & 0 & 1 & 1 & 1 & 0
\end{array}\right)(B) \\
& D^{\prime}=\left(\begin{array}{lllllll}
0 & 0 & 1 & 0 & 0 & 0 & 0
\end{array}\right)(C)
\end{aligned}
$$

Note que o indivíduo $A$ não foi selecionado, enquanto que o indivíduo $B$ foi selecionado duas vezes ( $B$ era o indivíduo com maior probabilidade de ser selecionado, já que possuía maior valor da função de aptidão). Agora pode-se aplicar o operador genético crossover na nova população. Com probabilidade de crossover $p_{c}=0.5$, espera-se que, na média, $50 \%$ dos indivíduos, ou seja, 
dois indivíduos, sofram crossover em cada geração. Considere que o operador de crossover seja aplicado nos indivíduos $A^{\prime}$ e $B^{\prime}$ depois da primeira posição, formando os individuos $A^{\prime \prime}=10110100$ e $B^{\prime \prime}=01101110$. A população atual agora é formada pelos seguintes indivíduos:

$$
\begin{aligned}
& A^{\prime \prime}=\left(\begin{array}{llllllll}
1 & 0 & 1 & 1 & 0 & 1 & 0 & 0
\end{array}\right) \\
& B^{\prime \prime}=\left(\begin{array}{llllllll}
0 & 1 & 1 & 0 & 1 & 1 & 1 & 0
\end{array}\right) \\
& C^{\prime}=\left(\begin{array}{llllllll}
1 & 1 & 1 & 0 & 1 & 1 & 1 & 0
\end{array}\right) \\
& D^{\prime}=\left(\begin{array}{llllllll}
0 & 0 & 1 & 0 & 0 & 0 & 0 & 0
\end{array}\right)
\end{aligned}
$$

O próximo operador genético a ser aplicado é o operador de mutação, com probabilidade $p_{m}=0.1$. Espera-se, assim, que 10\%, na média, dos elementos (genes) de cada vetor (indivíduo) sofram mutacão. Neste caso, há $4 \times 8=32$ genes na população, portanto, são esperadas 3.2 mutações, em média, em cada geração. Considere que o indivíduo $A^{\prime \prime}$ seja mutado no sexto gene, o indivíduo $C^{\prime}$ no segundo gene e o indivíduo $D^{\prime}$ no primeiro gene. A população agora é constituída pelos seguintes indivíduos:

$$
\begin{aligned}
& A^{\prime \prime}=\left(\begin{array}{llllllll}
1 & 0 & 1 & 1 & 0 & 0 & 0 & 0
\end{array}\right) \\
& B^{\prime \prime}=\left(\begin{array}{llllllll}
0 & 1 & 1 & 0 & 1 & 1 & 1 & 0
\end{array}\right) \\
& C^{\prime}=\left(\begin{array}{llllllll}
1 & 0 & 1 & 0 & 1 & 1 & 1 & 0
\end{array}\right) \\
& D^{\prime}=\left(\begin{array}{llllllll}
1 & 0 & 1 & 0 & 0 & 0 & 0 & 0
\end{array}\right)
\end{aligned}
$$

Com isso, uma geração é completada. Note que o melhor indivíduo foi perdido durante essa geração, mas a aptidão média da população aumentou de $\frac{12}{4}$ (12 valores 1's presentes nos quatro primeiros indivíduos $-A, B, C$ e $D$ ) para $\frac{15}{4}$ (15 valores 1 's presentes nos quatro últimos indivíduos $-A^{\prime \prime}, B^{\prime \prime}, C^{\prime} \mathrm{e}$ $\left.D^{\prime}\right)$.

O algoritmo genético clássico descrito é a base para a maioria das aplicações de AGs. Entretanto, em muitas casos, existe a necessidade de codificar os individuos de outra forma diferente da codificação com cadeias de bits. Além disso, em muitas aplicações é necessário realizar modificações nos operadores genéticos de mutação e crossover, além de muitas vezes ser necessário 
acrescentar novos operadores genéticos. Na próxima seção, são descritos alguns métodos de AGs que podem ser utilizados para evoluir classificadores simbólicos, objeto de estudo deste trabalho.

\subsection{Algoritmos Genéticos Aplicados na Evolução de Classificadores Simbólicos}

AGs é um dentre uma classe de paradigmas para simular a evolução utilizando os conceitos de evolução de Darwin para, de forma iterativa, gerar soluções apropriadas (individuos) incrementalmente em um ambiente estático ou que muda dinamicamente. Como mencionado, o AG clássico utiliza cadeias de bits de tamanho fixo para codificar os indivíduos e somente dois operadores para gerar aleatoriedade na população corrente de cada geração: o operador de crossover e o de mutação. Devido à dificuldade de se aplicar o algoritmo genético clássico, descrito anteriormente, a todo tipo de problema, várias implementações distintas foram propostas para problemas particulares. Aliás, uma representação natural de uma solução potencial para um dado problema somada à família de operadores "genéticos" aplicáveis poderia ser mais útil na aproximação de soluções de muitos problemas. Assim, vários pesquisadores têm explorado o uso de outras representações para codificar indivíduos, tais como listas ordenadas, listas embutidas, listas de elementos variáveis, cadeias de tamanhos variáveis (incluindo cadeias cujos elementos são regras if-then-else), estruturas mais complexas do que cadeias de bits, bem como o uso de operadores genéticos modificados para atender as necessidades de aplicações particulares (Michalewicz, 1999).

O principal objetivo de aprendizado de máquina envolve desenvolver e implementar algoritmos capazes de encontrar novo conhecimento ou melhorar conhecimento previamente construído, utilizando como informação de entrada observações (casos ou exemplos) do mundo. Nos últimos anos tem incrementado o interesse de aplicar técnicas de computação evolutiva em aprendizado de máquina devido à idéia atrativa de cromossomos, representando conhecimento, serem tratados como dados a serem manipulados por operadores genéticos, e, ao mesmo tempo, serem códigos executáveis para serem utilizados na realização de alguma tarefa.

No caso de aprendizado simbólico, i.e. aprendizado (indução) de classi- 
ficadores simbólicos, as seguintes duas abordagens têm sido propostas pela comunidade de $\mathrm{AGs}^{3}$ (Freitas, 2002a,b):

Pittsburgh - cada indivíduo codifica um conjunto de regras de conhecimento. Por ter sido inicialmente proposto por De Jong e Smith na Universidade de Pittsburgh, essa abordagem também recebeu o nome da universidade de origem, mas também é referenciada na literatura por “abordagem Pitt”.

Michigan - um indivíduo codifica uma única regra de conhecimento. Por ter sido inicialmente proposta por Holland e Reitman na década de 70 na Universidade de Michigan, essa abordagem recebeu o nome da universidade de origem.

A escolha entre uma dessas duas abordagens depende do tipo de regras de conhecimento que se quer descobrir. Supondo que o interesse seja classificação - Seção 2.1 na página 12 - geralmente há um maior interesse na qualidade do conjunto de regras como um todo do que na qualidade das regras individualmente, ou seja, a interação entre as regras é importante. Neste caso, a abordagem Pittsburgh parece mais natural (Freitas, 2002b).

Por outro lado, a abordagem Michigan parece mais natural quando se quer encontrar um pequeno conjunto de regras com alto nível de predição (ou com algum outro valor desejado utilizando alguma medida de avaliação de regras), e cada regra é avaliada independentemente de outras regras. Usos dessa abordagem são encontrados em (Noda et al., 1999; Weiss and Hirsh, 1998).

Também, deve ser levada em conta a complexidade da codificação e dos cálculos a serem realizados pelo AG. Na abordagem Michigan os indivíduos, os quais representam somente uma regra, são simples e relativamente pequenos. Esses fatores tendem a reduzir a complexidade do cômputo da função objetivo e a simplificar o projeto dos operadores genéticos. Todavia, essa vantagem tem um custo. Em primeiro lugar, desde que a função objetivo avalia a qualidade de cada regra individualmente, não é fácil computar a qualidade de um conjunto de regras, ou seja, considerar interações entre as regras no cômputo da função objetivo. Outro problema é impedir que o AG convirja a um indivíduo único quando se quer descobrir um conjunto de regras (indivíduos), e não uma única regra. Existem duas maneiras de resolver esse problema:

\footnotetext{
${ }^{3} \mathrm{Em}$ (Michalewicz, 1999), dá-se o nome de computação evolutiva quando se altera a maneira de codificar os indivíduos. Já em (Freitas, 2002a), não existe essa distinção. Neste trabalho, adotamos as definições propostas em (Freitas, 2002a).
} 
1. Utilizar um método de niching. Os métodos de niching fazem com que a população inicial convirja para um subgrupo (subpopulação) e não para um único indivíduo. Assim, esses métodos proporcionam uma extensão aos AGs, permitindo-os trabalhar em domínios que requerem múltiplas soluções, bem como manutenção nessas soluções (Mahfoud, 1995). Problemas de classificação e aprendizado de máquina estão incluídos nessa gama de problemas.

2. Executar o AG várias vezes, descobrindo em cada iteração uma regra diferente, o que é computacionalmente caro.

Exemplos de AG para o problema de classificação em aprendizado que utilizam a técnica Michigan são COGIN (Greene and Smith, 1993) e REGAL (Giordana and Neri, 1995). Nesses sistemas, cada indivíduo representa uma regra de conhecimento, e é codificado como uma cadeia bits. Tais cadeias de bits possuem uma codificação que contém informações de todos os atributos do domínio em questão. Portanto, mesmo que uma regra contenha poucos atributos participando das condições de seu corpo, ela ocupará o mesmo espaço em memória que uma regra que possua todos os atributos do conjunto de dados em condições do seu corpo.

Outra maneira de codificar regras de classificação leva em conta a interação entre as regras no cômputo da função objetivo. Essa abordagem é denominada Pittsburgh. Nos trabalhos encontrados na literatura relacionados a essa abordagem, os indivíduos são codificados como sendo um classificador (um conjunto de regras de conhecimento). Por utilizarem o mesmo método de codificação para regras que utilizam os métodos baseados na abordagem Michigan, os indivíduos são sintaticamente longos, muitas vezes levando à necessidade de modificações nas operações genéticas padrões (crossover e mutação) para lidar com esses indivíduos relativamente complexos. Ainda, por serem sintaticamente longos, os algoritmos possuem alta complexidade de tempo. Os primeiros algoritmos propostos baseados na abordagem Pittsburgh são GABIL (De Jong et al., 1993), GIL (Janikow, 1993) e HDPDCS (Pei et al., 1997). Esses algoritmos somente permitiam atributos discretos nos domínios em questão, além de não permitir muitas possibilidades na avaliação de individuos. Outro AG proposto baseado na abordagem Pittsburgh é o GENIFER (Llorà and i Guiu, 1999). O GENIFER é um AG cujas idéias são baseadas no GABIL, porém o GENIFER permite que atributos contínuos estejam 
presentes nos domínios utilizados para aprendizado de classificadores. Outro sistema também baseado na abordagem Pittsburgh e considerado interessante é o MERBIS (Setzkorn and Paton, 2003). Esse AG evolui conjuntos de regras (classificadores) compostos por regras fuzzy.

Como mencionado anteriormente, o objetivo deste trabalho consiste em: dada uma população inicial composta por classificadores simbólicos (constituídos por conjuntos de regras), construir um classificador simbólico que seja no mínimo tão preciso quanto, ou, preferencialmente, mais preciso que o menos preciso dentre todos os classificadores iniciais, utilizando AGs. Analisando as duas abordagens para tratarem do problema de utilização de algoritmos genéticos em aprendizado de máquina, pode-se observar que a abordagem Pittsburgh é a mais indicada para a tarefa de evolução de classificadores do que a abordagem Michigan, tendo em vista que o objetivo final obter uma solução única, composta por regras de classificador, sendo essa solução o classificador final do processo de evolução.

Nos trabalhos relacionados com evolução de classificadores simbólicos citados anteriormente, somente encontramos trabalhos que mapeiam os indivíduos em cadeias de bits, o que torna os individuos sintaticamente longos. Codificação de indivíduos que os torna sintaticamente longos dificulta a manipulação desses indivíduos e a execução de operadores genéticos por serem indivíduos sintaticamente longos, além de tornar os algoritmos genéticos bastante complexos em relação a tempo de execução, como mencionado. Neste trabalho, a sintaxe padrão $\mathcal{P} \mathcal{B M}$, proposta no ambiente Discover, descrito no Capítulo 3, permite-nos codificar os indivíduos de maneira automática, i.e, sem que seja necessário alguma conversão para cadeias de bits. A única transformação necessária é da linguagem de descrição do modelo do algoritmo que construiu as regras para a sintaxe padrão $\mathcal{P B} \mathcal{B}$, fazendo com que os indivíduos sejam sintaticamente menores, pois nessa codificação somente fazem parte do corpo da regra codificada as condições com os atributos que fazem parte do corpo da regra original. Como os individuos são sintaticamente menores, a implementação dos operadores genéticos do AG se torna mais fácil, como mostrado no Capítulo 7. 


\subsection{Proposta de um Algoritmo Genético para Evoluir Classificadores Simbólicos}

O AG proposto neste trabalho segue basicamente os passos do AG clássico descrito na Seção 6.2 - Algoritmo 4 -, entretanto há algumas variações para poder ser utilizado para evoluir classificadores simbólicos. O que varia nesta proposta são os componentes do AG, ou seja, a maneira que os indivíduos (classificadores) classificam novos exemplos e a função de avaliação para avaliar os cromossomos. Utilizando a abordagem Pittsburgh, na qual os indivíduos são codificados como sendo um conjunto de regras, propomos, além de utilizar as operações de crossover e mutação de maneira usual, usar diferentes funções de avaliação. Os passos seguidos pelo Algoritmo Genético proposto neste trabalho estão descritos no Algoritmo 5.

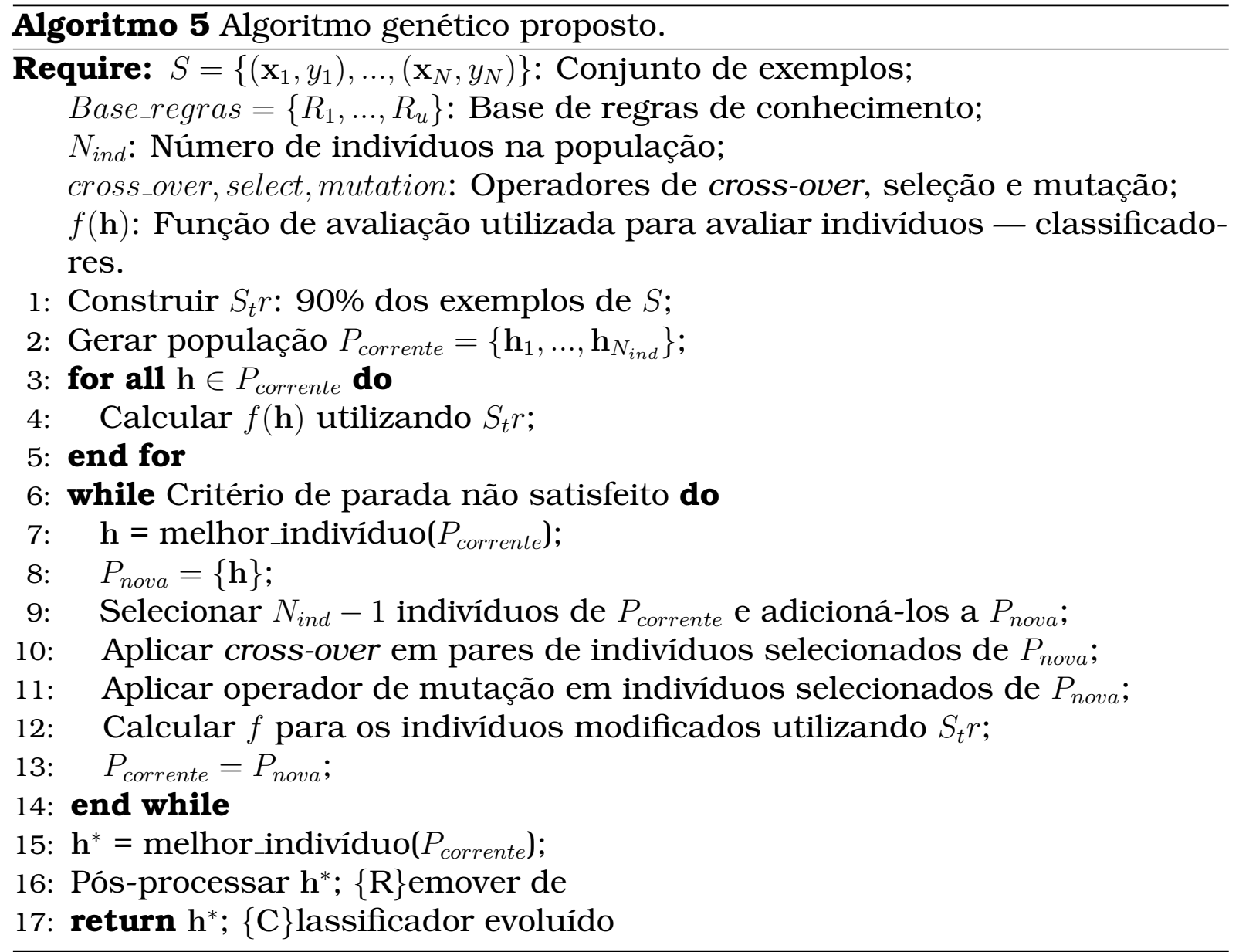

A seguir, são discutidos os componentes do AG proposto neste trabalho: codificação dos indivíduos, operadores genéticos utilizados - cross-over, 
mutação e seleção - funções de avaliação, critérios de parada e pós-processamento do indivíduo resultante.

\subsubsection{Codificação dos Indivíduos}

No algoritmo genético proposto neste trabalho - Algoritmo 5 -, para construir os classificadores (indivíduos) iniciais, são selecionadas regras (genes) de classificação de uma base de regras. Na Figura 6.2 é ilustrada uma base de regras com $W$ regras. Assim, cada gene de um indivíduo (classificador) é uma regra com um identificador único, e cada indivíduo é, portanto, uma seqüência de identificadores de regras (na verdade, é um conjunto de regras que, para vias de implementação, é transformado em uma seqüência de regras). Cada indivíduo é então codificado como sendo um vetor de identificadores de regras, ilustrado na Figura 6.3, sendo que cada regra participa somente uma vez em cada indivíduo. Para construir a base de regras mencionada, podem ser utilizadas regras construídas por especialistas do domínio, ou regras pertencentes a classificadores induzidos por algoritmos de aprendizado simbólicos - tais como $\mathcal{C N} 2$ (Clark and Niblett, 1989), $\mathcal{C} 4.5$ e $\mathcal{C} 4.5$ rules (Quinlan, 1988) - e um algoritmo de geração de regras de associação - Apriori (Borgelt and Kruse, 2002) ${ }^{4}$. Na realidade, esses classificadores podem também ser utilizados como indivíduos iniciais do AG. Tais classificadores, se utilizados, podem facilitar o processo de busca do AG pela melhor solução, já que esses classificadores provavelmente são soluções melhores que as soluções construídas aleatoriamente selecionando regras da base de regras. Todas as regras presentes na base de regras devem estar na sintaxe padrão de regras do Discover, $\mathcal{P} \mathcal{B} M$ (Prati et al., 2001b).

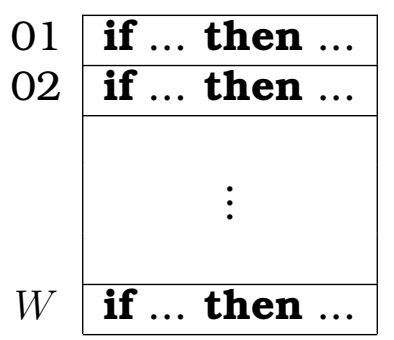

Figura 6.2: Base de regras na sintaxe padrão $\mathcal{P B} \mathcal{B}$.

\begin{tabular}{|l|l|l|l|l|l|}
\hline 01 & 10 & 15 & 09 & 07 & 15 \\
\hline
\end{tabular}

Figura 6.3: Exemplo de codificação de um indivíduo, composto por identificadores de regras

Na população inicial, todos os indivíduos possuem o mesmo tamanho. En-

\footnotetext{
${ }^{4}$ Neste trabalho, são utilizadas somente as regras geradas pelo Apriori nas quais o lado direito da regra de associação somente possui um valor que é o valor do atributo classe.
} 
tretanto, com a aplicação dos operadores genéticos, os indivíduos podem variar de tamanho, conforme descrito mais adiante.

\subsubsection{Operadores Genéticos}

São dois os operadores genéticos utilizados no AG proposto - Algoritmo 5:

Crossover: O operador de crossover utilizado é o crossover assimétrico. Em um crossover assimétrico são escolhidas duas posições, uma para cada indivíduo pai. Os indivíduos pais são divididos em dois segmentos, conforme as posições escolhidas. Por fim, são criados os indivíduos filhos por meio da composição dos segmentos dos indivíduos pai. No caso do AG proposto, cada indivíduo é composto por regras (identificadores de regras). Por exemplo, considere os seguintes indivíduos pai compostos por seqüências de números inteiros (identificadores de regras), os quais correspondem a índices das regras que constituem esses classificadores, armazenadas na base de regras:

$$
\begin{array}{llllll}
\text { pai }_{1} & 0702110004080301 \\
\text { pai }_{2} & 0523100612092015
\end{array}
$$

O operador de crossover assimétrico escolhe duas posições. Por exemplo, suponha que para o indivíduo pai $_{1}$ a posição depois do terceiro gene é escolhida, e para o indivíduo $\mathrm{pai}_{2}$ é escolhida a posição depois do quinto gene.

$$
\begin{aligned}
& \text { pai }_{1} \quad 070211 \mid 0004080301 \\
& \text { pai }_{2} \quad 0523100612 \mid 092015
\end{aligned}
$$

Então, como resultado, são gerados os seguintes indivíduos filhos:

$$
\begin{array}{lrl}
\text { filho }_{1} & 070211092015 \\
\text { filho }_{2} & 05231006120004080301
\end{array}
$$


Por meio da seleção realizada a cada geração, o AG pode tender a aumentar ou diminuir o número de regras em cada indivíduo. Dessa forma, um número apropriado de regras para os individuos pode ser encontrado para o domínio analisado.

Mutação: A operação de mutação é utilizada de maneira usual: para aplicar a operação de mutação, seleciona-se um gene de um indivíduo (aleatoriamente) e troca-se a regra selecionada por outra selecionada da base de regras disponível. O número de genes selecionados é dado pela probabilidade de mutação $p_{m}$.

Além desses operadores, outro operador possivel de se utilizar é um operador de generalização/especialização de classificadores. Um indivíduo pode ser generalizado adicionando-se uma regra a ele. Essa operação generaliza um conjunto de regras (classificador) porque o conjunto de regras é uma disjunção de regras. Assim, quando uma regra é inserida no classificador, um disjunto está sendo adicionado ao conjunto, o que em geral tende a aumentar o número de exemplos cobertos pelo classificador. Ao contrário, um conjunto de regras pode ser especializado removendo uma regra do conjunto de regras (Freitas, 2002a). Neste trabalho, esse operador é utilizado após a aplicação das operações de crossover e mutação. Para esse operador, é definido pelo usuário um número mínimo de exemplos que uma regra precisa cobrir ( $\min _{\operatorname{cov}_{R}}$ ), um número mínimo de exemplos que o classificador (indivíduo) precisa cobrir $\left(\min _{\operatorname{cov}_{\mathbf{h}}}\right)$ e uma probabilidade de aplicação desse operador $\left(p_{e}\right)$. Assim, dos indivíduos selecionados são excluídas as regras que cobrem menos exemplos que $\min _{\operatorname{cov}_{R}}$, bem como é adicionada uma regra da base de regras caso a cobertura do indivíduo seja menor que $\min _{\operatorname{cov}_{\mathbf{h}}}$.

\subsubsection{Funções de Avaliação}

Para avaliar um conjunto de regras, deve-se avaliar o comportamento do conjunto de regras (classificador) sobre um conjunto de exemplos de teste. Assim, pode-se avaliar o comportamento do conjunto de regras tanto como uma “caixa preta" quanto fazer uma avaliação do conjunto de regras juntamente com o comportamento das regras individuais. Para avaliar os classificadores como sendo uma caixa preta, pode-se utilizar as medidas de acurácia, precisão e $F_{1}$, definidas na Seção 2.3. Para avaliar as regras individualmente, podese utilizar as medidas de avaliação de regras descritas no Apêndice A. Neste 
trabalho, é proposto o uso das 5 (cinco) medidas seguintes - Equações 6.1 a 6.5 - denominadas $H Q$ (Hypothesis Quality) para avaliar o desempenho do classificador.

$$
\begin{gathered}
H Q_{A c c}(\mathbf{h})=\operatorname{Acc}(\mathbf{h}) \\
H Q_{P r e c}(\mathbf{h})=\operatorname{Prec}(\mathbf{h}) \\
H Q_{F 1}(\mathbf{h})=F 1(\mathbf{h}) \\
H Q_{A \times C}(\mathbf{h})=\operatorname{Acc}(\mathbf{h}) \times \operatorname{mean}\left(\operatorname{Cov}\left(R_{i}\right)\right), \forall R_{i} \in \mathbf{h} \\
H Q_{P \times C}(\mathbf{h})=\operatorname{Prec}(\mathbf{h}) \times \operatorname{mean}\left(\operatorname{Cov}\left(R_{i}\right)\right), \forall R_{i} \in \mathbf{h}
\end{gathered}
$$

Deve ser observado que, por se tratar de classificadores simbólicos, podem ser utilizadas diversas maneiras para se descobrir a classificação de um novo exemplo, i.e., dado um exemplo $\mathrm{x}$ e um classificador $\mathbf{h}=\left\{R_{1}, \ldots, R_{N_{R}}\right\}$, podese utilizar diversos métodos para classificar x. Existem três maneiras para verificar como um conjunto de regras cobre um novo exemplo, como descrito na Seção 2.4 na página 18: ordenada, não-ordenada e ordenada entre classes. Uma vez que não existe uma ordem implícita nas regras que compõem os individuos, os métodos para classificar $\mathrm{x}$ propostos neste trabalho consideram os conjuntos de regras como sendo conjuntos de regras não ordenados.

Além disso, neste trabalho são propostos diversos métodos para classificar $\mathrm{x}$ dado um indivíduo (classificador) denominados $S R$ (Single Rule classification method) e $M R$ (Multiple Rule classification method). Os métodos $S R$ classificam $\mathrm{x}$ considerando a "melhor" regra do classificador, segundo uma medida de qualidade de regras, enquanto que os métodos $M R$ utilizam todo o conjunto de regras que cobrem x para realizar a classificação. As medidas de avaliação de regras utilizadas foram $A c c(R), \operatorname{Lacc}(R), \operatorname{Cov}(R)$ e um índice de precisão menos erro, denominado $P E$, definido pela Equação 6.6. 


$$
P E=f_{b h}-f_{b \bar{h}}
$$

Foram selecionadas essas medidas por serem medidas utilizadas em algoritmos de indução de classificadores, ou por serem intuitivamente consideradas mais interessantes para seleção de regras para classificação de exemplos. Assim, a seguir são propostos 8 (oito) métodos propostos para classificar $\mathrm{x}$ dado um indivíduo (classificador), os quais são uma combinação das medidas de avaliação utilizadas e dos grupos de métodos de classificação utilizados ( $S R$ ou $M R)$.

1. $S R_{A c c}$ : É utilizada a melhor regra segundo a medida de avaliação de regra precisão $(A c c)$ - Equação A.1 - para classificar x;

2. $S R_{\text {Lacc }}$ : É utilizada a melhor regra segundo a medida de avaliação de regra precisão de Laplace (Lacc) - Equação A. 19 - para classificar x.

3. $S R_{C o v}$ : É utilizada a melhor regra segundo a medida de avaliação de regra cobertura $(C o v)$ - Equação A.6 - para classificar x.

4. $S R_{P E}$ : É utilizada a melhor regra segundo o índice de precisão menos erro $(P E)$ - Equação 6.6 - para classificar $\mathbf{x}$.

5. $M R_{A c c}$ : São utilizadas todas as regras que cobrem $\mathrm{x}$ para encontrar sua classificação. Para determinar a classe de $\mathbf{x}$, para cada classe $C_{v} \in$ $\left\{C_{1}, \ldots, C_{N_{C l}}\right\}$ é somado o valor da medida de precisão (Acc) - Equação A. 1 para as regras que classificam o exemplo na classe em questão. A classe com maior valor total é a classificação de $\mathrm{x}$.

6. $M R_{\text {Lacc }}$ : São utilizadas todas as regras que cobrem $\mathrm{x}$ para encontrar sua classificação. Para determinar a classe de $\mathbf{x}$, para cada classe $C_{v} \in$ $\left\{C_{1}, \ldots, C_{N_{C l}}\right\}$ é somado o valor da medida de precisão de laplace ( $L a c c$ ) Equação A. 19 - para as regras que classificam o exemplo na classe em questão. A classe com maior valor total é a classificação de x.

7. $M R_{C o v}$ : São utilizadas todas as regras que cobrem $\mathrm{x}$ para encontrar sua classificação. Para determinar a classe de $\mathbf{x}$, para cada classe $C_{v} \in$ $\left\{C_{1}, \ldots, C_{N_{C l}}\right\}$ é somado o valor da medida de cobertura (Cov) - Equação A.6 - para as regras que classificam o exemplo na classe em questão. A classe com maior valor total é a classificação de $\mathrm{x}$. 
8. $M R_{P E}$ : São utilizadas todas as regras que cobrem $\mathrm{x}$ para encontrar sua classificação. Para determinar a classe de $\mathrm{x}$, para cada classe $C_{v} \in$ $\left\{C_{1}, \ldots, C_{N_{C l}}\right\}$ é somado o valor do índice de precisão menos cobertura $(P E)$ - Equação 6.6 - para as regras que classificam o exemplo na classe em questão. A classe com maior valor total é a classificação de $\mathrm{x}$.

\subsubsection{Critério de Parada}

Neste trabalho, são utilizados dois critérios de parada:

1. Por um número máximo de gerações que o AG executa. Como saída, o AG oferece o melhor indivíduo dentre todas as gerações executadas;

2. Utilizando um método de convergência. Dado um número de gerações $N_{g e n}$, se a função de avaliação do melhor indivíduo não melhorar nas últimas $N_{\text {gen }}$ gerações, o algoritmo genético pára de executar.

\subsubsection{Pós-processamento do Indivíduo Resultante}

Como saída, o AG oferece um classificador simbólico. Analogamente aos algoritmos de indução de classificadores, no AG aqui proposto é realizado um pós-processamento desse classificador resultante da execução do AG, da seguinte maneira: antes de iniciar a execução do AG, é retirado do conjunto de treinamento $S_{t r}^{\prime}$ oferecido como entrada ao AG, uma amostra com $10 \%$ dos exemplos dessa base, denominada $S_{v a l}$. Os exemplos restantes em $S_{t r}^{\prime}$, que compõem $S_{t r}$, são utilizados em cada geração do AG, e o conjunto de exemplos $S_{t r}^{\prime}=S_{t r} \cup S_{v a l}$ é utilizado no pós-processamento. Nessa fase de pósprocessamento, são retiradas do classificador resultante todas as regras que não cobrem nenhum exemplo em $S_{t r}^{\prime}$. 


\subsection{Considerações Finais}

Neste capitulo, foram abordados conceitos relativos a algoritmos evolutivos e algoritmos genéticos. Também, foi descrito o algoritmo genético clássico, bem como foi proposto um algoritmo genético para evolução de classificadores simbólicos. Foram descritos todos os componentes do AG proposto, incluindo as funções de avaliação propostas. Neste trabalho, o AG necessita ser avaliado variando seus componentes, ou seja, utilizando as diferentes funções de avaliação propostas anteriormente e variando os parâmetros do AG. Para facilitar essa tarefa, foi implementado um ambiente computacional, integrado ao ambiente DISCOVER, sendo uma de suas funcionalidades a implementação desse algoritmo genético proposto. 


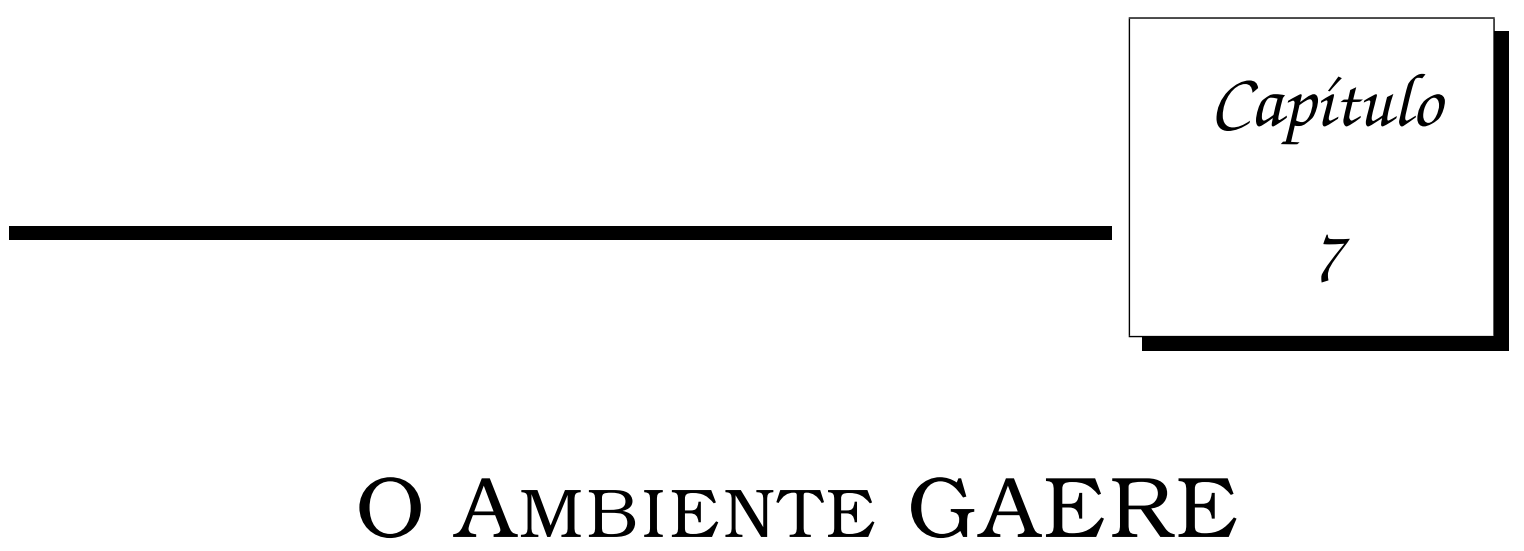

"Não faça pequenos planos: Eles não possuem a mágica para ferver o sangue dos homens."

\section{- Daniel H. Burnham}

onforme mencionado, um dos aspectos mais importantes quando se induz classificadores sobre um determinado domínio diz respeito à avaliação experimental desses classificadores, pois não existem instrumentos formais para decidir qual algoritmo de aprendizado é ótimo (Dietterich, 1989; Kibler and Langley, 1988; Schaffer, 1994). Assim, também é necessário realizar a avaliação experimental do AG proposto neste trabalho, além de fornecer ao usuário uma maneira de evoluir classificadores simbólicos utilizando o referido AG. No Capítulo 5, mais especificamente na Seção 5.1, é descrita a maneira de construção das árvores de diretórios utilizadas para estimar os erros dos ensembles e dos classificadores que o compõem. Para avaliar o AG, é necessário avaliar o classificador final construído. Também neste caso, são utilizados conjuntos de dados de pequeno a médio porte. Ainda, com a finalidade de ter uma base de comparação, podem ser utilizados classificadores induzidos por algoritmos de AM como indivíduos iniciais 
do AG proposto para compará-los com o indivíduo evoluído. Como esse processo de evolução de classificadores também pode ser visto como um método de combinação de classificadores em um único classificador final, é proposta uma metodologia de avaliação análoga à metodologia de avaliação do ambiente ELE, para avaliação do classificador final, evoluído pelo AG. Tal metodologia foi implementada em um módulo, denominado GATREE. Tanto a referida metodologia quanto o módulo GATREe são descritos neste capítulo. Além do módulo GATREe, foram construídos 3 (três) outros módulos para compor o sistema GAERE: o módulo GA, no qual está implementado o AG proposto neste trabalho, o módulo RULESTRUCT, responsável por carregar classificadores simbólicos no formato padrão $\mathcal{P B M}$ em uma única base de regras, e o módulo RULESETGA, responsável por construir os indivíduos do AG e manipulá-los, bem como classificar novos exemplos dado um indivíduo (classificador) segundo os métodos de classificação propostos na Seção 6.4.

\subsection{Avaliação Experimental do Algoritmo Genético Pro- posto}

Para evoluir classificadores simbólicos utilizando o AG por nós proposto, primeiramente é necessário construir a população inicial composta de classificadores simbólicos. Para construir a população inicial, podem ser utilizadas tanto regras criadas pelo usuário do AG quanto podem ser utilizadas regras induzidas por algoritmos de aprendizado simbólico. Para facilitar a construção do sistema GAERE e facilitar a execução do AG, foram utilizados os ambientes SNIFFER, o qual foi estendido para atender as particularidades so sistema proposto, e DLE - Capítulo 3. Para facilitar a construção da população inicial, foi decidido utilizar regras construídas pelos algoritmos de aprendizado simbólico $\mathcal{C N} 2$ (Clark and Niblett, 1989), $\mathcal{C} 4.5$ e $\mathcal{C} 4.5$ rules (Quinlan, 1988) e pelo algoritmo de geração de regras de associação Apriori (Borgelt and Kruse, 2002), conforme mencionado anteriormente. Dado um conjunto de exemplos $S$, são induzidos classificadores utilizando os indutores indicados pelo usuário dentre os previamente mencionados (podem ser utilizados todos eles, inclusive). Para utilizar o AG, é necessário utilizar um conjunto de treinamento para avaliar os classificadores construídos a cada geração, um conjunto de validação para realizar pós-processamento no classificador resultante e um conjunto de teste utilizado para testar o classificador final. 
Para avaliar o AG proposto, pode-se utilizar diversas técnicas. Neste trabalho, a metodologia proposta para avaliar o AG é baseada na técnica de $k$ fold cross-validation estratificado. Na Figura 7.1 é ilustrada essa metodologia, a qual é explicada observando essa figura da esquerda para a direita. Inicialmente, o conjunto de dados $S$ é dividido em $k$ partições $S_{0}^{\prime}, \ldots, S_{(k-1)}^{\prime}$. $\mathrm{Na}$ primeira iteração do $k$-fold cross-validation, $S_{t r_{0}}^{\prime}=S_{1}^{\prime} \cup \ldots \cup S_{(k-1)}^{\prime} \cdot S_{t r_{0}}^{\prime}$ é então utilizado para construir regras utilizando os algoritmos $\mathcal{C} 4.5$ e/ou $\mathcal{C} 4.5$ rules e/ou $\mathcal{C N} 2$ e/ou Apriori e/ou simplesmente regras fornecidas pelo usuário/especialista. As regras induzidas/geradas formam a base de regras $B R_{0}$. Do mesmo conjunto $S_{t r_{0}}^{\prime}$ é extraída uma amostra com $10 \%$ do número de exemplos de $S_{t r_{0}}^{\prime}$. Tal amostra forma o conjunto $S_{v a l_{0}}$ e a diferença entre os conjuntos $S_{t r_{0}}^{\prime}$ e $S_{v a l_{0}}$ forma o conjunto $S_{t r_{0}}$; i.e., $S_{t r_{0}}=S_{t r_{0}}^{\prime}-S_{v a l_{0}}$. O AG é então executado, sendo que a base de regras $B R_{0}$ é utilizada para construir a população inicial e fornecer regras para os operadores de crossover e mutação; o conjunto de dados $S_{t r_{0}}$ é utilizado para avaliar os individuos (classificadores) a cada geração do AG, já que a tarefa de avaliar um classificador depende de um conjunto de dados; o conjunto de dados $S_{t r_{0}}^{\prime}=S_{t r_{0}} \cup S_{v a l_{0}}$ é utilizado para realizar pós-processamento no classificador resultante das iterações do algoritmo genético, i.e., são retiradas regras que não cobrem nenhum dos exemplos pertencentes a $S_{t r_{0}}^{\prime}$; e, finalmente, a partição restante $S_{0}^{\prime}$ é utilizada como conjunto de teste $S_{t e_{0}}$ para avaliar o classificador gerado após a tarefa de pósprocessamento - dessa avaliação, é extraída a taxa de erro $\varepsilon_{1}^{*}$. Na segunda iteração do $k$-fold cross-validation, $S_{t r_{1}}^{\prime}=S_{0}^{\prime} \cup S_{2}^{\prime} \cup \ldots \cup S_{(k-1)}^{\prime}$. Analogamente, $S_{t r_{1}}^{\prime}$ é então utilizado para construir regras que formam a base de regras $B R_{1}$ e do mesmo conjunto $S_{t r_{1}}^{\prime}$ é extraída uma amostra com 10\% dos exemplos, formando o conjunto $S_{v a l_{1}}$ e $S_{t r_{1}}=S_{t r_{1}}^{\prime}-S_{v a l_{1}}$. Da mesma maneira, o AG é então executado, sendo usados $B R_{1}, S_{t r_{1}}, S_{v a l_{1}}$ e $S_{t e_{1}}$ e sendo encontrada a taxa de erro $\varepsilon_{1}^{*}$. O processo se repete até que sejam realizadas $k$ iterações, tendo como resultado $k$ taxas de erro. De $\varepsilon_{0}^{*}, \ldots, \varepsilon_{(k-1)}^{*}$ extrai-se a estimativa da taxa de erro do $\mathrm{AG} \varepsilon^{*}$ segundo os parâmetros utilizados.

Para executar essa metodologia para avaliação do AG proposto, no sistema GAERE foi feita uma extensão do ambiente SNIFFER - Seção 3.4 - de maneira a reconhecer identificadores do AG proposto. Para utilizar o ambiente SNIFFER, é necessário construir uma árvore de diretórios para que o SNIFFER possa ser chamado. Antes de descrever a construção e a estrutura de tal árvore de diretórios, é necessário definir que, quando queremos indicar um caminho na árvore de diretórios de um diretório < dir_pai > para um di- 
retório $<$ dir_filho $>$, sendo que $<$ dir_filho $>$ está dentro do diretório $<$ dir_pai $>$, representamos como sendo $<$ dir_pai $>\rightarrow<$ dir_filho $>$. Na Figura 7.2 é ilustrada a árvore de diretórios utilizada para construir as regras que formam as bases de regras nas $k$ iterações do $k$-fold cross-validation. Dado um conjunto de exemplos $S$ no formato padrão DSX, cujo arquivo está localizado no diretório Experimento, inicialmente são construídos $k$ diretórios itO,..., it(k-1). Dentro de cada diretório ito,..., it(k-1) são colocados os arquivos de dados representando o conjunto de treinamento, o conjunto de validação e o conjunto de teste da respectiva iteração. Para construir esses conjuntos, o conjunto de dados inicial $S$ é dividido em $k$ partições $S_{0}, \ldots, S_{(k-1)}$. Em it_0 o conjunto $S_{0}^{\prime}$ é colocado como sendo o conjunto de teste $S_{t e_{0}}$; do conjunto $S_{t r_{0}}=S_{1}^{\prime} \cup \ldots \cup S_{(k-1)}^{\prime}$ é extraída uma amostra com 10\% dos exemplos, sendo essa amostra colocada em it_0 como conjunto de validação $S_{v a l_{0}}$ e o restante dos exemplos em $S_{t r_{0}}^{\prime}$ é colocado em it_0 como o conjunto de treinamento $S_{t r_{0}}$; em it_l o conjunto $S_{1}^{\prime}$ é colocado como sendo o conjunto de teste $S_{t e_{1}}$, do conjunto $S_{t r_{1}}^{\prime}=S_{0}^{\prime} \cup S_{2}^{\prime} \cup \ldots \cup S_{(k-1)}$ é extraída uma amostra com 10\% dos exemplos, sendo essa amostra colocada em it_1 como conjunto de validação $S_{v a l_{1}}$ e o restante dos exemplos em $S_{U_{1}}$ é colocado em it_l como o conjunto de treinamento $S_{t r_{1}}$; e assim sucessivamente. Ainda, dentro de cada diretório it0,..., it(k-1) é construído um diretório denominado Classifierslnduction. Dentro de cada diretório Classifierslnduction é construído um diretório $S_{-}$, com $\mathrm{I}=1, \ldots, L$, onde $L$ é o número de algoritmos de aprendizado de máquina selecionados pelo usuário. Dentro de cada diretório S_l, é construído um diretório cujo nome é dado pelo identificador do algoritmo de aprendizado $^{1}$. Dentro de cada um desses diretórios, é construído um diretório denominado itO.

Dadas as regras construídas em arquivos no formato $\mathcal{P B M}$ presentes na árvore de diretórios ilustrada na Figura 7.2, é construída outra árvore de diretórios, ilustrada na Figura 7.3 para o AG ser executado. Nessa figura, $<$ GAld $>$ pode assumir os identificadores listados na Tabela 7.1. Deve ser observado que os identificadores são diferentes conforme o método de classificação de cada exemplo e a função de avaliação escolhidos pelo usuário. Nos diretórios it_0,..., it_(k-1) da Figura 7.3, devem estar presentes os arquivos $i$ correspondentes, $i=0, \ldots,(k-1)$ contendo as regras construídas, pertencentes ao conjunto $B R_{i}$, e os conjuntos de treinamento $S_{t r_{i}}$, validação $S_{v a l_{i}}$ e teste $S_{t e_{i}}$. Se na raíz da árvore ilustrada na Figura 7.2, indicada pelo nó Experimento,

\footnotetext{
${ }^{1}$ Os identificadores reconhecidos pelo SNIFFER após realizada a extensão podem ser encontrados na Seção 3.4
} 
for encontrado um arquivo nomeado GA.conf, esse arquivo é também copiado para cada um dos diretórios it_0,...,it_(k-1). Esse arquivo contém valores de parâmetros para execução do AG. Caso não seja encontrado esse arquivo, o AG é executado com seus parâmetros default. Em Bernardini and Monard (2006a), são encontrados maiores detalhes desse arquivo de configuração do AG bem como as configurações default mencionadas.

\begin{tabular}{|c|c|c|}
\hline $\begin{array}{c}\text { Identificador } \\
\text { (FitnessFunction) }\end{array}$ & $\begin{array}{c}\text { Método Utilizado para } \\
\text { Classificar Novos Exemplos }\end{array}$ & $\begin{array}{l}\text { Função Utilizada para Avaliar } \\
\text { o Desempenho do Classificador }\end{array}$ \\
\hline $\begin{array}{l}\text { GA.sracc.hqacc } \\
\text { GA.srlap.hqacc } \\
\text { GA.srcov.hqacc } \\
\text { GA.srpe.hqacc } \\
\text { GA.mracc.hqacc } \\
\text { GA.mrlap.hqacc } \\
\text { GA.mrcov.hqacc } \\
\text { GA.mrpe.hqacc } \\
\end{array}$ & $\begin{array}{l}S R_{\text {Acc }} \\
S R_{\text {Lacc }} \\
S R_{\text {Cov }} \\
S R_{\text {Ipe }} \\
M R_{\text {Acc }} \\
M R_{\text {Lacc }} \\
M R_{\text {Cov }} \\
M R_{\text {Ipe }} \\
\end{array}$ & $H Q_{A c c}$ \\
\hline $\begin{array}{l}\text { GA.sracc.hqprec } \\
\text { GA.srlap.hqprec } \\
\text { GA.srcov.hqprec } \\
\text { GA.srpe.hqprec } \\
\text { GA.mracc.hqprec } \\
\text { GA.mrlap.hqprec } \\
\text { GA.mrcov.hqprec } \\
\text { GA.mrpe.hqprec }\end{array}$ & $\begin{array}{l}S R_{\text {Acc }} \\
S R_{\text {Lacc }} \\
S R_{\text {Cov }} \\
S R_{\text {Ipe }} \\
M R_{\text {Acc }} \\
M R_{\text {Lacc }} \\
M R_{\text {Cov }} \\
M R_{\text {Ipe }} \\
\end{array}$ & $H Q_{\text {Prec }}$ \\
\hline $\begin{array}{l}\text { GA.sracc.hqf1 } \\
\text { GA.srlap.hqf1 } \\
\text { GA.srcov.hqf1 } \\
\text { GA.srpe.hqf1 } \\
\text { GA.mracc.hqf1 } \\
\text { GA.mrlap.hqf1 } \\
\text { GA.mrcov.hqf1 } \\
\text { GA.mrpe.hafl } \\
\end{array}$ & $\begin{array}{l}S R_{\text {Acc }} \\
S R_{\text {Lacc }} \\
S R_{\text {Cov }} \\
S R_{\text {Ipe }} \\
M R_{\text {Acc }} \\
M R_{\text {Lacc }} \\
M R_{\text {Cov }} \\
M R_{\text {Ipe }} \\
\end{array}$ & $H Q_{F 1}$ \\
\hline $\begin{array}{l}\text { GA.sracc.hqpc } \\
\text { GA.srlap.hqpc } \\
\text { GA.srcov.hqpc } \\
\text { GA.srpe.hqpc } \\
\text { GA.mracc.hqpc } \\
\text { GA.mrlap.hqpc } \\
\text { GA.mrcov.hqpc } \\
\text { GA.mrpe.hqpc }\end{array}$ & $\begin{array}{l}S R_{\text {Acc }} \\
S R_{\text {Lacc }} \\
S R_{\text {Cov }} \\
S R_{\text {Ipe }} \\
M R_{\text {Acc }} \\
M R_{\text {Lacc }} \\
M R_{\text {Cov }} \\
M R_{\text {Ipe }}\end{array}$ & $H Q_{P C}$ \\
\hline
\end{tabular}

Tabela 7.1: Identificadores que indicam qual função de avaliação utilizar na execução do algoritmo genético 


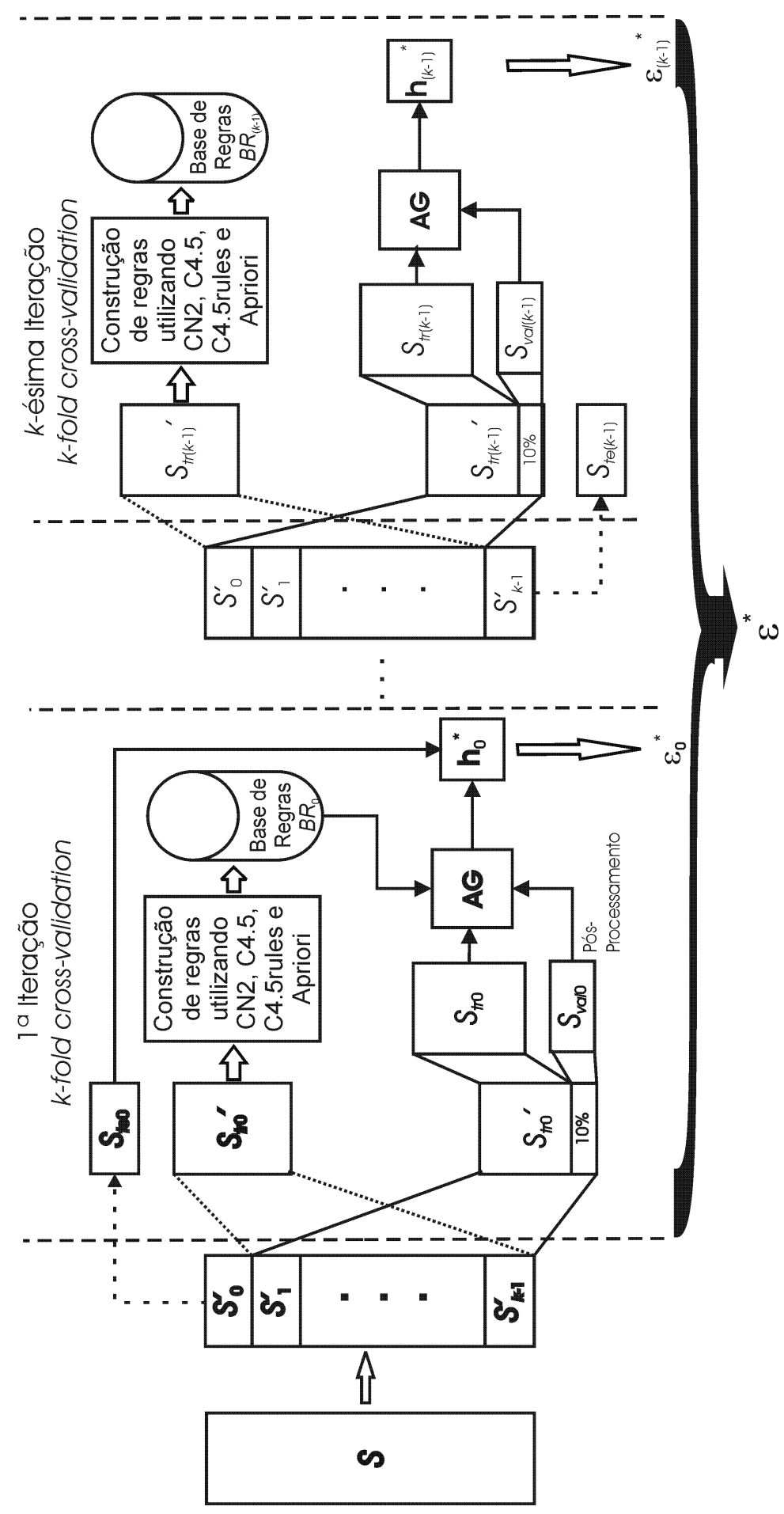

Figura 7.1: Estimativa de erro $\varepsilon^{*}$ de um classificador $\mathbf{h}^{*}$ evoluído com o AG proposto 


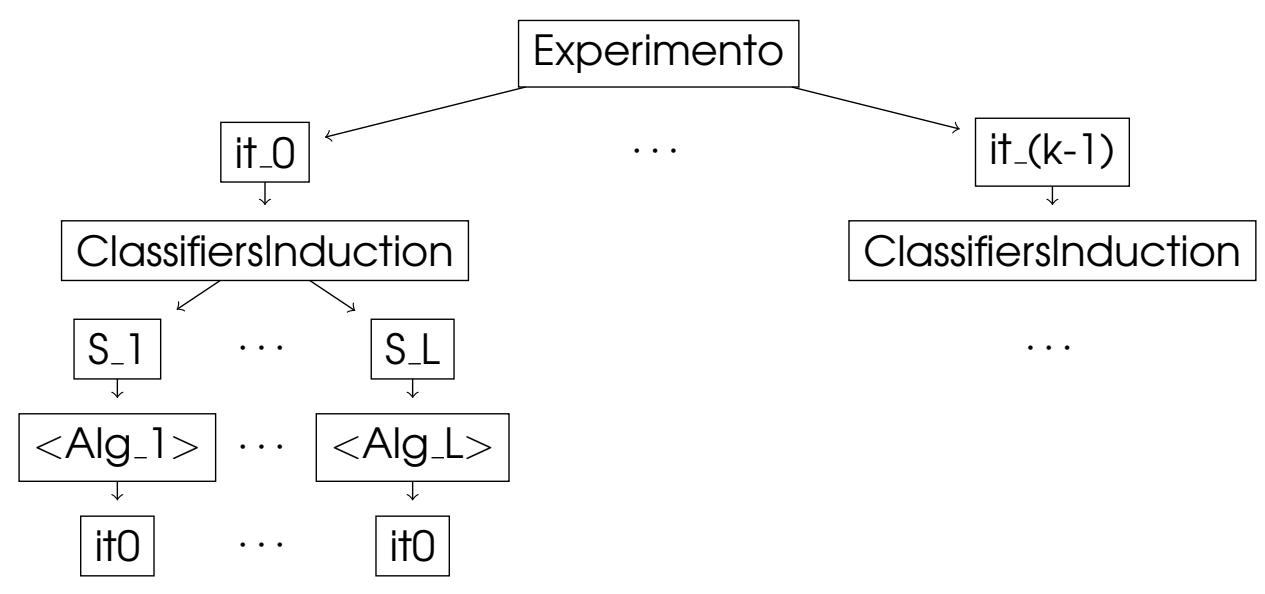

Figura 7.2: Configuração da árvore de diretórios para induzir os classificadores simbólicos cujas regras compõem a população inicial do(s) AG(s) a ser(em) executado(s)

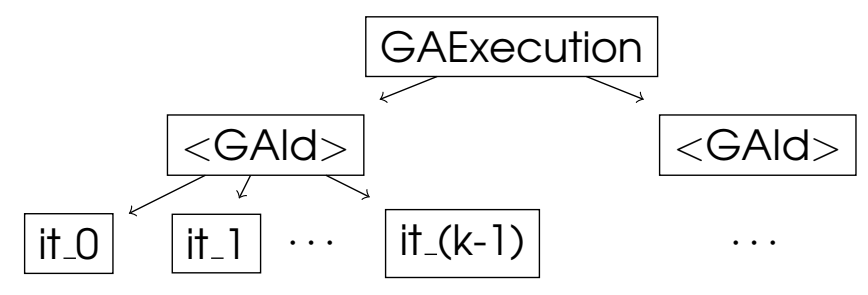

Figura 7.3: Configuração da árvore de diretórios para executar o algoritmo genético proposto 
Exemplo de Construção das Árvores de Diretórios: Para facilitar o entendimento de como são construídas essas árvores de diretórios, a seguir ilustraremos a construção delas com um exemplo. Vamos supor que queremos avaliar o AG proposto utilizando os identificadores de AG GA.mracc.hqprec, GA.mracc.hqpc e GA.srlap.hqprec bem como utilizando 10-fold cross-validation. Suponha também que representam o conjunto de dados completo os arquivos ds.data e ds.names. Para evoluir uma população inicial de classificadores construída aleatoriamente, queremos que as regras que compõem essa população inicial sejam provenientes dos classificadores induzidos por $\mathcal{C N} 2, \mathcal{C} 4.5$ e $\mathcal{C} 4.5$ rules, provenientes do conjunto de regras construído pelo $\mathcal{A}$ priori, e provenientes do especialista/usuário ${ }^{2}$. Assim, inicialmente deve ser construída uma instanciação da árvore geral ilustrada na Figura 7.2. Tal instanciação é ilustrada na Figura 7.4. Após execução do SNiffer nessa árvore, cada diretório folha it0 vai conter uma hipótese (ou um conjunto de regras caso o algoritmo para construção de regras seja o $\mathcal{A}$ priori, ou caso as regras sejam provenientes do usuário). Assim, a árvore ilustrada na Figura 7.5 é construída. Nessa figura, o diretório

\section{GAExecution $\rightarrow$ GA.mracc.hqprec $\rightarrow$ it_o}

contém os arquivos com regras presentes nos diretórios

$$
\begin{aligned}
& \text { Experimento } \rightarrow \text { it } \mathbf{0} \rightarrow \text { ClassifiersInduction } \rightarrow \mathrm{S}_{-} 1 \rightarrow \mathrm{c} 4.5 \rightarrow \text { it0, } \\
& \text { Experimento } \rightarrow \text { it } \mathbf{0} \rightarrow \text { ClassifiersInduction } \rightarrow \mathrm{S} \text {.2 } \rightarrow \text { c4.5rules } \rightarrow \text { it0, } \\
& \text { Experimento } \rightarrow \text { it_0 } \rightarrow \text { ClassifiersInduction } \rightarrow \text { S_3 } \rightarrow \mathrm{cn} 2 \rightarrow \text { it0 } \mathrm{e} \\
& \text { Experimento } \rightarrow \text { it_o } \rightarrow \text { ClassifiersInduction } \rightarrow \mathrm{S}_{-} 4 \rightarrow \text { apriori } \rightarrow \text { it0 } \\
& \text { Experimento } \rightarrow \text { it_ } \mathbf{0} \rightarrow \text { ClassifiersInduction } \rightarrow \text { S_5 } \rightarrow \text { user } \rightarrow \text { it0 }
\end{aligned}
$$

Tais arquivos são nomeados ds1.out, ds2.out, ds3.out, ds4.out e ds5.out, respectivamente, e são convertidos para a sintaxe padrão $\mathcal{P B M}$, sendo criados os arquivos ds 1.stdrules, ds2.stdrules, ds3.stdrules, ds4.stdrules e ds5.stdrules. Também, contém os arquivos representando os conjuntos de dados de validação $S_{v a l_{0}}$ e teste $S_{t e_{0}}$ presentes no diretório Experimento $\rightarrow$ it_0. Já o diretório

$$
\text { GAExecution } \rightarrow \text { GA.mracc.haprec } \rightarrow \text { it_1 }
$$

\footnotetext{
${ }^{2}$ Os arquivos do usuário devem ser construídos já na sintaxe padrão e colocados na árvore de diretórios manualmente.
} 
contém os arquivos com regras presentes nos diretórios

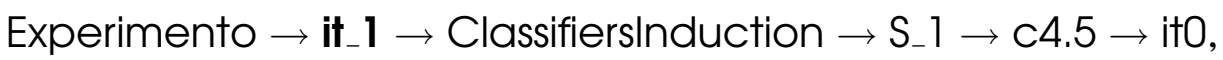

$$
\begin{aligned}
& \text { Experimento } \rightarrow \text { it_ } 1 \rightarrow \text { Classifiersinduction } \rightarrow \text { S_2 } \rightarrow \text { c4.5rules } \rightarrow \text { it0, } \\
& \text { Experimento } \rightarrow \text { it_1 } \rightarrow \text { Classifiersinduction } \rightarrow \text { S_3 } \rightarrow \text { cn2 } \rightarrow \text { itO e } \\
& \text { Experimento } \rightarrow \text { it_ } 1 \rightarrow \text { Classifiersinduction } \rightarrow \mathrm{S}_{-} 4 \rightarrow \text { apriori } \rightarrow \text { it0 } \\
& \text { Experimento } \rightarrow \text { it_l } \mathbf{l} \rightarrow \text { Classifierslnduction } \rightarrow \text { S_5 } \rightarrow \text { user } \rightarrow \text { itO }
\end{aligned}
$$

também nomeados, respectivamente, ds1.out, ds2.out, ds3.out, ds4.out e ds5. out, e são convertidos para a sintaxe padrão $\mathcal{P} \mathcal{B M}$, sendo então criados ds 1 . stdrules, ds2.stdrules, ds3.stdrules, ds4.stdrules e ds5.stdrules, e contém os arquivos representando os conjuntos de dados de validação $S_{v a l_{1}}$ e teste $S_{t e_{1}}$ presentes no diretório Experimento $\rightarrow$ it_1. Esse processo é repetido para as iterações seguintes. Tal estrutura se repete nos diretórios GAExecution $\rightarrow$ GA.mracc.hqpc e GAExecution $\rightarrow$ GA.srlap.hqprec. Então, SNIfFErGA Seção 3.4 - é chamado nessa árvore de diretórios, chamando o AG passando qual o método de classificação e qual a função de avaliação a ser utilizada.

Deve ser observado que árvore construída pelo GATREE, ilustrada na Figura 7.5, pode ser construída “à mão”, ou seja, sem utilizar o módulo GATREE. Neste caso, supondo que os arquivos referentes ao conjunto de dados sejam ds.data e ds.names, precisam estar presentes diretórios it $i, i=0, \ldots,(k-1)$, os arquivos ds.data, ds.names, ds.validation, ds.test, referentes ao conjunto de dados, e um arquivo dsl.stdrules contendo regras criadas pelo usuário na sintaxe padrão $\mathcal{P} \mathcal{B} \mathcal{M}$, além de arquivos ds $j$.stdrules, $j=2, \ldots, L$, também na sintaxe padrão, provenientes de algoritmos de aprendizado ou de outras fontes, a critério do usuário.

\subsection{O Módulo GATREE}

Lembrando que, para execução do algoritmo genético, em nossa proposta é necessário ter regras iniciais para construir a população inicial de indivíduos, e que utilizaremos algoritmos de aprendizado para construir essas regras iniciais, para facilitar tais tarefas utilizamos as facilidades do ambiente SNIFFER e do módulo Ensembletree para construir o módulo GATree. GATree é uma extensão da classe ENSEMBLETREE, única classe pertencente ao módulo Ensembletree. A classe EnsembleTree foi modificada de forma a permitir que somente sejam construídos os classificadores, sem que suas taxas de 


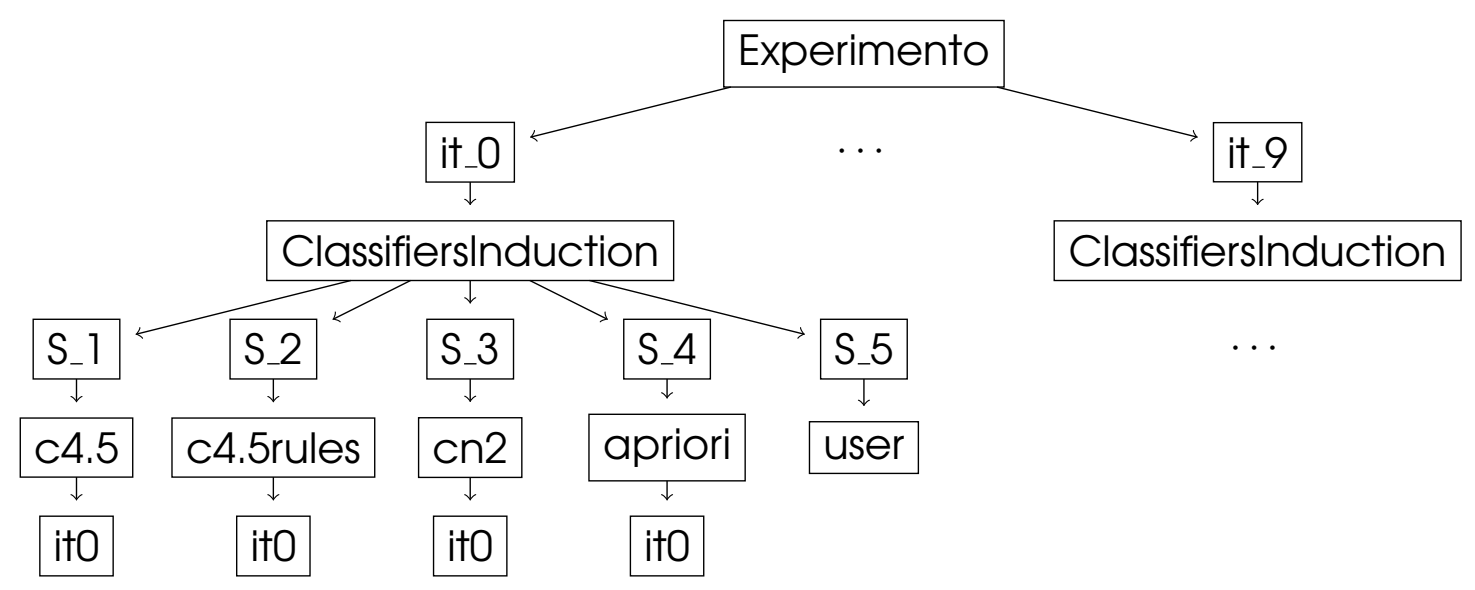

Figura 7.4: Árvore de diretórios instanciada para induzir os classificadores simbólicos cujas regras compõem a população inicial do(s) AG(s) a ser(em) executado(s)

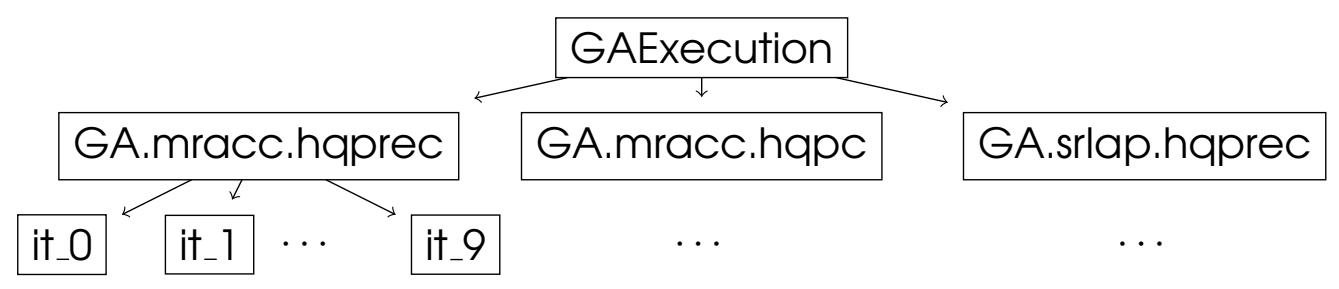

Figura 7.5: Instanciação da árvore de diretórios para executar os AGs representados pelos identificadores GA.mracc.hqprec, GA.mracc.hqpc e GA.srlap.hqprec 
erro fossem estimadas. A tarefa da classe GATREe é construir a árvore de diretórios onde se executa o algoritmo genético - Figura 7.3. Assim, para criar um objeto da classe GATREE, é necessário passar como parâmetro um objeto ENSEMBLETREE, onde estão presentes as regras construídas pelos algoritmos $\mathcal{C N} 2, \mathcal{C} 4.5, \mathcal{C} 4.5$ rules e Apriori.

\subsection{O Módulo RuleStruct}

O módulo RuleStRUCT armazena e gerencia a base de regras utilizada para compor os indivíduos da população inicial e as regras utilizadas para realizar as operações de mutação e crossover. As regras armazenadas em uma mesma instância do módulo RULESTRUCT devem pertencer a um domínio comum, isto é, devem fazer referência a um conjunto comum de atributos. Em outras palavras, utilizam exemplos do mesmo domínio. As regras são armazenadas em uma instância do módulo RULESTRUCT na sintaxe padrão de regras $\mathcal{P B M}$ (Prati et al., 2001b). Também, para as regras armazenadas, o módulo calcula a matriz de contingência das regras para avaliação das regras armazenadas.

A principal classe do módulo RuleStruct é também denominada RuleStruct. Essa classe cria uma base de regras que contém todas as regras dos classificadores simbólicos já na sintaxe $\mathcal{P} \mathcal{B M}$. Para carregar essas regras na base é utilizada a classe LoadRule. Como mencionado, os $L$ classificadores (conjuntos de regras) de entrada podem ser:

- fornecidos pelo usuário/especialista do sistema; e/ou

- gerados utilizando algoritmos de construção de regras de associação ou outros mecanismos de construção de regras de conhecimento; e/ou

- induzidos utilizando $L$ sistemas de aprendizado diferentes sobre um mesmo conjunto de dados; utilizando um ou mais sistemas de aprendizado, com variações dos parâmetros desses sistemas de aprendizado sobre o mesmo conjunto de dados, ou utilizando um ou mais sistemas de aprendizado sobre diversas amostras de um mesmo conjunto de dados

Logo, pode ser observado que a variabilidade nos conjuntos de regras iniciais é enorme. Um argumento contra essa variabilidade pode ser relacionada 
à facilidade de simplesmente inicializar as regras aleatoriamente. Entretanto, inserir classificadores induzidos por algoritmos de aprendizado simbólico muitas vezes facilita o processo de busca do AG por um bom classificador; inserir regras do usuário pode incrementar o conhecimento de fundo do domínio; e inserir regras do Apriori adiciona maior aleatoriedade ao AG. O processo de construção de conjuntos de regras $\operatorname{com} \mathcal{C N} 2, \mathcal{C} 4.5, \mathcal{C} 4$.5rules e $\mathcal{A}$ priori pode ser facilitado utilizando o módulo GATREE, descrito anteriormente.

O módulo RULESTRUCT provê diversas funcionalidades para a manipulação de regras. Entre as principais estão: prover informações sobre a matriz de contingência das regras e sobre o sistema de aprendizado que induziu as regras; informar quais são as regras default e remover essas regras da base de regras; prover informações sobre a complexidade sintática das regras e verificar se uma regra cobre um determinado exemplo, entre outros. As regras armazenadas na base são referenciadas por meio de um índice, isto é, cada regra possui um índice único que a identifica. Os demais módulos do ambiente GAERE que utilizam o módulo RULESTRUCT armazenam somente os índices das regras armazenadas, e utilizam esses índices para realizar operações sobre as regras.

\subsection{O Módulo RuleSetGA}

O módulo RuleSETGA é responsável por construir e manipular os indivíduos do AG, inclusive classificar um conjunto de exemplos dado um indivíduo e dado o método de classificação que deve ser utilizado $\left(S R_{A c c}, S R_{L a c c}\right.$, $S R_{C o v}, S R_{\text {Ipe }}, M R_{A c c}, M R_{\text {Lacc }}, M R_{\text {Cov }}$ e $M R_{\text {Ipe }}$ - Seção 6.4.3). Esse módulo é composto pelas classes RuleSetGA, RuleSetSRAcc, RuleSetSRLap, RuleSetSRCov, RuleSetSRPE, RuleSetMRAcc, RuleSetMRLap, RuleSetMRCov e RuleSetMRPE.

\subsection{O Módulo GA}

O módulo GA é composto pelas classes GA, HypQualityAcc, HypQualityPrec, HypQualityLap, HypQualityF1, HypQualityAC e HypQualityPC. A classe GA implementa o AG proposto na Seção 6.4. Inclusive, o AG implementado inicializa os indivíduos iniciais. Como parâmetro default do AG, são também carregados como indivíduos iniciais os classificadores induzidos pelos algoritmos de aprendizado simbólico. Entretanto, o usuário pode solicitar 
para não serem carregados os classificadores como indivíduos, utilizando um parâmetro do AG - o LOADCLASS. Maiores detalhes sobre os parâmetros do AG proposto encontram-se em Bernardini and Monard (2006a).

Para avaliar os indivíduos em cada geração do AG, são utilizadas as classes HypQualityAcc, HypQualityPrec, HypQualityLap, HypQualityF1, HypQualityAC e HypQualityPC. Na Figura 7.6 é apresentado o projeto dos módulos RuLESTRUCT, RULESETGA e GA por meio de um diagrama de classes em $\mathrm{UML}^{3}$ (Booch et al., 1998).

\subsection{Considerações Finais}

Neste capítulo, foram descritos os módulos que compõem o ambiente GAE$\mathrm{RE}$, cujo objetivo é implementar o algoritmo genético proposto para evoluir classificadores simbólicos. Também, foi descrito o método utilizado para avaliar o AG proposto. O esforço requerido para projetar e implementar esse método de avaliação utilizado foi bastante grande, já que tal método deve ser cuidadosamente projetado e bastante rigoroso para garantir a qualidade dos resultados obtidos bem como a qualidade da análise realizada sobre esses resultados. No próximo capítulo é apresentada a avaliação experimental dos métodos propostos este trabalho, i.e, construção de ensebles de classificadores e combinação de classificadores utilizando um algoritmo genético, implementados nos ambientes ELE e GAERE respectivamente.

\footnotetext{
${ }^{3}$ Unified Modeling Language
} 


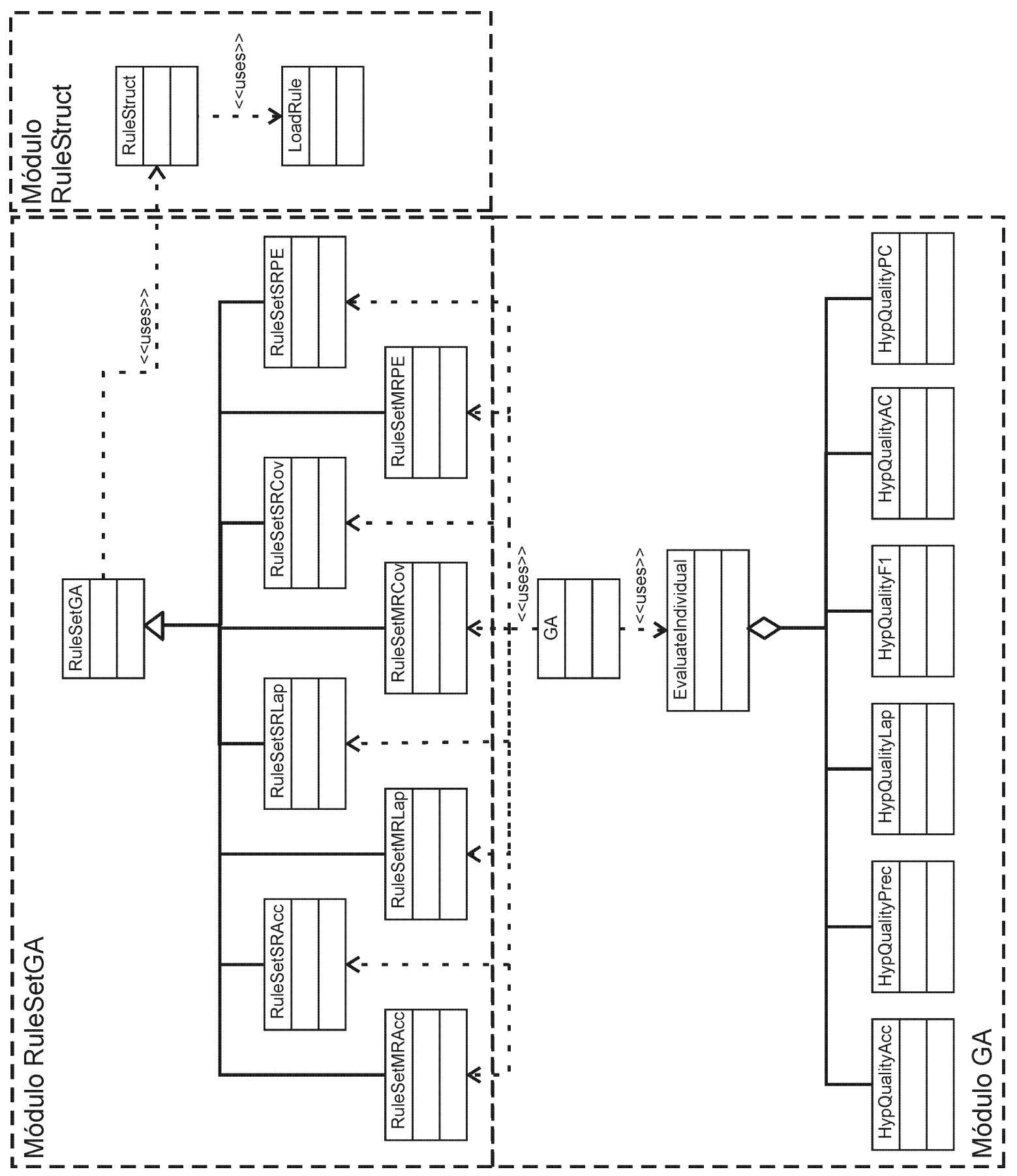

Figura 7.6: Diagrama UML dos módulos RuleStruct, RuleSetGA e GA 


\section{Capítulo}

\section{AVALIAÇÃO EXPERIMENTAL}

"Algo só é impossível até que alguém duvide e prove o contrário."

- Albert Einstein

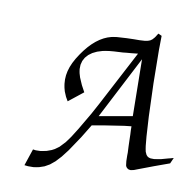

avaliação experimental realizada tem como objetivo responder às seguintes questões:

1. É possível obter um bom poder de predição combinando poucos classificadores simbólicos induzidos sobre conjuntos dispersos sobre algum domínio em questão? Ou seja, é possível extrair amostras diferentes de um conjunto de dados, induzir classificadores, combiná-los e melhorar o poder de predição do ensemble desses classificadores? Quais métodos de combinação de classificadores são mais apropriados?

2. O método utilizado neste trabalho para resumir a explicação fornecida pelos ensembles de classificadores simbólicos construídos consegue reduzir significativamente o número de regras oferecido ao usuário para explicar as decisões tomadas por um ensemble construído pelo ambiente computacional ELE? 
3. É possível obter melhoria no poder de predição ao evoluir classificadores simbólicos induzidos sobre amostras de um conjunto de dados utilizando o AG proposto e implementado no ambiente computacional GAERE? Tal melhoria é significativamente melhor ou pior que a melhoria (se houver) oferecida pelos métodos de combinação de classificadores implementados no ELE?

Tendo tais questões em vista, os experimentos realizados com os ambientes computacionais ELE e GAERE podem ser divididos em duas fases. Na primeira fase - Fase I - , foram utilizados 3 conjuntos de dados da UCI (Blake et al., 1998) com mais de 1000 exemplos. O objetivo da realização dos experimentos dessa fase é tentar responder às questões 1 e 2. Na segunda fase dos experimentos - Fase 2 -, foram utilizados 7 conjuntos de dados, também da UCI, para tentar responder à questão 3 .

Para selecionar os conjuntos de dados da UCI, realizamos um levantamento bibliográfico e selecionamos alguns dos artigos mais representativos da literatura, relacionados a construção de ensembles e combinação de classificadores. Os principais artigos utilizados para o levantamento de conjunto de dados utilizados foram (Todorovski and Dzeroski, 2003; Leung and Parker, 2003; Rückert and Kramer, 2004; Prati and Flach, 2005; Dzeroski and Zenko, 2002; Niyogi et al., 2000; Kuncheva et al., 2000; Alexandre et al., 2000; Bauer and Kohavi, 1999; Dietterich, 2000a). Nesse levantamento, foi verificado quais conjuntos de dados da UCI foram utilizados pelos autores, e ainda quantas vezes esses conjuntos de dados foram utilizados. Para cada uma das duas fases da avaliação experimental, foram selecionados os conjuntos de dados que mais vezes foram utilizados nos experimentos descritos nos artigos selecionados. A seguir são descritos os experimentos e os resultados obtidos em ambas as fases.

\subsection{Descrição dos Experimentos - Fase I}

Nesta fase, foram selecionados os conjuntos de dados com mais de 1000 exemplos que mais vezes foram utilizados nos artigos selecionados. Esse requisito (ter mais de 1000 exemplos) foi necessário já que nos experimentos foram retiradas amostras sem reposição do conjunto de dados para verificar a validade da proposta de construção de ensembles de classificadores, combi- 
nando classificadores induzidos de diferentes amostras do conjunto de dados inicial.

Os conjuntos de dados da UCI utilizados nesta fase de experimentos foram Nursery, Chess e Splice. Na Tabela 8.1 são descritas as principais características desses conjuntos de dados: número de exemplos (\# Ex.); número de atributos (contínuos, discretos) (\# Atr.); distribuição de exemplos nas classes (Classe \%); erro majoritário dos conjuntos de dados; presença ou ausência de valores desconhecidos (Val. Desc?); número de exemplos duplicados ou conflitantes.

\begin{tabular}{c|c|c|cc|c|c|c}
$\begin{array}{c}\text { Conj. de } \\
\text { Dados }\end{array}$ & \# Ex. & $\begin{array}{c}\text { \# Atributos } \\
\text { (cont.,disc.) }\end{array}$ & $\begin{array}{c}\text { Classe } \\
\text { e }\end{array}$ & Classe \% & $\begin{array}{c}\text { Erro } \\
\text { Majoritário }\end{array}$ & $\begin{array}{c}\text { Val. } \\
\text { Desc? }\end{array}$ & $\begin{array}{c}\text { Exemplos } \\
\text { Dup./Conf. }\end{array}$ \\
\hline \hline Nursery & 12958 & $8(0,8)$ & not_recom & $33.34 \%$ & $66.66 \%$ & $\mathrm{~N}$ & 0 \\
& & & $\begin{array}{c}\text { very_recom } \\
\text { priority }\end{array}$ & $\begin{array}{l}2.53 \% \\
\text { em not_recom }\end{array}$ & & $(0.00 \%)$ \\
& & & spec_prior & $31.21 \%$ & & & \\
\hline Chess & 3196 & $36(0,36)$ & nowin & $47.78 \%$ & $66.66 \%$ & $\mathrm{~N}$ & $(0.00 \%)$ \\
\hline Splice & 3190 & & won & $52.22 \%$ & em not_recom & & 0 \\
& & & EI & $24.01 \%$ & $48.12 \%$ & $\mathrm{~N}$ & 184 \\
& & & IE & $24.08 \%$ & em N & & $(5.77 \%)$
\end{tabular}

Tabela 8.1: Resumo das características dos conjuntos de dados utilizados na Fase I de experimentos

\subsubsection{Avaliação da Performance dos Métodos de Construção de Ensembles}

Diversos experimentos foram realizados utilizando os algoritmos de aprendizado simbólico $\mathcal{C N} 2$ (Clark and Niblett, 1989) e $\mathcal{C} 4.5$ (Quinlan, 1988) para induzir os classificadores que compõem os ensembles. Foram utilizados 5 (cinco) cenários diferentes para realização desses experimentos. A diferença entre cada cenário está na variação do número de amostras de exemplos retiradas do conjunto de exemplos inicial sem reposição, ou seja, na variação do número de classificadores que compõem os ensembles, e na variação do algoritmo de aprendizado utilizado em cada amostra para induzir o classificador componente, como é mostrado na Tabela 8.2. Por exemplo, no primeiro cenário (ScnI 1), 3 (três) amostras foram retiradas do conjunto inicial e foi utilizado o algoritmo $\mathcal{C N} 2$ para induzir os 3 (três) classificadores componentes, enquanto que no cenário $S c n I 4$, foram retiradas 5 (cinco) amostras, sendo que $\mathcal{C N} 2$ foi utilizado em 3 (três) amostras e $\mathcal{C} 4.5$ em 2 (duas) amostras.

Nas Tabelas 8.3, 8.4 e 8.5 são mostrados, para cada conjunto de dados, 


\begin{tabular}{c|c|l} 
Cenário & \# de Classificadores & Algoritmos de aprendizado \\
\hline ScnI 1 & 3 & $\mathcal{C N} 2-\mathcal{C N} 2-\mathcal{C N} 2$ \\
ScnI 2 & 3 & $\mathcal{C} 4.5-\mathcal{C} 4.5-\mathcal{C} 4.5$ \\
ScnI 3 & 5 & $\mathcal{C N} 2-\mathcal{C N} 2-\mathcal{C N} 2-\mathcal{C N} 2-\mathcal{C N} 2$ \\
ScnI 4 & 5 & $\mathcal{C N} 2-\mathcal{C N} 2-\mathcal{C N} 2-\mathcal{C} 4.5-\mathcal{C} 4.5$ \\
ScnI 5 & 5 & $\mathcal{C} 4.5-\mathcal{C} 4.5-\mathcal{C} 4.5-\mathcal{C} 4.5-\mathcal{C} 4.5$
\end{tabular}

Tabela 8.2: Descrição dos cenários utilizados para realização dos experimentos na Fase I de experimentos

os resultados obtidos nesses 5 (cinco) cenários. Nas primeiras 5 (cinco) linhas dessas tabelas, rotuladas por $S_{1}, S_{2}, S_{3}, S_{4}$ e $S_{5}$, são apresentados os resultados relacionados a cada classificador componente. As taxas de erro foram estimadas utilizando a técnica de 10-fold cross-validation estratificado. Na seqüência, são mostrados os resultados obtidos com os métodos de construção de ensembles propostos. Essas taxas de erro também foram estimadas utilizando a técnica de 10-fold cross-validation estratificado. Os valores entre parênteses referem-se ao erro padrão das taxas de erro. Ainda nessas tabelas, os identificadores que contém a palavra "Class", como por exemplo "UV-Class", indicam que os ensembles construídos utilizam a decisão do próprio classificador para classificar exemplos; "Acc" nos identificadores indica que, para classificar um exemplo, foi utilizada a melhor regra que cobre o exemplo segundo a medida de avaliação de precisão - Equação A.1 na página 159 —; "Lacc” indica que foi utilizada a melhor regra segundo a medida de precisão de Laplace Equação A. 19 na página 157 —; "NegRel" indica que foi utilizada a melhor regra segundo a medida de confiança negativa - Equação A.3 na página 159. Já "UV" indica que é utilizado o método de combinação de classificadores UV no ensemble; "WMV" indica que é utilizado o método de combinação WMV; e "WMSV" indica que é utilizado o método de combinação WMSV — Seção 4.3.

Pode ser observado nas Tabelas 8.3 e 8.5 que em todos os experimentos a taxa de erro dos ensembles de classificadores é menor que a taxa de erro dos classificadores que os compõem. Esse resultado tem 95\% de confiança segundo o teste de hipóteses $t$. Em relação ao conjunto de dados Chess, na Tabela 8.4 pode ser observado que somente no cenário ScrI 4 a taxa de erro dos ensembles de classificadores é menor que a taxa de erro dos classificadores que os compõem, com 95\% de confiança segundo o teste de hipóteses t; nos cenários ScnI 2, ScnI 3 e ScnI 5 a taxa de erro dos ensembles de classificadores é menor que a taxa de erro dos classificadores que os compõem porém não se garante essa informação com o teste $t$ com 95\% de confiança; 
e somente no ScnI 1 são obtidas taxas de erro dos ensembles maiores que os classificadores componentes.

É importante observar que na maioria dos experimentos, ainda quando utilizado o mesmo algoritmo de aprendizado, ou seja, quando a variabilidade dos classificadores induzidos é mais restrita, foram obtidas melhorias significativas nas taxas de erro dos ensembles de classificadores em relação a seus classificadores componentes com 95\% de confiança na maioria dos experimentos. Considerando o número reduzido de classificadores que compõem o ensemble ( 3 a 5), esses resultados podem ser considerados muito bons.

\begin{tabular}{c|c|c|c|c|c} 
& ScnI 1 & ScnI & ScnI & ScnI 4 & ScnI 5 \\
\hline$S_{1}$ & $5,60(0,13)$ & $6,16(0,23)$ & $7,64(0,24)$ & $7,75(0,19)$ & $7,92(0,18)$ \\
$S_{2}$ & $5,66(0,25)$ & $6,47(0,21)$ & $7,24(0,21)$ & $7,86(0,10)$ & $7,77(0,24)$ \\
$S_{3}$ & $5,43(0,18)$ & $5,97(0,09)$ & $7,93(0,26)$ & $7,47(0,27)$ & $7,80(0,17)$ \\
$S_{4}$ & - & - & $7,83(0,22)$ & $7,50(0,17)$ & $7,73(0,24)$ \\
$S_{5}$ & - & - & $7,82(0,16)$ & $7,94(0,29)$ & $7,46(0,24)$ \\
\hline UV-Class & $3,86(0,13)$ & & $4,51(0,16)$ & $4,42(0,15)$ & \\
WMV-Class & $4,13(0,13)$ & & $5,06(0,18)$ & $4,81(0,11)$ & \\
WMSV-Class & $4,18(0,14)$ & & $4,95(0,19)$ & $4,88(0,13)$ & \\
UV-Acc & $3,30(0,18)$ & & $3,86(0,14)$ & $4,41(0,11)$ & \\
WMV-Acc & $3,53(0,19)$ & & $4,47(0,16)$ & $4,75(0,08)$ & \\
WMSV-Acc & $3,57(0,21)$ & $4,81(0,18)$ & $4,38(0,14)$ & $4,81(0,12)$ & $6,41(0,14)$ \\
UV-Lacc & $3,85(0,14)$ & & $4,47(0,15)$ & $4,51(0,14)$ & \\
WMV-Lacc & $4,11(0,14)$ & & $5,02(0,16)$ & $4,85(0,12)$ & \\
WMSV-Lacc & $4,17(0,15)$ & & $4,91(0,15)$ & $4,93(0,13)$ & \\
UV-NegRel & $3,80(0,14)$ & & $4,30(0,17)$ & $4,24(0,16)$ & \\
WMV-NegRel & $4,24(0,14)$ & & $5,09(0,21)$ & $4,65(0,14)$ & \\
WMSV-NegRel & $4,24(0,16)$ & & $4,94(0,21)$ & $4,70(0,14)$ &
\end{tabular}

Tabela 8.3: Resultados experimentais obtidos utilizando o conjunto de dados Nursery - Fase I de experimentos

\begin{tabular}{c|c|c|c|c|c} 
& ScnI & ScnI 2 & ScnI 3 & ScnI 4 & ScnI 5 \\
\hline$S_{1}$ & $2,72(0,35)$ & $1,69(0,29)$ & $3,82(0,73)$ & $3,63(0,72)$ & $3,04(0,35)$ \\
$S_{2}$ & $2,47(0,32)$ & $1,25(0,19)$ & $3,57(0,44)$ & $2,75(0,36)$ & $3,00(0,46)$ \\
$S_{3}$ & $2,72(0,49)$ & $1,75(0,28)$ & $2,88(0,27)$ & $3,00(0,35)$ & $2,53(0,35)$ \\
$S_{4}$ & - & - & $2,94(0,47)$ & $2,22(0,28)$ & $3,13(0,51)$ \\
$S_{5}$ & - & - & $3,04(0,44)$ & $2,50(0,27)$ & $3,04(0,48)$ \\
\hline UV-Class & $2,50(0,33)$ & & $2,25(0,33)$ & $1,60(0,25)$ & \\
WMV-Class & $2,50(0,33)$ & & $2,25(0,33)$ & $1,60(0,25)$ & \\
WMSV-Class & $2,53(0,33)$ & & $2,25(0,31)$ & $1,56(0,26)$ & \\
UV-Acc & $2,50(0,33)$ & & $2,25(0,33)$ & $1,60(0,25)$ & \\
WMV-Acc & $2,50(0,33)$ & & $2,25(0,33)$ & $1,60(0,25)$ & \\
WMSV-Acc & $2,53(0,33)$ & $0,91(0,16)$ & $2,25(0,31)$ & $1,56(0,26)$ & $2,32(0,35)$ \\
UV-Lacc & $2,72(0,35)$ & & $2,32(0,32)$ & $1,63(0,27)$ & \\
WMV-Lacc & $2,72(0,35)$ & & $2,32(0,32)$ & $1,63(0,27)$ & \\
WMSV-Lacc & $2,53(0,33)$ & & $2,25(0,31)$ & $1,56(0,26)$ & \\
UV-NegRel & $2,50(0,33)$ & & $2,25(0,33)$ & $1,60(0,25)$ & \\
WMV-NegRel & $2,72(0,35)$ & & $2,32(0,32)$ & $1,63(0,27)$ & \\
WMSV-NegRel & $2,50(0,33)$ & & $2,25(0,33)$ & $1,60(0,25)$ &
\end{tabular}

Tabela 8.4: Resultados experimentais obtidos utilizando o conjunto de dados Chess - Fase I de experimentos

Os resultados das Tabelas 8.3, 8.4 e 8.5 foram plotados em gráficos, mostrados respectivamente nas Figuras 8.1, 8.2 e 8.3. Nesses gráficos, o eixo 


\begin{tabular}{c|c|c|c|c|c} 
& ScnI 1 & ScnI & ScnI 3 & ScnI 4 & ScnI 5 \\
\hline$S_{1}$ & $18,50(1,85)$ & $9,03(0,38)$ & $15,33(0,97)$ & $14,61(0,73)$ & $11,25(0,70)$ \\
$S_{2}$ & $15,52(1,04)$ & $9,37(0,47)$ & $14,80(0,92)$ & $16,02(1,20)$ & $13,01(0,67)$ \\
$S_{3}$ & $15,92(1,28)$ & $9,00(0,48)$ & $15,30(0,64)$ & $19,75(1,73)$ & $11,41(0,40)$ \\
$S_{4}$ & - & - & $15,45(1,45)$ & $11,72(0,74)$ & $12,13(0,55)$ \\
$S_{5}$ & - & - & $16,77(0,93)$ & $11,32(0,52)$ & $13,26(0,71)$ \\
\hline UV-Class & $11,54(0,49)$ & $7,55(0,39)$ & $9,72(0,45)$ & $7,30(0,70)$ & $8,68(0,42)$ \\
WMV-Class & $11,13(0,39)$ & $7,34(0,27)$ & $9,84(0,41)$ & $7,08(0,66)$ & $8,53(0,53)$ \\
WMSV-Class & $11,19(0,37)$ & $7,59(0,38)$ & $9,59(0,37)$ & $7,15(0,62)$ & $8,53(0,52)$ \\
UV-Acc & $11,50(0,38)$ & $7,55(0,39)$ & $10,56(0,55)$ & $8,09(0,71)$ & $8,68(0,42)$ \\
WMV-Acc & $11,69(0,46)$ & $7,34(0,27)$ & $10,50(0,58)$ & $7,74(0,64)$ & $8,53(0,53)$ \\
WMSV-Acc & $11,69(0,46)$ & $7,59(0,38)$ & $10,38(0,55)$ & $7,68(0,58)$ & $8,53(0,52)$ \\
UV-Lacc & $10,75(0,44)$ & $7,55(0,39)$ & $9,66(0,42)$ & $7,27(0,78)$ & $8,68(0,42)$ \\
WMV-Lacc & $10,82(0,52)$ & $7,34(0,27)$ & $9,81(0,46)$ & $7,05(0,74)$ & $8,53(0,53)$ \\
WMSV-Lacc & $10,88(0,49)$ & $7,59(0,38)$ & $9,56(0,40)$ & $7,05(0,66)$ & $8,53(0,52)$ \\
UV-NegRel & $12,85(0,61)$ & $7,55(0,39)$ & $9,94(0,43)$ & $7,52(0,65)$ & $8,68(0,42)$ \\
WMV-NegRel & $12,13(0,28)$ & $7,34(0,27)$ & $10,16(0,45)$ & $7,34(0,64)$ & $8,53(0,53)$ \\
WMSV-NegRel & $12,26(0,26)$ & $7,59(0,38)$ & $9,87(0,38)$ & $7,40(0,60)$ & $8,53(0,52)$
\end{tabular}

Tabela 8.5: Resultados experimentais obtidos utilizando o conjunto de dados Splice - Fase I de experimentos

das abcissas (eixo x) é referente à taxa de erro dos ensembles e o eixo das ordenadas é referente à taxa de erro do melhor classificador componente do ensemble, ou seja, a taxa de erro do classificador componente que apresentou a menor taxa de erro. Os pontos que estão acima da linha diagonal indicam que o ensemble obteve melhor resultado que seu melhor classificador componente.

Com relação aos três métodos de combinação utilizados, i.e UV, WMV e WMSV, não foi observada diferença significativa entre eles para os conjuntos de dados utilizados. Deve ser observado que em todos os experimentos realizados, o algoritmo $\mathcal{C} 4.5$ foi utilizado com a opção de induzir árvores de decisão, as quais foram transformadas em regras if-then. Nos experimentos realizados nos cenários ScnI 2 e ScnI 5, nos quais todos os classificadores foram induzidos com $\mathcal{C} 4.5$, podem ser observados resultados idênticos entre os três métodos de combinação propostos para os conjuntos de dados Nursery e Chess - Tabelas 8.3 e 8.4. Ainda, para todos os conjunto de dados, os resultados mostram que, utilizando somente árvores de decisão para compor o ensemble, variar o método de combinação de classificadores dentre os três propostos não altera, ou altera muito pouco, a taxa de erro dos ensembles construídos com os métodos UV, WMV e WMSV. Esses resultados são esperados e ocorrem porque as regras que compõem uma árvore de decisão são disjuntas.

Deve ser observado que foram selecionadas as medidas de avaliação de regras utilizadas nos experimentos com base nas medidas utilizadas para 
construção de classificadores pelos algoritmos de indução conhecidos, e também por serem medidas que indicam de uma maneira mais adequada qual a melhor regra, das que cobrem um exemplo, que melhor poderia classificá-lo.

Nursery Dataset

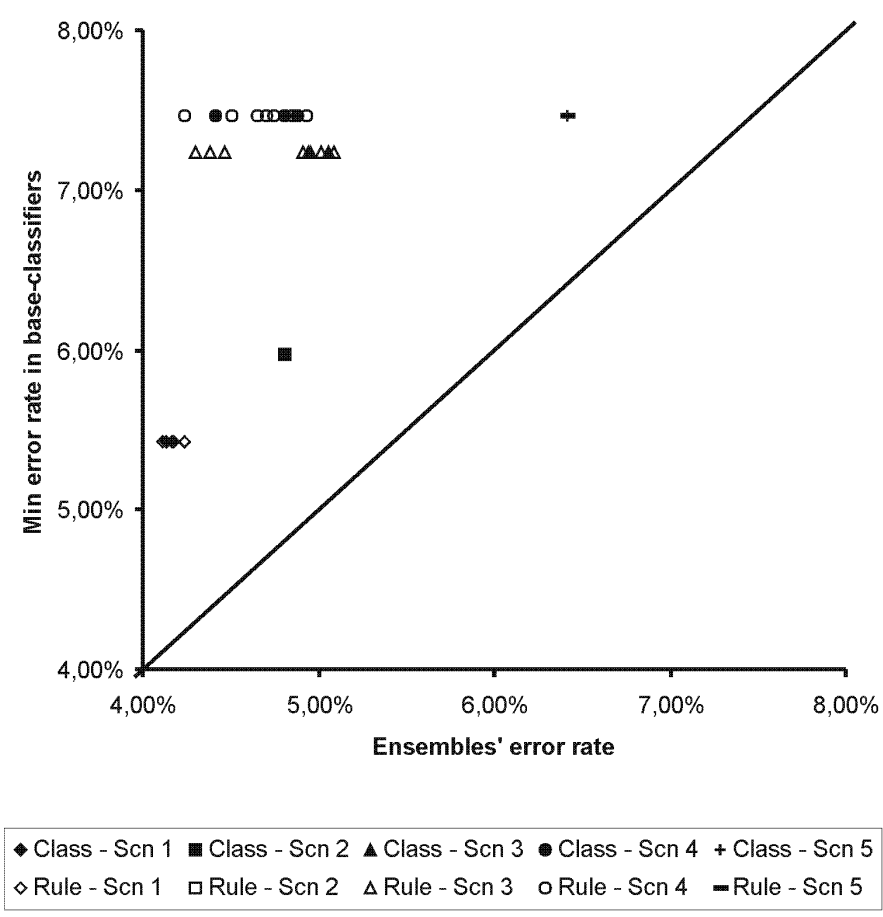

Figura 8.1: Gráfico dos resultados dos experimentos utilizando o conjunto de dados Nursery - Fase I de experimentos

\subsubsection{Avaliação da Performance do Algoritmo de Simplificação da Explicação}

Para avaliar a performance do algoritmo de simplificação de explicação, foi analisada a taxa de redução do número de regras entre o conjunto $\mathbf{A}_{\text {expl }}$ inicial e o conjunto $\mathbf{A}_{\text {expl }}$ final construído utilizando o Algoritmo 3 - Seção 4.4. 
Chess Dataset

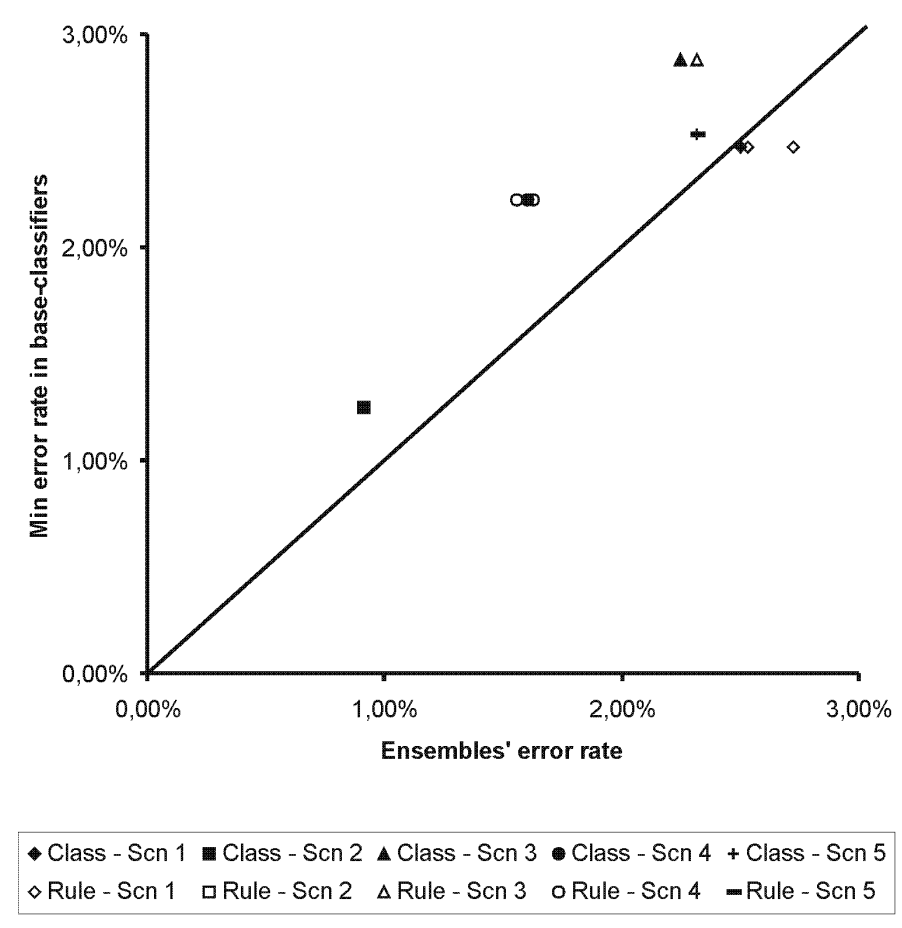

Figura 8.2: Gráfico dos resultados dos experimentos utilizando o conjunto de dados Chess - Fase I de experimentos

Esse conjunto final será denominado $\mathbf{A}_{\text {expl }}^{\prime}$. Dado um exemplo $\mathbf{x}$, a taxa de redução no número de regras entre o conjunto inicial $\mathbf{A}_{\text {expl }}(\mathbf{x})$ e o conjunto final $\mathbf{A}_{\text {expl }}^{\prime}(\mathbf{x})$ da explicação da classificação do exemplo $\mathbf{x}, T R(\mathbf{x})$, é definida pela Equação 8.1 .

$$
T R(\mathbf{x})=\frac{\left|\mathbf{A}_{\text {expl }}(\mathbf{x})\right|-\left|\mathbf{A}_{\text {expl }}^{\prime}(\mathbf{x})\right|}{\left|\mathbf{A}_{\text {expl }}(\mathbf{x})\right|} .
$$

Como mencionado, para construir os ensembles de classificadores, para cada um dos conjuntos de dados utilizados - Nursery, Chess e Splice foram construídos ensembles de classificadores para cada um dos cenários descritos na Tabela 8.2, utilizando como método de classificação de exemplos a decisão do próprio classificador, e como método de combinação os métodos UV, WMV e WMSV - Seção 4.3. Por exemplo, para o conjunto de dados Nursery, no cenário ScnI 1 foram retiradas 3 (três) amostras sem reposição do conjunto de dados, foram induzidos 3 (três) classificadores com o algoritmo $\mathcal{C N} 2$ utilizando cada amostra, e a combinação das decisões desses classificadores 


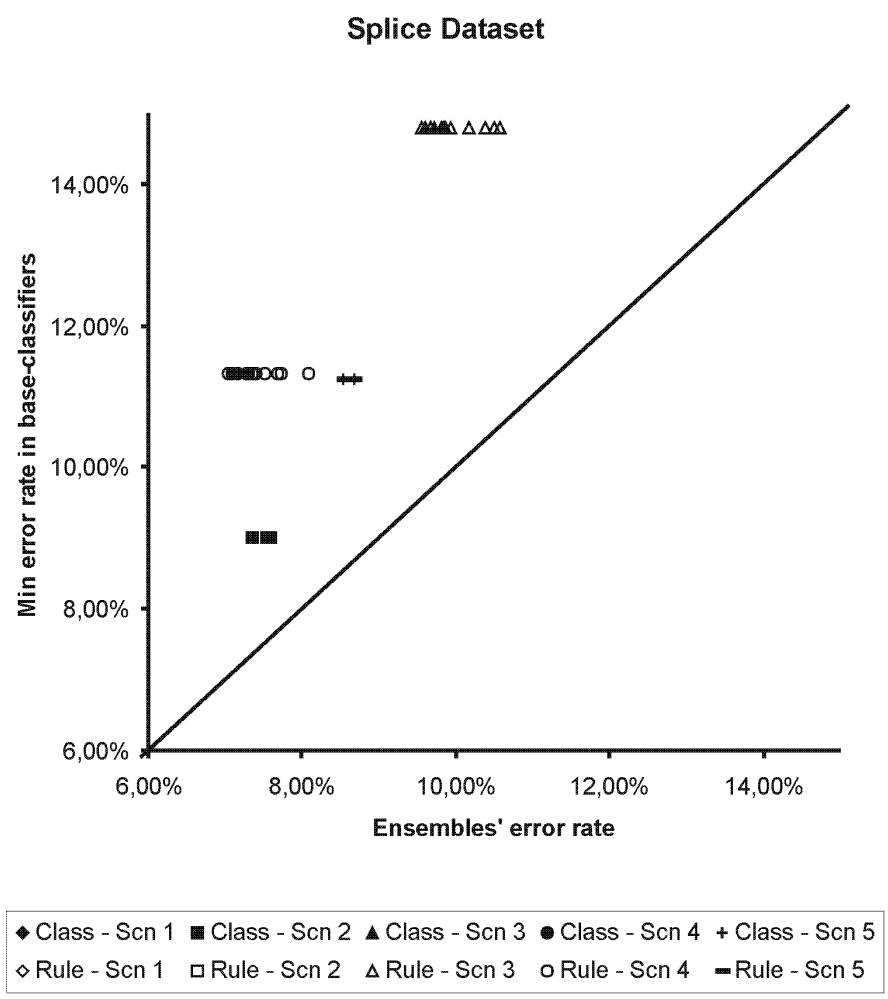

Figura 8.3: Gráfico dos resultados dos experimentos utilizando o conjunto de dados Splice - Fase I de experimentos

nos 3 (três) ensembles foi feita utilizando os métodos UV, WMV e WMSV. De maneira análoga, foram construídos os outros ensembles nos outros cenários utilizando os outros conjuntos de dados.

Para obter a média e o erro padrão da taxa de redução para cada ensemble construído, foram utilizadas as taxas de redução de cada exemplo nos conjuntos de dados Nursery, Chess e Splice. Nas Tabelas 8.6, 8.7 e 8.8 são mostrados, para cada conjunto de dados, os resultados obtidos nessa fase de simplificação. Especificamente, são mostrados o número médio de regras em $\mathbf{A}_{\text {expl }}$ e $\mathbf{A}_{\text {expl }}^{\prime}$ e o erro padrão correspondente, bem como a média da taxa de redução nesse conjunto de dados. No caso de resultados idênticos somente um valor é reportado.

Como pode ser observado, para todos os conjuntos de dados, o número médio de regras diferentes $\left|\mathbf{A}_{\text {expl }}\right|$ que cobrem um exemplo é sempre maior quando o algoritmo $\mathcal{C N} 2$ foi utilizado - cenários ScnI 1, com 3 (três) classificadores, e ScnI 3, com 5 (cinco) classificadores. O próximo maior número de regras diferentes encontra-se nos experimentos do cenário ScnI 4, no qual 


\begin{tabular}{c|c|c|c|c|c|c} 
& Mét. Comb. & ScnI 1 & ScnI 2 & ScnI 3 & ScnI 4 & ScnI 5 \\
\hline \multirow{2}{*}{$\left|\mathbf{A}_{\text {expl }}\right|$} & UV & & & $6.52(3.22)$ & $5.77(2.06)$ & \multirow{2}{*}{ WMV } \\
& WMSV & $4.04(2.20)$ & $2.92(0.26)$ & $6.51(3.24)$ & $5.77(2.08)$ & $4.78(0.55)$ \\
& & & $6.51(3.25)$ & $5.77(2.07)$ & \\
\hline \multirow{2}{*}{$\left|\mathbf{A}_{\text {expl }}^{\prime}\right|$} & UV & $1.70(1.11)$ & & $2.01(1.41)$ & & \\
& WMV & $1.69(1.12)$ & $1.17(0.38)$ & $2.00(1.42)$ & $1.80(1.16)$ & $1.16(0.40)$ \\
& WMSV & $1.69(1.12)$ & & $2.00(1.42)$ & & \\
\hline \multirow{2}{*}{$R R \%$} & UV & $58.19(16.19)$ & & $68.88(17.46)$ & $68.88(16.25)$ & \\
& WMV & $58.18(16.22)$ & $59.43(14.22)$ & $68.76(17.75)$ & $68.79(16.49)$ & $75.02(10.61)$ \\
& WMSV & $58.18(16.21)$ & & $68.77(17.39)$ & $68.92(16.15)$ & \\
\hline
\end{tabular}

Tabela 8.6: Resultados obtidos utilizando o conjunto de dados Nursery na fase de simplificação de explicação — Fase I de experimentos

\begin{tabular}{c|c|c|c|c|c|c} 
& Mét. Comb. & ScnI 1 & ScnI 2 & ScnI 3 & ScnI 4 & ScnI 5 \\
\hline$\left|\mathbf{A}_{\text {expl }}\right|$ & UV, WMV e WMSV & $4.22(2.19)$ & $2.99(0.09)$ & $7.18(3.50)$ & $6.14(1.97)$ & $4.92(0.36)$ \\
\hline$\left|\mathbf{A}_{\text {expl }}^{\prime}\right|$ & UV, WMV e WMSV & $1.91(1.16)$ & $1.05(0.22)$ & $2.48(1.68)$ & $2.83(1.51)$ & $1.06(0.29)$ \\
\hline$R R \%$ & UV, WMV e WMSV & $52.46(19.93)$ & $64.89(7.43)$ & $63.52(20.95)$ & $53.73(21.23)$ & $77.98(9.83)$ \\
\hline
\end{tabular}

Tabela 8.7: Resultados obtidos utilizando o conjunto de dados Chess na fase de simplificação de explicação - Fase I de experimentos

\begin{tabular}{|c|c|c|c|c|c|c|}
\hline & Mét. Comb. & ScnI 1 & ScnI 2 & ScnI 3 & ScnI 4 & ScnI 5 \\
\hline \multirow{3}{*}{$\left|\mathbf{A}_{\text {expl }}\right|$} & UV & & & $7.07(3.54)$ & $6.09(2.54)$ & \multirow{3}{*}{$4.69(0.64)$} \\
\hline & WMV & 4.69 (2.99) & $2.89(0.31)$ & 7.07 (3.54) & $6.10(2.51)$ & \\
\hline & WMSV & & & 7.06 (3.55) & $6.10(2.51)$ & \\
\hline \multirow{3}{*}{$\left|\mathbf{A}_{\text {expl }}^{\prime}\right|$} & UV & \multirow{3}{*}{$3.84(2.34)$} & \multirow{3}{*}{$1.52(0.61)$} & $5.53(2.77)$ & $4.63(2.03)$ & \multirow{3}{*}{$1.83(0.88)$} \\
\hline & WMV & & & $5.54(2.76)$ & $4.64(2.01)$ & \\
\hline & WMSV & & & $5.53(2.77)$ & $4.64(2.01)$ & \\
\hline \multirow{3}{*}{$R R \%$} & UV & \multirow{3}{*}{14.07 (14.57) } & \multirow{3}{*}{46.79 (21.89) } & $17.93(18.94)$ & $22.65(15.40)$ & \multirow{3}{*}{$59.39(22.21)$} \\
\hline & WMV & & & $17.91(18.94)$ & 22.67 (15.39) & \\
\hline & WMSV & & & 17.93 (18.94) & 22.67 (15.39) & \\
\hline
\end{tabular}

Tabela 8.8: Resultados obtidos utilizando o conjunto de dados Splice na fase de simplificação de explicação — Fase I de experimentos 
$\mathcal{C N} 2$ foi utilizado para induzir 3 (três) dos 5 (cinco) classificadores utilizados nos experimentos desse cenário. Outro aspecto a ser observado é que, para cada conjunto de dados, o número médio de regras diferentes $\left|\mathbf{A}_{\text {expl }}\right|$, bem como o número médio de regras após a simplificação $\left|\mathbf{A}_{\text {expl }}^{\prime}\right|$, lembrando que $\mathbf{A}_{\text {expl }}^{\prime}$ é o conjunto de regras utilizado para fornecer ao usuário a explicação da classificação, são praticamente idênticos para cada cenário e método de combinação utilizado. A máxima taxa de redução, para todos os conjuntos de dados, corresponde ao ScnI 5: $75.02 \%$ para o conjunto de dados Nursery; $77.98 \%$ para o conjunto de dados Chess; e 59.42\% para o conjunto de dados Splice. Nesse cenário ScnI 5, é utilizado o algoritmo $\mathcal{C} 4.5$ para induzir os cinco classificadores (árvores de decisão), portanto, como as regras são disjuntas, no máximo uma regra de cada classificador pode classificar corretamente esse exemplo. Considerando a elevada taxa de redução das regras no conjunto final $\mathbf{A}_{\text {expl }}^{\prime}$, pode-se concluir que várias das regras no conjunto $\mathbf{A}_{\text {expl }}$ são simplesmente especializações de outras regras também em $\mathbf{A}_{\text {expl }}$. Como esperado, quando o algoritmo $\mathcal{C N} 2$ é utilizado, o número de regras em $\mathbf{A}_{\text {expl }}$ é sempre maior que o número de classificadores utilizados - ScnI 1, ScnI 3 e ScnI 4. Quanto à taxa de redução nesses cenários, ela foi sempre a mínima no cenário ScnI 1: $58.18 \%$ para o conjunto de dados Nursery; $52.46 \%$ para o conjunto de dados Chess; e 14.07\% para o conjunto de dados Splice. Quanto aos outros dois cenários nos quais o algoritmo $\mathcal{C N} 2$ também é utilizado, a taxa de redução varia dependendo do conjunto de dados utilizado.

\subsection{Descrição dos Experimentos - Fase II}

Nesta fase, foram utilizados conjuntos de dados de menor porte devido ao tempo de execução dos experimentos utilizando 10-fold cross-validation para avaliar o algoritmo genético, variando-se as funções de avaliação e os critérios de parada propostos ${ }^{1}$. Os conjuntos de dados da UCI utilizados nesta fase de experimentos foram Autos, Balance (Balance-scale ${ }^{2}$ ), Heart e Ionosphere. Na Tabela 8.9 são descritas as principais características desses conjuntos de

\footnotetext{
${ }^{1}$ Deve ser observado que, para obter os resultados experimentais para os quatro conjuntos de dados utilizando todas as funções de avaliação propostas, os diferentes cenários de experimentos e a validação dos resultados, o algoritmo genético foi executado mais de 4000 vezes.

${ }^{2}$ Foi utilizada uma versão modificada do conjunto de dados original removendo exemplos pertencentes à classe $\mathrm{B}$, já que essa classe, no conjunto de dados original, possui somente $7,84 \%$ do número de exemplos, ou seja, 49 exemplos, o que introduz o problema adicional de classes desbalanceadas (Batista et al., 2005, 2004).
} 
dados: número de exemplos (\# Ex.); número de atributos (contínuos, discretos) (\# Atr.); distribuição de exemplos nas classes (Classe \%); erro majoritário dos conjuntos de dados; presença ou ausência de valores desconhecidos (Val. Desc?); número de exemplos duplicados ou conflitantes.

\begin{tabular}{|c|c|c|c|c|c|c|c|}
\hline $\begin{array}{c}\text { Conj. de } \\
\text { Dados }\end{array}$ & \# Ex. & $\begin{array}{l}\text { \# Atributos } \\
\text { (cont.,disc.) }\end{array}$ & Classe & Classe \% & $\begin{array}{c}\text { Erro } \\
\text { Majoritário }\end{array}$ & $\begin{array}{c}\text { Val. } \\
\text { Desc? }\end{array}$ & $\begin{array}{c}\text { Exemplos } \\
\text { Dup./Conf }\end{array}$ \\
\hline Autos & 205 & $25(15,10)$ & $\begin{array}{l}\text { safe } \\
\text { risky }\end{array}$ & $\begin{array}{l}44.88 \% \\
52.12 \%\end{array}$ & $\begin{array}{l}44.88 \% \\
\text { em risky }\end{array}$ & $\mathrm{Y}$ & $\begin{array}{c}0 \\
(0.00 \%)\end{array}$ \\
\hline Balance & 576 & $4(0,4)$ & $\begin{array}{l}\mathrm{L} \\
\mathrm{R}\end{array}$ & $\begin{array}{l}46.08 \% \\
46.08 \% \\
\end{array}$ & $\begin{array}{c}53.92 \% \\
\text { em L }\end{array}$ & $\mathrm{N}$ & $\begin{array}{c}0 \\
(0.00 \%)\end{array}$ \\
\hline Heart & 270 & $13(5,8)$ & $\begin{array}{l}1 \\
2\end{array}$ & $\begin{array}{l}55.56 \% \\
44.44 \%\end{array}$ & $\begin{array}{c}44.44 \% \\
\text { em } 1\end{array}$ & $\mathrm{Y}$ & $\begin{array}{c}0 \\
(0.00 \%)\end{array}$ \\
\hline Ionosphere & 351 & $33(33,0)$ & $\begin{array}{l}\text { good } \\
\text { bad }\end{array}$ & $\begin{array}{l}64.10 \% \\
35.90 \%\end{array}$ & $\begin{array}{l}35.90 \% \\
\text { em good }\end{array}$ & $\mathrm{N}$ & $\begin{array}{c}1 \\
(0.28 \%)\end{array}$ \\
\hline
\end{tabular}

Tabela 8.9: Resumo das características dos conjuntos de dados utilizados na Fase II de experimentos

\subsubsection{Avaliação da Performance do Algoritmo Genético}

Para avaliar a performance do algoritmo genético proposto e comparar sua performance à performance dos métodos de construção de ensembles também propostos, diversos experimentos foram realizados utilizando os algoritmos de aprendizado simbólico $\mathcal{C} \mathcal{N} 2$ (Clark and Niblett, 1989), $\mathcal{C} 4.5$ e $\mathcal{C} 4.5$ rules (Quinlan, 1988) para induzir os classificadores que:

1. são classificadores componentes dos ensembles; e

2. são utilizados tanto para compor a base de regras do AG quanto como indivíduos da população inicial do AG.

Com o objetivo de comparar a performance de classificadores evoluídos utilizando o algoritmo genético com os métodos de construção de ensembles de classificadores propostos, foram construídos ensembles de três classificadores simbólicos induzidos utilizando os algoritmos $\mathcal{C N} 2, \mathcal{C} 4.5$ e $\mathcal{C} 4.5$ rules, utilizando cada uma das bases de dados. Esses classificadores foram induzidos utilizando o conjunto de dados como única amostra. Foram realizadas as estimativas de erro utilizando 10 -fold cross-validation implementado para avaliação de ensembles de classificadores - Seção 5.1 -, cujos resultados são mostrados na Tabela 8.10. Nessa tabela, na primeira linha encontram-se os nomes dos conjuntos de dados utilizados; na segunda linha, o erro majoritário de cada um dos conjuntos de dados; nas linhas a seguir, as taxas 
de erro e erro padrão entre parênteses obtidos pelos classificadores induzidos com os algoritmos $\mathcal{C} \mathcal{N} 2, \mathcal{C} 4.5$ rules e $\mathcal{C} 4.5$, respectivamente; e nas demais linhas, a estimativa do erro e erro padrão entre parênteses dos ensembles construídos com esses três classificadores, utilizando os diferentes métodos propostos para classificar exemplos. Utilizando o teste $t$ de hipóteses, foi verificado que não há melhoria significativa na taxa de erro dos ensembles de classificadores quando comparada à taxa de erro do melhor classificador, i.e., com a menor taxa de erro, que compõe o ensemble.

\begin{tabular}{l|c|c|c|c} 
& Autos & Balance & Heart & Ionosphere \\
\hline \hline EM & 44.88 & 53.92 & 44.44 & 35.90 \\
\hline $\mathcal{C N} 2$ & 12.14 & 15.11 & 22.22 & 8.25 \\
& $(3.29)$ & $(1.55)$ & $(2.82)$ & $(1.15)$ \\
$\mathcal{C} 4.5$ rules & 9.14 & 15.12 & 21.11 & 10.52 \\
$\mathcal{C} 4.5$ & $(3.22)$ & $(1.71)$ & $(2.28)$ & $(1.73)$ \\
& 8.69 & 28.48 & 22.96 & 11.08 \\
& $(2.95)$ & $(1.61)$ & $(3.16)$ & $(1.68)$ \\
\hline \hline UV-Acc & 8.17 & 15.97 & 20.74 & 11.37 \\
& $(2.84)$ & $(1.77)$ & $(2.66)$ & $(1.76)$ \\
UV-Class & 16.48 & 15.46 & 21.11 & 10.51 \\
& $(3.00)$ & $(1.82)$ & $(2.82)$ & $(1.96)$ \\
UV-Lacc & 10.62 & 15.81 & 20.74 & 10.22 \\
& $(3.47)$ & $(1.76)$ & $(2.77)$ & $(1.92)$ \\
\hline WMV-Acc & 8.17 & 15.97 & 20.74 & 11.37 \\
& $(2.84)$ & $(1.77)$ & $(2.66)$ & $(1.76)$ \\
WMV-Class & 16.48 & 15.46 & 21.11 & 10.51 \\
& $(3.00)$ & $(1.82)$ & $(2.82)$ & $(1.96)$ \\
WMV-Lacc & 10.62 & 15.81 & 20.74 & 10.22 \\
& $(3.47)$ & $(1.76)$ & $(2.77)$ & $(1.92)$ \\
\hline WMSV-Acc & 8.17 & 15.97 & 20.74 & 11.37 \\
& $(2.84)$ & $(1.77)$ & $(2.66)$ & $(1.76)$ \\
WMSV-Class & 16.48 & 15.46 & 21.11 & 10.51 \\
& $(3.00)$ & $(1.82)$ & $(2.82)$ & $(1.96)$ \\
WMSV-Lacc & 10.62 & 15.81 & 20.74 & 10.22 \\
& $(3.47)$ & $(1.76)$ & $(2.77)$ & $(1.92)$
\end{tabular}

Tabela 8.10: Resultados obtidos na Fase de Experimentos II utilizando os métodos de construção de ensembles propostos - Fase II de experimentos

Já nos experimentos para execução do AG, além dos classificadores induzidos pelos algoritmos $\mathcal{C N} 2, \mathcal{C} 4.5$ e $\mathcal{C} 4.5$ rules, também foram utilizadas regras construídas pelo $\mathcal{A}$ priori que podem ser vistas como regras de classificação para compor a base de regras ${ }^{3}$. Foram, então, utilizados 6 (seis) cenários diferentes para realização desses experimentos com os AGs. A diferença entre cada cenário está na variação do critério de parada do AG e na utilização ou não de regras do Apriori para compor a base de regras, como é mostrado na Tabela 8.11. Por exemplo, no primeiro cenário (ScnII 1), é utilizado o critério

\footnotetext{
${ }^{3}$ Deve ser observado que o algoritmo de construção de regras de associação $\mathcal{A}$ priori trabalha somente com atributos discretos. Neste trabalho, no caso de atributos contínuos, os mesmos são discretizados e, após obtidas as regras com o $\mathcal{A}$ priori, essas regras são re-escritas utilizando os operadores de desigualdade. Para discretizar os algoritmos, foi utilizado o algoritmo de discretização não-supervisionado, implementado no ambiente $\mathcal{W}$ eka (Witten and Frank, 2005).
} 
de parada NumGen - o AG pára de executar quando um número máximo de iterações é atingido - , e não são utilizadas regras do $\mathcal{A}$ priori na base de regras; e no quarto cenário (ScnII 4), é utilizado o critério de parada Converge - ou seja, o AG pára de executar quando a função de avaliação do melhor indivíduo não melhorar nas últimas $N_{\text {gen }}$ gerações - , e são utilizadas regras do $\mathcal{A}$ priori na base de regras.

\begin{tabular}{c|c|c} 
Cenário & Crit. Parada AG & Utiliza Apriori? \\
\hline ScnII 1 & NumGen & Não \\
ScnII 2 & NumGen & Sim \\
ScnII 3 & Converge, $N_{\text {gen }}=5$ & Não \\
ScnII 4 & Converge, $N_{\text {gen }}=5$ & Sim \\
ScnII 5 & Converge, $N_{\text {gen }}=10$ & Não \\
ScnII 6 & Converge, $N_{\text {gen }}=10$ & Sim
\end{tabular}

Tabela 8.11: Descrição dos cenários utilizados para realização dos experimentos com o AG na fase II

Como mencionado, em todos os experimentos, as regras individuais que participam dos classificadores induzidos por $\mathcal{C N} 2, \mathcal{C} 4.5$ e $\mathcal{C} 4.5$ rules foram utilizadas para compor a base de regras, a qual fornece regras para a construção dos indivíduos do AG. Além disso, nos experimentos realizados incluímos três indivíduos que correspondem aos classificadores induzidos por esses algoritmos. Utilizar esses classificadores como classificadores (indivíduos) iniciais no AG permite que:

1. o processo de busca do AG inicialize a busca por regiões provavelmente próxima a boas soluções, agilizando assim esse processo; e

2. tais classificadores (indivíduos) possam ser utilizados para comparação com os resultados obtidos com o AG.

Nas Figuras 8.4 a 8.11 , são resumidos os resultados os resultados obtidos nos experimentos realizados utilizando o algoritmo genético proposto. Nessas figuras, a linha contínua mostra o erro do melhor classificador, o qual é um dos indivíduos da população inicial do AG; a linha tracejada mostra o erro majoritário do conjunto de exemplos. Tais resultados foram obtidos para cada um dos cenários ScnII 1 a ScnII 6, variando os conjuntos de dados em cada cenário. Os resultados obtidos (média do erro e erro padrão do erro) são descritos com mais detalhes no Anexo B. Nessas figuras, pode ser observado que nem todas as execuções do AG variando as funções de avaliação 
oferecem bons resultados, entretanto, quando é conseguida uma melhoria nos resultados, a taxa de melhoria é significativa. Mais especificamente, vários resultados utilizando os métodos de classificação $M R$ (Multiple Rule) mostram que o classificador evoluído é melhor que o melhor classificador que participa da população inicial. Entretanto, o classificador evoluído pelo AG utilizando os métodos de classificação $S R$ (Single Rule) não apresenta bons resultados Figuras 8.8 a 8.11. O mesmo aconteceu quando utilizamos como método de classificação a melhor regra segundo uma medida de avaliação de regra nos experimentos realizados de construção de ensembles de classificadores. Por outro lado, analisando as taxas de erro de cada classe, observou-se que para alguns conjuntos de dados a taxa de erro em uma dada classe é $0.00 \%$. Ou seja, há uma preferência do AG para cobrir bem uma classe em detrimento das outras. Este aspecto do método de classificação $S R$ deverá ser melhor pesquisado no futuro. A seguir, analisamos os resultados obtidos pelo método de classificação $M R$ (Multiple Rule).

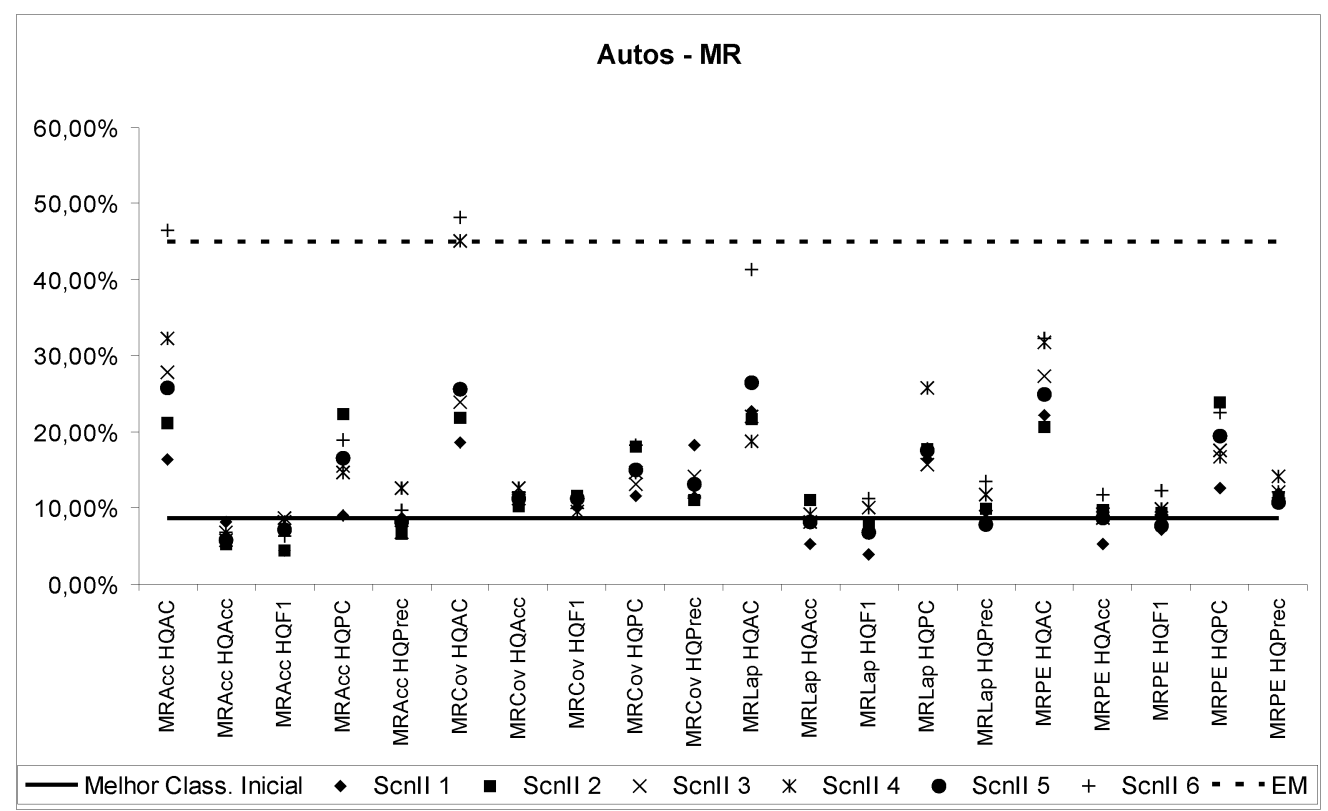

Figura 8.4: Gráfico dos resultados dos experimentos utilizando o conjunto de dados Autos e métodos de classificação $M R$ - Fase II de experimentos

Ainda, nesses experimentos foram calculados os tempos de execução do algoritmo genético para as seguintes duas tarefas:

1. inicialização da base de regras, cálculo das matrizes de contingência de cada regra utilizando o conjunto de treinamento e inicialização de 


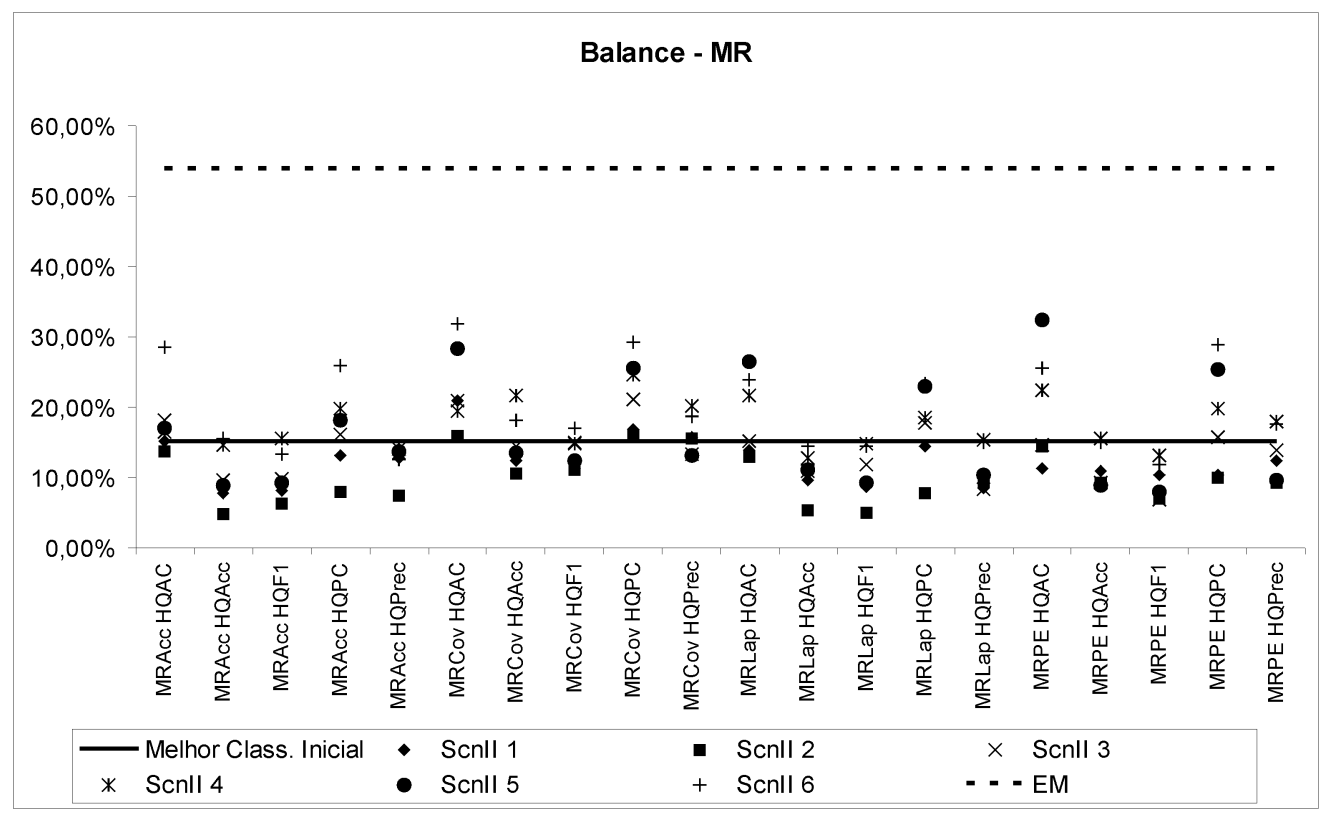

Figura 8.5: Gráfico dos resultados dos experimentos utilizando o conjunto de dados Balance e métodos de classificação $M R$ - Fase II de experimentos

parâmetros do algoritmo genético quando necessário - por exemplo, se o usuário não especificar o número de regras em cada indivíduo, é calculada a média do número de regras nos classificadores iniciais dado como entrada, sendo o valor absoluto dessa média utilizado como número de regras de cada indivíduo;

2. execução do algoritmo genético, a qual é composta pelo conjunto completo de iterações.

Em média, o tempo gasto para a tarefa 1 foi de 10 segundos, e para a tarefa 2 , o tempo médio foi de 1 minuto. Algumas execuções dessas tarefas levaram tempos maiores, mas como o tempo gasto para a tarefa 2 foi maior quando também foi maior o tempo gasto para a tarefa 1 - por exemplo, em uma execução, o tempo gasto para a tarefa 2 foi de 38 minutos e o tempo gasto para a tarefa 1 foi de 2 minutos - , atribuímos esses tempos maiores a uma possivel sobrecarga da máquina onde os processos estavam sendo executados. Consideramos, assim, a performance do algoritmo genético muito boa em termos de tempo de execução.

Foi utilizado o teste $t$ para realizar a comparação dos resultados obtidos nos experimentos utilizado o AG com a taxa de erro do melhor classificador na 


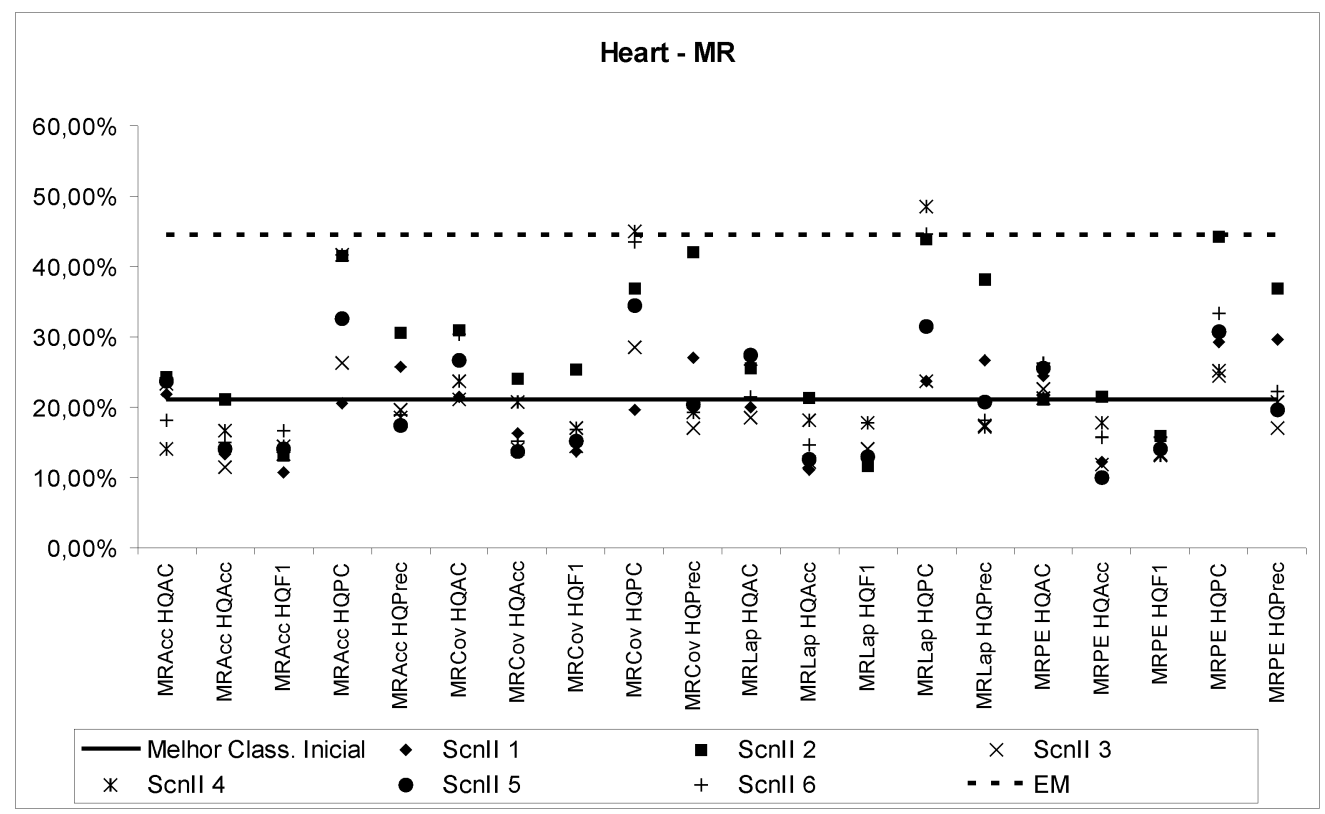

Figura 8.6: Gráfico dos resultados dos experimentos utilizando o conjunto de dados Heart e métodos de classificação $M R$ - Fase II de experimentos

população inicial, ou seja, do classificador inicial com menor taxa de erro. Na Tabela 8.12, são mostrados graficamente os resultados obtidos com o teste $t$ nos 420 experimentos realizados. Nessa tabela, uma célula contendo o símbolo “ム” indica que há melhoria significativa com 95\% de confiança no resultado do $\mathrm{AG}$ em relação ao melhor classificador da população inicial; uma célula contendo o símbolo " $\triangle$ " indica que há melhoria no resultado do AG em relação ao melhor classificador da população inicial, mas a diferença não é significativa; uma célula contendo o símbolo “ $\Downarrow$ ” indica que há piora significativa com 95\% de confiança no resultado do AG em relação ao melhor classificador da população inicial; e uma célula contendo o símbolo “ $\downarrow$ ” indica que há piora no resultado do AG em relação ao melhor classificador da população inicial, mas a diferença não é significativa.

Considerando os resultados com todos os conjuntos de dados, é possível observar que em todos os casos, as melhores funções de avaliação foram a $H Q_{A c c}$, que utiliza a medida de precisão $A c c(\mathbf{h})$ para avaliar um classificador - Equação 2.2 - e a $H Q_{F 1}$, que utiliza a medida $F 1(\mathbf{h})$ para avaliar um classificador - Equação 2.6. Para essas funções de avaliação, somente foram observados dois resultados no qual o classificador evoluído é significativamente pior que o melhor classificador inicial, sendo mais especificamente os resultados utilizando o conjunto de dados Balance e o método $H Q_{A c c}$, nos 


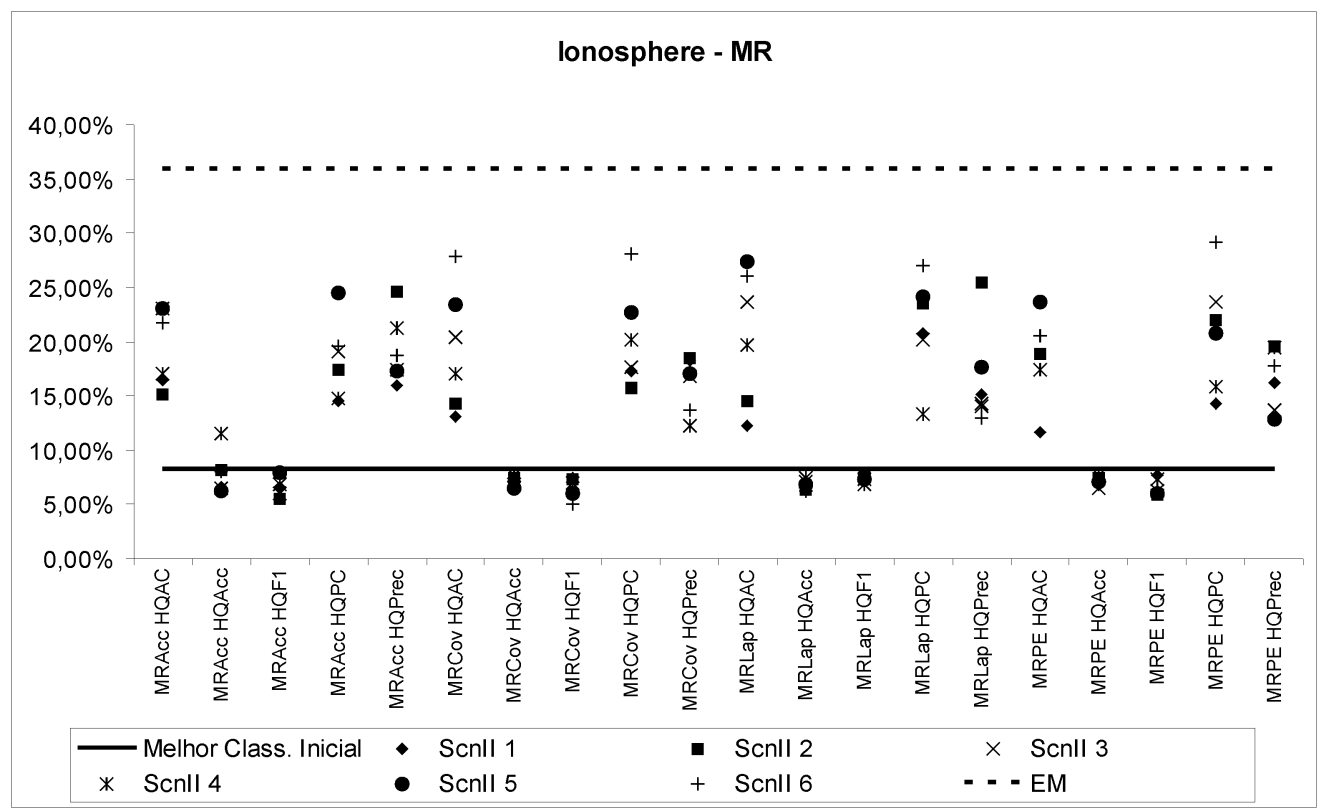

Figura 8.7: Gráfico dos resultados dos experimentos utilizando o conjunto de dados Ionosphere e métodos de classificação $M R$ - Fase II de experimentos

cenários ScnII 4 e ScnII 6. Para todos os outros experimentos nos quais os métodos $H Q_{A c c}$ e $H Q_{F 1}$ foram utilizados (190 experimentos, que representam $34.6 \%$ do total de 480 experimentos), não foi observado nenhum resultado tal que o classificador evoluído fosse significativamente pior que o classificador inicial. Também, considerando somente os resultados obtidos com $H Q_{A c c}$ e $H Q_{F 1}$, é possivel observar que os melhores entre eles foram os obtidos com os métodos $M R_{A c c}$ e $M R_{P E}$. Lembrando, $M R_{A c c}$ soma, para cada classe, o valor da medida de precisão de regra $(A c c)$ - Equação A. 1 - de cada regra que cobre o exemplo a ser classificado, e classifica o exemplo com a classe que apresentar maior somatório; e $M R_{P E}$, analogamente, soma, para cada classe, o valor de um índice de precisão menos erro $P E$ - Equação 6.6 - de cada regra que cobre o exemplo a ser classificado, e classifica o exemplo com a classe que apresentar maior somatório.

Quanto aos resultados obtidos com cada conjunto de dados e cenário, os resultados variam. O melhor caso foi atingido pelo conjunto de dados Balance no cenário ScnII 2, que obteve $14 \Delta, 3 \Delta$ e $3 \downarrow$; o segundo melhor caso foi também com esse conjunto de dados no cenário ScnII 1: $10 \Delta, 6 \Delta, 3 \downarrow$ e $1 \Downarrow$; enquanto que o terceiro melhor caso foi atingido pelo conjunto de dados Heart no cenário ScnII 3: $8 \Delta, 5 \Delta, 6 \downarrow$ e $1 \Downarrow$. 


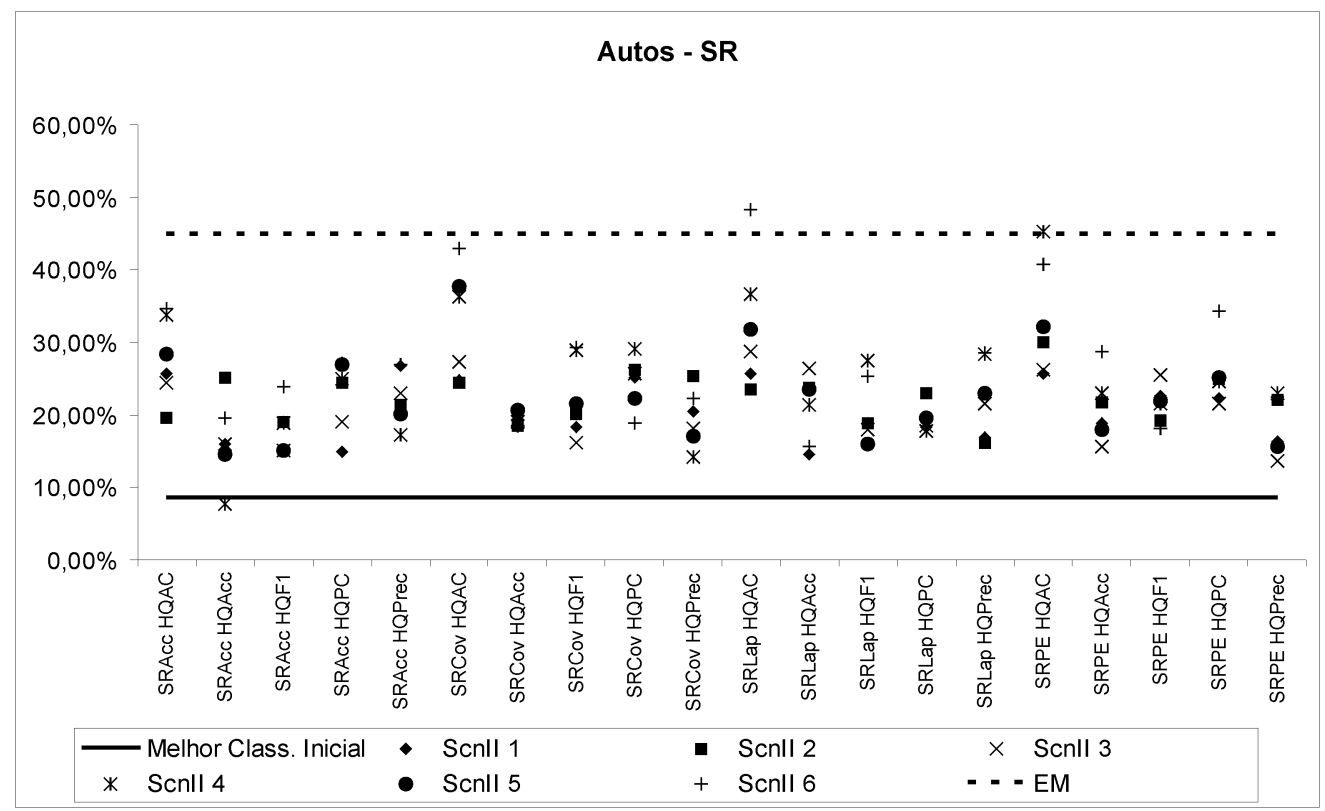

Figura 8.8: Gráfico dos resultados dos experimentos utilizando o conjunto de dados Autos e métodos de classificação $S R$ - Fase II de experimentos

Considerando os resultados globais de cada conjunto de dados em todos os cenários, é possivel observar que os resultados com Balance foram os melhores, seguidos por Heart, Autos e finalmente Ionosphere. Cada uma dessas duas últimas bases de dados apresentam somente um resultado (dentre os 120 resultados possíveis para cada uma) em que o classificador evoluído é significativamente melhor que o melhor classificador inicial. Para o conjunto de dados Autos, em 41 dos 120 casos (34,2\%), o classificador evoluído foi significativamente pior que o melhor classificador inicial. Para Ionosphere esse resultado deu-se em 71 casos (aproximadamente 60\% dos 120 casos). Observando as características dos conjuntos de dados — Tabela $8.9-$, pode ser notado que Autos e Ionosphere são as bases de dados descritas por um maior número de atributos: 25 atributos para Autos, sendo 15 contínuos e 10 discretos, e 33 atributos todos contínuos para Ionosphere. Porém, considerando o resultado absoluto de todos os experimentos realizados, o melhor resultado foi atingido com a base de dados Autos, cenário ScnII 1, função de avaliação $M R_{\text {Lacc }} H Q_{F 1}$ - Tabela B.1 —, cujo modelo evoluído é mostrado adiante. Assim, uma possível explicação para o mal desempenho do conjunto de dados Ionosphere pode ser o elevado número de atributos contínuos. Esse aspecto deverá ser melhor pesquisado no futuro. 


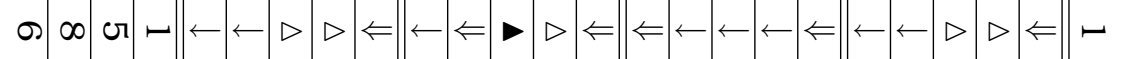
$\infty \infty \triangleright 0 \leftarrow \Leftarrow \leftarrow \leftarrow \Leftarrow \leftarrow \leftarrow \triangleright \leftarrow \Leftarrow \leftarrow \Leftarrow \leftarrow \leftarrow \leftarrow \triangleright \leftarrow \triangleright \triangleright \downarrow \leftarrow)$ $\infty \infty \triangleright \circ \leftarrow \leftarrow \leftarrow \leftarrow \leftarrow \leftarrow \leftarrow \triangleright \triangleright \leftarrow \Leftarrow \leftarrow \leftarrow \leftarrow \leftarrow \triangleright \leftarrow \leftarrow \triangleright \leftarrow) \omega$

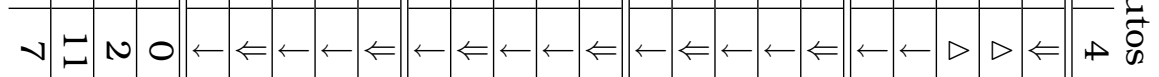

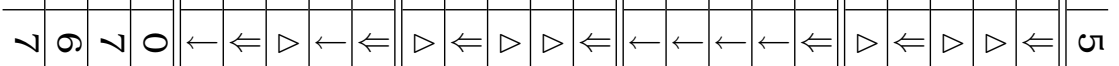

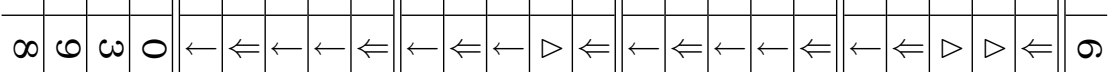

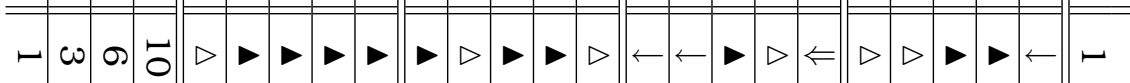

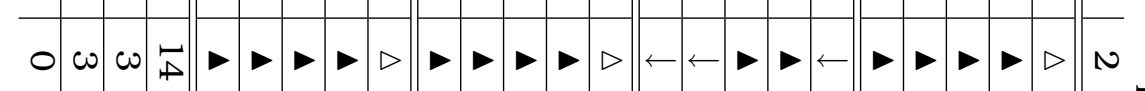

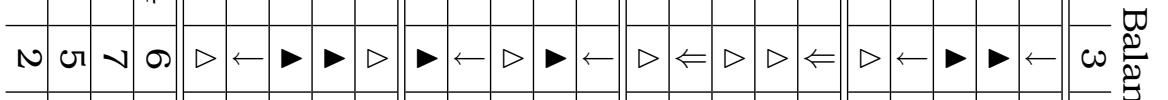
$の \infty \odot \circ \leftarrow \leftarrow \triangleright \leftarrow \Leftarrow \leftarrow \leftarrow \triangleright \triangleright \Leftarrow \Leftarrow \Leftarrow \triangleright \Leftarrow \Leftarrow \triangleright \leftarrow \leftarrow \triangleright \leftarrow \triangleright \varnothing \varnothing$

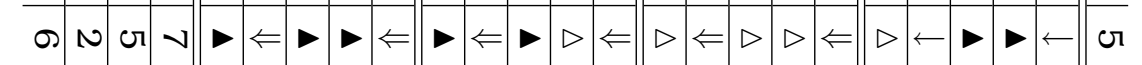
$\bullet \triangleright \vee 0 \leftarrow \Leftarrow \triangleright \triangleright \Leftarrow \triangleright \Leftarrow \triangleright \triangleright \Leftarrow \leftarrow \Leftarrow \leftarrow \Leftarrow \Leftarrow \triangleright \Leftarrow \triangleright \leftarrow \Leftarrow \sigma$

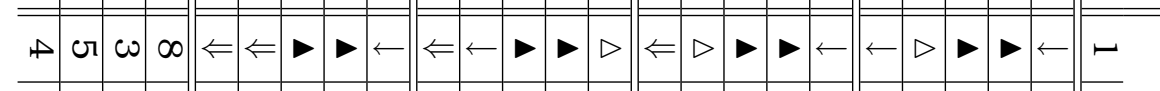

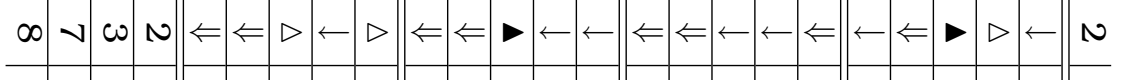

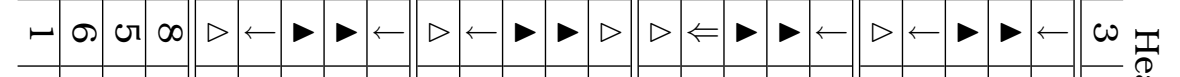

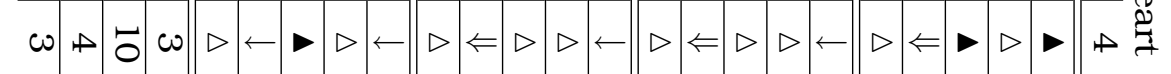

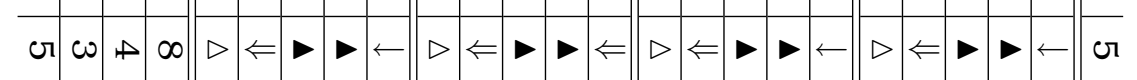
ज $\omega \vee v \leftarrow \leftarrow \triangleright \triangleright \leftarrow \triangleright \Leftarrow \triangleright \triangleright \leftarrow \triangleright \Leftarrow \triangleright \triangleright \Leftarrow \triangleright \Leftarrow \triangleright \triangleright \triangleright \mid \bar{\sigma}$

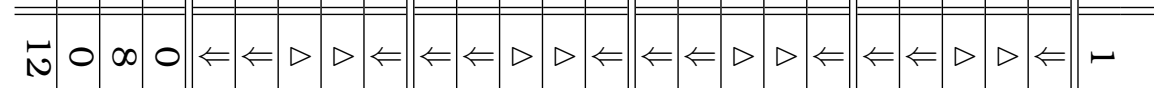

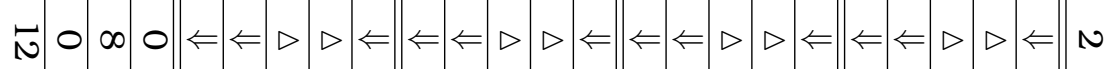

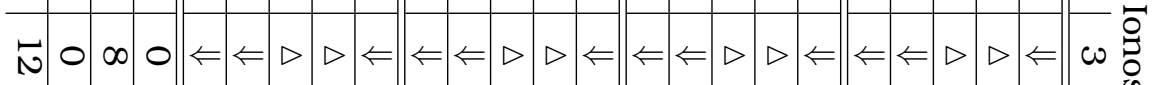

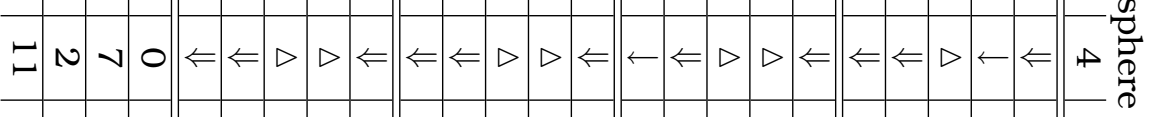

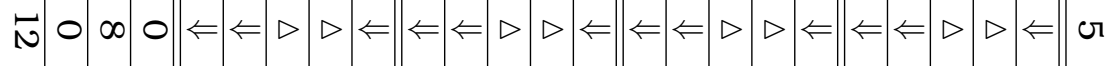

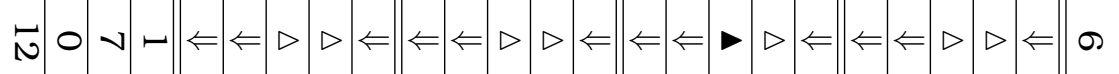

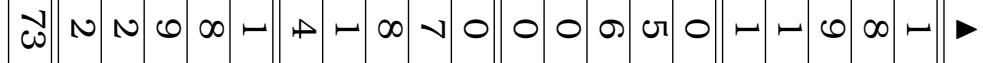

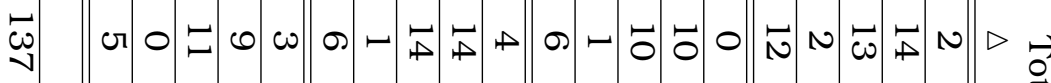




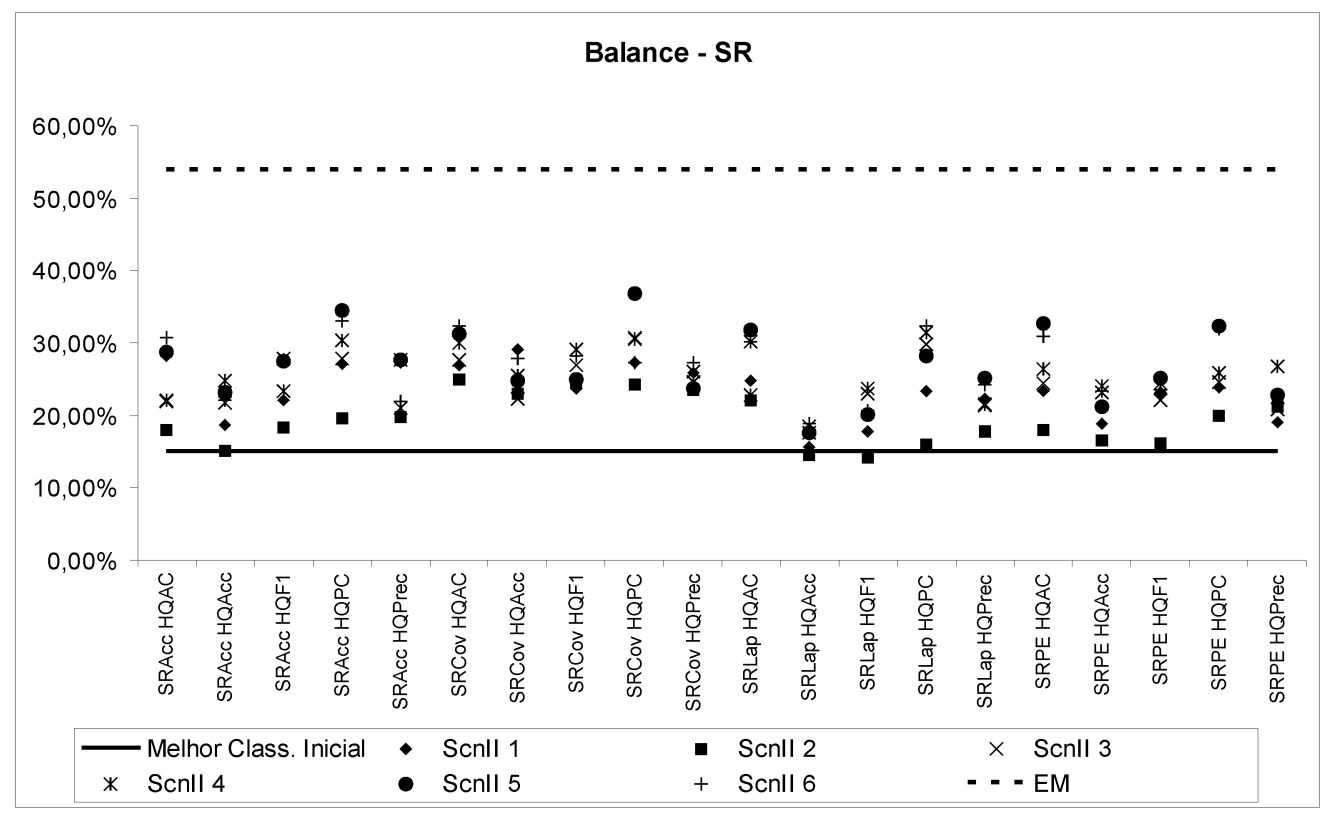

Figura 8.9: Gráfico dos resultados dos experimentos utilizando o conjunto de dados Balance e métodos de classificação $S R$ - Fase II de experimentos

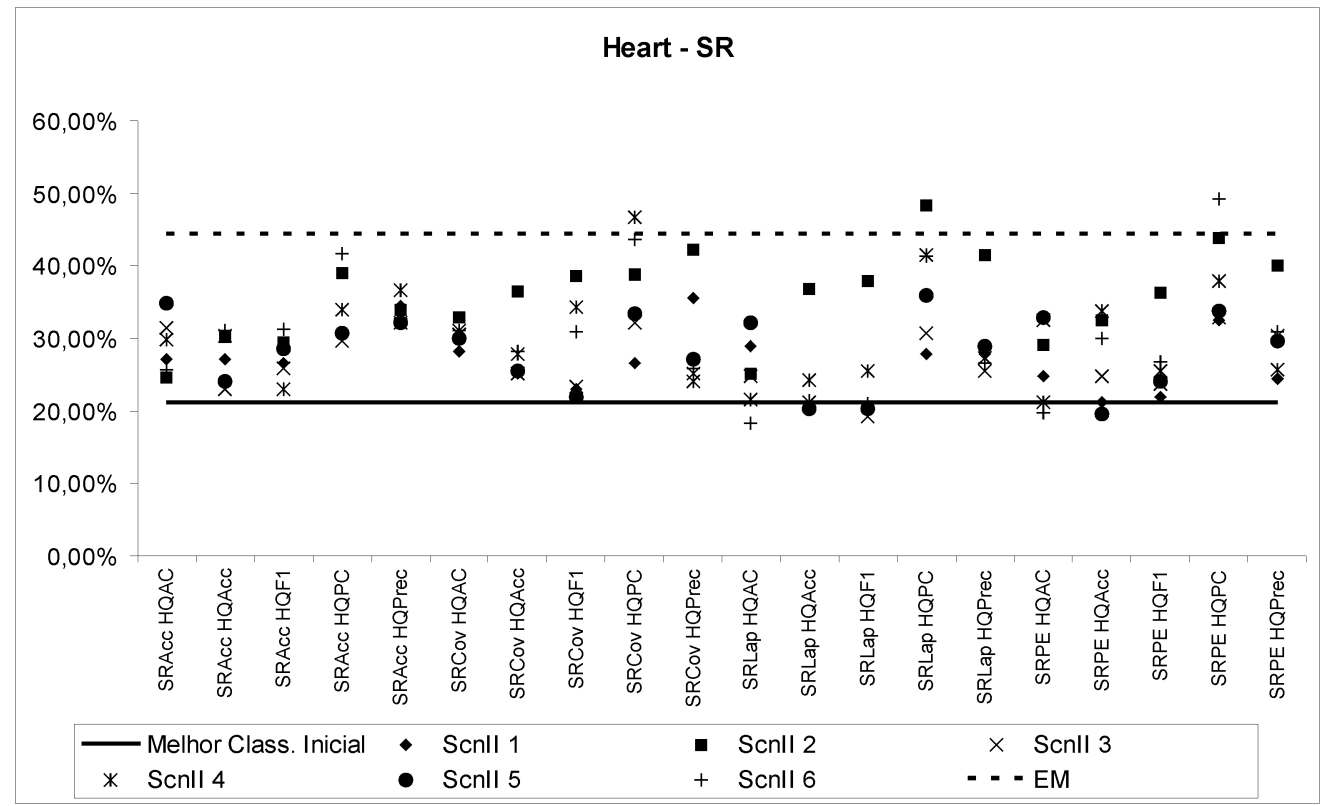

Figura 8.10: Gráfico dos resultados dos experimentos utilizando o conjunto de dados Heart e métodos de classificação $S R$ - Fase II de experimentos 


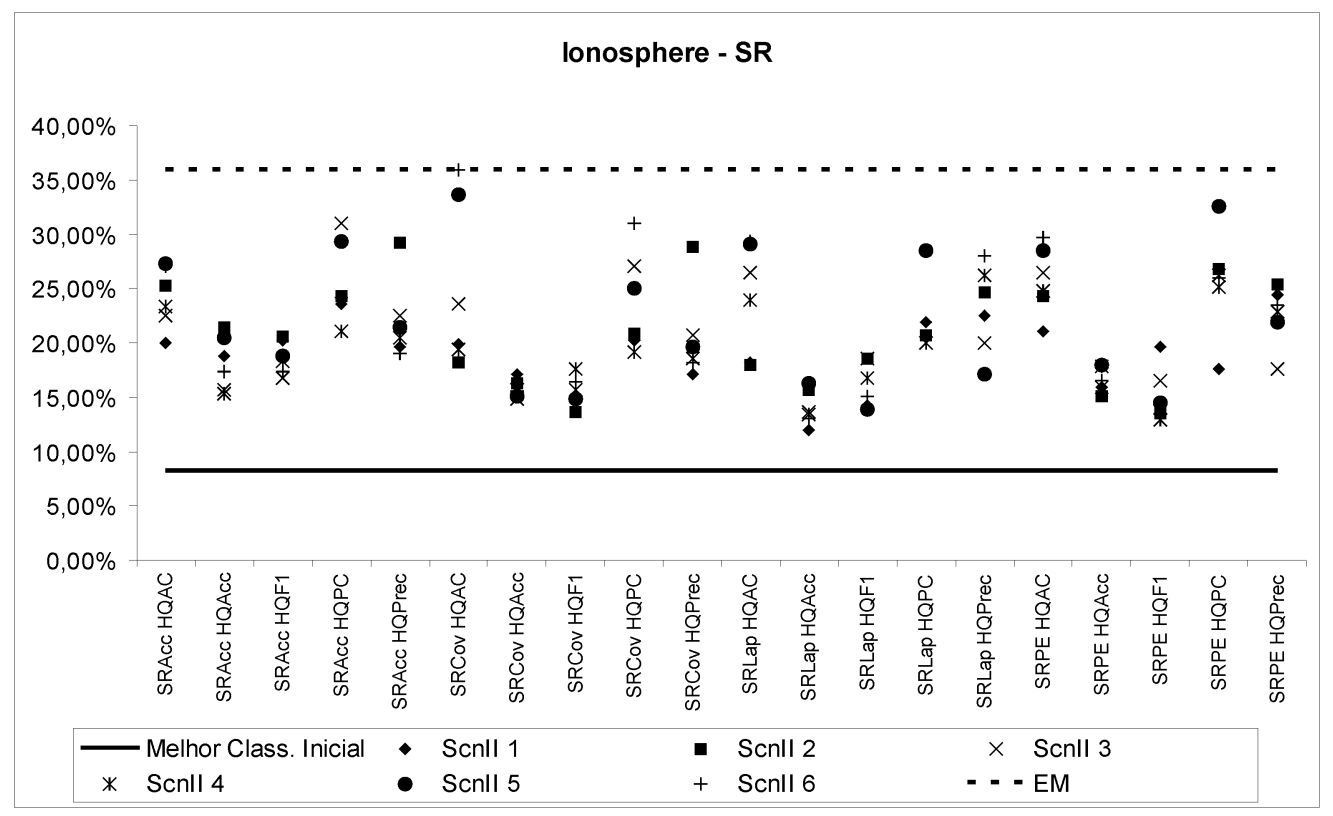

Figura 8.11: Gráfico dos resultados dos experimentos utilizando o conjunto de dados Ionosphere e métodos de classificação $S R$ - Fase II de experimentos 


\subsubsection{Análise do Classificador Evoluído com o Algoritmo Genético}

Além de comparar a precisão do classificador evoluído pelo AG com o melhor classificador na população inicial, foram também analisados os modelos construídos pelo AG, considerando os modelos que apresentam melhor precisão com 95\% de confiança. A fim de ilustrar, dos 73 modelos com essa característica, é mostrado a seguir o modelo que apresentou o mínimo erro de classificação segundo 10-fold cross-validation estratificado: o modelo do cenário ScnII 1, utilizando como função de avaliação a combinação dos métodos $M R_{\text {Lacc }}$ e $H Q_{F 1}$ no conjunto de dados Autos - Tabela B.1.

Para evoluir o classificador a ser analisado a seguir, inicialmente foram induzidos, com todo o conjunto de dados Autos, 3 (três) classificadores utilizando os algoritmos $\mathcal{C N} 2, \mathcal{C} 4.5$ e $\mathcal{C} 4$.5rules, os quais são mostrados, respectivamente, nas Figuras 8.13, 8.14 e 8.15. As regras desses classificadores compuseram a base de regras, a partir da qual foram gerados 12 (doze) classificadores aleatoriamente. Unindo esses 12 (doze) classificadores e os 3 (três) classificadores induzidos, foi formada a população inicial do AG, com um total de 15 classificadores. A execução do AG foi realizada com 10 (dez) gerações, ou iterações. A convergência da função de avaliação nessa execução é ilustrada no gráfico da Figura 8.12.

Como pode ser observado nas Figuras 8.13 a 8.15, o classificador induzido por $\mathcal{C N} 2$ tem 19 regras que utilizam 16 atributos diferentes; o induzido por $\mathcal{C} 4.5$ tem 3 regras que utilizam somente dois atributos diferentes; e o induzido por $\mathcal{C} 4.5$ rules tem 10 regras que utilizam 7 atributos diferentes. O classificador evoluído é mostrado na Figura 8.16. Ele contém 13 regras que utilizam 11 atributos diferentes ${ }^{4}$. Esses resultados encontram-se condensados na Tabela 8.13. Nessa tabela, a primeira coluna indica o tipo de atributo - c (contínuo) ou d (discreto) - , na segunda coluna consta o nome do atributo, e as demais colunas referem-se, respectivamente, aos classificadores induzidos pelos algoritmos $\mathcal{C} \mathcal{N} 2, \mathcal{C} 4.5$ e $\mathcal{C} 4.5$ rules e ao classificador evoluído pelo AG no cenário ScnII 1 utilizando como função de avaliação $M R_{L a c c} H Q_{F 1}$ no conjunto de dados Autos. Ainda, células marcadas com "•" indicam que o atributo faz parte de um ou mais corpos de regras do classificador correspondente. Nas duas últimas linhas, são mostrados o número de atributos, sendo entre

\footnotetext{
${ }^{4}$ Deve ser observado que a regra default dos classificadores (individuos) que participam do AG atribui a classe majoritária.
} 
parênteses o número de atributos contínuos e discretos, e o número de regras que aparecem no respectivo classificador.

Na Tabela 8.14, é mostrada a origem das regras que compõem o classificador evoluído pelo AG. Nessa tabela, a primeira coluna mostra o identificador da regra (Id. Regra), o indutor que induziu a regra e o número de condições presentes na respectiva regra (\# Cond.).

Segundo os testes estatísticos realizados, espera-se que o modelo criado com o algoritmo genético seja aproximadamente $44.4 \%$ mais preciso que o melhor dos classificadores iniciais. Considerando as regras que participam do classificador evoluído, foi possivel comprovar que a soma dos valores da diagonal principal da matriz de contingência de cada regra - Tabela 2.4 na página 19 - i.e. $h b+\overline{h b}$, é sempre superior à metade dos exemplos na base de dados. Quanto a exemplos classificados erroneamente pela regra, i.e., aqueles cobertos pelo corpo da regra mas cuja classe é diferente da predita pela regra $(\bar{h} b)$, esse valor é nulo ou muito pequeno (aproximadamente $2 \%$ dos exemplos) para todas as regras, exceto para a regra R00009, a qual prediz o rótulo errado de $12 \%$ dos exemplos por ela cobertos. Porém, essa é a regra que mais cobre exemplos, ou seja, que tem o máximo valor de $h b$. Em outras palavras, é uma regra bastante geral. Como o método de classificação utiliza múltiplas regras, podemos concluir que o erro do classificador diminui pois um conjunto de outras regras mais especializadas cobrem esses exemplos corretamente e são responsáveis pela classificação final.

\subsection{Considerações Finais}

Neste capitulo foram descritos os resultados experimentais obtidos utilizando-se os métodos de construção de ensembles que explicam suas decisões, bem como os resultados obtidos utilizando-se o algoritmo genético proposto para evolução de classificadores simbólicos em um único classificador final. Lembrando, neste trabalho foram propostos métodos para construção de ensembles de classificadores simbólicos e um algoritmo genético para evolução de classificadores também simbólicos que utilizam para classificar um exemplo tanto métodos que utilizam uma única regra, a qual é selecionada utilizando uma medida de avaliação de regras, quanto métodos que utilizam diversas regras que cobrem o exemplo a ser classificado. Pode ser observado nos resultados obtidos que tanto os métodos de construção de ensembles quanto o 


\begin{tabular}{|c|c|c|c|c|c|}
\hline Tipo & Atributo & $\mathcal{C N} 2$ & $\mathcal{C} 4.5$ & C4.5rules & $\mathrm{AG}$ \\
\hline c & length & - & & & - \\
\hline $\mathrm{c}$ & width & $\bullet$ & & & $\bullet$ \\
\hline $\mathrm{c}$ & bore & $\bullet$ & & & $\bullet$ \\
\hline $\mathrm{c}$ & wheel_base & $\bullet$ & $\bullet$ & $\bullet$ & $\bullet$ \\
\hline $\mathrm{c}$ & normalized_losses & $\bullet$ & & & $\bullet$ \\
\hline $\mathrm{c}$ & height & $\bullet$ & & $\bullet$ & \\
\hline $\mathrm{c}$ & compression_ratio & $\bullet$ & & & $\bullet$ \\
\hline $\mathrm{c}$ & peak_rpm & $\bullet$ & & & \\
\hline $\mathrm{c}$ & stroke & $\bullet$ & & & $\bullet$ \\
\hline $\mathrm{c}$ & price & $\bullet$ & & & $\bullet$ \\
\hline $\mathrm{c}$ & curb_weight & $\bullet$ & & & \\
\hline $\mathrm{c}$ & engine_size & $\bullet$ & & $\bullet$ & \\
\hline $\mathrm{d}$ & num_doors & $\bullet$ & $\bullet$ & $\bullet$ & $\bullet$ \\
\hline $\mathrm{d}$ & body_style & $\bullet$ & & & \\
\hline $\mathrm{d}$ & make & $\bullet$ & & $\bullet$ & $\bullet$ \\
\hline $\mathrm{d}$ & aspiration & $\bullet$ & & & \\
\hline $\mathrm{d}$ & drive_wheels & $\bullet$ & & & \\
\hline $\mathrm{d}$ & num_cylinders & & & $\bullet$ & $\bullet$ \\
\hline \multirow[t]{2}{*}{$\mathrm{d}$} & fuel_system & & & $\bullet$ & \\
\hline & $\begin{array}{l}\text { \# atributos (cont., disc.) } \\
\text { \# regras }\end{array}$ & $\begin{array}{c}16(11,5) \\
19\end{array}$ & $\begin{array}{c}2(1,1) \\
2\end{array}$ & $\begin{array}{c}7(3,4) \\
10\end{array}$ & $\begin{array}{c}11(8,3) \\
14\end{array}$ \\
\hline
\end{tabular}

Tabela 8.13: Número de regras e atributos diferentes relacionados aos classificadores induzidos pelos algoritmos $\mathcal{C N} 2, \mathcal{C} 4.5$ e $\mathcal{C} 4.5$ rules e ao classificador evoluído pelo AG no cenário ScnII 1 utilizando como função de avaliação $M R_{L a c c} H Q_{F 1}$ no conjunto de dados Autos

\begin{tabular}{ccc} 
Id. Regra & Indutor & \# Cond. \\
\hline \hline R0001 & $\mathcal{C N} 2$ & 3 \\
R0002 & $\mathcal{C} 4.5$ rules & 2 \\
R0003 & $\mathcal{C} 4.5$ & 2 \\
R0004 & $\mathcal{C N} 2$ & 2 \\
R0005 & $\mathcal{C N} 2$ & 2 \\
R0006 & $\mathcal{C} 4.5$ rules & 2 \\
R0007 & $\mathcal{C N} 2$ & 5 \\
R0008 & $\mathcal{C N} 2$ & 1 \\
R0009 & $\mathcal{C} 4.5$ rules & 2 \\
R0010 & $\mathcal{C} 4.5$ rules & 2 \\
R0011 & $\mathcal{C} 4.5$ rules & 1 \\
R0012 & $\mathcal{C N} 2$ & 2 \\
R0013 & $\mathcal{C} 4.5$ rules & 1
\end{tabular}

Tabela 8.14: Origem das regras que compõem o classificador evoluído pelo algoritmo genético 


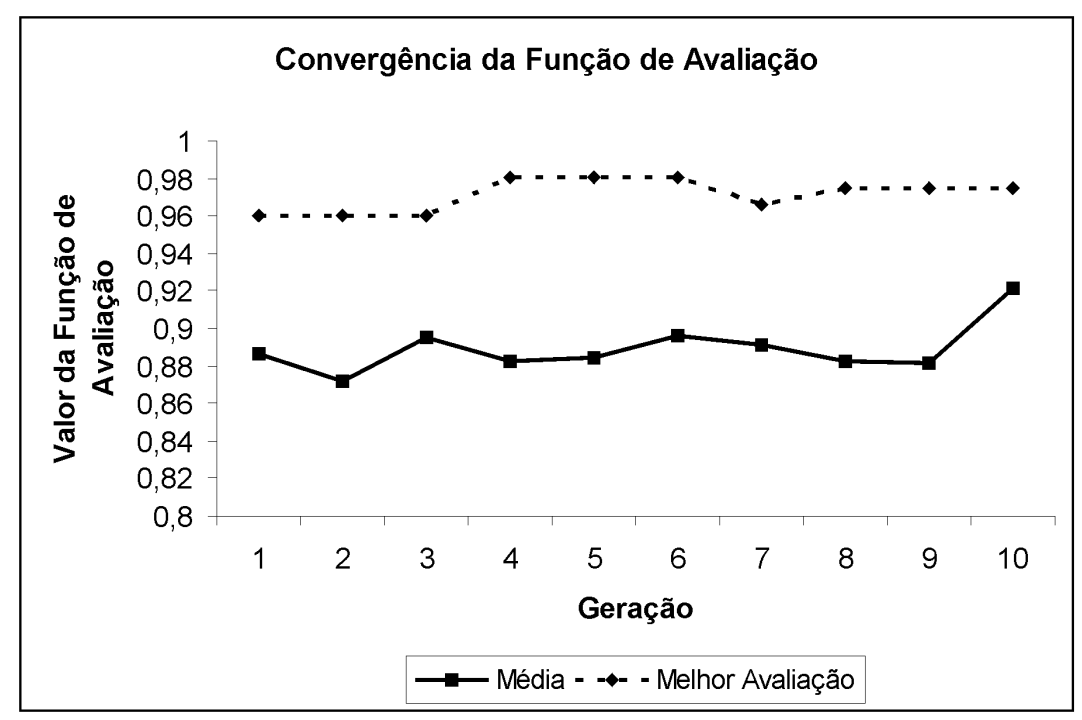

Figura 8.12: Gráfico de convergência da função de avaliação $M R_{L a c c} H Q_{F 1}$ utilizando o conjunto de dados Autos no cenário ScnII 1

AG utilizando como método de classificação uma única regra para classificar exemplos não obtiveram bons resultados. Por outro lado, utilizando diversas regras para classificar exemplos, foram obtidos bons resultados para ambas as abordagens utilizadas - construção de ensembles de classificadores e evolução de classificadores utilizando o AG proposto - , mas obtivemos ainda melhores resultados utilizando o algoritmo genético. Também, é interessante observar as regras obtidas no classificador evoluído com a AG, as quais são qualitativamente boas segundo a medida de precisão. No capítulo a seguir, são apresentadas as conclusões a respeito deste trabalho bem como trabalhos futuros. 


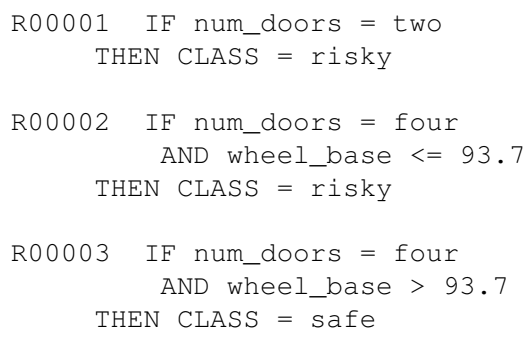

Figura 8.14: Regras pertencentes ao classificador induzido $\mathcal{C} 4.5$ no formato padrão de regras $\mathcal{P B M}$

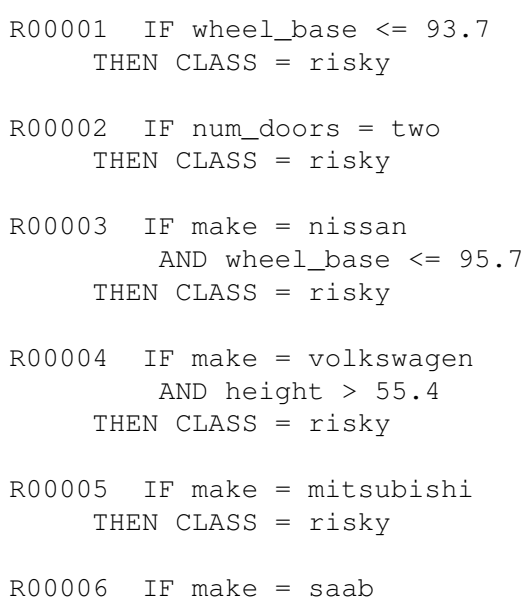

R00006 IF make = saab

Figura 8.15: Regras pertencentes ao classificador induzido $\mathcal{C} 4.5$ rules no formato padrão de regras $\mathcal{P B M}$ 


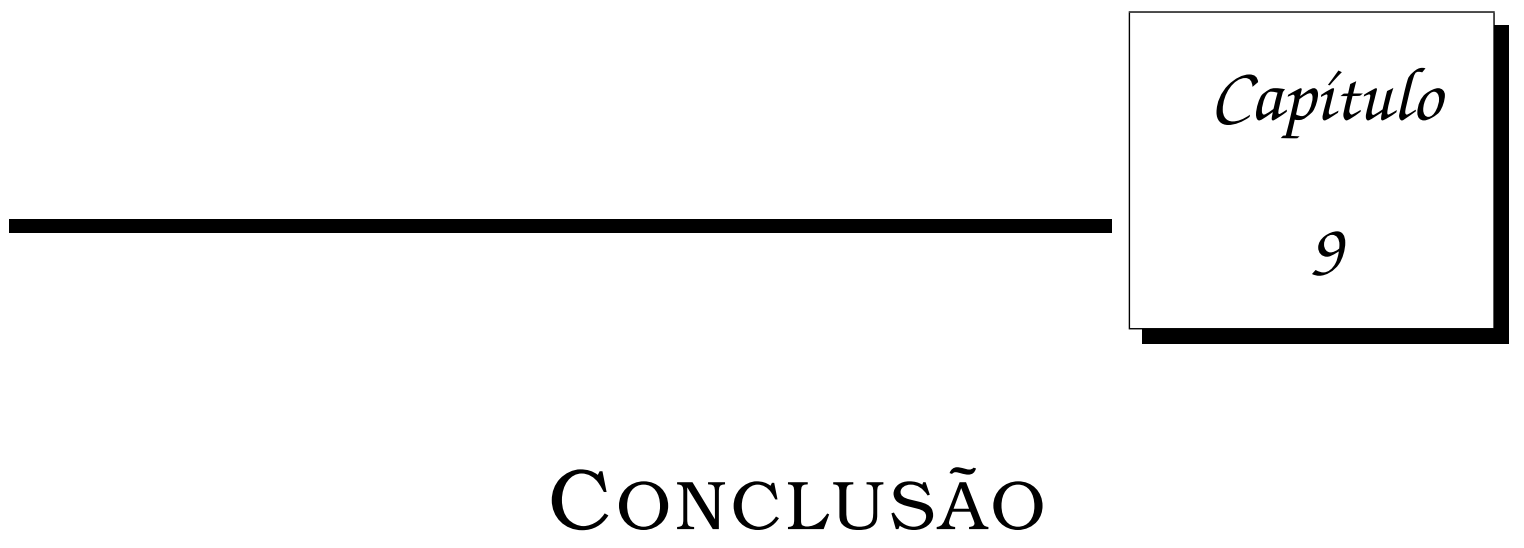

"Não tenha medo da perfeição, você nunca vai atingi-la."

\footnotetext{
Ceste capítulo, são feitas as conclusões deste trabalho, sendo descritos resumidamente os principais objetivos e os principais resultados obtidos. Também, são descritas as principais contribuições para a comunidade científica da área, sendo citados os trabalhos publicados resultantes deste trabalho de doutorado, assim como as principais limitações do presente trabalho. Ainda, são abordados possiveis trabalhos futuros.
}

\subsection{Resumo dos Objetivos e Resultados Obtidos}

Em muitas aplicações de mineração de dados, é necessário extrair conhecimento de bases de dados para auxiliar a tomada de decisões futuras. Para extração de conhecimento dessas bases, geralmente são utilizados algoritmos de aprendizado de máquina simbólico, já que o conhecimento extraído por tais classificadores é mais facilmente compreensível por seres humanos que 
os modelos extraídos por algoritmos de aprendizado não simbólicos. Entretanto, quando estão disponíveis para o processo de extração de conhecimento bases de dados que possuem grande quantidade de exemplos, os algoritmos de aprendizado disponíveis não estão preparados para tratar essas bases inteiras. Uma maneira para tentar resolver esse problema é extrair amostras do conjunto de dados original, induzir classificadores utilizando diversos algoritmos de aprendizado simbólico, e combinar esses classificadores de maneira que seja mantida a capacidade de explicação. As duas questões principais consideradas neste trabalho são:

1. É possivel obter um bom poder de predição quando um número limitado de classificadores simbólicos é combinado?

2. É possivel melhorar o poder de predição dos classificadores iniciais que são combinados e ainda manter a capacidade de explicação?

Para responder tais perguntas, primeiramente propomos neste trabalho métodos para realizar a combinação de classificadores relacionadas a duas abordagens: construção de ensembles de classificadores que explicam suas decisões e utilização de um algoritmo genético para evoluir classificadores simbólicos em um único classificador final, também simbólico. Mais especificamente, neste trabalho, foram propostos:

- métodos de construção de ensembles de classificadores simbólicos, de maneira que ensembles construídos com os métodos por nós propostos explicam suas decisões;

- um método para simplificar a explicação fornecida pelos ensembles construídos com os métodos por nós propostos, de maneira que a explicação simplificada possua uma quantidade menor de regras a ser analisada pelo usuário/especialista;

- um algoritmo genético para evolução de classificadores simbólicos em um único classificador simbólico final.

Essas propostas foram implementadas em dois módulos do ambiente DisCOVER - ELE e GAERE. A implementação dos métodos propostos foi trabalhosa, pois levam em conta o processo de avaliação experimental desses 
métodos, automatizando esse processo. Caso o processo de avaliação experimental não tivesse sido automatizado, consideramos que teria sido inviável realizar com segurança a grande variedade de avaliações experimentais relacionadas com este trabalho. Para realizar a avaliação experimental dos métodos propostos, foram utilizados diversos conjuntos de dados da UCI (Blake et al., 1998). Para selecionar os conjuntos de dados, foi realizado um levantamento dos principais artigos encontrados na literatura relacionados com combinação de classificadores simbólicos. Foram utilizados os conjuntos de dados que foram mencionados com maior frequência nos artigos do levantamento realizado. Os experimentos foram, então, divididos em duas fases.

$\mathrm{Na}$ primeira fase de experimentos, o nosso objetivo foi analisar os resultados obtidos quando são extraídas amostras do conjunto de dados inicial, dessas amostras dão induzidos classificadores utilizando algoritmos de aprendizado simbólico, e esses classificadores são então combinados. Para simular bases de dados de maior porte, foram retiradas amostras sem reposição de conjuntos de dados com mais de 1000 exemplos. Nesta fase de experimentos, foram utilizados diversos métodos de construção de ensembles de classificadores. Os resultados obtidos foram bastante interessantes e promissores, já que a maioria dos ensembles construídos possuem taxas de erro menores que a menor taxa de erro obtida pelos classificadores iniciais que compõem os ensembles. Analisando os conjuntos de regras oferecidos para explicação de exemplos classificados pelos ensembles construídos nessa primeira fase de experimentos, observou-se que, em cada conjunto, diversas regras eram especializações de outras. Assim, utilizamos um método simples para simplificação de explicação. Os resultados obtidos com o método de explicação foram muito bons, já que a quantidade de regras para explicar novas classificações após a simplificação é reduzida para mais da metade, comparada à quantidade de regras inicialmente oferecidas para a explicação da classificação dada pelo ensemble.

Na segunda fase de experimentos, o nosso objetivo foi testar a variabilidade do algoritmo genético. Porém, devido ao grande número de combinações dos diversos parâmetros do algoritmo genético a ser testado, decidimos utilizar conjuntos de dados de menor porte e construir os ensembles de classificadores utilizando uma amostra, que consiste do próprio conjunto de dados. Foram também evoluídos classificadores simbólicos iniciais em um único classificador final, também simbólico, utilizando o AG proposto, variando-se os compo- 
nentes propostos do AG, tais como funções de avaliação e critérios de parada. Os resultados obtidos utilizando o AG foram ainda mais promissores para algumas combinações de componentes, em relação à construção de ensembles de classificadores.

Assim, consideramos que a resposta para as questões iniciais 1 e 2 é afirmativa. Ou seja, é possível combinar classificadores iniciais, induzidos utilizando amostras do conjunto de dados inicial, de maneira a melhorar o poder de predição desses classificadores iniciais e ainda manter o poder de explicação. Os resultados obtidos com o AG proposto também validam essa resposta, mesmo sem retirar amostras do conjunto de dados inicial, já que o conjunto de dados completo também pode ser visto como uma única amostra do conjunto de dados inicial.

\subsection{Principais Contribuições e Limitações}

Os métodos de construção de ensembles de classificadores se mostraram bastante eficientes para combinar classificadores induzidos de diferentes amostras de dados. Entretanto, o fato de variar os métodos de combinação de classificadores que compõem os métodos de construção de ensembles não ofereceu diferença na taxa de erro obtida nos ensembles construídos. Dessa maneira, o método de combinação sem peso pode ser mais indicado por não requerer o cálculo da estimativa de taxa de erro dos classificadores componentes, diminuindo assim o tempo de construção de ensembles. Em relação aos métodos de classificação de exemplos utilizados pelos classificadores componentes dos ensembles, utilizando somente a melhor regra para classificar os exemplos, os resultados não foram tão bons quanto utilizando o classificador como um todo. Quanto à publicação de resultados, a descrição do sistema computacional ELE que implementa os métodos de construção de ensembles propostos foi realizada em um relatório técnico, publicado no ICMC (Bernardini and Monard, 2004). Como resultado da avaliação dos métodos de construção de ensembles propostos utilizando conjuntos de dados de médio porte da UCI Blake et al. (1998), foram publicados artigos em conferências do meio científico (Bernardini and Monard, 2005a; Bernardini et al., 2005) e um artigo foi convidado a ser publicado em um periódico (Bernardini et al., 2006). Já utilizando o método para simplificação de explicação, foi publicado um artigo em uma conferência (Bernardini and Monard, 2005b). 
Os resultados obtidos com o algoritmo genético proposto são muito bons e bastante promissores, já que:

1. foram obtidos classificadores com excelentes taxas de erro, quando comparadas com as taxas de erro dos classificadores induzidos pelos algoritmos de aprendizado de máquina simbólicos utilizados; e

2. o tempo de execução do algoritmo genético é considerado bastante satisfatório - 1 minuto em média.

Entretanto, ao contrário do esperado, as taxas de erro obtidas com o critério de parada de convergência foram maiores que as taxas de erro obtidas utilizando o critério de parada que faz com que o AG seja executado um número máximo de iterações. Esses resultados nos levam a acreditar que há necessidade de se investigar mais profundamente o critério de convergência utilizado, bem como provavelmente propor novos critérios de parada relacionados à convergência. Quanto à publicação de resultados, a descrição do sistema computacional GAERE que implementa AG proposto foi realizada em um relatório técnico, publicado no ICMC (Bernardini and Monard, 2006a). Utilizando o AG proposto para evolução de classificadores sobre conjuntos de dados naturais também da UCI, um artigo está em fase de publicação em uma conferência do meio científico (Bernardini and Monard, 2006b) e outro artigo foi submetido a outra conferência (Bernardini and Monard, 2006c).

\subsection{Trabalhos Futuros}

Em relação aos métodos de construção de ensembles de classificadores, outras abordagens podem ser investigadas para combinação das decisões de classificadores de maneira a manter o poder de explicação do ensemble construído. Para isso, podem ser utilizadas diversas maneiras para atribuir pesos às decisões dos classificadores individuais. Também, consideramos interessante utilizar classificadores "não simbólicos" para auxiliar o processo de classificação, já que classificadores induzidos com algoritmos que utilizam outros paradigmas de aprendizado, como o paradigma conexionista ou estatístico, em vários domínios apresentam menores taxas de erro que classificadores simbólicos. Nesses casos, uns poucos classificadores não-simbólicos, mas com uma taxa de erro bem pequena, poderíam ser utilizados para auxiliar na decisão da classificação do ensemble, utilizando como explicação a 
explicação fornecida pelos classificadores simbólicos que constituem o ensemble.

Quanto ao algoritmo genético proposto, pretendemos investigar outros operadores genéticos e outros critérios de parada para verificar se conseguimos melhorar ainda mais os modelos finais, tanto em termos de precisão quanto em termos da qualidade das regras oferecidas pelo AG. Em relação às funções de avaliação, futuramente pretendemos analisar com maior profundidade as funções de avaliação que utilizam uma única regra para classificação $(S R$ Single Rule), com o objetivo de justificar por que tais funções de avaliação conseguem gerar classificadores que classificam muito bem determinadas classes em detrimento de outras. Serão também exploradas combinação de medidas de avaliação de classificadores, como as utilizadas, com outros tipos de medidas que levem em conta, por exemplo, a complexidade sintática dos classificadores induzidos. Esse é um problema multiobjetivo que trata de medidas diferentes (precisão e complexidade sintática das regras), que pretendemos investigar utilizando os rankings de ambas as medidas como função de avaliação. 


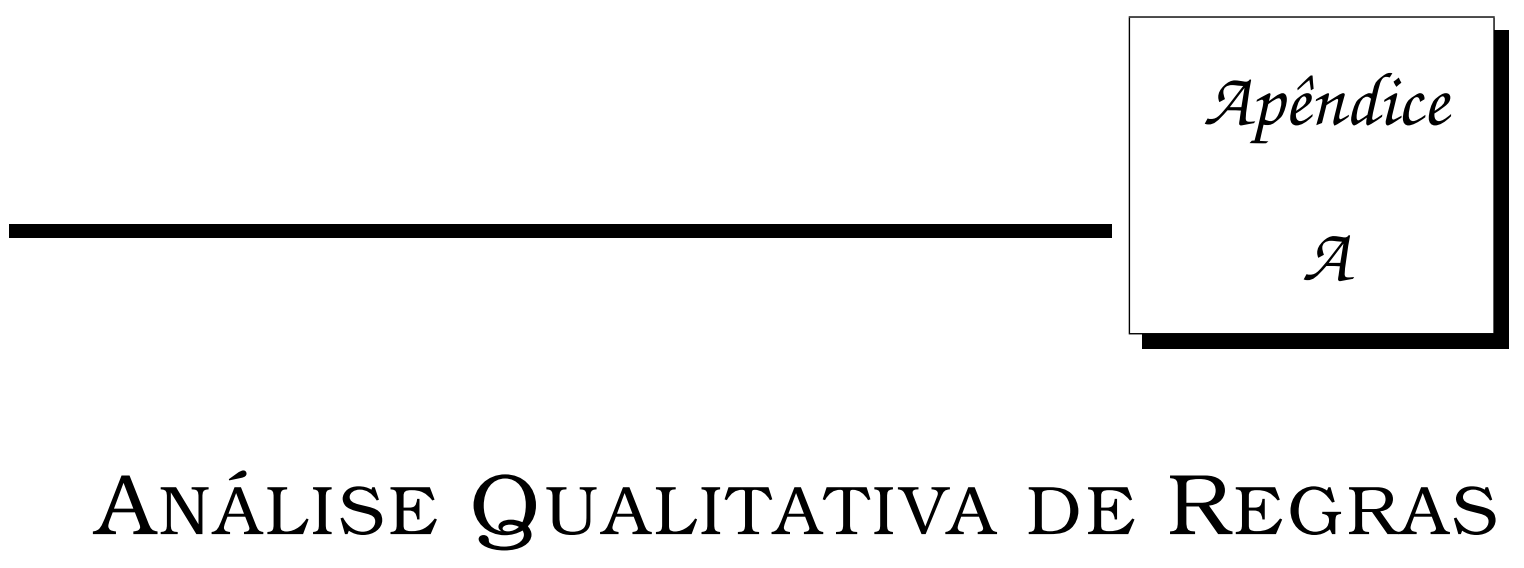

\section{ANÁlise QUALITATIVA DE REGRAS}

ob o aspecto qualitativo, regras são avaliadas com o objetivo de saber quais são aquelas melhor sustentadas pelos dados (Lavrac et al., 1999). A análise qualitativa de regras pode ser efetuada por meio de procedimentos que implementam medidas de avaliação de regras. Nesta seção, são descritas as medidas de avaliação de regras unificadas no framework proposto por Lavrac et al. (1999), bem como são descritos outros critérios de avaliação de regras. Em (Gomes, 2002) encontra-se uma descrição mais abrangente que inclui outras medidas de avaliação de regras.

\section{A.1 Uma Visão Unificada de Medidas de Avaliação de Regras}

Esta seção está baseada no trabalho de Lavrac et al. (1999). O objetivo do framework proposto nesse trabalho é proporcionar uma análise unificada de medidas de avaliação de regras selecionadas da literatura. Para calcular essas medidas de avaliação de regras, é necessário construir a matriz de 
contingência de cada regra a ser avaliada - Seção 2.4 na página 18. Nesse framework, algumas medidas de avaliação encontradas na literatura foram unificadas, considerando uma regra $R$ na forma $B \rightarrow H$. Essas medidas, definidas nas respectivas tabelas, podem ser divididas nas seguintes categorias:

1. Medidas genéricas de avaliação - Tabela A.1;

2. Medidas relativas de avaliação - Tabela A.2;

3. Medidas relativas de avaliação com peso — Tabela A.3.

Baseada na medida de novidade, Lavrac mostra que as medidas relativas de avaliação com peso são iguais entre si e iguais a medida de novidade da regra, i.e.

$$
\begin{gathered}
W R A c c(B \rightarrow H)=W R \operatorname{Sens}(B \rightarrow H)=W \operatorname{RSpec}(B \rightarrow H) \\
=W R \operatorname{NegRel}(B \rightarrow H)=\operatorname{Nov}(B \rightarrow H)
\end{gathered}
$$

Geralmente, medidas de avaliação são úteis para determinar quais são as "melhores" regras de um classificador simbólico h. As "melhores" regras podem ser aquelas que apresentam o maior (ou menor) valor para uma determinada medida de avaliação. Por exemplo, pode ser considerado que as "melhores" regras $R_{u}$ de um classificador simbólico $\mathbf{h}$, são aquelas que possuem maior valor para a medida de precisão (ou menor valor para a medida de erro).

\section{A.2 Outros Critérios para Seleção de Regras}

Existem outros critérios para selecionar a melhor regra de uma hipótese $\mathbf{h}$ (Horst and Monard, 2000; Gomes, 2002). Um dos possiveis critérios consiste em escolher a regra com o melhor grau de adequação (rule fitness) para o problema em questão. Dada uma regra $R$, na forma $B \rightarrow H$, o grau de adequação de $R$ pode ser denotado por $r f(B \rightarrow H)$. O critério de seleção $r f$ escolhe a melhor regra como sendo aquela que possui maior valor de $r f$. Existem três possiveis critérios que permitem estimar o grau de adequação de uma regra:

1. Confiabilidade Positiva; 
2. Precisão de Laplace; e

3. Novidade

descritas a seguir.

Confiabilidade Positiva: Utiliza a precisão de regra $(A c c)$, definida pela Equação A. 1. Entretanto, a confiabilidade positiva possui uma propriedade indesejada. Por exemplo, dadas duas regras $R_{u}$ e $R_{q}$, supondo que $\operatorname{Acc}\left(R_{u}\right)=$ 1 e $\operatorname{Acc}\left(R_{q}\right)=0.98$, segundo este critério a regra $R_{u}$ é melhor que a regra $R_{q}$. Entretanto, se a regra $R_{u}$ cobre somente um exemplo e a regra $R_{q}$ cobre 200 exemplos (portanto, 4 deles são cobertos erroneamente), a regra $R_{q}$ é claramente melhor que a regra $R_{u}$.

Precisão de Laplace Uma solução para o problema apresentado pela confiabilidade positiva $(A c c)$ consiste em substituí-la pela precisão de Laplace (Clark and Boswell, 1991), definida pela Equação A.19, onde $N_{C l}$ é o número de classes do conjunto de exemplos, bh é o número de exemplos cobertos corretamente pela regra e $b \bar{h}$ é o número de exemplos cobertos incorretamente pela regra.

$$
r f(B \rightarrow H) \stackrel{\text { def }}{=} \operatorname{Lacc}(B \rightarrow H)=\frac{b h+1}{b+N_{C l}}=\frac{b h+1}{b h+b \bar{h}+N_{C l}}
$$

Considerando esse critério, quanto maior o valor da precisão de Laplace, melhor é a regra. Para o exemplo anterior em um problema com $N_{C l}=2$ classes, tem-se que $\operatorname{Lacc}\left(R_{u}\right)=0.66$ e $\operatorname{Lacc}\left(R_{q}\right)=0.98$, indicando que a regra $R_{q}$ é melhor que a regra $R_{u}$. Assim como a confiabilidade positiva, a precisão de Laplace assume valores no intervalo $0 \leq \operatorname{Lacc}(B \rightarrow H) \leq 1$.

Novidade: Utiliza a medida de novidade de regra ( $N o v)$, definida pela Equação A.8. Em (Todorovski et al., 2000), são mostrados alguns experimentos nos quais se utiliza a medida de novidade no algoritmo $\mathcal{C N} 2$ para induzir classificadores compostos por regras ordered e unordered. Nos experimentos nos quais foram construídas hipóteses com regras unordered, o uso da medida de novidade reduziu, em média, nove vezes o número de regras não ordenadas induzidas pelo algoritmo $\mathcal{C N} 2$, com um aumento de erro em torno de 5\%. Essa redução do número de regras, com pequena perda de precisão, constitui um avanço no sentido de uma 
maior compreensibilidade do conjunto final de regras por seres humanos, o que torna a medida novidade bastante interessante. 
Precisão

$$
A c c(B \rightarrow H)=P(H \mid B)=\frac{h b}{b}
$$

Erro

$$
\operatorname{Err}(B \rightarrow H)=P(\bar{H} \mid B)=\frac{\bar{h} b}{b}
$$

Confiança Negativa

$$
N e g R e l(B \rightarrow H)=P(\bar{H} \mid \bar{B})=\frac{\overline{h b}}{\bar{b}}
$$

Sensibilidade

$$
\operatorname{Sens}(B \rightarrow H)=P(B \mid H)=\frac{h b}{h}
$$

Especificidade

$$
\operatorname{Spec}(B \rightarrow H)=P(\bar{B} \mid \bar{H})=\frac{\overline{h b}}{\bar{h}}
$$

Cobertura

$$
\operatorname{Cov}(B \rightarrow H)=P(B)=\frac{b}{N}
$$

Suporte

$$
\operatorname{Sup}(B \rightarrow H)=P(H B)=\frac{h b}{N}
$$

Novidade

$$
N o v(B \rightarrow H)=P(H B)-P(H) P(B)=\frac{1}{N}\left(h b-\frac{h \cdot b}{N}\right)
$$

Satisfação

$$
\operatorname{Sat}(B \rightarrow H)=\frac{(P(\bar{H})-P(\bar{H} \mid B))}{P(\bar{H})}=\frac{\frac{\bar{h}}{N}-\frac{\bar{h} b}{b}}{\frac{\bar{h}}{N}}=1-\left(\frac{\bar{h} b}{b} \cdot \frac{N}{\bar{h}}\right)
$$

Tabela A.1: Medidas genéricas de avaliação de regras 
Precisão Relativa

$$
R A c c(B \rightarrow H)=P(H \mid B)-P(H)=\frac{h b}{b}-\frac{h}{N}
$$

Confiança Negativa Relativa

$$
R N e g R e l(B \rightarrow H)=P(\bar{H} \mid \bar{B})-P(\bar{H})=\frac{\overline{h b}}{\bar{b}}-\frac{\bar{h}}{N}
$$

Sensibilidade Relativa

$$
R \operatorname{Sens}(B \rightarrow H)=P(B \mid H)-P(B)=\frac{h b}{h}-\frac{b}{N}
$$

Especificidade Relativa

$$
R \operatorname{Spec}(B \rightarrow H)=P(\bar{B} \mid \bar{H})-P(\bar{B}) \frac{\overline{h b}}{\bar{h}}-\frac{\bar{b}}{N}
$$

Tabela A.2: Medidas relativas de avaliação de regras

\section{Precisão Relativa com Peso}

$$
W R A c c(B \rightarrow H)=P(B)(P(H \mid B)-P(H))=\frac{b}{N}\left(\frac{h b}{b}-\frac{h}{N}\right)
$$

Confiança Negativa Relativa com Peso

$$
W R N e g R e l(B \rightarrow H)=P(\bar{B})(P(\bar{H} \mid \bar{B})-P(\bar{H}))=\frac{\bar{b}}{N}\left(\frac{\overline{h b}}{\bar{b}}-\frac{\bar{h}}{N}\right)
$$

Sensibilidade Relativa com Peso

$$
W R \operatorname{Sens}(B \rightarrow H)=P(H)(P(B \mid H)-P(B))=\frac{h}{N}\left(\frac{h b}{h}-\frac{b}{N}\right)
$$

Especificidade relativa com Peso

$$
W R \operatorname{Spec}(B \rightarrow H)=P(\bar{H})(P(\bar{B} \mid \bar{H})-P(\bar{B}))=\frac{\bar{h}}{N}\left(\frac{\overline{h b}}{\bar{h}}-\frac{\bar{b}}{N}\right)
$$

Tabela A.3: Medidas relativas de avaliação de regras com peso 


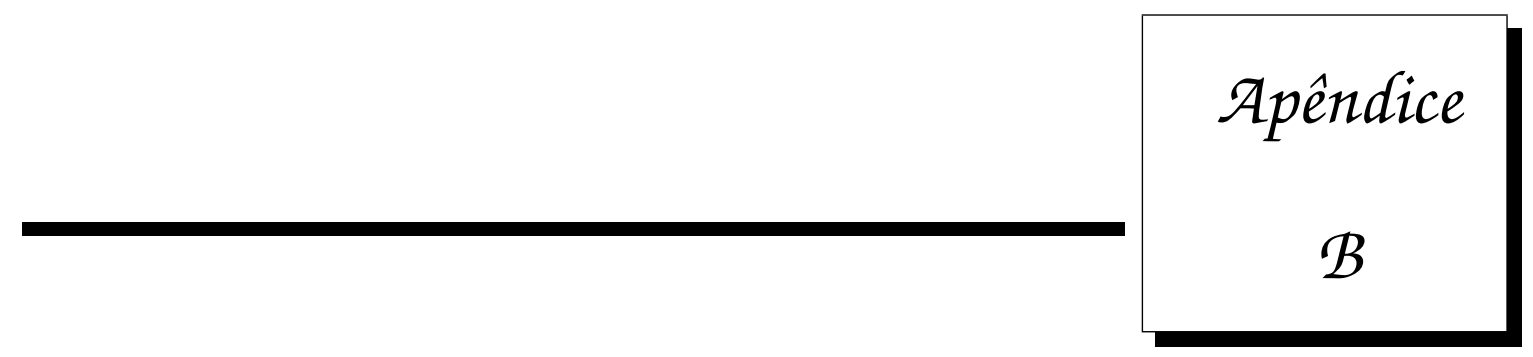

Resultados Obtidos com o AG PROPOSTO 


\begin{tabular}{|c|c|c|c|c|}
\hline & Autos & Balance & Heart & Ionosphere \\
\hline EM & 44.88 & 53.92 & 44.44 & 35.90 \\
\hline $\mathcal{C N} 2$ & $12.14(3.29)$ & $15.11(1.55)$ & $22.22(2.82)$ & $8.25(1.15)$ \\
\hline C4.5rules & $9.14(3.22)$ & $15.12(1.71)$ & $21.11(2.28)$ & $10.52(1.73)$ \\
\hline $\mathcal{C} 4.5$ & 8.69 (2.95) & $28.48(1.61)$ & $22.96(3.16)$ & 11.08 (1.68) \\
\hline$M R_{A c c} H Q_{A C}$ & $16.43(3.64)$ & $15.23(2.71)$ & $21.85(2.79)$ & $16.47(3.62)$ \\
\hline$M R_{A c c} H Q_{A c c}$ & $8.17(4.60)$ & 7.70 (1.09) & $13.33(2.54)$ & $6.56(1.27)$ \\
\hline$M R_{A c c} H Q_{F 1}$ & $4.36(1.95)$ & $8.08(1.54)$ & $10.74(2.10)$ & $6.57(1.21)$ \\
\hline$M R_{A c c} H Q_{P C}$ & $9.14(3.43)$ & $13.12(3.28)$ & $20.53(3.11)$ & $14.50(3.17)$ \\
\hline$M R_{A c c} H Q_{\text {Prec }}$ & $8.71(2.53)$ & $12.72(3.16)$ & $25.66(3.60)$ & $15.97(2.67)$ \\
\hline$M R_{C o v} H Q_{A C}$ & $18.55(5.36)$ & $21.00(3.27)$ & $21.48(2.52)$ & $13.10(1.22)$ \\
\hline$M R_{C o v} H Q_{A c c}$ & $11.19(2.77)$ & $12.50(1.24)$ & $16.30(2.29)$ & $6.83(1.21)$ \\
\hline$M R_{C o v} H Q_{F 1}$ & $10.17(3.67)$ & $11.30(1.67)$ & $13.70(2.07)$ & 7.39 (1.27) \\
\hline$M R_{C o v} H Q_{P C}$ & $11.62(2.74)$ & $16.82(2.56)$ & $19.63(2.53)$ & $17.34(3.16)$ \\
\hline$M R_{\text {Cov }} H Q_{\text {Prec }}$ & $18.36(3.70)$ & $15.82(2.77)$ & $27.04(3.13)$ & $18.24(2.30)$ \\
\hline$M R_{\text {Lacc }} H Q_{A C}$ & $22.74(4.85)$ & $13.90(2.34)$ & $20.00(2.01)$ & $12.24(2.40)$ \\
\hline$M R_{L a c c} H Q_{A c c}$ & $5.33(1.83)$ & $9.55(1.24)$ & $11.11(1.56)$ & $6.83(1.21)$ \\
\hline$M R_{L a c c} H Q_{F 1}$ & $3.86(1.39)$ & $8.69(1.04)$ & $12.96(1.77)$ & $1.28)$ \\
\hline$M R_{L a c c} H Q_{P C}$ & $16.43(4.30)$ & $14.41(2.67)$ & $23.70(2.15)$ & $20.83(3.11)$ \\
\hline$M R_{\text {Lacc }} H Q_{\text {Prec }}$ & $9.74(1.60)$ & $8.51(1.36)$ & $26.67(2.80)$ & $15.11(3.25)$ \\
\hline$M R_{P E} H Q_{A C}$ & $22.21(5.43)$ & $11.29(1.73)$ & $24.44(3.71)$ & $11.68(1.38)$ \\
\hline$M R_{P E} H Q_{A c c}$ & $5.33(1.51)$ & $10.95(1.50)$ & $12.22(1.47)$ & 6.83 (1.05) \\
\hline$M R_{P E} H Q_{F 1}$ & $7.26(2.58)$ & 10.44 & $14.07(2.26)$ & .59) \\
\hline$M R_{P E} H Q_{P C}$ & $12.62(1.59)$ & 10.41 & $29.26(4.15)$ & 14.25 \\
\hline$M R_{P E} H Q_{P r e c}$ & $12.05(2.93)$ & $12.34(2.53)$ & $29.63(2.47)$ & $16.22(3.03)$ \\
\hline$S R_{A c c} H Q_{A C}$ & $25.69(5.12)$ & $28.26(2.48)$ & $27.04(2.65)$ & $19.95(2.86)$ \\
\hline$S R_{A c c} H Q_{A c c}$ & $15.93(4.23)$ & $18.77(2.03)$ & $27.04(3.62)$ & $18.81(2.34)$ \\
\hline$S R_{A c c} H Q_{F 1}$ & (3.93) & 22.06 & 26.67 & 20.2 \\
\hline$S R_{A c c} H Q_{P C}$ & $14.95(4.76)$ & $27.05(3.12)$ & $30.37(3.11)$ & $23.65(2.41)$ \\
\hline$S R_{\text {Acc }} H Q_{\text {Prec }}$ & $26.74(4.79)$ & $27.30(2.52)$ & $34.44(2.87)$ & $19.67(2.84)$ \\
\hline$S R_{C o v} H Q_{A C}$ & $24.71(4.05)$ & $26.90(2.81)$ & $28.15(3.08)$ & $19.90(3.35)$ \\
\hline$S R_{C o v} H Q_{A c c}$ & $19.40(4.66)$ & $29.02(2.76)$ & $25.19(2.75)$ & $17.10(3.04)$ \\
\hline$S R_{C o v} H Q_{F 1}$ & $18.36(4.20)$ & $23.78(1.19)$ & $22.96(2.91)$ & $15.11(2.14)$ \\
\hline$S R_{C o v} H Q_{P C}$ & $25.07(4.67)$ & $27.26(2.44)$ & $26.67(3.16)$ & $20.18(3.34)$ \\
\hline$S R_{\text {Cov }} H Q_{P r e c}$ & $20.45(3.68)$ & 25.92 & 35.56 (3.75) & 17.09 \\
\hline$S R_{\text {Lacc }} H Q_{A C}$ & 25.69 (4 & 24.84 & $28.89(2.86)$ & $18.24(3.44)$ \\
\hline$S R_{L a c c} H Q_{A c c}$ & $14.55(3.54)$ & $15.63(1.62)$ & $20.37(2.23)$ & $11.97(2.03)$ \\
\hline$S R_{L a c c} H Q_{F 1}$ & $18.93(3.64)$ & 17.86 (1.69) & $20.00(1.67)$ & $14.24(2.88)$ \\
\hline$S R_{\text {Lacc }} H Q_{P C}$ & $18.40(3.88)$ & $23.43(2.89)$ & $27.78(3.63)$ & $21.94(2.89)$ \\
\hline$S R_{\text {Lacc }} H Q_{\text {Prec }}$ & $16.93(3.99)$ & $22.24(2.75)$ & 27.78 (2.93) & $22.54(3.48)$ \\
\hline$S R_{P E} H Q_{A C}$ & 25.76 (3.68) & $23.28(1.18)$ & $24.81(2.47)$ & 21.09 (3.74) \\
\hline$S R_{P E} H Q_{A c c}$ & $18.88(3.97)$ & $18.92(2.49)$ & $21.11(2.07)$ & $15.95(3.30)$ \\
\hline$S R_{P E} H Q_{F 1}$ & $22.69(5.57)$ & $23.24(2.71)$ & $21.85(2.17)$ & $19.67(2.65)$ \\
\hline$S R_{P E} H Q_{P C}$ & $22.31(3.73)$ & $23.81(2.78)$ & $32.59(3.57)$ & $17.63(3.04)$ \\
\hline$S R_{P E} H Q_{\text {Prec }}$ & $16.43(3.61)$ & $19.07(2.43)$ & $24.44(3.46)$ & $24.49(3.48)$ \\
\hline
\end{tabular}

Tabela B.1: Resultados obtidos na Fase de Experimentos II, Cenário ScnII 1, utilizando o algoritmo genético proposto. 


\begin{tabular}{|c|c|c|c|c|}
\hline & & e & 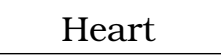 & \\
\hline EM & 44.88 & 53.92 & 44.44 & 35.90 \\
\hline $\mathcal{C N} 2$ & .29) & 55) & $2.22(2.82)$ & $8.25(1.15)$ \\
\hline $\mathcal{C}$ & , & .12 & $.11(2.28)$ & 10.52 \\
\hline $\mathcal{C} 4.5$ & 691 & .48 & 2.96 & 11.08 \\
\hline$M$ & 8) & 371 & 1) & 5.1 \\
\hline & Z) & 4.88 & .02 & 8.20 \\
\hline$M R$ & 10 & 6.26 & .10 & 0) \\
\hline$M R_{A}$ & 0) & 7.88 & 38) & 17.4 \\
\hline$M R_{A c}$ & 6.64 & 7.48 & $0.56(8.46)$ & 24.6 \\
\hline$M R_{C o v} H Q_{A C}$ & $1.81(5.08)$ & 15.99 & 3.59) & 14.2 \\
\hline & & 10.5 & & \\
\hline & & & & \\
\hline$M$ & & 4) & 7) & 12) \\
\hline$M R_{C}$ & 37) & 3) & 2.08 & 18.4 \\
\hline$M R_{\text {Lacc }} H Q_{A C}$ & .19) & 3.02 & 5.64 & 14.56 \\
\hline$M R_{L}$ & & 3 & 2) & 6) \\
\hline & & & & \\
\hline & & & & 23. \\
\hline$M I$ & & 9.36 & 1) & 25) \\
\hline$M F$ & & & 2) & 77) \\
\hline$M I$ & & & & 2) \\
\hline & & & & \\
\hline & & & & 9) \\
\hline$M R_{P}$ & 3) & 9.2 & 5) & 19.5 \\
\hline & & & & (b) \\
\hline & & & & 31) \\
\hline & & & & \\
\hline & & & & 24. \\
\hline$S R$ & & 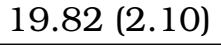 & 2) & 29.2 \\
\hline & & 0 & $.62)$ & 18.26 \\
\hline & & 3) & 9) & 33) \\
\hline & & & & 13.6 \\
\hline$S h$ & & & & 20.8 \\
\hline & & & & \\
\hline & & & & \\
\hline & & & 7) & 15.7 \\
\hline & & 0 & 8) & .81) \\
\hline & & & & 30) \\
\hline & & 3) & 70) & 24.6 \\
\hline & (4.59) & $17.88(1.06)$ & $29.10(3.54)$ & 24.26 \\
\hline$S R_{P E} H Q_{A}$ & & & & $15.12(2.18)$ \\
\hline & & & & \\
\hline & & & & \\
\hline & $22.05(5.36)$ & $21.19(3.24)$ & $40.12(2.92)$ & $25.42(3.0$ \\
\hline
\end{tabular}

Tabela B.2: Resultados obtidos na Fase de Experimentos II, Cenário ScnII 2, utilizando o algoritmo genético proposto. 


\begin{tabular}{|c|c|c|c|c|}
\hline & Autos & Balance & Heart & Ionosphere \\
\hline EM & 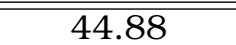 & $\overline{53.92}$ & 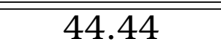 & 35.90 \\
\hline $\mathcal{C N} 2$ & $12.14(3.29)$ & $15.11(1.55)$ & $22.22(2.82)$ & 8.25 (1.15) \\
\hline $\mathcal{C} 4.5$ rules & $9.14(3.22)$ & $15.12(1.71)$ & $21.11(2.28)$ & $10.52(1.73)$ \\
\hline $\mathcal{C} 4.5$ & 8.69 (2.95) & $28.48(1.61)$ & $22.96(3.16)$ & 11.08 \\
\hline$M R_{A c c} H Q_{A C}$ & $27.90(3.80)$ & $18.23(3.85)$ & $23.33(3.03)$ & $23.06(3.96)$ \\
\hline$M R_{A c c} H Q_{A c c}$ & $5.86(1.60)$ & $9.56(2.36)$ & $11.52(1.78)$ & $6.51(2.16)$ \\
\hline$M R_{A c c} H Q_{F 1}$ & $8.71(2.46)$ & $9.88(2.14)$ & $13.33(2.29)$ & $5.96(1.54)$ \\
\hline$M R_{A c c} H Q_{P C}$ & $15.60(2.33)$ & $16.16(2.33)$ & $26.30(3.29)$ & $19.04(3.27)$ \\
\hline$M R_{A c c} H Q_{P r e c}$ & $6.81(1.47)$ & $14.09(2.15)$ & $19.63(3.22)$ & 17.39 \\
\hline$M R_{C o v} H Q_{A C}$ & $23.90(4.04)$ & $20.99(2.90)$ & $21.11(1.66)$ & 20.47 (3.09) \\
\hline$M R_{C o v} H Q_{A c c}$ & $11.29(1.97)$ & $14.38(1.75)$ & $14.07(3.16)$ & $6.82(1.40)$ \\
\hline$M R_{C o v} H Q_{F 1}$ & $10.74(2.60)$ & $15.08(1.74)$ & $14.44(2.50)$ & 6.53 (1.69) \\
\hline$M R_{C o v} H Q_{P C}$ & $13.21(2.06)$ & $21.15(3.23)$ & $28.52(3.31)$ & $17.61(4.37)$ \\
\hline$M R_{\text {Cov }} H Q_{\text {Prec }}$ & $14.14(2.08)$ & $13.36(2.21)$ & $17.04(2.36)$ & $16.76(3.26)$ \\
\hline$M R_{L a c c} H Q_{A C}$ & $22.05(4.07)$ & $15.11(2.71)$ & $18.52(2.41)$ & $23.62(3.81)$ \\
\hline$M R_{L a c c} H Q_{A c c}$ & $8.24(3.19)$ & $10.92(2.26)$ & $12.22(2.35)$ & 7.09 (1.88) \\
\hline$M R_{L a c c} H Q_{F 1}$ & $7.81(2.22)$ & $11.77(2.30)$ & $14.07(2.52)$ & $7.37(1.77)$ \\
\hline$M R_{L a c c} H Q_{P C}$ & $15.69(2.93)$ & $17.86(3.14)$ & $23.70(3.79)$ & $20.24(3.73)$ \\
\hline$M R_{\text {Lacc }} H Q_{\text {Prec }}$ & $8.81(1.61)$ & $8.32(1.32)$ & $17.41(3.13)$ & $14.25(3.19)$ \\
\hline$M R_{P E} H Q_{A C}$ & $27.38(4.69)$ & $14.56(2.37)$ & $22.59(3.80)$ & $17.37(1.72)$ \\
\hline$M R_{P E} H Q_{A c c}$ & $8.79(1.90)$ & $9.35(2.49)$ & $11.85(1.98)$ & 6.52 (1.93) \\
\hline$M R_{P E} H Q_{F 1}$ & $8.74(2.12)$ & $6.76(0.97)$ & $13.33(2.15)$ & $6.24(1.71)$ \\
\hline$M R_{P E} H Q_{P C}$ & 17.64 (3.69) & $15.77(2.17)$ & $24.44(3.41)$ & $23.61(3.80)$ \\
\hline$M R_{P E} H Q_{\text {Prec }}$ & $12.21(2.06)$ & $13.90(2.15)$ & $17.04(2.36)$ & $13.67(2.36)$ \\
\hline$\overline{S S R_{A c c} H Q_{A}}$ & $24.40(4.59)$ & $21.87(2.41)$ & $31.48(3.18)$ & 22.47 (3.37) \\
\hline$S R_{A c c} H Q_{A c c}$ & $16.07(3.83)$ & $21.71(2.11)$ & $22.96(2.52)$ & $15.67(1.29)$ \\
\hline$S R_{A c c} H Q_{F 1}$ & $15.17(2.58)$ & $27.93(2.87)$ & $25.93(3.22)$ & $16.81(1.67)$ \\
\hline$S R_{A c c} H Q_{P C}$ & $19.02(3.57)$ & $27.77(3.07)$ & $29.63(2.70)$ & $31.04(2.85)$ \\
\hline$S R_{\text {Acc }} H Q_{\text {Prec }}$ & $23.05(4.14)$ & $27.60(1.77)$ & $32.22(3.31)$ & $22.49(2.82)$ \\
\hline$S R_{C o v} H Q_{A C}$ & $27.24(5.40)$ & $27.58(1.76)$ & $31.11(4.03)$ & $23.61(3.44)$ \\
\hline$S R_{C o v} H Q_{A c c}$ & $20.10(4.99)$ & $22.22(1.26)$ & 25.19 (3.53) & $14.82(1.47)$ \\
\hline$S R_{C o v} H Q_{F 1}$ & $16.12(2.17)$ & $26.91(2.50)$ & $23.33(3.36)$ & $15.67(1.29)$ \\
\hline$S R_{C o v} H Q_{P C}$ & $25.74(3.87)$ & $30.71(1.65)$ & $32.22(3.45)$ & $27.06(3.28)$ \\
\hline$S R_{\text {Cov }} H Q_{\text {Prec }}$ & $18.07(3.95)$ & $26.02(2.25)$ & $25.19(3.90)$ & $20.75(3.36)$ \\
\hline$S R_{\text {Lacc }} H Q_{A C}$ & $28.69(5.77)$ & $30.18(3.46)$ & $24.81(3.83)$ & $26.52(3.87)$ \\
\hline$S R_{L a c c} H Q_{A c c}$ & $26.33(5.25)$ & $17.54(1.07)$ & $21.11(1.57)$ & $13.67(1.63)$ \\
\hline$S R_{L a c c} H Q_{F 1}$ & $18.02(4.10)$ & $23.07(2.12)$ & $19.26(2.12)$ & $18.53(3.94)$ \\
\hline$S R_{\text {Lacc }} H Q_{P C}$ & $18.55(3.28)$ & $29.82(3.00)$ & $30.74(3.31)$ & 19.95 (3.59) \\
\hline$S R_{\text {Lacc }} H Q_{\text {Prec }}$ & $21.60(4.58)$ & $21.37(2.23)$ & $25.56(3.10)$ & $19.95(3.02)$ \\
\hline$S R_{P E} H Q_{A C}$ & $26.24(5.10)$ & $24.44(2.26)$ & 32.59 (3.78) & 26.47 (3.27) \\
\hline$S R_{P E} H Q_{A c c}$ & $15.57(4.24)$ & $23.25(2.40)$ & $24.81(2.53)$ & $15.95(1.42)$ \\
\hline$S R_{P E} H Q_{F 1}$ & $25.43(5.21)$ & $22.05(1.28)$ & $23.70(2.36)$ & $16.52(2.58)$ \\
\hline$S R_{P E} H Q_{P C}$ & $21.55(4.52)$ & $24.66(2.54)$ & $32.96(3.42)$ & $26.23(4.22)$ \\
\hline$S R_{P E} H Q_{P r}$ & $13.69(2.27)$ & $20.84(1.74)$ & $30.37(2.75)$ & $17.61(3.25)$ \\
\hline
\end{tabular}

Tabela B.3: Resultados obtidos na Fase de Experimentos II, Cenário ScnII 3, utilizando o algoritmo genético proposto. 


\begin{tabular}{|c|c|c|c|c|}
\hline & & B & & \\
\hline EM & 44.88 & 53.92 & 44.44 & 35.90 \\
\hline $\mathcal{C N}$ & .29) & .11 & $2.22(2.82)$ & $8.25(1.15)$ \\
\hline $\mathcal{C}$ & , & 12 & $.11(2.28)$ & 10.52 \\
\hline $\mathcal{C} 4.5$ & 69 & $.4 \varepsilon$ & 2.96 & 11.08 \\
\hline$M$ & 24 & 47 & 39) & $17.1 \mathrm{c}$ \\
\hline & ग) & 61 & .71 & 11.57 \\
\hline$M R_{A}$ & 7) & .59 & 46) & 50) \\
\hline$M R_{A c}$ & 2) & .77 & 8) & 1.7 \\
\hline$M R_{A_{c}}$ & $2.65(2.30)$ & 4.1 & $8.48(2.32)$ & $5.24)$ \\
\hline$M R_{C o v} H Q_{A C}$ & 80 & 9.4 & $3.71(3.78)$ & 17.0 \\
\hline & & 21.6 & 0.7 & \\
\hline & & 3) & 6) & \\
\hline$M$ & & 3) & 7) & 3.77) \\
\hline$M R_{C}$ & 3) & .12 & 4) & .63) \\
\hline$M R_{\text {Lacc }} H Q_{A C}$ & 18.8 & 1.68 & .26) & 19.6 \\
\hline$M R_{L}$ & & & & \\
\hline & & & & \\
\hline & & & & 54) \\
\hline$M I$ & & 7 & 2) & 85) \\
\hline$M R$ & & & 5) & .77) \\
\hline$M I$ & & & 39) & 7) \\
\hline & & & & \\
\hline & & & & \\
\hline$M R_{P}$ & & 5) & 7) & 19. \\
\hline & & & & (1) \\
\hline & & & & 18) \\
\hline & & & & 0) \\
\hline & & & & \\
\hline$S R$ & & ? & 8) & 38) \\
\hline & & $\pi$ & .60) & 19.38 \\
\hline & & & & 15.6 \\
\hline & & & 5) & 17.6 \\
\hline$S R$ & & & & 13) \\
\hline$S R_{C}$ & & & & \\
\hline & & & & \\
\hline & & & 32) & 08) \\
\hline & & 7) & 71) & 76 \\
\hline & & & 8) & 4) \\
\hline & 5) & 1) & 3.90) & 26.22 \\
\hline & $45.32(1.82)$ & $26.37(3.30)$ & $21.27(3.10)$ & $24.81(3.58)$ \\
\hline$S R_{P E} H Q_{\text {. }}$ & & & & $17.90(2.24)$ \\
\hline & & & & \\
\hline & & & & \\
\hline & $22.95(5.01)$ & $26.73(2.25)$ & 25.69 (3.56) & 22.89 (3.7 \\
\hline
\end{tabular}

Tabela B.4: Resultados obtidos na Fase de Experimentos II, Cenário ScnII 4, utilizando o algoritmo genético proposto. 


\begin{tabular}{|c|c|c|c|c|}
\hline & Autos & Balance & Heart & Ionosphere \\
\hline EM & 44.88 & 53.92 & 44.44 & 35.90 \\
\hline $\mathcal{C N} 2$ & $12.14(3.29)$ & $15.11(1.55)$ & $22.22(2.82)$ & $8.25(1.15)$ \\
\hline C4.5rules & $9.14(3.22)$ & $15.12(1.71)$ & $21.11(2.28)$ & $10.52(1.73)$ \\
\hline $\mathcal{C} 4.5$ & 8.69 (2.95) & $28.48(1.61)$ & $22.96(3.16)$ & 11.08 (1.68) \\
\hline$M R_{A c c} H Q_{A C}$ & $25.79(4.61)$ & $17.08(2.75)$ & $23.70(2.08)$ & $23.10(3.48)$ \\
\hline$M R_{A c c} H Q_{A c c}$ & $5.83(1.75)$ & $8.88(1.47)$ & $14.07(1.98)$ & 6.23 (1.95) \\
\hline$M R_{A c c} H Q_{F 1}$ & 7.24 (2.79) & $9.33(2.70)$ & $14.10(2.57)$ & $7.96(2.74)$ \\
\hline$M R_{A c c} H Q_{P C}$ & $16.57(2.60)$ & $18.19(2.49)$ & 32.59 (3.53) & 24.47 (3.40) \\
\hline$M R_{A c c} H Q_{\text {Prec }}$ & $8.29(1.62)$ & $13.65(3.08)$ & $17.41(1.84)$ & $17.33(4.10)$ \\
\hline$M R_{C o v} H Q_{A C}$ & $25.62(5.02)$ & 28.27 (3.55) & $26.67(3.53)$ & $23.38(3.52)$ \\
\hline$M R_{C o v} H Q_{A c c}$ & $11.29(1.97)$ & $13.53(2.47)$ & $13.70(2.07)$ & $6.53(1.74)$ \\
\hline$M R_{C o v} H Q_{F 1}$ & $11.21(2.61)$ & $12.49(1.04)$ & $15.19(2.24)$ & $5.96(1.60)$ \\
\hline$M R_{C o v} H Q_{P C}$ & $15.10(3.57)$ & 25.55 (3.89) & $34.44(3.13)$ & $22.75(3.72)$ \\
\hline$M R_{C o v} H Q_{P r e c}$ & $13.24(1.96)$ & 13.19 (1.09) & 20.37 (1.49) & 17.05 (3.59) \\
\hline$M R_{\text {Lacc }} H Q_{A C}$ & $26.52(4.80)$ & $26.52(3.93)$ & $27.41(3.54)$ & $27.33(3.33)$ \\
\hline$M R_{L a c c} H Q_{A c c}$ & $8.21(3.28)$ & $11.09(2.66)$ & 12.59 (1.93) & $6.82(1.70)$ \\
\hline$M R_{L a c c} H Q_{F 1}$ & $6.83(1.82)$ & $9.35(2.35)$ & $12.96(2.88)$ & $7.37(1.92)$ \\
\hline$M R_{L a c c} H Q_{P C}$ & $17.60(2.76)$ & $22.90(4.35)$ & $31.48(3.75)$ & $24.20(3.92)$ \\
\hline$M R_{\text {Lacc }} H Q_{\text {Prec }}$ & $7.83(1.50)$ & $10.41(1.13)$ & $20.74(3.13)$ & $17.67(2.13)$ \\
\hline$M R_{P E} H Q_{A C}$ & $24.88(4.55)$ & 32.46 (3.59) & $25.56(3.00)$ & $23.67(3.42)$ \\
\hline$M R_{P E} H Q_{A c c}$ & $8.74(2.57)$ & $8.82(2.47)$ & $10.00(1.75)$ & $7.10(1.58)$ \\
\hline$M R_{P E} H Q_{F 1}$ & $7.76(2.18)$ & 7.961 & $14.07(2.12)$ & 76) \\
\hline$M R_{P E} H Q_{P C}$ & $19.52(3.00)$ & $25.46(3.48)$ & $30.74(3.08)$ & $20.75(3.51)$ \\
\hline$M R_{P E} H Q_{P r e c}$ & $10.76(1.59)$ & $9.54(1.48)$ & $19.63(1.11)$ & $12.82(2.22)$ \\
\hline$S R_{A c c} H Q_{A C}$ & $28.38(5.70)$ & $28.81(2.52)$ & $34.81(3.28)$ & $27.33(3.76)$ \\
\hline$S R_{A c c} H Q_{A c c}$ & $14.55(4.29)$ & $23.09(2.20)$ & $24.07(4.21)$ & $20.52(2.59)$ \\
\hline$S R_{A c c} H Q_{F 1}$ & $15.17(2.48)$ & 27.42 & 28.52 & .14) \\
\hline$S R_{A c c} H Q_{P C}$ & $26.98(4.69)$ & 34.41 (2.95) & $30.74(3.31)$ & $29.33(3.10)$ \\
\hline$S R_{A c c} H Q_{P r e c}$ & $20.12(3.91)$ & $27.61(2.35)$ & $32.22(2.71)$ & $21.39(3.48)$ \\
\hline$S R_{C o v} H Q_{A C}$ & $37.64(4.72)$ & $31.24(4.08)$ & $30.00(3.42)$ & $33.61(1.88)$ \\
\hline$S R_{C o v} H Q_{A c c}$ & $20.57(4.95)$ & $24.81(2.66)$ & $25.56(2.37)$ & $15.10(0.73)$ \\
\hline$S R_{C o v} H Q_{F 1}$ & $21.62(4.05)$ & $24.99(2.22)$ & $21.85(3.51)$ & $14.81(1.79)$ \\
\hline$S R_{C o v} H Q_{P C}$ & $22.36(3.66)$ & 36.84( & 33.33 (3.79) & $25.04(3.62)$ \\
\hline$S R_{\text {Cov }} H Q_{\text {Prec }}$ & $17.00(4.07)$ & $23.76(2.18)$ & $27.04(3.22)$ & $19.61(3.14)$ \\
\hline$S R_{\text {Lacc }} H Q_{A C}$ & $31.71(5.40)$ & $31.76(2.62)$ & $32.22(4.55)$ & $29.10(3.53)$ \\
\hline$S R_{L a c c} H Q_{A c c}$ & $23.45(5.32)$ & $17.52(1.53)$ & $20.37(2.88)$ & $16.25(2.86)$ \\
\hline$S R_{L a c c} H Q_{F 1}$ & $16.07(3.85)$ & $20.10(2.16)$ & $20.37(2.77)$ & $13.95(2.26)$ \\
\hline$S R_{\text {Lacc }} H Q_{P C}$ & $19.50(3.36)$ & 28.13 (2.99) & $35.93(3.66)$ & $28.52(2.94)$ \\
\hline$S R_{\text {Lacc }} H Q_{\text {Prec }}$ & $23.07(5.46)$ & $25.16(2.30)$ & $28.89(3.90)$ & $17.10(1.70)$ \\
\hline$S R_{P E} H Q_{A C}$ & $32.14(3.91)$ & $32.63(2.63)$ & $32.96(3.38)$ & $28.47(3.21)$ \\
\hline$S R_{P E} H Q_{A c c}$ & $18.02(3.79)$ & $21.15(2.16)$ & $19.63(3.45)$ & $17.95(2.63)$ \\
\hline$S R_{P E} H Q_{F 1}$ & $22.00(4.66)$ & $25.16(1.51)$ & $24.07(2.36)$ & $14.52(1.81)$ \\
\hline$S R_{P E} H Q_{P C}$ & $25.07(4.59)$ & $32.31(2.50)$ & $33.70(3.80)$ & $32.52(2.17)$ \\
\hline$S R_{P E} H Q_{P r e}$ & $15.57(3.24)$ & $22.75(2.03)$ & $29.63(3.36)$ & $21.90(2.73)$ \\
\hline
\end{tabular}

Tabela B.5: Resultados obtidos na Fase de Experimentos II, Cenário ScnII 5, utilizando o algoritmo genético proposto. 


\begin{tabular}{|c|c|c|c|c|}
\hline & & & & \\
\hline EM & 44.88 & 53.92 & 44.44 & 35.90 \\
\hline $\mathcal{C N}$ & .29) & .11 & $2.22(2.82)$ & $8.25(1.15)$ \\
\hline $\mathcal{C}$ & 41 & 12 & $.11(2.28)$ & 10.52 \\
\hline $\mathcal{C} 4.5$ & 691 & 1) & 2.96 & 11.08 \\
\hline$M$ & 46 & .52 & 1) & 1.2 \\
\hline & 81( & 5.52 & .00 & 7.99 \\
\hline$M R$ & 1) & 3.37 & .73) & 7.49 \\
\hline$M R_{A}$ & 4) & 5.89 & .67 & 9.5 \\
\hline$M R_{A_{c}}$ & 9.71 & 2.62 & $8.89(2.43)$ & 18.69 \\
\hline$M R_{C o v} H Q_{A C}$ & 8.23 & 1.91 & $3.68)$ & 27.9 \\
\hline & t) & 18.22 & 3) & \\
\hline & & ) & & \\
\hline$M$ & & 3) & 4) & 21) \\
\hline$M R_{C}$ & 77) & 8.73 & 9.26 & 13.6 \\
\hline$M R_{\text {Lacc }} H Q_{A C}$ & 3) & 3.8 & 1.52 & 26.1 \\
\hline$M R_{L}$ & & & 8) & \\
\hline & & & & \\
\hline & & & & 27. \\
\hline$M I$ & & 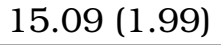 & 7) & 12. \\
\hline$M R$ & & & 5) & 20.5 \\
\hline$M I$ & & & & 6.8 \\
\hline & & & & \\
\hline & & & & \\
\hline$M R_{P}$ & 2) & 3) & 5) & 17.7 \\
\hline & & & & (0) \\
\hline & & & & 2) \\
\hline & & & & \\
\hline & & & & 21) \\
\hline$S R$ & & 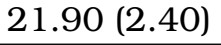 & 8) & 40) \\
\hline & & 2.3 & $61)$ & .45) \\
\hline & & 0 & & 4) \\
\hline & & & 3) & 16.4 \\
\hline & & & & 31. \\
\hline & & & & \\
\hline & & & & \\
\hline & & & 5) & 1) \\
\hline & & 1) & 1) & 51 \\
\hline & & 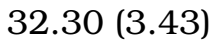 & 2) & 9) \\
\hline & )) & 2) & .62) & 28.0 \\
\hline & $40.76(4.99)$ & $30.93(2.18)$ & $19.68(2.76)$ & $29.67(3.01)$ \\
\hline$S R_{P E} I$ & & & & $16.53(2.37)$ \\
\hline & & & & \\
\hline & & & & \\
\hline & $22.48(5.57)$ & $22.76(1.57)$ & $30.81(4.81)$ & 23.48 (3.3 \\
\hline
\end{tabular}

Tabela B.6: Resultados obtidos na Fase de Experimentos II, Cenário ScnII 6, utilizando o algoritmo genético proposto. 


\section{REFERÊNCIAS BIBLIOGRÁFICAS}

Agrawal, R. and Srikant, R. (1994). Fast algorithms for mining association rules. In Bocca, J. B., Jarke, M., and Zaniolo, C., editors, Proceedings of the 20th International Conference on Very Large Data Bases - VLDB'94, pages 487-499. Morgan Kaufmann Publishers. Citado na página 24.

Alexandre, L. A., Campilho, A. C., and Kamel, M. (2000). Combining independent and unbiased classifiers using weighted average. In Proc. 15th International Conference on Pattern Recognition - ICPR'OO, volume 2, pages 495-498. Citado na página 120.

Baranauskas, J. A. and Batista, G. E. A. P. A. (2000). O projeto Discover: Idéias iniciais (comunicação pessoal). Citado nas páginas 25 and 28.

Batista, G. E. A. P. A. (2001). Sintaxe padrão do arquivo de exemplos do projeto Discover. http://www.icmc.sc.usp.br/〜gbatista/Discover/ SintaxePadraofinal.htm. Citado nas páginas 29, 30, and 69.

Batista, G. E. A. P. A. (2003). Pré-processamento de dados em aprendizado de máquina supervisionado. Tese de Doutorado, ICMC/USP. http: //Www . teses.usp.br/teses/disponiveis/55/55134/tde-06102003-160219/.

Citado nas páginas 27 and 30.

Batista, G. E. A. P. A. and Monard, M. C. (2003). Descrição da arquitetura e do projeto do ambiente computacional Discover Learning Environment - DLE. Technical Report 187, ICMC/USP. ftp://ftp.icmc.usp.br/pub/ BIBLIOTECA/rel_tec/RT_187.PDF. Citado nas páginas 29, 30, 32, 34, 71, and 72 .

Batista, G. E. A. P. A. and Monard, M. C. (2006). The Discover Object Library 
(DOL) User's Manual. Technical Report em preparação, ICMC/USP. Citado na página 29.

Batista, G. E. A. P. A., Prati, R. C., and Monard, M. C. (2004). A study of the behavior of several methods for balancing machine learning training data. SIGKDD Explorations, 6(1):20-29. Citado na página 129.

Batista, G. E. A. P. A., Prati, R. C., and Monard, M. C. (2005). Balancing strategies and class overlapping. In International Symposium on Intelligent Data Analysis (IDA'2005), volume 3646 of Lecture Notes in Computer Science, pages 24-35, Madrid (Spain). Springer. Citado na página 129.

Bauer, E. and Kohavi, R. (1999). An empirical comparison of voting classification algorithms: Bagging, boosting and variants. Machine Learning, 36(1/2):105-139. Citado nas páginas 50 and 120.

Bernardini, F. C. (2002). Combinação de classificadores simbólicos para melhorar o poder preditivo e descritivo de ensembles. Dissertação de Mestrado, ICMC/USP. http: / / www.teses.usp.br/teses/disponiveis/55/ 55134/tde-29042003-091747/. Citado na página 4.

Bernardini, F. C. and Monard, M. C. (2004). Descrição da arquitetura e do projeto do sistema computacional para construção de ensembles de classificadores simbólicos ELE. Technical Report 243, ICMC/USP. ftp: / / ftp.icmc.usp.br/pub/BIBLIOTECA/rel_tec/RT_243.pdf. Citado nas páginas $29,75,78$, and 152 .

Bernardini, F. C. and Monard, M. C. (2005a). Methods for constructing symbolic ensembles from symbolic classifiers. In Frontiers in Artificial Intelligence and Applications, volume 132, pages 161-168, Hyogo, Japan. Netherlands: IOS Press. Citado nas páginas 6 and 152 .

Bernardini, F. C. and Monard, M. C. (2005b). Uma proposta para a construção de ensembles simbólicos que explicam suas decisões. In Conferencia Latinoamericana de Informatica - CLEI 2005, volume 1, pages 151-162, Cali, Colômbia. Cali: Feriva. Citado nas páginas 6 and 152.

Bernardini, F. C. and Monard, M. C. (2006a). Descrição da arquitetura e do projeto do sistema computacional gaere para realizar evolução genética de classificadores simbólicos. Technical Report 275, ICMC/USP. http:/ /www . 
icmc.usp.br/〜biblio/download/RT_275.pdf. Citado nas páginas 37, 109, 117, and 153.

Bernardini, F. C. and Monard, M. C. (2006b). Uma proposta para evoluir classificadores simbólicos utilizando um algoritmo genético. In Conferencia Latinoamericana de Informatica - CLEI 2006, volume 1, Santiago, Chile. Citado nas páginas 6 and 153.

Bernardini, F. C. and Monard, M. C. (2006c). Utilizando a abordagem pittsburgh para evolução de classificadores simbólicos. In Submetido ao Workshop de Teses e Dissertações de Inteligência Artificial - WTDIA 2006, volume 1, Ribeirão Preto, SP. Citado nas páginas 6 and 153.

Bernardini, F. C., Monard, M. C., and Prati, R. C. (2005). Constructing ensembles of symbolic classifiers. In International Conference on Hybrid Intelligent Systems - HIS 2005, volume 1, pages 315-320, Rio de Janeiro. California: IEEE Computer Society. Citado nas páginas 6 and 152.

Bernardini, F. C., Monard, M. C., and Prati, R. C. (2006). Constructing ensembles of symbolic classifiers. Invited to submit to International Journal on Hybrid Intelligent Systems. (in print). Citado nas páginas 6 and 152.

Blake, C., Keogh, E., and Merz, C. (1998). UCI repository of machine learning databases. http://www.ics.uci.edu/ mlearn/MLRepository.html. Citado nas páginas 2, 6, 34, 120, 151, and 152 .

Blum, A. and Rivest, R. (1988). Training a 3-node neural network is NPcomplete (extended abstract). In Proceeding of the 1988 Workshop on Computacional Learning Theory, pages 9-18, San Mateo, California. Morgan Kaufmann Publishers. Citado na página 46.

Booch, G., Jacobson, I., Rumbaugh, J., and Rumbaugh, J. (1998). The Unified Modeling Language User Guide. Addison Wesley. Citado nas páginas 72 and 117.

Borgelt, C. and Kruse, R. (2002). Induction of association rules: Apriori implementation. In Proceedings of 15th Conference on Computational Statistics. Citado nas páginas 37, 97, and 106.

Boswell, T. (1990). Manual for NewId version 4.1. Technical Report TI/P2154/RAB/4/2.3, The Turing Institute. Citado nas páginas 31 and 35. 
Breiman, L. (1996). Bagging predictors. Machine Learning, 24(2):123-140. Citado nas páginas 2 and 47.

Cabena, P., Hadjinian, P., Stadler, R., Verhees, J., and Zanasi, A. (1998). Discovering Data Mining: from Concept to Implementation. Prentice Hall. Citado na página 1.

Carvalho, A. C. P. L. F., Braga, A. P., and Ludermir, T. B. (2003). Computação Evolutiva, chapter 9, pages 225-248. In Rezende (2003). Citado na página 87.

Chiara, R. (2003). Aplicações de técnicas de data mining em logs de servidores web. Dissertação de Mestrado, ICMC/USP. http://www.teses. usp.br/teses/disponiveis/55/55134/tde-19012004-093205/. Citado na página 29.

Clark, P. and Boswell, R. (1991). Rule induction with $\mathcal{C N} 2$ : Some recent improvements. In Kodratoff, Y., editor, Proceedings of the 5th European Working Session on Learning (EWSL 91), pages 151-163. Citado nas páginas 31, 35, and 157.

Clark, P. and Niblett, T. (1989). The $\mathcal{C N} 2$ induction algorithm. Machine Learning, 3(4):261-283. Citado nas páginas 97, 106, 121, and 130.

De Jong, K. A., Spears, W., and Gordon, D. (1993). Using genetic algorithms for concept learning. Machine Learning, 13:161-188. Citado nas páginas 3 and 94.

Demšar, J. (2006). Statistical comparisons of classifiers over multiple data sets. Journal of Machine Learning Research, 7:1-30. Citado na página 4.

Dietterich, T. G. (1989). Limitations on inductive learning (extended abstract). In Proceedings of the Sixth International Workshop on Machine Learning, pages 124-128, Ithaca, NY. Morgan Kaufmann Publishers. Citado nas páginas 57 and 105.

Dietterich, T. G. (1990). Exploratory research in machine learning. Machine Learning, 5(1):5-10. Citado na página 3.

Dietterich, T. G. (2000a). An experimental comparison of three methods for constructing ensembles of decision trees: Bagging, boosting and randomization. Machine Learning, 40:139-157. http://www. cs. orst. edu/ tgd/. Citado na página 120. 
Dietterich, T. G. (2000b). Ensemble methods in machine learning. In First International Workshop on Multiple Classifier Systems. Lecture Notes in Computer Science, volume 1857, pages 1-15, New York. Springer Verlag. http: //www.cs.orst.edu/ tgd/. Citado nas páginas 2, 42, 45, and 47.

Dzeroski, S. and Zenko, B. (2002). Is combining classifiers better than selecting the best one? In Proc. 19th International Conference on Machine Learning - ICML 2002, pages 123-130. Citado na página 120.

Efron, B. and Tibshirani, R. (1993). An Introduction to Bootstrap. Springer Verlag. Citado na página 47.

Ferro, M. (2006). Aquisição de conhecimeno utilizando aprendizado de máquina relacional. Qualificação de Doutorado, ICMC/USP. Citado na página 29.

Fischer, S., Klinkenberg, R., Mierswa, I., and Ritthoff, O. (2002). Yale: Yet another learning environment - tutorial. Technical Report CI-136/02, University of Dortmund, Collaborative Research Center 531. Citado na página 28.

Freitas, A. A. (1998a). A multi-criteria approach for the evaluation of rule interestingness. In Proceedings of the International Conference on Data Mining, pages 7-20, Rio de Janeiro, RJ. Citado na página 23.

Freitas, A. A. (1998b). On objective measures of rule surprisingness. In Proc. 2nd European Symp. on Principles of Data Mining and Knowledge Discovery (PKDD-98). Lecture Notes in Artificial Intelligence, volume 1510, pages 1-9. Springer Verlag. Citado na página 23.

Freitas, A. A. (2002a). Data Mining and Knowledge Discovery with Evolutionary Algorithms. Springer Verlag. Citado nas páginas 3, 81, 82, 87, 93, and 99.

Freitas, A. A. (2002b). A survey of evolutionary algorithms for data mining and knowledge discovery. In Ghosh, A. and Tsui, S., editors, Advances in Evolutionary Computation. Citado nas páginas 3 and 93.

Freund, Y. and Schapire, R. (1997). A decision-theoretic generalization of on-line learninng and an application to boosting. Journal of Computer and System Sciences, 55(1):119-139. Citado nas páginas 2, 48, and 51. 
Gamma, E., Helm, R., R.Johnson, and Vlissides, J. (1995). Design Patterns: Elements of Reusable Object-Oriented Software. Addison Wesley. Citado nas páginas 71 and 72 .

Giordana, A. and Neri, F. (1995). Search-intensive concept induction. Evolutionary Computation, 3(4):375-416. Citado na página 94.

Goldberg, D. (1989). Genetic Algorithms in Search, Optimization and Machine Learning. Addison Wesley. Citado nas páginas 2 and 84.

Gomes, A. K. (2002). Medidas de avaliação de regras. Dissertação de Mestrado, ICMC/USP. http: / / www.teses.usp.br/teses/disponiveis/ 55/55134/tde-04072002-144610/. Citado nas páginas 155 and 156.

Greene, D. and Smith, S. (1993). Competition-based induction of decision models from examples. Machine Learning, 13:229-257. Citado na página 94.

Hansen, L. and Salamon, P. (1990). Neural networks ensembles. IEEE Transactions on Pattern Analysis and Machine Intelligence, 12(10):993-1001. Citado na página 41 .

Hilderman, R. J. and Hamilton, H. J. (1999). Knowledge discovery and interestingness measures: A survey. Technical Report s4s, University of Regina. Citado na página 23.

Holland, J. (1975). Adaptation in Natural and Artificial Systems. The MIT Press. Citado na página 84.

Horst, P. and Monard, M. C. (2000). Um sistema computacional para avaliação de regras induzidas por algoritmos de aprendizado de máquina. In Proceedings IBERAMIA-SBIA 2000 Open Discussion Track, pages 167-176, Atibaia, SP, Brasil. Citado na página 156.

Hyafil, L. and Rivest, R. (1976). Constructing optimal binary decision trees is NP-complete. Information Processing Letters, 5(1):15-17. Citado na página 46.

Janikow, C. (1993). A knowledge-intensive genetic algorithm for supervised learning. Machine Learning, 13:189-228. Citado nas páginas 3 and 94.

Kibler, D. and Langley, P. (1988). Machine learning as an experimental science. Machine Learning, 3(1):5-8. Citado nas páginas 57 and 105. 
Kohavi, R. and Li, C. (1995). Oblivious decision trees, graphs, and top-down pruning. In Proc. of the 14th IJCAI, pages 1071-1077, Montreal, Canada. Citado na página 4 .

Kohavi, R., Sommerfield, D., and Dougherty, J. (1994). $\mathcal{M L C}^{++}$: A Machine Learning Library in $C^{++}$. IEEE Computer Society Press. Citado na página 28.

Kuncheva, L., Whitaker, C., Shipp, C., and Duin, R. (2000). Is independence good for combining classifiers? In Proc. 15th International Conference on Pattern Recognition, pages 168-171. Citado na página 120.

Langley, P. (2000). Crafting papers on machine learning. In Proc. 17th International Conf. on Machine Learning - ICML 2000, San Francisco, CA. Morgan Kaufmann. Citado na página 3.

Lavrac, N., Flach, P., and Zupan, B. (1999). Rule evaluation measures: a unifying view. In Proc. 9th International Workshop on Inductive Logic Programming. Lecture Notes in Artificial Intelligence, volume 1634, pages 74185. Springer Verlag. Citado nas páginas 19, 22, 23, and 155.

Lee, H. D. (2005). Seleção de atributos importantes para a extração de conhecimento de bases de dados. Tese de Doutorado, ICMC/USP. http://www.teses.usp.br/teses/disponiveis/55/55134/ tde-22022006-172219/publico/tese_huei.pdf. Citado na página 29.

Leung, K. T. and Parker, D. S. (2003). Empirical comparisons of various voting methods in bagging. In Conference on Knowledge Discovery in Data Archive. Proceedings of the 9th ACM SIGKDD International Conference on Knowledge Discovery and Data Mining, pages 595-600. Citado na página 120.

Llorà, X. and i Guiu, J. M. G. (1999). Genifer: A nearest neighbour based classifier system using ga. In Proceedings of the Genetic and Evolutionary Computation Conference - GECCO 1999, volume 1, page 797, Orlando, Florida. Morgan Kaufmann Publishers. Citado nas páginas 3 and 94.

Mahfoud, S. (1995). Niching Methods for Genetic Algorithms. PhD thesis, Univ. of Illinois at Urbana-Champaign. IlliGAL Report No 95001. Citado na página 94 .

Mannila, H. (1996). Data mining: Machine learning, statistics, and database. Technical Report FIN-00014, Department of Computer Science, University of 
Helsinki, Helsinki, Finland. http://www.cs.helsinki.fi/ mannila. Citado na página 1 .

Margineantu, D. and Dietterich, T. G. (1997). Pruning adaptive boosting. In Proc. 14th International Conference on Machine Learning - ICML 97, pages 211-218, San Mateo, California. Morgan Kaufmann Publishers. Citado na página 2.

Martins, C. A. (2003). Uma abordagem para pré-processamento de dados textuais em algoritmos de aprendizado. Tese de Doutorado, ICMC/USP. http://www.teses.usp.br/teses/disponiveis/55/55134/ tde-08032004-164855/. Citado na página 29.

Matsubara, E. T. (2004). O algoritmo de aprendizado semi-supervisionado co-training e sua aplicação na rotulação de documentos. Dissertação de Mestrado, ICMC/USP. http: / / www.teses.usp.br/teses/disponiveis/ 55/55134/tde-19082004-092311/. Citado na página 29.

Melanda, E. (2004). Pós-processamento de conhecimento de regras de associação. Tese de Doutorado, ICMC/USP. http://www.teses.usp. br/teses/disponiveis/55/55134/tde-13012006-171753/publico/ TeseEdsonMelandaVersaoCorrigida.pdf. Citado na página 29.

Metz, J. (2004). Interpretação de clusters gerados por algoritmos de agrupamento hierarquico. Dissertação de Mestrado, ICMC/USP. Citado na página 29.

Michalewicz, Z. (1999). Genetic Algorithms + Data Structures = Evolution Programs. Springer Verlag. Citado nas páginas 3, 87, 92, and 93.

Milaré, C. R. (2003). Extração de conhecimento de redes neurais artificiais utilizando sistemas de aprendizado simbólico e algoritmos genéticos. Tese de Doutorado, ICMC/USP. http: / / www . teses.usp.br/teses/disponiveis/ 55/55134/tde-11082004-004358/publico/claudia_milare.pdf. Citado nas páginas $29,37,39$, and 87 .

Mitchell, M. (1997a). An Introduction to Genetic Algorithms. The MIT Press. Citado nas páginas 2,84 , and 89.

Mitchell, T. (1997b). Machine Learning. McGraw Hill. Citado na página 12. 
Mitchell, T. (1999). Machine learning and data mining. Communications of the ACM, 42(11):30-36. http://cs.cmu.edu/user/mitchell/ftp/tomhome. html. Citado na página 2.

Monard, M. C. and Baranauskas, J. A. (2003). Indução de Regras e Árvores de Decisão, chapter 5, pages 115-140. In Rezende (2003). Citado na página 12.

Niyogi, P., Pierrot, J. B., and Siohan, O. (2000). Multiple classifiers by constrained minimization. In Proc. International Conference on Acoustics, Speech, and Signal Processing, volume 6, pages 3462-3465. Citado na página 120.

Noda, E., Freitas, A. A., and Lopes, H. S. (1999). Discovering interesting prediction rules with a genetic algorithm. In Proc. Conference on Evolutionary Computation - 1999 (CEC-99), pages 1322-1329, Washington D.C., USA. Citado na página 93.

Paula, M. F. (2003). Ambiente para disponibilização de conhecimento. Dissertaçao de Mestrado, ICMC/USP. Citado na página 29.

Pei, M., Goodman, E., and Punch, W. (1997). Pattern discovery from data using genetic algorithms. In Proc. 1st Pacific-Asia Conf. Knowledge Discovery \& Data Mining - PAKDD-97. http: / /www.egr.msu.edu/ pei/paper/ GApaper96-01.ps. Citado nas páginas 3 and 94 .

PERL (1999). Programming in PERL. Morgan Kaufmann Publishers, Inc. Citado nas páginas 28 and 38 .

Pila, A. D. (2003). Algoritmos genéticos para construção de regras de conhecimento com propriedades específicas. Exame de Qualificação de Doutorado, ICMC/USP. Citado na página 29.

Prati, R. C. (2003). O framework de integração do sistema Discover. Dissertação de Mestrado, ICMC/USP. http://www.teses.usp.br/teses/ disponiveis/55/55134/tde-20082003-152116/. Citado na página 28.

Prati, R. C. (2006). Novas abordagens em aprendizado de máquina para a geração de regras, classes desbalanceadas e ordenação de casos. Tese de Doutorado, ICMC/USP. Citado na página 29.

Prati, R. C., Baranauskas, J. A., and Monard, M. C. (2001a). Extração de informações padronizadas para a avaliação de regras induzidas por algoritmos de aprendizado de máquina simbólico. Technical Report 145, 
ICMC/USP. ftp://ftp.icmc.sc.usp.br/pub/BIBLIOTECA/rel_tec/RT_ 145.ps.zip. Citado nas páginas 28 and 72.

Prati, R. C., Baranauskas, J. A., and Monard, M. C. (2001b). Uma proposta de unificação da linguagem de representação de conceitos de algoritmos de aprendizado de máquina simbólicos. Technical Report 137, ICMC/USP. ftp://ftp.icmc.sc.usp.br/pub/BIBLIOTECA/rel_tec/RT_ 137.ps.zip. Citado nas páginas 28, 38, 72, 97, and 115.

Prati, R. C. and Flach, P. (2005). RoccER: An algorithm for rule learning based on ROC analysis. In Proceedings of the Nineteenth International Joint Conference on Artificial Intelligence (IJCAI'2005), pages 823-828, Edinburgh, Scotland, UK. Citado na página 120.

Pugliesi, J. B. (2004). O pós-processamento em extração de conhecimento de bases de dados. Tese de Doutorado, ICMC/USP. Citado na página 29.

Quinlan, J. (1986). Induction of decision trees. Machine Learning, 1:81-106. Citado nas páginas 31 and 35.

Quinlan, J. (1987). Generating production rules from decision trees. In Proceedings os the Tenth International Joint Conference in Artificial Intelligence, pages 304-307, Italy. Citado nas páginas 31 and 35.

Quinlan, J. (1988). C4.5 Programs for Machine Learning. Morgan Kaufmann Publishers. Citado nas páginas 31, 35, 97, 106, 121, and 130.

Rezende, S. O. (2003). Sistemas Inteligentes: Fundamentos e Aplicações. Editora Manole, Barueri, SP, Brasil. Citado nas páginas 172, 177, and 178.

Rezende, S. O., Pugliesi, J. B., Melanda, E. A., and Paula, M. F. (2003). Mineração de Dados, chapter 12, pages 307-336. In Rezende (2003). Citado na página 2.

Rozante, T. A. A. (2003). Implantação do reuso de componentes no processo de desenvolvimento de software. Dissertação de Mestrado, ICMC/USP. Citado na página 28.

Rückert, U. and Kramer, S. (2004). Towards tight bounds for rule learning. In Proc. 21st International Machine Learning Conference - ICML 2004. http://www.machinelearning.org/proceedings/ icml2004/papers/195.pdf. Citado na página 120. 
Ruta, D. and Gabrys, B. (2001). Application of the evolutionary algorithms for classifier selection in multiple classifier systems with majority voting. In Proceedings of the 2nd International Workshop on Multiple Classifier Systems MCS'2001. Lecture Notes in Computer Science, volume 2096, pages 399-408, Cambridge, UK. Springer Verlag. http://cis.paisley.ac.uk/ruta-cio/ downloads/paper4.pdf. Citado na página 3.

Sanches, M. K. (2003). Aprendizado de máquina semi-supervisionado: Proposta para rotular exemplos a partir de poucos exemplos rotulados. Dissertação de Mestrado, ICMC/USP. http://www.teses.usp.br/teses/ disponiveis/55/55134/tde-12092003-101358/. Citado na página 29.

Schaffer, C. (1994). A conservation law for generalization performance. In Cohen, W. W. and Hirsh, H., editors, Eleventh International Conference on Machine Learning, pages 259-265, New Brunswick, New Jersey. Morgan Kaufmann Publishers. Citado nas páginas 57 and 105.

Setzkorn, C. and Paton, R. C. (2003). Merbis - a multi-objective evolutionary rule base induction system. Technical Report ULCS-03-016, Department of Computer Science, University of Liverpool, Liverpool, U.K. http://www . Csc.liv.ac.uk/research/techreports/tr2003/ulcs-03-016.ps. Citado nas páginas 3 and 95.

Shalloway, A. and Trott, J. R. (2002). Design Patterns Explained: A New Perspective on Object-Oriented Design. Addison Wesley. Citado nas páginas 71 and 72 .

Todorovski, L. and Dzeroski, S. (2003). Combining classifiers with meta decision trees. Machine Learning, 50(3):223-249. Citado na página 120.

Todorovski, L., Flach, P., and Lavrac, N. (2000). A report on experiments with weighted relative accuracy in CN2. Technical Report CSTR-00-003, Department of Computer Science, University of Bristol. http://www.compsci. bristol.ac.uk/Tools/Reports/Ps/. Citado na página 157.

Weiss, G. M. and Hirsh, H. (1998). Learning to predict rare events in event sequences. In Proc. 4th Int. Conf. KnowledgeDiscovery and Data Mining, pages 359-363. AAAI Press. Citado na página 93.

Weiss, S. and Indurkhya, N. (1998). Predictive Data Mining: a Practical Guide. 
Morgan Kaufmann Publishers. http://www.data-miner.com.or. Citado na página 2.

Witten, I. H. and Frank, E. (2005). Data Mining: Practical Machine Learning Tools and Techniques. Morgan Kaufmann, 2nd edition. Citado nas páginas 28 and 131. 